\title{
Common standards for enterprises
}

\author{
By Florence Nicolas
}

with the cooperation of Jacques Repussard 


\section{NOTICE}

This publication was prepared outside the European Commission. The views expressed are those of the author alone, and do not necessarily reflect the opinion of the Commission.

Cataloguing data can be found at the end of this publication.

Luxembourg: Office for Official Publications of the European Communities, 1995

ISBN 92-826-8110-6

(C) ECSC-EC-EAEC, Brussels • Luxembourg, 1994

Reproduction is authorized, except for commercial purposes, provided the source is acknowledged.

Printed in Italy 


\section{Contents}

Introduction $\quad 9$

Addendum $\quad 11$

\section{Part 1: Standardization and certification in Europe}

1. Standardization, the best way of organizing economic relations 14

$\begin{array}{ll}\text { 1.1. Definition } & 14\end{array}$

1.1.1. A written document approved by a qualified or recognized body 15

1.1.2. A document available to the public 15

1.1.3. A document drawn up by a method requiring the approval of all interests
concerned and to the benefit of all

1.1.4. A document for repeated or continuous application 16

1.1.5. A non-mandatory document 16

$\begin{array}{ll}\text { 1.2. The content of standards } & 17\end{array}$

$\begin{array}{ll}\text { 1.2.1. The different types of standards } & 17\end{array}$

1.2.2. The major sectors of standardization 19

1.3. Standardization objectives and uses 19

$\begin{array}{ll}\text { 1.3.1. Standardization objectives } & 19\end{array}$

$\begin{array}{ll}\text { 1.3.2. The main uses of standards } & 21\end{array}$

1.4. Comparative table 23

2. Standardizing methods in Europe $\quad 24$

2.1. National methods $\quad 24$

2.1.1. Similarities and differences in national standardization structures $\quad 24$

2.1.2. The specific case of the electrotechnical field 26

$\begin{array}{ll}\text { 2.2. The European structures } & 27\end{array}$

2.2.1. Introduction $\quad 27$

2.2.2. CEN and its associated structures $\quad 27$

$\begin{array}{ll}2.2 .3 \text {. Cenelec } & 31 \\ 2.2 .4 & 37\end{array}$

2.2.4. ETSI 34

2.2.5. Coordination at European level 37

2.3. Relations with consumers, trade unions and other interest groups 39

2.4. The way in which European standardization works $\quad 40$

2.4.1. Introduction $\quad 40$

2.4.2. Programming $\quad 40$ 
2.4.3. Preparation of draft standards by CEN's TCs

2.4.4. Preparation of draft standards within ISO Committees 43

$\begin{array}{ll}\text { 2.4.5. Adoption of European standards } & 44\end{array}$

2.4.5.1. CEN/Cenelec public comment 44

$\begin{array}{ll}\text { 2.4.5.2. Formal vote } & 44\end{array}$

2.4.6. National transposition of European standards 45

2.4.7. The special cases of harmonization documents (HDs) and experimental
European standards (ENVs)

2.4.8. The specificity of ETSI procedures 48

3. Methods for evaluating and certifying conformity 49

3.1. Introduction $\quad 49$

3.2. Who can demand come from?

$\begin{array}{ll}\text { 3.2.1. 'Customers' } & 49\end{array}$

3.2.2. 'Suppliers' 50

3.3. What frames of reference are used to carry out the assessment? 51

3.4. Who carries out the assessment and how? 51

3.4.1. The declaration of conformity 51

$\begin{array}{ll}\text { 3.4.2. Tests and checks } & 52\end{array}$

$\begin{array}{ll}\text { 3.4.3. Certification procedures } & 52\end{array}$

3.4.4. Approval and accreditation $\quad 52$

4. Access to information on standards and certification in Europe 56

4.1. Numbering of European standards $\quad 56$

4.2. Publication of European standards and their dissemination 57

4.3. Data bases $\quad 58$

4.3.1. The information procedure set forth in Directive 83/189/EEC 58

4.3.2. ICONE 59

4.3.3. The information systems of the Central Secretariats of CEN and Cenelec $\quad 59$

4.3.4. Other computerized products relating to standardization information $\quad-60$

$\begin{array}{lll}\text { 4.3.5. Certificate } & 60\end{array}$

Part 2: European policies in the fields of standardization and certification of conformity

Introduction

1. The elimination of technical barriers to trade within the European context 63

$\begin{array}{ll}\text { 1.1. Definition } & 63\end{array}$

1.2. Description $\quad 64$

$\begin{array}{ll}\text { 1.2.1. Technical requirements } & 64\end{array}$

1.2.2. Certifications or attestations of conformity 65

1.3. The fight against technical barriers to trade within the framework of the Treaty
of Rome

$\begin{array}{ll}\text { 1.3.1. Introduction } & 67\end{array}$

1.3.2. Article $100 \quad 68$

1.3.3. Articles $30-36$ of the Treaty and related case law 68

$\begin{array}{ll}\text { 1.3.4. The Single Act } & 72\end{array}$

$\begin{array}{ll}\text { 1.3.4.1. Article 100A } & 72 \\ \text { 1.3.4. } & 74\end{array}$

$\begin{array}{ll}\text { 1.3.4.2. Article 118A } & 74\end{array}$ 
1.3.5.1. The objectives of Directive 83/189/EEC

1.3.5.2. The content of Directive 83/189/EEC . 75

1.3.5.3. The operation of Directive 83/189/EEC 78

2. Relations between European standards institutions and European institutions 80

2.1. Relations with Community institutions 80

2.1.1. Official reference documents of the European Communities 80

2.1.2. Contractual agreements between the EC and CEN and Cenelec 81

2.1.3. Green Paper on European standardization and Council resolution of 18 June 1992

2.2. Relations with the European Free Trade Association (EFTA)

3. The European standard - A regulator of competition and a driving force behind technical progress

3.1. The New Approach $\quad 90$

3.1.1. The main principles of the new approach $\quad 90$

3.1.2. Description of a 'standard' new approach Directive 91

3.1.3. Conclusion $\quad 94$

3.2. Harmonization Directives already adopted $\quad 94$

3.2.1. List of new approach Directives which have been adopted . 95

3.2.2. The 'low voltage' Directive (73/23/EEC of 19 February 1973) 96

3.2.3. The Directive on simple pressure vessels (87/404/EEC of 25 June 1987, as
amended by Directive $90 / 488 / \mathrm{EEC}$ of 17 September 1990)

3.2.4. The Directive on toys (88/378/EEC of 3 May 1988) 99

3.2.5. The Directive on construction products (89/106/EEC of 21 December 1988)

3.2.6. The Directive on electromagnetic compatibility (89/336/EEC of 3 May 1989)

3.2.7. The Directive on safety of machines (89/392/EEC of 14 June 1989 , as amended by Directive 91/368/EEC of 20 June 1991)

3.2.8. The Directive on personal protection equipment $(89 / 686 / \mathrm{EEC}$ of 21 December 1989)

3.2.9. The Directive on non-automatic weighing machines $(90 / 384 / \mathrm{EEC}$ of 20 June 1990)

3.2.10. The Directive on active implantable medical devices (90/385/EEC of 20 June 1990)

3.2.11. The Directive on appliances burning gaseous fuels $(90 / 396 / \mathrm{EEC}$ of 19 June 1990)

3.2.12. The Directive on telecommunications terminal equipment $(91 / 263 / \mathrm{EEC}$ of 29 April 1991)

3.2.13. The Directive on new hot-water boilers fired with liquid or gaseous fuels (92/42/EEC of 21 May 1992)

3.2.14. The Directive on explosives for civil uses (93/15/EEC of 5 April 1993) 118

3.2.15. The Directive on medical devices (93/42/EEC of 14 June 1993) 119

3.2.16. Draft new approach Directives currently being drawn up 120

3.3. Public contracts $\quad 121$

$\begin{array}{ll}\text { 3.3.1. Introduction and applicable documents } & 121\end{array}$

3.3.2. Definition of the public contracts referred to in the documents 122 3.3.3. Provisions of the public contract documents with regard to standard-
ization 
3.4. Standards as a tool of Community industrial policy 125

$\begin{array}{ll}\text { 3.4.1. General } & 125\end{array}$

3.4.2. The example of information technology 127

3.5. Research and development and European standards 131

3.6. Standardization and intellectual property law 133

3.7. Conclusion: The standard as a general tool for supporting legislation and European construction

4. European Community policy on the assessment and certification of conformity 138

4.1. The Global Approach and the Council resolution of 21 December 1989

4.2. The implementation of the Global Approach at regulatory level 142

4.2.1. The Council Decision on modules of 13 December $1990 \quad 142$

$\begin{array}{ll}\text { 4.2.1.1. The principles } & 142\end{array}$

$\begin{array}{lll}4.2 .1 .2 & \text { The modules } & 144\end{array}$

4.2.2. The Directive and decision on CE marking $\quad 145$

$\begin{array}{ll}\text { 4.2.3. Relations with third countries in the regulatory sphere } & 147\end{array}$

5. Organization of voluntary certification in the single internal market 149

5.1. Market access for products: Non-regulatory requirements 149

5.2. The objective: To establish mutual recognition by winning the confidence of business interests

5.3. The four essential conditions for instilling confidence 150

5.3.1. The existence of a recognized technical doctrine at European level $\quad 150$

5.3.2. Negotiations between suppliers and customers, on a sector-by-sector basis, at European level

5.3.3. The ability of technical bodies to establish technical and commercial cooperation

5.3.4. Overall political will to achieve the objective $\quad, \quad 152$

5.4. Existing European certification agreements 153

5.4.1. The electrotechnical sector 153

5.4.1.1. The CCA (Cenelec Certification Agreement) 153

5.4.1.2. The HAR Agreement 154

5.4.1.3. The CECC (Cenelec Electronic Components) Agreement 154

5.4.1.4. Emedca (European Active Medical Device Certification Agree-
ment)

5.4.1.5. The LOVAG (Low Voltage Agreement Group) Agreement 155

5.4.1.6. The STL-A Agreement 155

$\begin{array}{ll}\text { 5.4.1.7. The LUM Agreement } & 155\end{array}$

$\begin{array}{ll}\text { 5.4.1.8. The EMCEL Agreement } & 156\end{array}$

5.4.2. The Cencer certification system $\quad 156$

5.4.2.1. Objectives and development of the system 156

5.4.2.2. The spheres of application of the Cencer system 157

$\begin{array}{ll}\text { 5.4.3. The information technology sector } & 158\end{array}$

5.4.3.1. Open Systems Testing Consortium (OSTC) 158

5.4.3.2. European Testing Consortium for Office and Manufacturing
(ETCOM)

5.4.3.3. European testing of electromagnetic compatibility of information technology products (EMCIT)

5.4.3.4. Assessment and certification of quality systems in. information technology (ITQS) 
5.4.3.6. Triple X Agreement Group (3X AG) 159

5.4.3.7. POSIX Agreement Group for Testing and Certification (POSAT) 159

$\begin{array}{ll}\text { 5.4.4. European Fire and Security Group } & 159\end{array}$

5.4.5. Quality assurance: EQ-Net 159

5.5. The EOTC: European Organization for Testing and Certification 160

$\begin{array}{ll}\text { 5.5.1. Background } & 160\end{array}$

$\begin{array}{ll}\text { 5.5.2. Description } & 160\end{array}$

$\begin{array}{ll}\text { 5.5.2.1. Objectives and principles } & 161\end{array}$

$\begin{array}{ll}5.5: 2.2 \text {. The role of the EOTC } & 162\end{array}$

5.5.3. The current structure of the EOTC 164

\section{Part 3: Relations between Europe and the rest of the world}

1. Access for third countries to standardization and certification: The principles 168

1.1. Relations with countries authorized to form part of the European Economic Area $\quad 169$

$\begin{array}{ll}\text { 1.1.1. The status of affiliate to CEN and Cenelec } & 169\end{array}$

$\begin{array}{ll}\text { 1.1.2. The PHARE programme } & 171\end{array}$

1.2. Relations with other countries 172

$\begin{array}{ll}\text { 1.3. CEN's 'third-country' unit } & 172\end{array}$

2. Relations with international standards institutions: The Vienna and Lugano Agreements

2.1. The Vienna Agreement (ISO/CEN) 174

2.2. The Lugano Agreement (IEC/Cenelec) 176

$\begin{array}{lr}\text { 3. GATT } & 178\end{array}$

Part 4: Conclusion

List of appendixes

Appendix 1: List of members of CEN (Part 1, Chapter 2, paragraph 2.2) 185

Appendix 2: List of members of Cenelec (Part 1, Chapter 2, paragraph 2.3) 187

Appendix 3: Directive 83/189/EEC (Part 2, Chapter 1, paragraph 3.5) 191

Appendix 4: CEN/Cenelec Memorandum No 4 containing the general guidelines for cooperation between the Commission of the European Communities (CEC) and the European Free Trade Association (EFTA) and the European Free Trade Association and the European standards institutions (Part 2, Chapter 2, paragraph 1.2)

Appendix 5: Resolution of the EC Council of Ministers of 18 June 1992 on European standardization (Part 2, Chapter 2, paragraph 1.3)

Appendix 6: Resolution of the EC Council of Ministers of 7 May 1985 on the new approach (Part 2, Chapter 3) 
Appendix 7: Resolution of the EC Council of Ministers of 21 December 1989 on the global approach (Part 2, Chapter 4, §1)

Appendix 8: Decision of the EC Council of Ministers of 13 December 1990 on modules (Part 2, Chapter 4, § 2)

Appendix 9: List of the members and statutes of the EOTC (Part 2, Chapter 5, 5 )

Appendix 10: Agreement on technical cooperation between ISO and CEN (Vienna Agreement) (Part 3, Chapter 2, $\$ 1$ )

Appendix 11: IEC-Cenelec Agreement on exchange of technical information between both organizations (1989) (Part 3, Chapter 2, § 2) 


\section{Introduction}

From the beginning of the 1980 s, voluntary standards ceased to be considered at Community level as representing a source of technical barriers to trade within Europe, and have instead gone on to become one of the most important mechanisms for bringing about the technical harmonization which is at the heart of the creation of the internal market.

As 1993 came ever nearer and as moves were made to achieve alignment with EFTA countries, so European standardization went hand in hand with the various stages in the process of bringing about the internal market and European economic integration: thanks to the innovative spirit of the 'new approach', the drafting of European standards which are primarily intended to support Community legislation has, among other things, made it possible to involve all business interests in the harmonization process in an effective way.

However, the role of European standards is not confined to this aspect of harmonization: these standards also provide ways of opening-up public procurement contracts, facilitate the emergence of trans-European systems in the fields of transport, telecommunications, information technology, energy, etc., not to mention their purely private and traditional role as a joint communication vector between enterprises: even now, in many industrial sectors, partners prefer to have European standards, or even international ones, rather than purely national specifications.

European standardization is essentially based on the principle of ever greater cooperation. and integration between the national standardization systems of Member States of the European Union and the European Free Trade Association. This approach enables national enterprises, and all the other socioeconomic partners involved, to benefit from a gradual transition from national specifications to European-based standards.

Since standardization operates on the basis of principles of consensus and the greatest possible involvement for the parties involved, and because standards - which have become one of the most important vehicles for achieving European integration - are becoming ever more important within the economy, it is important to popularize a number of their important aspects. How they are drafted, what they are used for, how they are connected with European legislation, how conformity with standards which gives market access is assessed, what degree of cooperation exists between the countries of Central and Eastern Europe and the other countries of the world, what the link is between European and international standardization, etc. 
The main objective of this study, which updates and expands on a previous publication from 1988, is therefore to help disseminate information on subjects which are a priori complex and sometimes even dull - namely standardization, technical harmonization and certification of conformity - in the hope that a better understanding will encourage readers to take part in the process of bringing about European standardization. 


\section{Addendum}

This document was produced in February 1994, since when the following changes have been made to Community legislation:

1. Part 2, paragraph 1.3.5 - Directive $83 / 189 /$ EEC

The second amendment of Directive $83 / 189 / E E C$ referred to in the text was approved by the European Parliament and the Council on 23 March 1994. The text was published in OJ L 100, 19.4.1994, p. 30. The second amendment will enter into force on I July 1995.

2. Part. 2, paragraph 3.2.1. - List of new approach directives adopted

The following two directives must be added:

- Directive 94/9/EEC of the European Parliament and the Council adopted on 23 March 1994 concerning equipment and protective systems intended for use in potentially explosive atmospheres (see OJ L 100, 19.4.1994, p. I).

- Directive 94/25/EEC of the European Parliament and the Council of 16 June 1994 relating to recreational craft (see OJ L 164, 15.6.1994, p. 15). 
Part 1: Standardization and certification in Europe 


\section{Standardization, the best way of organizing economic relations}

\subsection{Definition}

According to the definition accepted by the International Organization for Standardization (ISO) and the United Nations Economic Commission for Europe (UNECE), a standard is a:

'Technical specification or other document available to the public, drawn up with the cooperation and consensus or general approval of all interests affected by it, based on the consolidated results of science, technology and experience, aimed at the promotion of optimum community benefits and approved by a body recognized on the national, regional or international level.'

This definition has been adopted by almost all the official national standards institutions. It is therefore virtually universal. However, there is another definition that should be mentioned: it is to be found in the 1979 GATT Agreement on technical barriers to trade and in the Directive of the Council of the European Economic Community of 28 March 1983, as amended on 22 March 1988, laying down a procedure for the provision of information in the field of technical standards and regulations known as the 'Directive $83 / 189 /$ EEC'. According to these documents, a standard is

'A technical specification approved by a recognized standardizing body for repeated or continuous application, with which compliance is not mandatory.'

The main reason for the difference between these two definitions is that the GATT code and Directive $83 / 189 /$ EEC are concerned with standards only as part of the fight against technical barriers to trade, while ISO and UN-ECE - and, through them, the national standardization bodies - have adopted the definition which best described the activities which they were in practice engaged in on a daily basis, and which corresponds to a broader economic view of the role of standards.

Let us look at the individual components of these two definitions so as to see what the main characteristics of a standard are:

a standard takes the form of a written document approved by a recognized body;

this document is available to the public; 
it is drawn up by a method requiring the approval of all interests concerned and to the benefit of all;

it is intended for repeated or continuous application;

its application is not normally mandatory.

Now let us consider. each of these requirements.

\subsubsection{A written document approved by a qualified or recognized body}

The qualified or recognized body may be national, regional or international. It is recognized either by the public authorities (through a contract, a treaty or by way of legislation or regulation), or (formally or not) by the business partners, which generally founded it in the first place. It is always separate from manufacturers' associations so as to guarantee the necessary independence and objectivity.

The bodies concerned are first and foremost the national standards institutions, which are generally members of ISO. This non-governmental international organization was set up in 1947 and now comprises the national standards institutions of 90 countries (71 members and 19 corresponding members, equivalent to observer status in intergovernmental organizations). There is only one member per country. ISO has to date published more than 7500 international standards drafted by some 2600 technical committees.

The main function of ISO and all of its member bodies is to provide a forum for the standards-making process, to approve standards by a set procedure which ensures their validation (see 1.1.3. below) and to publish them.

\subsubsection{A document available to the public}

The standard is produced by all interested parties to be applied by all interested parties, as shown later. This means that it must be readily available. Consequently, the national and international standards institutions publish their standards and sell them to the public. They also have agreements for the sale of standards to each other so that anyone wishing to obtain a standard of any country, either an international or European standard, has only to apply to the institution in his own country.

\subsubsection{A document drawn up by a method requiring the approval of all interests concerned and to the benefit of all}

These are fundamental characteristics of standards which distinguish them from both technical regulations and industrial specifications.

In content these categories of document may be quite similar since the essential aim is to lay down 'characteristics of a product or a service such as levels of quality, performance, 
safety or dimensions, (including) terminology, symbols, testing and test methods, packaging, marketing or labelling requirements' (ISO definition of a technical specification).

It is clear that technical specifications may be found in numerous documents that are not necessarily standards. Although a technical regulation is drawn up, adopted and published by a public authority without necessarily consulting or obtaining the agreement of other circles and is mandatory, a standard is always the outcome of cooperation between all those concerned. The standards institution which publishes it does so only after ensuring that there is a genuine consensus on the text by circulating it for public comment so as to involve people other than those who took part in the drafting of the standard. Once the public-comment stage has come to an end, the standards institution goes on to validate the standard in accordance with procedures which are peculiar to each country.

The standardization work is essentially carried out in committees or technical groups and any individual or legal entity is free to attend and take part in the work. This distinguishes the standard from the technical regulation, and also from the industrial or company specification or standard drawn up in a select group representing only some of the interests involved, and applicable not to the whole economic fabric like standards or regulations which are universally valid, but merely to a specific company or category.

\subsubsection{A document for repeated or continuous application}

This is the feature that distinguishes the standard from the public or private procurement specification: a standard is considered to be generally valid for a product or service. It is of course used as a reference in numerous contracts - that is even one of its prime functions - but a purchaser may want to obtain a product or service with specific characteristics differing from the products or services normally available on the market. He will then draw up a call for tenders in which he will add a number of criteria to the standard in force.

The standard is therefore intended to meet the needs of the greatest number: it is a sort of highest common denominator in a given economic and industrial area. Historically, the standard, has in most cases, followed on the heels of progress, laying down the characteristics of products already widely marketed for which a reference has become necessary so as to organize production or the market as efficiently as possible. This is not the case nowadays: increasingly, standards are issued almost contemporaneously with technological developments as a result of the increasing rate at which new products and technologies are appearing on the market and also a need to have standards to ensure the economic success of such new technologies. In addition, standards are becoming increasingly concerned with defining the characteristics of services. Finally, it should be pointed out that standards are regularly revised so as to keep abreast of technological development.

\subsubsection{A non-mandatory document}

This characteristic, which distinguishes the standard from the technical regulation, has much to do with the way in which the standard is drawn up (voluntary initiative and 
participation, adoption by consensus or vote), and also with the very foundations of liberal societies where everything that is not prohibited is allowed and those involved in the economy are left the greatest possible degree of freedom.

Making standards mandatory in a general way would also tend to inhibit progress if it had the effect of imposing a given technological solution (this is particularly the case with standards concerning 'means'; see below). However, there are countries in which all standards are mandatory as they have a different economic and social organization. Until very recently, this was the case in the countries of Central and Eastern Europe with planned economies. However, these countries are now in the process of reorganizing their entire regulatory and standardization systems so as to bring them into line with those which exist in the countries of Western Europe. In market-economy countries, the State may make certain standards mandatory and sometimes does so, essentially for safety reasons, but this is never general practice.

\subsection{The content of standards}

\subsubsection{The different types of standards}

There are several typologies for standards:

\section{(1) Structural typology}

A distinction is drawn here between the standard concerning the means and the standard concerning results or performance.

The former describes in detail the means to be used to ensure that the required characteristics are actually attained. As a result, it is in principle very detailed and may describe in the tiniest detail the manufacturing process to be followed and all the technical properties of the materials and components used.

The latter merely contains a precise description of the characteristics its subject is required to have without describing its make-up or the means that have to be used to achieve the required result.

Standardizers now tend to prefer the standard concerning performance to the standard concerning means for two reasons. Firstly, as will be seen, the standard specifying means may put up technical barriers to trade and secondly it may, by freezing technology at a given level, impede later technological progress.

The exclusive use of standards concerning performance may, however, lead to complicated, time-consuming and expensive test procedures which have to be specified in the absence of any precise description of the means to be employed. 


\section{(2) Functional typology}

Here the various types of standards are distinguished by content. There are several classifications involving various degrees of detail.

The classification considered here is as follows:

Basic standard: a general standard containing general provisions applicable to a field that may or may not be specific (for example, this category includes measurement standards).

Terminology standard: a standard concerned exclusively with terms, usually accompanied by their definition and sometimes by symbols, explanatory notes, illustrations and examples.

Product standard: a standard specifying all or a part of the requirements (dimensional characteristics which make it possible to achieve consistency or compatibility in respect of the products, quality levels, specifications relating to compatibility with the environment, etc.) to be fulfilled by a product or group of products to establish its fitness for purpose. Some product standards are often referred to as being 'horizontal' in nature, in the sense that they cover characteristics which are common to many products. This is particularly the case in the field of safety (machinery, for example).

Testing standard: a standard concerned with test methods to verify whether a product or material has the characteristics required of it; it may also contain provisions relating to the test in question, such as sampling, use of statistical methods, etc.).

Safety standard: a standard containing specifications to guarantee the safety of people, animals and property.

Service standard: a standard specifying all or a part of the requirements to be fulfilled by a service to establish its fitness for purpose. The standard will contain a clear description of the characteristics of the service and also their acceptance criteria.

Engineering or planning standard: a standard for the design, production or installation of plant, apparatus and structures together with working or operating conditions.

Organization standard: a standard specifying the organizational methods to be employed to ensure that the various departments of the enterprise run efficiently (e.g. the quality assurance department which manages the enterprise's quality control system in accordance with the ISO 9000 series of standards, or certification and accreditation bodies which must be organized in accordance with the EN 45000 series of standards).

\section{(3) Administrative typology}

This is merely mentioned for the record; it distinguishes standards according to their administrative classification in the various collections of national standards: for example, a definitive or experimental standard. 


\subsubsection{The major sectors of standardization}

This is a different typology of a technological nature, i.e. a classification broadly corresponding to the major economic sectors.

This is how standards are classified in collections of national standards and it gives an idea of the scope of standardizing activity in the main industrial branches.

We shall take as an example the classification used by CEN/Cenelec for the purposes of the European procedure for the provision of information on standards: (it should be noted that this classification system, which was established in 1985, should be refined to take account of changes in the subjects covered by standardization, such as: service standards, analysis standards, multi-sectoral standards, etc.).

\begin{tabular}{ll}
\hline Reference & Sector \\
\hline B & Building and construction \\
C & Chemicals, chemical engineering and food products \\
F & Fundamental standards \\
H & Products for domestic and leisure use \\
I & Mechanical engineering \\
M & Metallic materials \\
N & Non-metallic materials \\
S & Health, environment and medical equipment \\
T & Transport, mechanical handling and packaging \\
$\mathrm{U}$ & General electrotechnical standards \\
V & Electronic engineering \\
W & Electrical engineering \\
X & Undetermined standardization area ' \\
Z & Information technology \\
\hline
\end{tabular}

1 This is reserved for one or more future categories of standards not yet identified.

\subsection{Standardization objectives and uses}

\subsubsection{Standardization objectives}

The definition of a standard states that it is aimed at 'the promotion of optimum community benefits'.

This expression should be clarified in order to obtain a better idea of the contribution made by standardization to social and economic life. Of the various documents which exist on this subject, British standard BS 0, Part 1 summarizes the expected advantages as follows:

(a) 'promotion of quality of products, processes and services by defining the characteristics which determine their capacity to meet given needs, i.e. their fitness for use; 
(b) promotion of improvements in the quality of life, safety, health and the protection of the environment;

(c) promotion of economy in human effort, materials and energy in the production and exchange of products;

(d) promotion of clear and unambiguous communication between all interested parties, in a form which is suitable for use as a reference or quotation in documents which have legal force;

(e) promotion of international commerce by the elimination of barriers caused by differences in national practices;

(f) promotion of industrial efficiency through control of variety.'

The first comment to be made on this list concerns (c) and (f): they form the prime objective of standardization. It facilitates mass production and interchangeability of components and products, i.e. the very foundation of industrial production, and trade on a large scale. It also explains why, a long time ago, standardization as we know it today was started by associations of manufacturers.

This first objective, based on the principle of rationalizing the economy, was rapidly joined by objectives in the general interest, i.e. of society as a whole, which have now gained considerably in importance (see (a) and (b) of the definition above): it is a question of guaranteeing not only safety, health and environmental protection but also production quality (hence the famous ISO 9000 standards on quality assurance systems in enterprises).

There is also a growing need to make the relationships between business partners clearer and more transparent by promoting a certain code of ethics via a standard (in France, for example, the relationship between franchisers and franchisees is covered by a standard, in the same way as the after-sales service in many countries). These elements reflect a continuous and gradual move towards greater responsibility for the inhabitants of market-economy countries. The latter (manufacturers, consumers and scientists) are taking on responsibility for collective well-being through the process of standardization.

More generally, standards are now primarily considered as providing an important vehicle for communication (see (d) of the definition above) in that they enable the various parties involved to find their bearings through a shared language.

Finally, it should be added that more and more standards are directly aimed at making communication possible, e.g. intert-operability standards in the fields of telecommunications and information technology.

The main characteristic of standardization objectives is therefore their adaptability, since these are in fact the objectives pursued at a given moment in time by a particular society (for example, environmental protection is currently giving rise to major standards programmes around the world). It should also be noted that successive objectives are not eliminated, but gradually become stratified as time goes by (in developed societies, the safety of domestic electrical appliances is taken for granted by the general public, and consumers will in future be interested in their characteristics in terms of design, energy saving, pollution, etc.). 
Standardization is organized in the light of the aforementioned objectives, not only as regards procedural rules (committee work, search for a consensus, etc.) but also as regards its purpose, i.e. the standard itself. Before any standardization work is started, the following questions must be asked:

Is the standard necessary, economically speaking? (Priorities to be established.)

Is the standard wanted by the main parties involved? (If it is not wanted it will not be applied.)

Is the standard feasible? (Not only technically but also as regards the existence of patents, for example, or restrictive regulations on the same subject.)

The standardization work should not be started until all these criteria have been studied and answered in the affirmative.

\subsubsection{The main uses of standards}

This has already been discussed in 1.1., 'definition of standards', and will merely be mentioned briefly here.

\section{(1) The standard in inter-industry and commercial relations}

Standards are used in almost all business activities; a company issuing a call for tenders or seeking suppliers will do so on the basis of standards describing the product it wishes to buy, possibly accompanied by additional specifications relevant to its specific requirements. (In the same way, manufacturers' catalogues describe products in relation to standardized characteristics). It will then pay for its order by standardized processes (cheque, transfer, etc.). The production process within the company, testing, measurement and quality control are also organized on the basis of standards, to say nothing of the distribution chain for goods which is standardized from the packaging stage until the product appears on the supermarket shelf.

In some countries, insurance companies even impose extra premiums on firms using equipment not complying with standards. The standard is therefore a tool without which our extremely sophisticated societies could not function: it provides a link and indeed a common language for all the business parties involved, which is all the more necessary in that it concerns activities which in actual fact constitute networks which only run properly if they are technically consistent (this is the case with telecommunications, the transport sector and even the water cycle sector).

\section{(2) The standard in public regulations}

To avoid the need for regulations to contain a detailed description of the requirements to be satisfied by a given category of products, the public authorities in many countries frequently make use of standards. Standards can be used in regulations in several ways: 
The standard is made binding by a legal instrument issued by the competent public authorities (and not by the standards institution itself).

The standard is recommended or advised by what is known as 'reference' to standards. The reference to standards technique varies depending on the country and the aims pursued. It may be a reference to a precise dated standard, in which case the regulation obviously has to be amended later if and when the standard is revised. It may be an undated reference in which only the number of the standard or standards is mentioned in the regulation. Finally, it may be a general reference to standards as 'acknowledged rules of technology' as they are usually called.

In that case, where products comply with all the standards concerning the subject covered by the regulations they are assumed to be in conformity with those regulations. (Lists of standards to which it is possible to refer in the case of a particular regulation are generally published by the competent authorities in their official journals.)

For the sake of completeness, it should be mentioned that standards are also very frequently used by public-sector purchasers to ensure the quality of services (policy on quality, testing, public-sector contracts, etc.) in their contracts either because they are legally obliged to do so or because they do so voluntarily.

It will be seen later (Part 2) that these different ways of using standards have been adopted and developed by the European Union, resulting in a coordinated and consistent policy for establishing and regulating the European internal market by means of standards.

\section{(3) Standards and attestation of conformity (more commonly known as 'certification')}

The various types of certification of conformity are examined in detail later, in Chapter 4 of this part of the study.

However, the concept of certification of conformity needs to be defined more precisely at this juncture: as its name indicates, this activity involves certifying that a product or service conforms to one or more technical specifications (and therefore, for example, to standards). Such certification of conformity may be provided by the supplier of the product or service (which may be the manufacturer, though this is not always the case) or by an outside body, i.e. a body independent of the manufacturer.

Such certification serves to guarantee that the product or service in question actually meets a number of criteria, thus indicating that it is fit for its intended purpose.

\section{(4) Standards and case-law}

Since standards codify what is known as 'the state of the art', they are very frequently used by courts as technical supporting documents in the event of disputes. 


\subsection{Comparative table}

The following table compares standards within the meaning of ISO and other standardizing documents and clarifies the main differences between these documents at the various stages of their 'life': drafting, adoption and application.

\begin{tabular}{|c|c|c|c|c|c|}
\hline & $\begin{array}{l}\text { Company } \\
\text { standards }\end{array}$ & $\begin{array}{l}\text { Codes of } \\
\text { practice or } \\
\text { professional } \\
\text { specifications }\end{array}$ & Standards & $\begin{array}{c}\text { Public } \\
\text { contract } \\
\text { specifications }\end{array}$ & Regulations \\
\hline Drafting & Company & $\begin{array}{c}\text { Members of a } \\
\text { profession }\end{array}$ & $\begin{array}{l}\text { All interested } \\
\text { parties }\end{array}$ & $\begin{array}{l}\text { All interested } \\
\text { parties }\end{array}$ & $\begin{array}{c}\text { Public } \\
\text { authorities }\end{array}$ \\
\hline Adoption & Company & $\begin{array}{c}\text { Members of a } \\
\text { profession }\end{array}$ & $\begin{array}{l}\text { Consensus } \\
\text { and } \\
\text { validation }\end{array}$ & $\begin{array}{c}\text { Public } \\
\text { authorities }\end{array}$ & $\begin{array}{c}\text { Public } \\
\text { authorities }\end{array}$ \\
\hline Application & $\begin{array}{l}\text { Company/ } \\
\text { companies }\end{array}$ & $\begin{array}{c}\text { Members of one } \\
\text { or more } \\
\text { professions }\end{array}$ & $\begin{array}{c}\text { Business } \\
\text { interests } \\
\text { (voluntarily) }\end{array}$ & $\begin{array}{c}\text { Business } \\
\text { interests } \\
\text { (public } \\
\text { contracts) }\end{array}$ & $\begin{array}{c}\text { Business } \\
\text { interests } \\
\text { (compulsorily) }\end{array}$ \\
\hline & & \multicolumn{3}{|c|}{$\begin{array}{l}\text { The public authorities may make these } \\
\text { documents compulsory or refer to them }\end{array}$} & \\
\hline
\end{tabular}




\section{Standardizing methods in Europe}

\subsection{National methods}

\subsubsection{Similarities and differences in national standardization structures}

Set up for the most part early in the 20th century and especially between the two world wars, the standards institutions are the main instruments of standardization policy in European countries.

There are great similarities in the statutes and operating methods of these bodies: they are almost always associations set up by trade associations and are generally supported by public authorities, with their primary role being to prepare and publish standards by a procedure ensuring that all those involved can have a say. National public authorities recognize these documents as national standards and give them preference as references in public procurement specifications or as a reference document for the application of technical regulations.

Unlike the situation in the USA and Canada, where several hundred organizations publish standards, each in its own field, the European countries have centralized structures although, largely for historical reasons, the electrotechnical sector is an exception (see 2.1.2. below). More recently, the telecommunications sector - which had hitherto been dealt with at national level by the regulations, with a number of standards administered within the usual framework of standardization - has moved towards standardization at European level within the ETSI (see 2.2.4. below).

By and large, however, the organization adopted at national level for standardization in this sector does not differ from the other sectors, or, if it does, the choice is not a definitive one. This is why telecommunications will only be studied from the 'European' point of view.

Because of this situation and because the national bodies all operate in a similar way, Europe has been able to play a key role in setting up an international standardization system patterned on national systems:

- Sectoral 'technical committees' bring together experts on topics in the work programme for the preparation of draft standards. These unpaid experts come mainly from industry which, as stated earlier, looks upon standardization as an essential investment for growth.

- A system of supporting structures, which is sometimes decentralized, provides the logistic support needed and through the circulation of documents for public comment ensures that a consensus is attained.

- A system for the commercial publication and distribution of the standards adopted. 


\section{Comparative table of some standards institutions in Europe}

(The figures are taken from ISO and CEN

documents and refer mainly to 1990)

\begin{tabular}{|c|c|c|c|c|c|c|}
\hline Country & $\begin{array}{l}\text { Standards } \\
\text { institution }\end{array}$ & Status ' & Staff & $\begin{array}{l}\text { Number of } \\
\text { pages of } \\
\text { standards }{ }^{3}\end{array}$ & $\begin{array}{c}\text { Annual } \\
\text { output of } \\
\text { standards }\end{array}$ & $\begin{array}{l}\text { CEN-ECISS } \\
\text { Secretariat } \\
\text { (out of } 242 \\
\text { technical } \\
\text { committees) } \\
\text { (1991 figures) }\end{array}$ \\
\hline Denmark & DS & 1 & 90 & $\begin{array}{l}20000 \\
\left(\begin{array}{ll}3 & 261\end{array}\right)\end{array}$ & 259 & 10 \\
\hline Germany & DIN & 2 & 800 & $\begin{array}{l}120000 \\
(24000)\end{array}$ & 1500 & 68 \\
\hline Spain & AENOR & 1 & 97 & $\begin{array}{l}85190 \\
(8597)\end{array}$ & 600 & 0 \\
\hline France & AFNOR & 1 & 530 & $\begin{array}{l}166034 \\
(15230)\end{array}$ & 1100 & 50 \\
\hline Italy & UNI & 1 & 90 & $\begin{array}{l}43566 \\
(8341)\end{array}$ & 537 & 18 \\
\hline Netherlands & NNI & 2 & 170 & $\begin{array}{r}104756 \\
(5318)\end{array}$ & 450 & 14 \\
\hline United Kingdom & BSI & 1 & $1700^{2}$ & $\begin{array}{l}278000 \\
(11600)\end{array}$ & 1100 & 55 \\
\hline \multicolumn{7}{|c|}{$\begin{array}{l}\text { Status: 1. Organization under private law but given a public service function by the State. 2. Private organization. } \\
2 \text { More than half the staff is engaged on testing laboratory and certification work. } \\
\text { "The approximate number of standards is given in brackets. } \\
\text { + Order of magnitude: it should also be stressed that this number includes not only standards resulting from international an } \\
\text { European processes but also those resulting from the purely national process. }\end{array}$} \\
\hline
\end{tabular}

National variations around this basic pattern mainly concern the following aspects (illustrated in the above table):

The percentage breakdown of the different types of financial resources available to the standards institutions: voluntary contribution from industry, sale of standards and similar services (e.g. certification), public subsidies.

The extent to which the structures basically responsible for preparing draft standards are centralized: they may come under the auspices of trade associations (partially the case in Germany and France) or be integrated in the national institutions itself (United Kingdom).

The degree to which they are dependent on the national authorities, ranging from complete independence (Switzerland, for example) to the case of Portugal where the institution is a department of the Ministry of Industry. Similarly, the idea of 'public service' generally associated with standardization may be defined either contractually between the State and the institution (as in the Federal Republic of Germany and the United Kingdom) or by regulation (France, Italy and Spain). 
The degree to which they are involved in promoting CEN's technical activities, given that they all play an active part in implementing the public-comment and formal adoption procedures for European standards.

Finally, the size of the institution which may range from a staff of less than several dozen to over 1000 (BSI) where the institution has built up numerous services complementary to standardization proper.

\subsubsection{The specific case of the electrotechnical field}

From the end of the 19th century the development of consistent grid systems was seen as one of the essential conditions for the wider use of electricity.

The need to draw up new rules guaranteeing a level of safety sufficient to ensure that the new form of energy was socially accepted was also recognized at a very early stage.

Because of these two requirements the industries concerned (producers and distributors of electricity, manufacturers of electrical equipment) equipped themselves with collective facilities (laboratories and standardizing bodies) well before other industries.

Thus, from the beginning of the 20th century, 'electrotechnical committees', appeared in the main European countries and in the United States of America, comprising principally producers of electrical energy and electrical equipment manufacturers.

As from 1946 these bodies maintained institutionalized relations at European level with the CEE-el (International Commission on rules for the approval of electrical equipment), and in particular CENEL and Cenelcom, which merged to form Cenelec in 1973.

Relations at international level were established even earlier with the emergence of the IEC (International Electrotechnical Commission) founded in London in 1906 following decisions taken in 1904 at the Saint Louis Congress.

As, generally speaking, the national electrotechnical committees predate the formal establishment of national standards institutions covering all economic sectors, they have in most countries retained a high degree of independence from these general standardizing bodies.

Nevertheless, it should be pointed out that the procedures used to prepare standards in the electrotechnical sector are virtually identical to those used by national institutions, which in any case generally take over responsibility for the final phase of circulating the draft standard for public comment and give it its 'national' status.

This is reflected at European level in the existence of a whole array of common rules for the electrotechnical sector and the other sectors within CEN, particularly as regards the procedure for drafting and formally adopting standards (voting rules, etc.). In addition, because of the increasing interpenetration of technologies which sometimes blurs the dividing lines between sectors, coordination mechanisms have been established at several 
levels between CEN and Cenelec. Likewise, these two bodies work together with the telecommunications sector (see Section 2.2.5. with regard to cooperation between CEN/Cenelec and ETSI).

\subsection{The European structures}

\subsubsection{Introduction}

There are currently three European standards institutions, which operate autonomously but in a coordinated manner: one of them specializes in the electrotechnical sector (Cenelec: European Committee for Electrotechnical Standardization) and another specializes in the telecommunications sector (ETSI: European Telecommunications Standards Institute); the third institution, CEN (European Committee for Standardization), is responsible for covering all the other sectors and brings together the national standards institutions of the countries of Europe.

There is nothing surprising about the European standardization scene having this format if it is borne in mind that these organizations were not created in accordance with an original process, but resulted from a decision on the part of the national parties involved to move closer together so as to coordinate their action at European level: quite naturally, the electrotechnical sector - which had to a large extent become accustomed to dominant international standardization - reproduced its specific features at European level; in the same way, the telecommunications sector, in which the national administrations exert a decisive influence, and which likewise had an international technical forum (the CCITT: International Telegraph and Telephone Consultative Committee), has felt the need to create an independent standardization structure at European level.

\subsubsection{CEN and its associated structures}

The European Committee for Standardization (CEN) is a non-profit-making international association of a scientific and technical nature registered in accordance with Belgian law. Its statutes were published in the Moniteur belge on 29 January 1976; however, this body had been established back in 1961, and subsequently moved its headquarters from Paris to Brussels in 1975.

Until June 1992 the only members of this association were the national standards institutions of the 18 countries of Western Europe (the 12 members of the European Economic Community and six of the seven members of the European Free Trade Association, EFTA, with Liechtenstein not having a standards institution). The 13 organizations are also the European members of ISO, with the exception of Luxembourg, which is not affiliated to the international organization.

In June 1992, the General Assembly of CEN decided to create a new category of members within CEN; these members, known as 'the associates', will be 'the organizations representing economic and social interests at European level, whose status is governed by 
European law or the national law of one of the countries of the national members of CEN and which meet the following conditions:

participation in these organizations is open to the authorities or interested nationals of all countries which have a national member of CEN, provided that they meet the rules in force within these organizations;

they have a legitimate interest in European standardization in general, or at least in a broad area of activity;

they are capable, through their members and internal organization, to contribute usefully and in a representative manner to the objectives of CEN;

they undertake to further the objectives of CEN and to promote standardization'.

Associates do not have voting rights but may take part in discussions which take place prior to decision-making. They can also voice their opinions within the Technical Sector Boards which are responsible for managing CEN's standardization programmes in the major sectors of economic activity.

Responsibility for promoting the association's activities is entrusted to a central secretariat based in Brussels which currently has a staff of more than 80 people; however, it should be noted at this point that responsibility for organizing standardization work in Europe, which is described in more detail in Section 2.4. below, falls not only on this central secretariat but also on the national members as well as on a large number of experts who, at all levels of the organization, make their contribution to the drafting of European standards in a voluntary way.

A number of CEN bodies are thus made up purely of representatives of the national institutions which are members (e.g. the Administrative Board, which is responsible for supervising the general administration of the system, or the Technical Board, which is responsible for the satisfactory coordination of technical activities and for taking the necessary administrative decisions in connection with the standards adoption procedures, in accordance with the Rules of Procedure).

However, other bodies, which are much more numerous, involve experts from all areas affected by the activities of CEN (industry, public administrations, scientific fields, consumers, trade unions, etc.): these are the Technical Committees (TCs), which numbered more than 250 in 1991 and which are responsible for the drafting of European standards in well-defined sectors. The secretariat of each of these TCs generally goes to one of the national members of CEN, while the chairmanship goes to someone whose expertise is recognized by all the parties involved.

Programming Committees (PCs) and Technical Sector Boards (TSBs) have recently been set up in order to provide a better interface between CEN's general administrative bodies and the business parties affected by the standardization programmes. These sectoral bodies, which are responsible for coordinating activities in a fairly broad field sometimes covering several dozen Technical Committees (e.g. building, mechanical construction) - make it easier to devise a CEN strategy for action since they comprise representatives of the main parties involved, either in connection with the national delegations organized by the member institutes or directly at European level. 
The following Technical Sector Boards and Programming Committees exist:

Technical Sector Boards:

TSB 1: Building and civil engineering

TSB 2: Mechanical engineering

TSB 3: Health care

TSB 4: Health and safety in workplaces

TSB 5: Heating, cooling and ventilation

TSB 6: Transport and packaging

TSB 7: Information technology

\section{Programming Committees:}

PC 3: Gas

PC 4: Food products

PC 6: Water cycle

A 'railways' PC also exists which is organized jointly with Cenelec.

CEN's programme of activities currently includes the drafting of about 7200 European standards; in certain cases, the documents concerned have a slightly different legal status and are known as pre-standards (ENVs) or harmonization documents (HDs).

However, it should be noted that although CEN's procedures are systematically followed when each standard is adopted, the task of preparing these documents is not always entrusted to groups of experts working within a technical committee: this is because it is CEN policy to avoid the duplication of work (a pointless waste of experts, who are not easy to find) and also to make as much use as possible of agreements which have been concluded at international level so as to implement them at European level. Cenelec has a similar policy.

Thus, CEN has signed cooperation agreements with European bodies known as ASBs (associated bodies); the latter are required to prepare draft standards for CEN in certain specific sectors, with CEN for its part undertaking to proceed with the final stages of the public-comment process, formal adoption and official publication of the standards.

Some of these bodies, e.g. the aerospace sector covered by AECMA (European Association of Aerospace Manufacturers) or the electronic data exchange sector which is covered by Edifact, thus have autonomous structures, while others operate within the legal framework of CEN but in accordance with their own rules and with specific financial resources. This is the case, for example, with the steel sector (ECISS: European Committee for Iron and Steel Standardization) and the open information systems sector (EWOS: European Workshop for Open Systems).

In addition, CEN also signed an agreement with ISO in June 1991 which is generally known as the Vienna Agreement; this agreement establishes mechanisms for cooperation 


\section{Organization chart for $\mathrm{CEN}^{1}$}

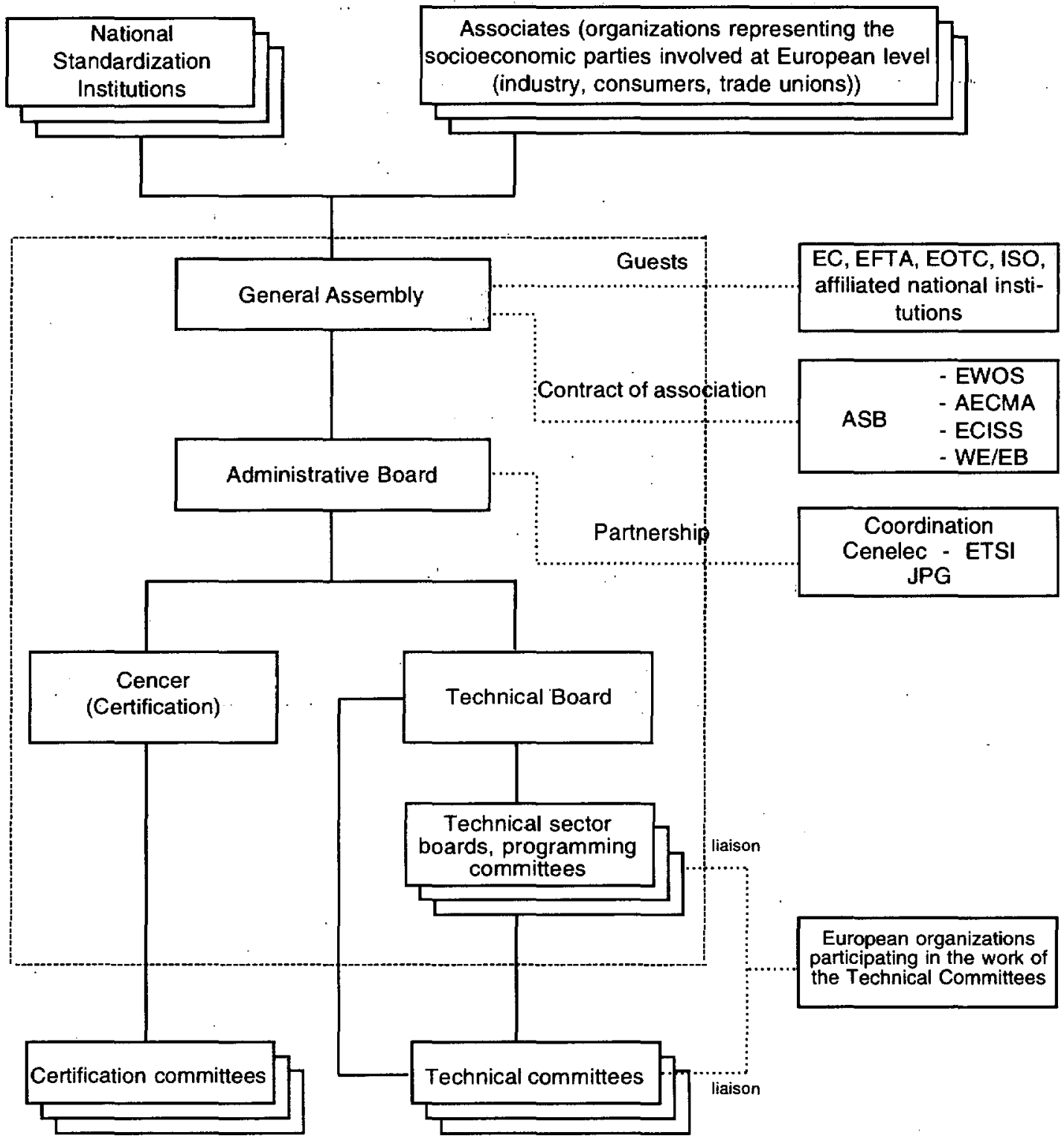

Bodies administered by the Central Secretariat

${ }^{1}$ For the explanation of the acronyms, refer to the glossary at the end of the report. 
between the two organizations, ranging from the exchange of information to the possibility of ISO having an observer on CEN's Technical Committees, and vice versa, or CEN having the option of asking ISO to undertake work which is to serve as a basis for the adoption of a European standard (see Part 3, Chapter 2 for details of how the Vienna Agreement works).

CEN funding is, to a large extent, provided by the national institutions which, in addition to financing their own activities in connection with the European standardization, provided $43 \%$ of the funding for the Central Secretariat in 1992. The rest of the funding for the Central Secretariat is mainly provided by the European Union and EFTA, which provide CEN with contracts which make it possible to formulate programmes of European standards which are intended to support the implementation of harmonizing directives as part of the 'new approach' policy as well as directives on the opening-up of public contracts and, more generally, European industrial policy (see Part 2).

It should also be noted that when such contracts exist, they also help with the partial defrayal of costs associated with the national institutes which provide the secretariat with the relevant technical committees.

To find out more about CEN, the various publications issued by this organization can (depending on the nature of one's interest) be consulted. These publications include a catalogue of European standards, a register of draft standards, a memorandum describing all the operational structures and a technical schedule describing the main programmes which are in operation within the various sectors. All this information is also available at national level from the member bodies of CEN (see the simplified organization chart for CEN below; a list of the national members of CEN is provided in Appendix 1 of this report).

\subsubsection{Cenelec (European Committee for Electrotechnical Standardization)}

Like CEN, Cenelec is a non-profit-making international association which is registered in accordance with Belgian law and whose 18 members are drawn from the same countries as those of CEN, namely:

the national Electrotechnical Committee which has a legal status (e.g. Italy, Sweden and the Netherlands),

a national organization which has a legal status and which is responsible for electrotechnical standardization activities (two possibilities exist in this case: the Cenelec member is the same as the CEN member, e.g. Greece, Spain and Portugal, or is a separate body: France and Switzerland), or

a chairman of a national electrotechnical committee or a national organization which is responsible for electrotechnical standardization activities without having legal status (e.g. Germany and the United Kingdom). 
As stated above, the working methods and standards adoption procedures of CEN and Cenelec are virtually the same and will therefore be studied together. Of course, the standards of the electrotechnical sector form an integral part of the national standards collections so as to ensure that the latter are consistent and cohesive and, to this end, national standard status is (except in the case of Italy) conferred solely by the national institution which is a member of CEN, which is legally responsible at national level for doing this.

Although Cenelec was established on 13 December 1972, European electrotechnical standardization actually began in the 1960 s (with a smaller number of countries) within structures known as Cenelcom, at EC level, and then CENEL, with the latter also including the member countries of EFTA (one of which was the United Kingdom at that time).

The existence of CECC (Cenelec Electronic Components Committee) within this group of bodies should also be noted, with this organization being responsible for harmonizing specifications for electronic components.

Cenelec, whose headquarters and Central Secretariat are located in Brussels (near those of $\mathrm{CEN}$ ), shares joint services with the latter (e.g. data-processing infrastructure).

Cenelec's remit essentially covers the following areas, and the resulting standards often provide references for implementing Community Directives, and particularly the Low Voltage Directive, whose adoption in 1973 gave a major boost to European harmonization activities in the electrotechnology sector (see Part 2):

- electrical safety of devices which use a low voltage (between $50 \mathrm{~V}$ and $1500 \mathrm{~V}$; see Directive 73/23/EEC relating to electrical safety, or low voltage, referred to above);

- specifications for certain items of electrical equipment covered by special Directives (electro-medical equipment, equipment used in explosive atmospheres, electrical safety of machinery, electromagnetic interference, electrical equipment for railways, etc.);

- the field of information technology and telecommunications, in close collaboration with CEN and ETSI;

other activities which may or may not be connected with implementing standardization mandates issued by the EC and EFTA, and which are intended to reduce technical barriers to trade in the electrotechnical sector, or which have an impact on this sector.

As with CEN, funding for Cenelec's Central Secretariat - which currently comprises 37 individuals - is provided via contributions from the national members and via funds from the EC/EFTA, in the proportion of $70 \%$ and $30 \%$ respectively.

It should be emphasized that Cenelec works very closely with the IEC at international level: in 1991, $90 \%$ of the standards adopted by Cenelec were the European version of the harmonization results negotiated within the IEC. Cenelec is linked to the IEC by the Lugano Agreement, which is examined in Part 3 of this report (Chapter 2). 


\section{Organization chart for Cenelec ${ }^{\prime}$}

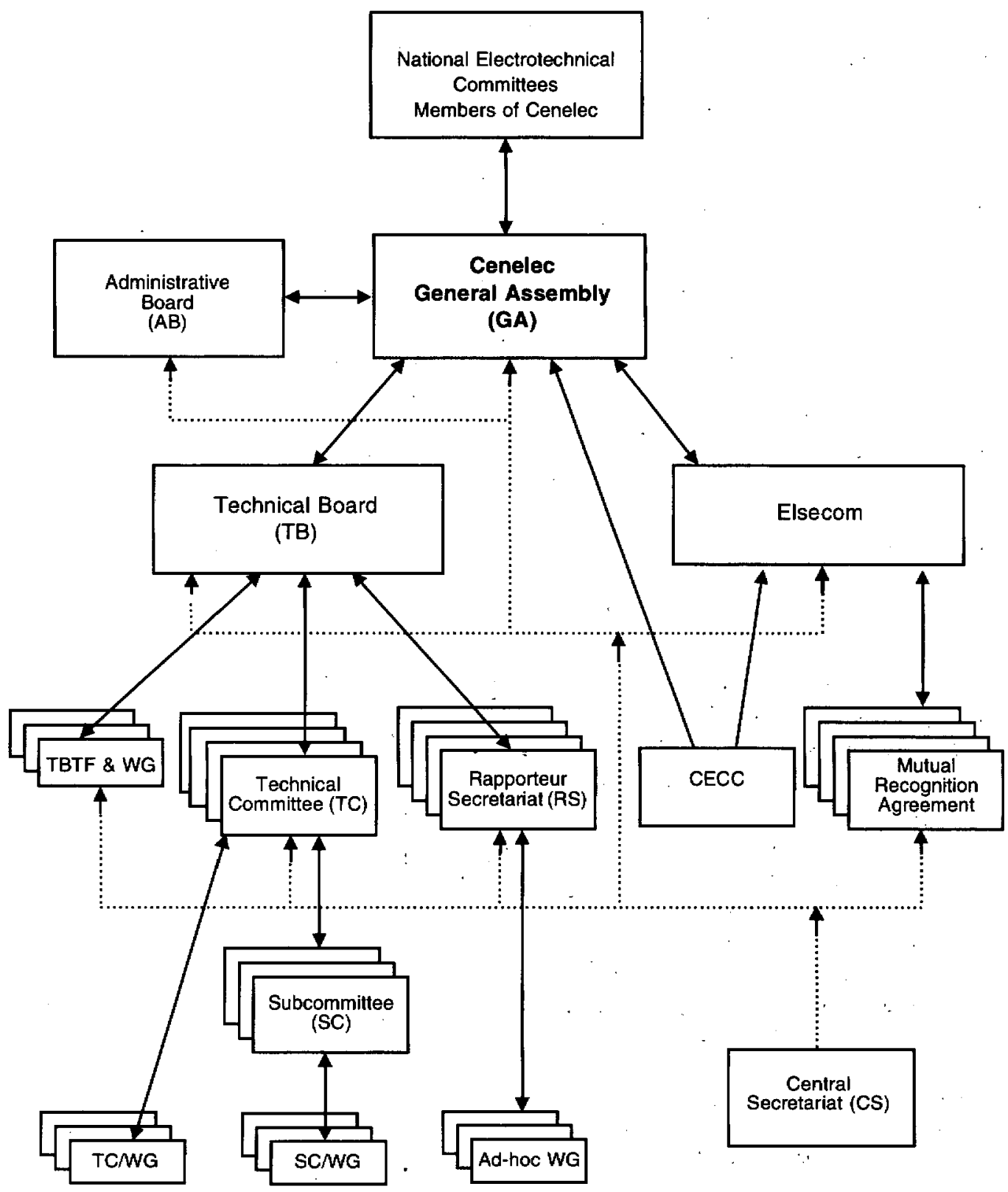

${ }^{1}$ For the explanation of the acronyms, refer to the glossary at the end of the report 
Up to now, Cenelec has adopted around 1.200 European documents (European standards and harmonization documents) and is currently working together with the IEC on some 1.300 subjects.

Cenelec has 71 Technical Committees which operate in accordance with joint rules with CEN (see Section 2.4. below).

As in the case of CEN, a number of publications are available which deal with Cenelec's activities (catalogue, annual report, programme of activities, etc.) both at national level and at the organization's headquarters in Brussels (see the simplified organization chart for Cenelec below; a list of the members of Cenelec is provided in Appendix 2 of this report).

\subsubsection{ETSI (European Telecommunications Standards Institute)}

ETSI was established in 1988 on the initiative of the European Conference of Post and Telecommunications Administrations (CEPT) and in response to the Green Book published by the European Commission on the subject of the development of telecommunications in Europe. Its establishment was prompted by the need to provide Europe with the necessary resources to speed up the technical harmonization process in the field of telecommunications, a process which was indispensable for networks, industry and new technologies to be able to make progress.

ETSI's task is therefore to define common standards (recognizable by the acronym 'ETS', European Telecommunications Standard) enabling Europeans to develop an integrated telecommunications infrastructure, ensure that new services offered to users in the future are compatible and guarantee the technical compatibility of the various terminal devices available on the market.

There is some measure of overlap between the fields of telecommunications and information technology. As a result, ETSI is a key partner of CEN and Cenelec, particularly within the coordination bodies which are referred to in the following section (2.2.5.).

ETSI is also active in the broadcasting sector (TV sound and pictures), cooperating with the competent bodies in this connection (particularly the European Broadcasting Union (UER)).

Part of ETSI's programme of activities, which currently covers 1020 subjects, is intended to provide support for Community policies on telecommunications, and is for this reason financed by the budget of the European Community and EFTA. ETSI's other resources are provided via contributions from members, special contributions from national telecommunications administrations and, to a small degree, by the sale of standards.

By the beginning of the last quarter of 1992, ETSI had published 80 standards, while around 300 others were at the public-comment or voting stage. 
ETSI, which is the most recent of the three European standardization organizations and which is geared entirely to advanced technologies, has acquired structures and a method of operation which diverge from those of CEN and Cenelec on many points.

The reason for this is that ETSI, whose headquarters are located at Sophia Antipolis (France), is a non-profit-making association which is governed by French legislation.

The following may become members of this association:

national administrations responsible for telecommunications and national standards bodies;

operators of public telecommunications networks;

companies involved in the telecommunications equipment market;

users of telecommunications services;

research bodies, consultancies, etc.

These partners may join as individuals or as part of the European bodies comprising them, and must come from member countries of the CEPT, i.e. the Member States of the European Union and EFTA, the countries of eastern Europe, Turkey, Cyprus and Malta. At the present time, 24 countries are represented within ETSI by fully authorized members.

ETSI also has an 'associate members' category which is reserved for organizations which cannot become full members of ETSI but whose interest in its work and contribution to ETSI justify participation. Such members, who may come from countries outside CEPT, do not have any voting rights. Israel and Australia are the two principal countries represented in this way.

ETSI is mainly organized around four main elements:

the General Assembly

the Technical Assembly

the Technical Committees

the Director and the Secretariat.

The General Assembly fulfils the role which is ordinarily reserved for this type of body in associations. It is the supreme authority which elects the Presidents, decides on admissions, passes the budgets, approves the accounts, rules of procedures, etc.

The technical assembly also brings the members together, and its main functions are:

to adopt the work programme and priorities, taking account of the available financial resources in particular;

to set up (or dissolve) technical committees and drafting groups;

to adopt draft standards and other technical documents prepared by ETSI (reports, etc.). 


\section{Organization chart for $\mathrm{ETSI}^{1}$}

\section{The telecommunications market}

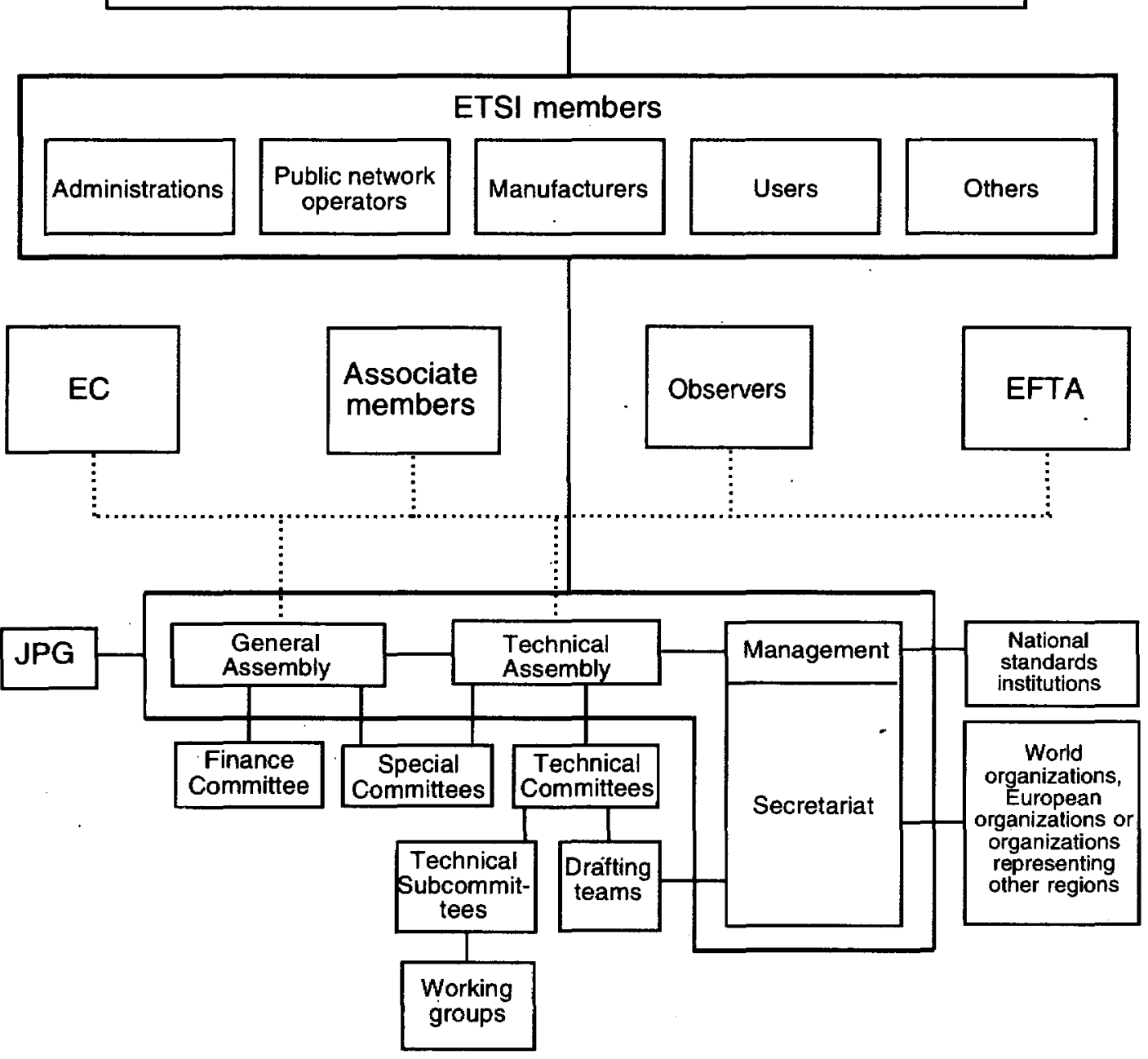

'For the explanations of the acronyms, refer to the glossary at the end of the report. 
Within these two assemblies, full members of ETSI each have a voting right, even though the usual practice is to seek consensus between the partners.

On certain matters, however, the statutes and rules of procedure specify that members are regrouped on the basis of national delegätions, and that they then collectively have a national vote which is weighted according to the size of the country. This arrangement applies in particular to all matters relating to votes on the adoption of standards and also decisions of vital importance to ETSI such as amendment of the statutes, dissolutions, etc.

Despite the fact that ETSI is organized on a different basis from CEN and Cenelec, this system enables the organization to implement a formal adoption procedure for standards which is strictly equivalent to the procedure which exists within CEN and Cenelec, thus making it possible, among other things, to adopt ETSI standards at national level and use them for Community regulation purposes.

The technical committees are the bodies responsible for preparing draft standards; the task of drafting these documents may be entrusted to drafting groups, with the latter having experts working full-time on a draft for a particular period of time. ETSI currently has 12 technical committees covering the major technological subjects on which ETSI works.

Lastly, the secretariat is responsible for administering the Institute and disseminating ETSI standards. It had a staff of around 60 at the end of 1991. (see the simplified organization chart for ETSI below).

\subsubsection{Coordination at European level}

Although the remits of the three European organizations are apparently well defined, it is none the less a fact that 'grey areas' inevitably exist. The main such grey area is of course the information technology sector, which combines information technology proper (the remit of ISO and therefore of $\mathrm{CEN}$ ), electronic components on which computers depend (Cenelec), and telecommunications systems which enable computers to communicate with each other (ETSI).

There are also other areas in which cooperation is indispensable; for example, although standardization in the electricity generation sector naturally calls on the competence of Cenelec experts, that of CEN experts is also required when the work involves parameters associated with buildings or other structures which are necessary for the operation of generating stations.

In order to manage these common boundaries and ensure effective cooperation between the three bodies, a special coordinating structure has gradually been established over the last few years. This structure is made up of the JPG (Joint Presidents Group), which comprises three delegations of six managers appointed by each body, and also the secretaries-general whose general responsibility is to prepare agreements relating to matters of joint interest. 
In particular, the JPG assists CEN, Cenelec and ETSI with achieving the following objectives:

undertaking urgent technical work by avoiding duplications and deficiencies in the work programmes and, where possible, taking international work as a basis;

developing and updating basic joint rules for procedures and the presentation of European standards so as to ensure consistency in technical work;

making information on technical work available by sharing a joint communication system which is capable of supplying information which is broadly accessible to users; promoting accessibility to activities for all business interests, e.g. by organizing conferences or joint round-table conferences;

developing European standardization in a way which reflects political developments in Europe, the single market, and more generally the European Economic Area in the context of world commerce.

The JPG is assisted by two bodies:

(i) the Information Technology Steering Committee (ITSTC), which deals with matters relating to technical work of joint interest in the fields of information technology and telecommunications;

(ii) the Joint Coordination Group (JCG), which deals with all coordination matters falling within the ambit of CEN, Cenelec and ETSI on which instances of overlap may arise, with the exception of IT which comes under the aegis of the ITSTC.

The JCG is in particular responsible for investigating, as a last resort, cases in respect of which no solution has been found via the three bodies' usual channels, which make provision for liaison procedures as briefly described below:

\section{Mode I - Exchange of information}

One of the organizations is entirely responsible for the activities of a specific sector and keeps the other(s) up to date on how activities are progressing.

\section{Mode 2 - Provision of contributions}

One of the organizations is responsible for directing activities and the other(s) submit(s) appropriate contributions in writing for such time as the activities are in progress. This type of relationship also implies the provision of full information.

\section{Mode 3 - Subcontracting}

One of the organizations is entirely responsible for carrying out work on a specific matter but, because another party has specialist knowledge of this area, some of the work is subcontracted to the latter and this part of the work is prepared under the responsibility of the second organization.

The necessary arrangements are made to ensure that the results of the subcontracted work can be correctly incorporated in the main part of the operation. This is why the whole of the public-comment process is carried out by the organization responsible for the greater part of the standardization work. 


\section{Mode 4-Collaboration}

One of the organizations directs activities; but delegates from the other(s) help out as observers at working sessions and meetings, in order to ensure that technical liaison is provided between the responsible organizations. Such observers are entitled to take part in discussions, but do not have any voting rights. The circulation of information is effected via this link-up.

\section{Mode 5 - Integration}

Joint Working Groups and joint Technical Committees hold joint meetings in order to carry out standardization work in accordance with the principle of full equality of participation. The results of the work of these integrated bodies are subject to common procedures. These procedures involve a single vote per country, in accordance with the procedures agreed on the joint vote.

\subsection{Relations with consumers, trade unions and other interest groups}

Socioeconomic partners at national level, consumers and trade unions are represented in the national standards bodies. In 1991, 11 of the 18 member institutes of CEN even had a committee specifically responsible for providing consumers with information on the format and progress of the programmes and for organizing participation on the part of consumer representatives on aspects where a need for this is felt.

Since the beginning of the 1980 s, however, consumers and trade unions have wanted to increase their involvement in European activities and offset the small number of experts at their disposal by gaining rights to participate in activities as part of a European delegation, and not just as members of national delegations.

In 1982, two agreements were signed enabling representatives appointed by the Consumers' Consultative Committee and the European Trade Union Confederation to participate in the Technical Committees.

The growing importance of the part played by standardization in numerous European policies nowadays means that such partners want to increase their capacity for dialogue with the European standards bodies.

In 1991, representatives of consumers and trade unions and also representatives of trade associations such as UNICE were invited, for the first time, to participate in an open meeting at the CEN General Assembly with a view to initiating a dialogue on the part which could be played in future, within CEN, by these European organizations representing certain socioeconomic interests, particularly via the new CEN associate status which had just been opened up to them.

Their participation within CEN's Technical Sector Boards, authorities with a strategic importance, is now established and has largely become a matter of fact, and a highly developed form of cooperation now exists between the Central Secretariat of CEN and 
the central technical body of the European Trade Union Confederation, the TUTB (European Trade Union Technical Bureau for Safety and Health), particularly in terms of information on programmes.

As regards consumers, both the Commission and the Council of Ministers have indicated - notably via a recommendation dated 10 December 1987 and a Council resolution dated 4 November 1988 - that consumer confidence in standards was crucial for the European Community. As stated above, the European standards bodies have long expressed a willingness to work with consumers too at European level. The latter are therefore now in the process of organizing themselves so that they can make the most of the opportunities being opened up to them, particularly in connection with the new CEN 'Associate' status.

It is likely that 1993 will see the emergence of a European body (EU + EFTA) representing the specific interests of consumers with regard to standardization and responsible for managing relations between the three European standards bodies.

\subsection{The way in which European standardization works}

\subsubsection{Introduction}

In order to meet the many needs mentioned in the previous chapters, the European standards bodies - and, owing to its multisectoral functions, CEN in particular - have in recent times had to process a very large number of drafts. CEN alone, for example, had to deal with some 7200 items of work in 1992 and envisages about 9500 in 1995.

The very scope of these programmes means that more effective decision-making and working methods need to be developed all the time to ensure that work is consistent and carried out quickly and that the basic principles of standardization (transparency, access for all interested parties, etc.) are maintained.

In order to clarify the main mechanisms of European standardization, this chapter describes the process currently in operation within CEN, a process which comprises three major phases: programming, drafting and adoption of standards. Apart from the literal description which follows, a flow chart is also provided below which is intended to illustrate this process, which operates in accordance with internal rules which are to a large extent also applicable within Cenelec. Although the process operating within ETSI, which was set up more recently, differs on a large number of points, the main decisionmaking criteria are the same, particularly as regards the adoption of standards.

\subsubsection{Programming}

The major part of standardization applications are nowadays handled via four complementary channels:

the national institutions, which pass on to the European level, applications which have generally been the subject of concerted consideration at national level with the business interests concerned; 


\section{Creation of a European standard'}

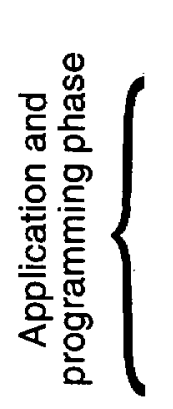

National members and

European organizations

Mandates proposed

(EC, EFTA)

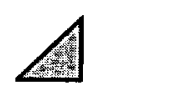

Technical board decision
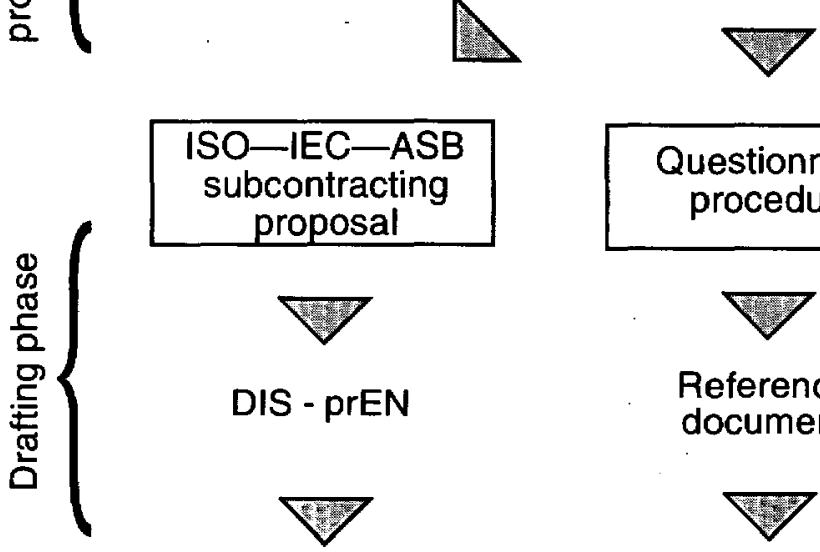
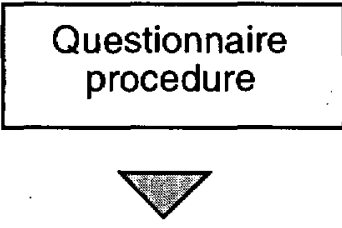

Reference document

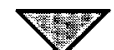

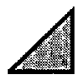

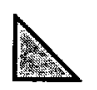

European technical committee

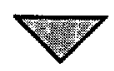

prEN

6-month public-comment stage

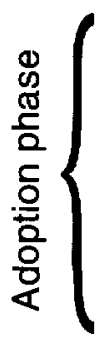

Final draft
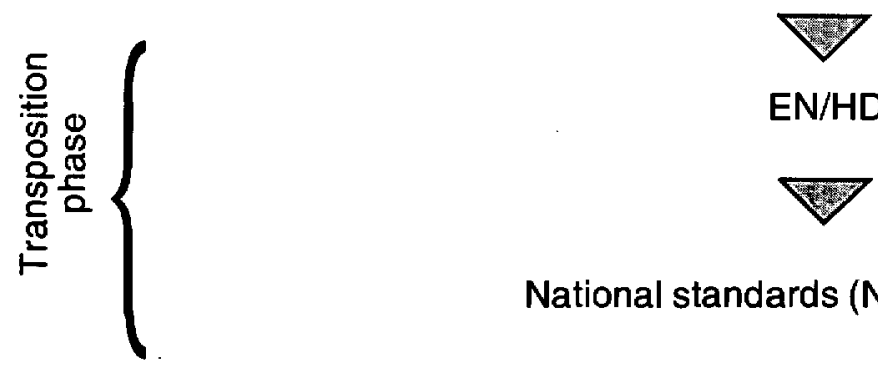

EN/HD

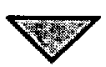

National standards (NS) -EN..., HD...

'For the explanation of the acronyms, refer to the glossary at the end of the report. 
the European institutions; in practice, this is essentially the Commission, as often as not supported by EFTA, with the latter dealing with applications for standards which come under certain European policies;

the ASBs mentioned above which have a high degree of independence in scheduling their own activities within their spheres of competence, with CEN for its part having undertaken to submit to its procedures for adopting the draft standards resulting from these programmes;

and, lastly, the European trade associations in certain cases.

The first of these channels works in the following way: the national institution wishing to submit a proposal sends the Central Secretariat a dossier containing various items of information which enable the interest of the subject to be assessed (dossier known as 'form A').

This dossier is then passed on, in the three official languages, to all the members of CEN. When the proposal receives the support of a minimum number of countries, the Central Secretariat proposes that the Technical Board act on it in a favourable way, in accordance with the procedures described below.

The second channel operates in accordance with the agreements concluded between CEN and the Commission/Secretariat of EFTA: the latter communicate their request. It should be stressed that this request may relate not only to work which is intended to be used in connection with Community legislation, but also to 'exploratory' work which is intended to provide a foundation for the development of a new industry, without for all that providing a basis for legislation. The Commission then acts as a 'spur' to European standardization.

The Central Secretariat, acting in liaison with the members, draws up a precise draft timetable and programme and also an estimate indicating the cost of the work undertaken. In certain cases, when the application relates to a vast area which has as yet been little explored, an intermediate stage may be introduced: a programming mandate is then given to CEN, which thus has specific resources to put together a team of experts entrusted with drawing up a report describing the programme which should be envisaged, the priorities and any difficulties which should be anticipated. This is a relatively new task as far as European standardization is concerned, even if it is quite usual at national level. The reason behind it, is that the establishment of priorities and constructed programmes has become a matter of pressing need given the explosion in demand for work to be done and the relatively limited human resources available to the standards institutions and business interests which, it should be remembered, bear a heavy responsibility in providing technical experts for the standardization process.

When, after enquiries have been made with the national institutions and the draft mandate has been validated from the point of view of, not only financial and human resources, but also policy (with regard to this latter aspect, within the framework of the Standing Committee for Directive 83/189/EEC and EFTA's TBT Committee), a formal contract is concluded between CEN and the Commission (and the Secretariat of EFTA in most cases) committing CEN to carry out the planned programme in accordance with the timetable laid down. 
These two channels for providing CEN with work topics then meet up, as regards the processes for taking decisions on procedures for implementing the programme, which is the last part of the programming phase.

This decision is taken by the Technical Board or, more and more frequently, delegated to the competent Technical Sector Board. A choice has to be made between three complementary methods for preparing draft European standards:

(a) when a reference document exists and this is probably acceptable provided that a number of amendments (e.g. an international standard which is already widely used in Europe) are made, a decision may be taken to undertake validation of this document as a European standard;

(b) if it appears, at European level, that it would be desirable to base the European standard on an international text and if ISO is willing and able to develop an international standard in accordance with the conditions and within the time-limits required by the Europeans, CEN may decide to entrust ISO with responsibility for supervising the work, with only one follow-up check by the Central Secretariat then being made until such time as a draft standard is available;

(c) in most cases, responsibility for developing the draft is entrusted to a Technical Committee of CEN, with one of the members acting as secretariat to the Committee.

Finally, it should be noted that a formal decision to start work on drawing up a European standard is always accompanied by a status-quo decision committing the members of CEN to refrain from proceeding with work on the same subject at national level.

\subsubsection{Preparation of draft standards by. CEN's TCs}

An initial draft is prepared by a group of experts under the collective responsibility of the TC. Commission mandates may in some cases make it possible to speed up the work by financing, say, teams working full-time for limited periods or laboratory work which is intended to validate certain hypotheses or compare several approaches, etc.

The initial draft then has to be approved, in principle in the three official languages, by the Technical Committee; the Secretariat then has to pass on the draft standard, which must be drawn up in accordance with the rules for the formal presentation of standards (PNE rules: presentation of European standards), to the Central Secretariat, which gives it its standard number with a view to the final adoption stage. The document is then called prEN No...

\subsubsection{Preparation of draft standards within ISO Committees}

The Vienna Agreement, which was signed by CEN and ISO in June 1991, makes provision for the procedures whereby this work may be carried out, at the European initiative, within ISO. In particular, drafts must be placed under the responsibility of a 
draft manager of European nationality, and at least five European countries must be active participants in the working groups of ISO's Technical Committees.

This procedure, which was devised in order to ensure a broad opening-up of Europe vis-à$v i s$ the rest of the world, is a new one and 1992 is to be devoted to trying it out on a limited number of cases. The reason for this is that the smooth operation of this procedure is directly connected with appropriate coordination of procedures between the Central Secretariats of CEN and ISO.

In particular, it is planned to organize the draft adoption vote in a simultaneous way within CEN and ISO respectively. The reason for this is that a single vote cannot suffice as the voting systems and the implications for European countries of adopting a European standard are very different from those which apply with regard to international standards. This simultaneous procedure is referred to in the Vienna Agreement as 'parallel voting'.

It should be noted that, with international economic integration now much more advanced, it is already normal practice in the electrotechnical sector for most of the texts which will become European standards ( $90 \%$ in 1991 - Source: Cenelec) to be prepared at international level, i.e. within the IEC.

Part 3 of this study should be consulted for further details on this.

\subsubsection{Adoption of European standards}

\subsubsection{CEN/Cenelec public comment}

At the initiative of the Central Secretariat, the prEN is submitted for public comment within the various countries, a process which generally lasts six months. At the end of this stage, comments are collected together and dealt with by the competent Technical Committee, which is required to formulate, in the three languages, a final draft corresponding to the broadest consensus.

\subsubsection{Formal vote}

This final text, which meets the PNE rules mentioned above, is then passed on to the Central Secretariat. The latter submits it to a 'formal vote' by the national members and also proposes an official publication date as well as the final date for transposing and implementing the national standard and, if necessary, withdrawing any divergent national standards. In general, this final date is six months after the first one.

During the formal vote, the members of CEN/Cenelec vote for or against the standard, or abstain, without making comments other than strictly editorial ones. The standard is adopted when the four criteria described in Table 1 below are simultaneously met, with the vote taking place on the basis of a weighted majority. The weighting is the same as 
that set forth in Article 148 of the Treaty of Rome in the case of EC Member States, while it is calculated on the basis of population in the case of other countries. A table of weightings is also provided below (Table 2).

It is interesting to note that, when it is reasonable to assume that a document is acceptable at European level, a procedure known as the unique acceptance procedure (UAP) may be applied to this document with a view to obtaining speedy approval of an EN or HD. This procedure may be applied to a document irrespective of its origin, and is used particularly with regard to international standards. The UAP combines the CEN/Cenelec publiccomment stage and the formal vote in a single procedure, and only comments of an editorial nature may be expressed, thus enabling the process for adopting European standards to be shortened.

\subsubsection{National transposition of European standards}

Under the terms of the rules governing CEN and Cenelec, European standards only acquire full status when they have been transposed and made applicable at national level. ETSI has recently introduced similar provisions in Article 14.6 of its rules of procedure. This rule is an essential element of the European standardization apparatus since it enables European standards to be integrated automatically in the national scene as regards the use of standards, irrespective of whether regulations, professional codes, procedures for certification or awarding contracts, etc. are concerned.

It should be recalled at this point that a European standard must be transposed and applied even in countries which had voted against it if the standard in question is adopted.'

This procedure also allows for the effective withdrawal of divergent national standards from collections of national standards, thus enabling the latter to retain their technical consistency.

In order to clarify the procedures implemented during this final phase and also the special characteristics of the official status of standards in the various countries of CEN, particularly as regards languages, the latter has recently published a monograph dealing with all the main aspects of national situations.

\footnotetext{
"It should be noted, however, that a rule exists enabling member countries of EFTA to be exempted from transposing EN standards if the adoption vote takes on certain very specific configurations. It is to be anticipated that these provisions will be abolished when the EEA is implemented.
} 
Table 1

Simple majority

Votes FOR $>=25$

Member voting AGAINST $<=3$

Votes AGAINST $<=22$

Table 2

Weighted voting

Counting of votes

\begin{tabular}{|c|c|}
\hline $\begin{array}{l}\text { Germany } \\
\text { France } \\
\text { Italy } \\
\text { United Kingdom }\end{array}$ & 10 \\
\hline Spain & 8 \\
\hline $\begin{array}{l}\text { Belgium } \\
\text { Greece } \\
\text { Netherlands } \\
\text { Portugal } \\
\text { Sweden } \\
\text { Switzerland }\end{array}$ & 5 \\
\hline $\begin{array}{l}\text { Austria } \\
\text { Denmark } \\
\text { Finland } \\
\text { Ireland } \\
\text { Norway }\end{array}$ & 3 \\
\hline Luxembourg & 2 \\
\hline Iceland & 1 \\
\hline Total & 96 \\
\hline
\end{tabular}




\subsubsection{The special cases of harmonization documents (HDs) and experi- mental European standards (ENVS)}

European documents resulting from harmonization work which are voted on are in most cases (at CEN at least) European standards (ENs), but may also be harmonization documents (HDs) or European prestandards (ENVs).

The differences between ENs and HDs essentially relate to the degree of obligation on the part of the national members vis-à-vis these documents:

An EN must compulsorily be implemented at national level by conferring national standard status on it and withdrawing any national standards which are inconsistent with it. An EN is implemented either by publishing an identical text at national level or by ratification (publication of a ratification sheet or announcement in the official bulletin of the member concerned).

An HD must compulsorily be implemented at national level, at least by public notification of the title and number of the HD and by the withdrawal of any conflicting national standard. However, a member is free to retain or publish a national standard dealing with a subject covered by the HD provided that it has a technically equivalent content. In addition, an HD allows for 'national divergences' under special conditions. Without going into procedural aspects, it should be noted that two categories of divergence exist: 'divergence $A$ ' to take account of a legal or national regulatory obligation, or 'divergence $B$ ' to take account of a problem of a technical nature. These divergences are normally only temporary.

Generally speaking, members of CEN and Cenelec prefer to make use of ENs rather than HDs so as to have a text which is identical in all countries.

As with ENs, when a HD has been adopted, even countries which have voted against this text are obliged to apply it, except for the special case of EFTA countries.

ENVs, meanwhile, may be drawn up as prospective standards for provisional application in technical fields where the degree of innovation is high or when an urgent need is felt for guidance and essentially when the safety of people and property is not involved. This category of European document has been created in order to respond to the challenge posed by information technology, and the methods for drawing it up, which give special treatment to the need for speed rather than the need for consensus, have led the members of CEN and Cenelec to decide on a smaller degree of obligation for these documents with respect to ENs and HDs. The status-quo rules do not apply when the ENV is being drawn up; after its adoption, which generally takes place under rules which are more flexible than in the case of an EN/HD, the members must quickly make the ENV available in an appropriate form at national level and announce its existence in the same way as for an EN/HD.

However, existing national standards which are inconsistent with the ENV may continue to be implemented until the final decision is taken to convert the ENV into an $\mathrm{EN} / \mathrm{HD}$. The reason for this is that the maximum term for an ENV is set at five years; unless this has been done earlier, an ENV must at the end of this period be converted into an EN or HD, or be abolished. 


\subsubsection{The specificity of ETSI procedures}

Finally, let us examine the process whereby ETS standards are drawn up, adopted and disseminated by ETSI, a process which differs slightly from that applicable within CEN and Cenelec although it now observes identical principles. The reason for this is that, in the course of discussions which took place over several years between the Commission and ETSI with regard to arrangements for recognizing the latter as a European standards institution alongside CEN and Cenelec, it became apparent that the procedures initially envisaged by ETSI did not provide for a 'national anchorage' of European standardization in the telecommunications sector, and that this situation could lead to numerous problems, particularly at the legal level.

It was, therefore, agreed to supplement the strictly internal ETSI process by adding a series of national procedures which are to be implemented either by the national member bodies of CEN (or Cenelec) or, in certain cases, by other institutions, under the terms of agreements between ETSI and these national bodies. These procedures relate to the implementation of the status quo, the public-comment process, the transposition of ETS standards at national level, their promotion and dissemination, and also the withdrawal of any pre-existing and divergent national standards.

The procedure for drawing up ETSs is therefore as follows:

drafts are prepared within the Technical Committees, often by drafting groups. The decision to examine a particular subject initiates a status quo which, by agreement with the national standards bodies, is also applied to the latter, even if they are not formally members of ETSI;

drafts are submitted to a public-comment process, on the initiative of the secretariat of ETSI. In most cases, this process is carried out on behalf of ETSI by the national standards institutions, and in other cases by specific national bodies, with everything taking place on the basis of an agreement between ETSI and all these organizations which was being finalized in 1992. In the case of drafts which are intended to serve as a reference for European regulatory instruments, the public-comment stage is extended to international level;

final drafts are adopted by the General Assembly (either in session or by correspondence) in accordance with the weighted national voting procedure mentioned above, with the acceptance criteria being the same as those applicable within CEN and Cenelec;

the standards are then published in English and, optionally, in French and German;

they must finally be incorporated in the national collections in accordance with the procedures defined by the agreement referred to above and on the basis of Article 14.6 of ETSI's rules of procedure. 


\section{Methods for evaluating and certifying conformity}

\subsection{Introduction}

Conformity is understood to denote 'the fact that a product, system, body, and even a person ... i.e. an entity in fact ... meets specified requirements' (definition from ISO/IEC Guide 2).

The keyword with regard to certification of conformity is 'confidence', a term which will be seen to crop up repeatedly below and in the rest of this study. The reason for this is that conformity certification procedures have been established with the main aim of creating or strengthening the confidence which business interests may have both with regard to each other and with regard to products, goods and services placed on the market.

Let us develop this idea: the existence of different methods for evaluating and certifying conformity derives from the demand from customers (in the broad sense of the term) to be assured of the characteristics of a product, service or body. It also derives from demand from producers themselves, whether it be to increase the level of quality of their production per se or to give their customers confidence. All conformity certification procedures are therefore based on the combined interests of the various parties.

As time has gone by, various procedures have been established on the basis of this demand, irrespective of whether the latter has been explicitly expressed. These procedures, which will be examined below, all tend to have a dual objective: to evaluate and control the quality of the product supplied or the service provided, and to promote confidence.

The coexistence of three elements thus appears to be of fundamental importance, namely: the existence of demand, the existence of a frame of reference which can be used to assess the entity in question and, lastly, the existence of organized procedures and structures for carrying out this assessment.

\subsection{Who can demand come from?}

\subsection{1. 'Customers'}

As is only fitting, the first category of 'customers' concerned by the procedures for evaluating and certifying conformity is made up of the regulatory authorities (whether 
local, national or international), with the aim of being assured that regulations are complied with.

These are followed by what are conventionally known as 'users of collective procedures'. This obscure term covers all parties which carry out their activities within an overall framework (e.g. insurance companies, public-sector purchasers, certain major distributors, etc.) and who would like not to have to carry out conformity checks themselves on the specifications they use, in the knowledge that these specifications are usually made up of documents for collective use, such as standards. The motivating reasons for this category of 'customers' are of course compliance with the regulations in force; but also the quality of the bodies, goods and services concerned and the simplification of relations with their partners, both upstream and downstream in the case of distributors, for example.

Finally, there are the customers who act in an individual capacity - whether it be the final consumer or another enterprise - and who are motivated by the same factors as those mentioned above. In addition, the final consumer will seek to obtain (and more so than the other parties mentioned above) certainty on matters of safety, fitness for use and also information on these characteristics, the impartiality of which is guaranteed by the involvement of a third party. The enterprise sometimes differs from the other parties mentioned above in that its demand may relate to characteristics which are not covered by documents of a collective nature, e.g. standards, but to a set of specifications which is specific thereto.

\subsection{2. 'Suppliers'}

The factors which motivate suppliers, manufacturers or importers often tie in with those which motivate customers, particularly when they are faced with conformity certification procedures involving a third party: the essential thing is to be assured that the regulations in force are being complied with - even in cases where a certificate is not compulsory, in order to market the product - and also to give customers confidence and simplify dealings with them.

However, there are other motivating factors of a more directly commercial nature, the main ones being as follows: to reduce the costs of procedures which are designed to guarantee conformity to the customer and minimize the number of audits and tests by utilizing a single recognized procedure rather than having to prove its conformity sometimes in a different way - to each potential purchaser; to improve the level of quality in the enterprise in part via the discipline required for certification, but also via the expertise of the specialist body involved in this connection; to gain a competitive advantage on a particular market via the 'plus point' which certification represents; and, why not, to sell at a higher price .... 


\subsection{What frames of reference are used to carry out the assessment?}

This question has two aspects to it: the nature of the frame of reference and to what it relates. As seen above, this is because the frame of reference may be a regulation, a standard, a public contract specification, a code of professional specifications, a company standard or any type of private specifications.

However, the frame of reference may also relate to different subjects: one naturally thinks of requirements which apply to a product, but in fact requirements increasingly cover characteristics relating to the production tool itself, as with the EN 29000 series of quality assurance standards (also known by the reference ISO 9000), or cover a 'service', as with standard EN 45001 on testing, which may even be applied within the company, or even requirements governing the qualifications of personnel, e.g. with regard to welding.

One interesting case which will become increasingly important in years to come, concerns what is known as the 'ecological balance', where it is necessary to evaluate the overall impact on the environment of a particular production cycle. The problem is that there is as yet no authoritative document in this area, particularly at European level. In all probability, only the methodology could be standardized in this case. This is an area in which demand will increase sharply in future years and in which evaluations are at the present time unreliable in the absence of frames of reference which are recognized by everyone.

The above considerations clearly show that the development of frames of reference used in conformity certification procedures is closely linked with the needs of the economy, as is the case with standards (see Chapter 1).

\subsection{Who carries out the assessment and how?}

\subsubsection{The declaration of conformity}

The first option - and the simplest one - is the supplier's 'declaration of conformity', which is sometimes incorrectly referred to as 'self-certification', this being a contradiction in terms. This is a procedure whereby the supplier provides a written assurance that a product, service, etc. conforms to one or more specified requirements. This declaration of conformity may be provided either directly or following various contributions by a third party, e.g. on large-scale production equipment after a type test has been performed by a laboratory.

In order to assist suppliers with drawing up their declarations of conformity, the standards bodies have formulated a European standard, namely EN 45014; compliance with this standard should, in addition, enable greater weight to be given to declarations of conformity vis-à-vis different customers.

It should be stressed that the declaration of conformity is the most widespread type of certification of conformity in free-market economies, in keeping with the way in which such economies are organized. 


\subsubsection{Tests and checks}

The purpose of a test is to evaluate the characteristics of a particular entity, generally by considering a specific frame of reference in relation to which conformity is to be verified, though not necessarily so: a test which is designed to determine the safety of a product may be carried out on the basis of the 'recognized state of the art', i.e. in actual fact on the basis of current scientific and technical knowledge in general; a broad measure of consideration is in this case given to the judgment of the expert carrying out the test.

In addition, a test may be performed on a particular type, without necessarily having to take into consideration series production or the repetition of actions or services (otherwise, the test becomes an integral part of a certification process). The test is carried out either by the entity in question or by an independent testing laboratory, which then issues a 'test report'.

The prime function of a check, on the other hand, is to verify that an entity conforms to a frame of reference; this is generally achieved by using the results of tests, though it may also involve other aspects, such as on-site inspections. The term 'audits' is used when a company's quality assurance system is checked.

\subsubsection{Certification procedures}

The aim of these procedures is to ascertain the conformity of an entity with respect to the chosen frame of reference. Although 'certification', in the widely accepted sense of the term, encompasses any procedure carried out by a party from outside the company and could thus cover certification by a 'second party', i.e. by the customer, it is preferable to restrict use of the term to procedures carried out by an independent body which comes from outside the entity in question and which is specifically designed to carry out such activities (third-party certification).

Certification may relate to a product (certification of products), the quality assurance system of an establishment or enterprise (quality-control system certification), the skills of an individual (personnel certification), or to a service (service certification). This is a procedure which generally involves long-term monitoring of the certified entity to ensure that the conditions under which certification was awarded still apply.

Certification always results in a written document (certificate) issued by the certifying body by which the latter provides an assurance that the entity in question conforms to the specified requirements. Generally speaking, third-party certification of products or services also results in the certified entity being entitled to use a mark granted to it or being authorized to use a distinctive sign.

\subsubsection{Approval and accreditation}

The question then arises as to what sort of credibility should be given to the various bodies which carry out the tests, audits, checks and certification referred to above and 
what sort of credibility should be given to the documents which they issue. In other words, who supervises the supervisors?

In this context, a distinction should be made between voluntary certification activities and activities which arise from a legal obligation, generally impinging on safety. In the latter case, the State calls on the services of a body which it both authorizes and compels to carry out checks. Only bodies appointed by the State may then become involved in this area.

With regard to activities which take place in a private context (the vast majority of cases), the approach adopted varies depending on the country.

In certain cases, there is no specific framework for monitoring the activities of these bodies. Increasingly, however, procedures have been established in order to inspire confidence in their satisfactory operation, from the point of view of not only technical or organizational aspects but also ethics. The procedures concerned may be ones in which full responsibility rests on the regulatory authorities: the latter establish a legislative or regulatory framework defining the conditions under which these activities may be carried out, and check that this has been implemented by issuing 'approvals' to bodies which fulfil the required conditions. This is the case in France, for example, where product certification is regulated by a law dating from 1978 which requires, inter alia, the approval of the various certifying bodies.

Another option exists, however, which is being used increasingly: the option of accreditation, which is a procedure whereby a body representing all the business interests concerned, and which is thus endowed with authority, formally recognizes that a body or individual is competent to carry out specific tasks in the various areas in question (tests, audits, certification, etc.). Accreditation could thus be likened to 'service certification', which is based on codes of good practice or frames of reference which are standardized internationally and which, to a large extent, originally resulted from the work of the ILAC (International Laboratories Accreditation Conference) and CASCO, the ISO Council Committee responsible for matters of conformity assessment and certification.

Virtually all the basic texts are now included in the 45000 series of European standards, and they lay down general criteria for:

the operation of testing laboratories (EN 45001);

the assessment of testing laboratories (EN 45002);

test laboratory accreditation bodies (EN 45003);

certification bodies operating product certification (EN 45011);

certification bodies operating quality system certification (EN 45012);

certification bodies operating certification of personnel (EN 45013);

inspection bodies (prEN 45004).

It is to be noted that only the testing laboratories are covered by standards for the three possible levels (operation of laboratories, evaluation of laboratories, criteria for accreditation bodies). The same work still has to be done, therefore, for the other activities. 
It should also be pointed out that a standard exists (ISO 10011) governing quality audits, with this standard being broken down into three parts:

(i) the audit itself (ISO 10011 Part 1);

(ii) the competence of quality auditors (ISO 10011 Part 2);

(iii) the management of audit programmes (ISO 10011 Part 3).

The accreditation bodies which now exist in several countries generally take the form of non-profit-making associations, with their administrative boards comprising not only representatives of the public authorities but also representatives of the organizations concerned and individuals from the world of science and technology.

Such accreditation bodies include the RNE (Réseau national d'essais) for the accreditation of laboratories, in France; NAMAS (National Measurement Accreditation Service) in the United Kingdom, which is responsible for calibration and laboratory testing, and, finally, the TGA GmbH (Trägergemeinschaft für Akkreditierung) in Germany, with the latter covering the various accreditation systems for non-regulatory purposes, whether these be testing laboratories or bodies which operate quality-system or product certification.

To conclude this chapter, the extraordinary development of all these activities over the last two decades should be noted, a development which is due to a number of factors: firstly, the growth of international competition has sparked a 'dash for quality and safety', thus leading to increased demand for forms of certification which are intended to demonstrate the safety and quality of products and services. In many cases, the sophistication of the technologies involved also prevents purchasers from personally verifying the characteristics of the products they wish to buy, prompting them to call on the services of a specialist third party. Finally, there is a trend towards deregulation in most economies, which is leading to greater reliance on 'private' voluntary procedures rather than on State control of markets.

The diagram below attempts to show the way in which the conformity certification systems are organized. 







\section{Access to information on standards and certification in Europe}

\subsection{Numbering of European standards}

European standards are identified by their title and by a number assigned by the Central Secretariat of either CEN, Cenelec or ETSI.

When a European standard is transposed into a national standard, the practice which currently applies in all countries consists of inserting the letters identifying the national institution in front of the European designation described below, and keeping the number assigned by the Central Secretariat (see Section 4.2. for an example). In the case of the oldest European standards, however, the national standard number may differ from the European standard number.

With regard to CEN and Cenelec, European standards are numbered in accordance with the following system:

EN - followed by a number comprising 1-5 digits, which is assigned in the following way:

- 1-19999: numbers assigned by CEN for standards drawn up by the technical committees of CEN or by the committees of associated bodies (the numbers 2000-6999 are thus reserved for aerospace standards prepared by AECMA, and numbers 1000010999 for standards relating to steel which are prepared by ECISS). The numbers are assigned in chronological order in each series.

- 20000-39999: numbers assigned to European standards which are identical to the international standards of ISO. The number is in this case formed in the following way: the figure 2 followed by the number of the ISO standard (e.g. the ISO 9000 series of standards on quality assurance becomes the EN 29000 series of European standards).

- 40000-44999: these numbers are reserved for standards drawn up jointly by CEN and Cenelec (e.g. EN 45000 standards on good practices with regard to certification, accreditation, etc.).

- 50000-69999: these numbers are assigned to Cenelec, with the 60000 series being devoted to the transposition of IEC international standards as European standards in accordance with the same principle as for ISO, i.e. by adding the figure 6 in front of the IEC number.

With regard to ETSI, the standards are designated by the letters ETS, followed by a number assigned by ETSI's Central Secretariat. 


\subsection{Publication of European standards and their dissemination}

European standards adopted by CEN, Cenelec and ETSI exist in their own right and are published, in the case of CEN and Cenelec, in the three official languages of these organizations (German, English and French), and only in English in the case of ETSI standards, with the latter being recognizable by their special prefix 'ETS' (European Telecommunications Standard). In addition, ENVs may in certain cases only be available in a single language.

The text of European standards which have been adopted by each organization can be obtained from the respective Central Secretariats, and is generally made available three months after formal ratification.

With regard to CEN and Cenelec, however, the actual printing of the standards is carried out in each of the three official languages by AFNOR, BSI and DIN respectively. These printed versions, whose typographical quality is better than that of the original text, are made available to the Central Secretariats and the other national institutions in order to facilitate national transposition, particularly in cases where the latter is carried out without publishing a text translated into the national language.

In order to rationalize the resources used for the commercial dissemination of standards, the dissemination of European standards is essentially carried out by the national members via the same networks as for national and international standards.

However, in order to promote information on the existence of new European standards as quickly as possible, the Central Secretariats of CEN and Cenelec have been able, since mid-1992, to make the ratified text of ENs available to other European or international organizations and also to the national standards institutions of third countries. In this respect, it should be stressed that matters connected with third-country rights to reproduce ENs are directly handled by the Central Secretariats on behalf of members.

Since the beginning of 1991, the profile of European standards in the national context has been bolstered by the decision adopted by CEN and Cenelec to use the following numbering system on a routine basis with regard to national standards which transpose European standards:

\begin{tabular}{|l|c|c|}
\hline $\begin{array}{l}\text { national prefix } \\
\text { (e.g. DIN, NF...) }\end{array}$ & EN & $\begin{array}{c}\text { XXX } \\
\text { number of CEN or Cenelec standard }\end{array}$ \\
\hline
\end{tabular}

The availability of European standards is made official and publicized in the following way:

- at European level, the 'CEN/Cenelec/ETSI Official Bulletin' indicates the numbers, titles and subject matter of ratified standards and also the deadlines for national transposition; 
- at national level, the official bulletins of the standards institutions specify national decisions on the transposition and availability of European standards. CEN has recently published a set of national monographs which bring together the various items of information which exist on the status of transposed European standards (see Section 2.4.6. above).

Under a series of bilateral agreements, a number of national standards institutions in countries which are not members of CEN or Cenelec (affiliated institutions) are also able to translate European standards, transpose them as national standards and disseminate them in this form.

\subsection{Databases}

\subsubsection{The information procedure set forth in Directive $83 / 189 / E E C$}

A central unit manned by CEN and Cenelec staff has been set up in Brussels in order to implement the information procedure established by Directive $83 / 189 /$ EEC. Since 1985 , this central unit has developed a database which incorporates the standards programmes of all the national institutes which are members of CEN and Cenelec as well as the programmes of CEN and Cenelec and those of ISO and the IEC.

In order to ensure that the database is kept up to date, each national institution is required to notify the central unit of any new drafts undertaken in its country (Article 2 of the Directive). Notification must also be provided of the progress of each draft, and more particularly of the public-comment stage (Article 4 of the Directive) and completion stage (publication of the standard or abandonment of the draft).

This information is centralized and processed at the central unit. The data are sorted according to sector of activity (sectors, sub-sectors) on the basis of the European classification system mentioned above in Section 1.2.2. of this part of the study.

The information procedure data are available in German, English and French.

European and international standards programmes are updated electronically on the basis of each organization's databases.

At the beginning of each month, the central unit passes on the national information received during the previous month in the form of 'registers' to the members of CEN and Cenelec, the European Commission and the Secretariat of EFTA. The formula of monthly registers has been used since 1990 so as to alert interested parties to new projects undertaken and the most recent developments in on-going projects. Access to complete national programmes which are centralized in the information system is not envisaged at the present time.

In order to supplement the national information which is disseminated each month, the European programme is disseminated twice a year and the international programme once a year. 


\subsubsection{ICONE}

In 1985, the Central Secretariat of CEN also established an information system relating to the national standards of the various countries of Europe which incorporate, either in whole or in part, European or international standards; this system is known as ICONE (comparative index of national and European standards).

In practice, the ICONE database makes it possible to determine in which country an international or European standard has been transposed as a national standard, under what reference, when, and what linguistic version is available.

The database also indicates the degree of equivalence between the national document and the European or international document.

This degree of equivalence can be divided into four categories:

(i) equivalent technical content and identical layout

(ii) equivalent technical content and different layout

(iii) different technical content

(iv) degree of equivalence not yet known.

This operation is being conducted with the aid of financial support from the European Commission and the Secretariat of EFTA.

The collated information is passed on to the members of CEN (and any Cenelec members who require it) on magnetic tape. Some members offer the ICONE information for sale in their country.

Information on the implementation of European standards in CEN member countries is also disseminated in a document known as ' $\mathrm{CEN} \mathrm{N} 525$ ', which is revised every year.

Information on the implementation of European standards in countries affiliated to CEN and Cenelec (see Part 3, Chapter 1 for a definition and list of these countries) will also be available via ICONE in the near future.

\subsubsection{The information systems of the Central Secretariats of CEN and Cenelec.}

A new information system is currently being prepared at the Central Secretariats of CEN and Cenelec in order to meet internal management and information requirements (monitoring of activities, publications, etc.) and also to satisfy the growing demand for access to data on European activities by the European partners of CEN and Cenelec. This system should replace the existing system and provide full and detailed information on the technical committees, the work programme, published standards, mandated work, the national implementation of ENs, HDs, etc.

The system should be operational in 1993. 


\subsubsection{Other computerized products relating to standardization information}

Work is currently in progress on developing computerized products which will provide the text of European standards (and standards in general), for example on CD-ROM. A number of partial products have been developed in Europe and the United States, but their success does not seem to be assured. The only products currently available as regards European standards, incorporate data in a bibliographical form, but do not yet contain the full text of the standards.

The best-known product in this connection is Perinorm, a CD-ROM produced jointly by AFNOR, BSI and DIN which combines the information contained in the databases of these three institutions, i.e. the references of the standards which are applicable in these countries (national, European and international standards and also regulations with regard to Germany and France).

Perinorm is currently being extended to include data from other European countries. The success of these new products, which require relatively heavy investment, is dependent on agreements being concluded at international level on standards for formatting and encoding these documents, in order to give users consistent software tools for research and operational purposes.

It may be anticipated that the development of these new products and their future largescale take-up in enterprises will have major implications on the ways in which standards are disseminated and offered for sale in Europe.

\subsubsection{Certificate}

The Certificate project has also been developed as part of a contract between CEN on the one hand, and the Commission and EFTA on the other. Its implementation has been subcontracted to AFNOR.

The project relates to a database which stores information on testing and certification facilities in all Members States of the European Union and EFTA and contains, among other things, an inventory of testing laboratories involved in the certification process and also information on Community Directives.

The database is trilingual (German, English and French) with regard to both data and inquiry languages. Although the initial project made provision for on-line access, it was decided in 1991 to make the database available to the public in the form of a hard-copy catalogue and disks for microcomputers.

The database was finished in June 1992. It has been marketed by the members of CEN since autumn 1992 and will have to be revised and updated carefully to provide a product which is of interest to the economic partners. This is an area which is in continual flux, with constant developments affecting facilities as well. 
Part 2: European policies in the fields of standardization and certification of conformity 


\section{Introduction}

The tools which have just been examined in the first part of this study have, until relatively recently, been used purely at national level. The reason for this is that they developed at the same time as the industrial and regulatory systems of the various States, in accordance with the approach adopted by the economic partners towards organizing their national economies (varying degrees of influence exercised by the authorities, differing priorities, the existence of enterprises of different sizes, etc.).

The signing of the Treaty of Rome did not have an immediate impact on the standardization aspects of policy in the various Member States, perhaps because these are cumbersome structural tools which reflect the way in which societies are organized, thus making it difficult to change them, and perhaps also because the European Community had more urgent priorities in 1957.

The fact remains that the implementation of Community policies on standards and certification did not really develop until the 1980s. This process had, howèver, been preceded by an initiative undertaken towards the end of the 1960s in an effort to eliminate technical barriers to trade, an initiative which was pursued either by calling national regulations into question on the basis of Article 30 of the Treaty of Rome or by adopting harmonized Community regulations on the basis of Article 100 of the said Treaty.

Community action as a whole is examined in the second part of this study in an order which is both chronological and thematic since the initiatives undertaken meant that these two aspects more or less coincided: the reason for this is that what had initially been a policy geared essentially to eliminating technical barriers to trade and which had been directed at national regulations has now become a policy for supporting the creation of the single internal market and sustaining the industrial fabric of Europe through the use of standardization and associated tools. 


\section{The elimination of technical barriers to trade within the European context}

\subsection{Definition}

The notion of a technical barrier to trade is one which deserves clarification. That said, an internationally accepted definition of this concept does not exist at the present time.

To gain a firmer grasp of the nature of this concept, however, the following definition can be proposed:

'Any obligation which is imposed, whether de facto or de jure, on an exporter or an importer to make his product conform to a technical specification other than that which applies in the country of manufacture before authorizing him to place his product on the market may be deemed to be a technical barrier to trade. An additional obstacle consists in obliging the exporter or importer to call on a third party to prove that his product conforms to the technical specification which must be complied with.'

The foregoing attempt at a definition does not make a value judgment as to the legitimacy of technical barriers to trade. Moreover, international texts which legislate on this subject - whether the GATT Code, or Directive $83 / 189 /$ EEC in the case of the European Community - implicity or explicitly recognize that certain technical barriers to trade are justified, and even sometimes necessary. This is because both documents set out to eliminate technical barriers which are 'unnecessary' or 'not legitimate'.

On the other hand, such barriers are sometimes necessary or legitimate and, as will be seen later on in an examination of the case-law of the European Court of Justice, justified by the need to protect citizens.

A good example of this is provided by the second 'Whereas' clause of Directive 83/189/EEC:

'Whereas barriers to trade resulting from technical regulations relating to products may be allowed only where they are necessary in order to meet essential requirements and have an objective in the public interest of which they constitute the main guarantee.'

It should be remembered that most technical barriers to trade are not intentional: they merely reflect the kind of regulatory and industrial practices and peculiarities on matters of safety which have developed within States in the course of their histories. Technical barriers erected for protectionist purposes are in fact uncommon, and can easily be 
identified with a bit of practice. That said, it is undeniable that the free movement of goods in Europe and the rest of the world is hampered by the existence of technical barriers.

\subsection{Description}

\subsubsection{Technical requirements}

The first problem faced by an exporter (or importer) with regard to technical barriers to trade is knowing what documents apply to his products: sometimes these are solely regulations, sometimes solely standards, sometimes a combination of the two, and sometimes other documents with a poorly defined status.

Standards do not form obstacles in themselves. They are only obstacles if compliance with them is required by the purchaser (owing to regulations, insurance policies, practices or a personal preference which is not based on any technical reason) and if they mean that the product must be modified.

An exporter faced with this requirement will then have to obtain the standard from the standards institution in either the country of export or his own country.

He will have to analyse it, which may necessitate its translation.

It may be that, during this process, the exporter realizes that this standard (or these standards) refer(s) to a number of other standards which are not, of course, in his possession.

It may also be that the standard provides highly detailed standardization for procedures or means, and that it describes in minute detail the specifications the product must meet, rather than merely describing the final requirements on the latter. In this case, the exporter may be forced to carry out very extensive modifications to his product, or even give up all idea of marketing it.

This is a fairly frequent scenario although most countries around the world pride themselves on basing their standards on international documents (ISO, the IEC, etc.). This is certainly true to a large extent, but with one reservation: in the course of inquiries which take place in connection with the conversion of international standards into national standards, certain business interests frequently express a need for the international document to be clarified, made more stringent, restricted, etc., and this may lead to substantial modifications. The latter often originate from the highly legitimate objectives and constraints which it was not possible to cater for during negotiation at international level owing to the need to reach a consensus.

For instance, a study carried out in 1989 by ISO and the IEC (see tables below) shows that, of the 7000 or so ISO standards in existence at the time, very few had been adopted 
in exactly the same way by the member countries which responded to the survey. Of course, the various countries also use ISO or IEC standards to underpin national standards, but it is impossible to determine the extent to which the text is close to that of the original international standard.

Most of the time, however, technical barriers have less to do with standards than with regulations, or sometimes the absence of regulations, which enables a product (however innovative it may be, for example) to be rejected on the grounds that there is no applicable document.

\subsubsection{Certifications or attestations of conformity}

Once the exporter is familiar with the documents he must comply with, all he has to do is bring his products in line with them so as to obtain the certification which is required or advised. This is the first stage in what can sometimes turn out to be a particularly complex and arduous process: first of all, it is possible that the declaration of conformity provided by the manufacturer or his authorized agent ('self-certification') is not accepted; in this case, the competent laboratory or laboratories has/have to be tracked down; it is then necessary to register in order to commission the requisite test(s), and there are sometimes long waiting lists.

Depending on the criteria, which are not always clear, the procedure adopted in foreign laboratories and certification bodies may be very variable in terms of time and expense; there are a number of famous cases in this regard, such as the case in which the approval process involved an inspection at the site used to manufacture the product, but where the inspectors or laboratory experts were not authorized to carry out their duties abroad: approval was therefore in fact impossible.

\section{Separate ISO responses}

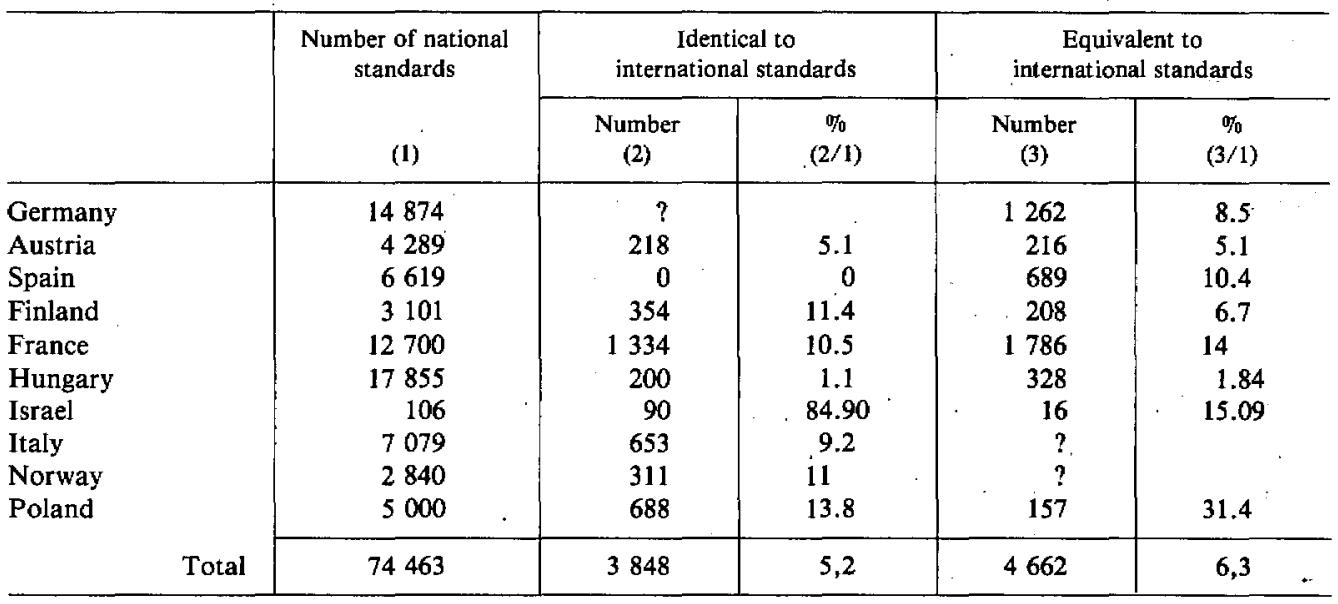

NB: the degree of equivalence is assessed by the country responding to the survey. 
IEC and ISO responses without separate analysis of the catalogue total

\begin{tabular}{|c|c|c|c|c|c|}
\hline & \multirow[t]{2}{*}{$\begin{array}{l}\text { Number of national } \\
\text { standards }\end{array}$} & \multicolumn{2}{|c|}{$\begin{array}{c}\text { Idèntical to } \\
\text { international standards }\end{array}$} & \multicolumn{2}{|c|}{$\begin{array}{l}\text { Equivalent to } \\
\text { international standards }\end{array}$} \\
\hline & & IEC & ISO & IEC & ISO \\
\hline South Africa & 2564 & 0 & 0 & 1 & 13 \\
\hline Denmark & 2618 & 427 & 956 & 46 & 108 \\
\hline United States & 8500 & 0 & 48 & $?$ & \\
\hline Greece 、 & 1100 & 7 & 400 & 8 & 68 \\
\hline Portugal & 2971 & 397 & 32 & 19 & 914 \\
\hline United Kingdom & 10328 & 536 & 2216 & 130 & 478 \\
\hline Czechoslovakia & 26000 & 40 & 10 & 30 & 50 \\
\hline Total & 54081 & 1407 & 3662 & 234 & 1631 \\
\hline
\end{tabular}

NB: the degree of equivalence is assessed by the country responding to the survey.

It may also be that, in the course of the approval process, the test results in the detection of a non-conformity which, though minor, necessitates the rest of the tests being postponed until such time as this non-conformity is rectified. The product will in that case be put back on the waiting list.

Depending on the tests involved, the certification process may take years; this will not only mean prohibitive testing costs for the exporter but will prevent him from marketing his product.

The exporter will in that case forgo obtaining the necessary certification and, consequently, abandon the market he was targeting.

There is one last possibility: it turns out that it is impossible to adapt one's product, either from the technical point of view because one is required to use components of a certain type which cannot figure in the actual design of the product, or from the financial point of view if the modifications to be made are too expensive, etc.

The variety of barriers to trade is infinite and it is therefore pointless trying to provide an exhaustive description of them here. The 'principles' mentioned above generally provide a useful aid to identifying those which are not simple technical barriers brought about by differences in legal, technical and economic culture between the various countries of the world, but rather barriers which are erected or maintained in order to prevent - or at least restrain - the importation of foreign products.

Before examining in detail the initiatives pursued by the European Economic Community on the basis of the Treaty of Rome, two other types of scheme which are designed to combat technical barriers to trade should also be mentioned.

The first of these is a scheme pursued on a multilateral basis, namely the 'Agreement on technical barriers to trade', one of the agreements resulting from the Tokyo Round of multilateral trade talks which took place as part of GATT (General Agreement on Tariffs and Trade). This Agreement is examined in Part 3, Chapter 3 of this study. 
The second scheme is pursued at national level: networks providing technical assistance to exporters have been established in several countries, with these networks having been set up on the basis either of bodies for certification and standards or of bodies with a general remit to provide export assistance. These networks sell companies a service which consists in helping them to bring their products into line with the regulations in force on foreign markets. This form of assistance may range from simply identifying and translating the documents involved right through to representing the company vis-à-vis the competent bodies in connection with conformity evaluation procedures, so as to procure the necessary certificates on its behalf.

It should be added that this 'final' phase will as often as not have been preceded by an audit of the company and advice on the modifications which need to be made to its product to ensure that conformity is achieved.

Existing networks include THE (technical help to exporters) in the United Kingdom, NOREX (normes et règles techniques à l'exportation = standards and technical regulations for export) in France, and the 'Teknisk Exportservice' = Technical Export Service in Sweden. A number of developing countries are currently attempting to set up this type of service for their national industries.

\subsection{The fight against technical barriers to trade within the framework of the Treaty of Rome}

\subsubsection{Introduction}

Let us return to the subject of actual Community action, since this provides by far the most original and interesting example of such action: when the Treaty of Rome was signed in 1957, the elimination of technical barriers to trade was a long way from being a priority. Reading through the Treaty, in fact, it might even be doubted whether the people who drafted it were aware of this question since the term 'technical barrier to trade' does not appear in it anywhere. Nevertheless, as the years went by and quotas, quota restrictions and other barriers were successively eliminated, the importance of barriers caused by various regulations, standards and certifications of conformity which had hitherto been masked by the need to solve previous problems which were more 'visible' - began to become much more apparent.

It was then realized that the Treaty of Rome contained two sets of articles which could be used to combat technical barriers to trade: Article 100, which allows for the harmonization of the bodies of law of Member States, and Articles 30 and 36 of the Treaty, which allow for the elimination of barriers which are not legitimate.

Other aids subsequently came to be added to this range of provisions, such as the case-law of the European Court of Justice, Directive 83/189/EEC, the New Approach and, lastly, certain articles of the Single Act. 


\subsubsection{Article 100}

Article 100 specifies the following: 'The Council shall, acting unanimously on a proposal from the Commission, issue Directives for the approximation of such laws, regulations or administrative provisions of the Member States as directly affect the establishment or functioning of the common market.'

To be applicable at national level, such Directives must be 'transposed', i.e. introduced into national law by some document or other within a period of time generally lasting between 12 months and two years. The reason for this is that, unlike regulations, which are mandatory in all their elements, a Directive is mandatory in all its aims, but not in its means, and Member States are at liberty to choose which methods to use to apply it.

It was thus Article 100 which came to be used for what is currently referred to as technical harmonization. Some Directives were adopted between 1960 and 1985 as a result of this provision, although the economic impact of these has been fairly limited for the following reasons:

(i) Problem one: the Directives in question are often highly specific ones which relate to a very specific product or even to a part of a product: in connection with cars, for instance, there are 43 Directives governing the various parts of cars.

(ii) Problem two: unanimous voting. With this system, where each country has one vote, it only takes one State to block the harmonization process in the Community. This arrangement, which was already a ticklish matter when the Community had only six members, became virtually unworkable when the Community was enlarged to 12 members.

The result of this has been that Directives adopted on the basis of Article 100 were initially too few in number (or not broad enough in coverage) to have a significant impact on the operation of the internal market and the free movement of goods, and then very quickly became obsolete once they were published owing to the fact that these were highly detailed documents which had taken a long time to prepare and which, in addition, had sometimes been left on the Council's table for several years prior to being adopted.

Faced with a situation where technical harmonization via the adoption of joint documents by the EC Council of Ministers had thus proved to be inadequate, the Commission and the Court of Justice were the first to resume the fight against technical barriers to trade by making use of Articles 30-36 of the Treaty.

\subsubsection{Articles 30-36 of the Treaty and related case-law}

Article 30 sets out the principle that 'quantitative restrictions on imports and all measures having equivalent effect shall be prohibited between Member States'. Article 36, meanwhile, constitutes an exception to Article 30 since it enables Member States to take or retain measures which restrict trade, subject to a number of-eonditions (see below for the text of Article 36). 
'The provisions of Articles 30 to 34 shall not preclude prohibitions or restrictions on imports, exports or goods in transit justified on grounds of public morality, public order or public security; the protection of health and life of humans, animals or plants; the protection of national treasuires possessing artistic, historic or archaeological value; or the protection of industrial and commercial property. Such prohibitions or restrictions shall not, however, constitute a means of arbitrary discrimination or a disguised restriction on trade between Member States.'

From the moment it became possible to class technical barriers to trade as 'measures having equivalent effect' within the meaning of Article 30 (Dassonville judgment of 1974: 'any commercial regulation of the Member States which is liable to hinder, whether directly or indirectly, and whether actually or potentially, trade within the Community'), the application of these two articles made it possible to lay the foundations for an entirely original and interesting body of case-law.

The first example of this case-law was provided by the Cassis de Dijon judgment of 1979, which is starting to gain world renown. The Court's aim in this ruling and those which followed was to authorize the greatest possible freedom of movement for goods while preserving the responsibility with which States have come to be vested over the course of history in relation to the protection of their citizens and their territory. As a result, in the Cassis de Dijon case and each subsequent case, the Court examined whether the measure which it was required to rule on was justified and, in particular, verified whether it was proportionate to the intended aim while at the same time giving considerable attention to the objectives of protecting collective interests generally advanced by States to justify themselves.

The Cassis de Dijon case can be summarized as follows: it was impossible to export the alcoholic beverage 'Cassis de Dijon' from France to the Federal Republic of Germany owing to problems associated with the application of German tax laws. The case was brought before the Court to establish the validity of this measure, and the Court ruled that the circumstances of the case could not under any circumstances justify a ban on the free movement of the product.

The most important sentence in the Cassis de Dijon judgment is the following: 'Any product lawfully produced and marketed in one Member State must be admitted to the market of any other Member State'. In other words, as from the moment when a product is deemed by the national authorities of one country as being suitable for sale on its home market, it should normally be deemed suitable for sale in the other Member States in the same way: this is the principle whereby the level of protection afforded to the various interests in the various countries is presumed to be equivalent, and it is up to the State in question to demonstrate that this is not the case (a course of action which is still left open).

The Cassis de Dijon judgment set a precedent, and the principle of equivalence has since become a benchmark against which the regulations of the various Member States are gauged when they are submitted to the Court of Justice. 
Another judgment which is also of interest as regards the free movement of goods is the 'biologische produkten' biological products ruling of 1981. This case involved a Dutch firm which wanted to import pesticides into the Netherlands from France, where they had been granted ministerial approval. The firm decided to import them without securing Dutch approval, and subsequently found itself facing legal proceedings in the Netherlands. It then brought the matter before the Court of Justice. The latter based its judgment not on the validity of the Dutch legislation, which it did not call into question, but on the way in which this legislation had been applied on this occasion by the Dutch authorities. While it was going through the approval process in France, the product had undergone a number of tests which had proved conclusive, and the Dutch authorities were unwilling to recognize these tests in connection with the issue of approval in their country. On this occasion, the Court ruled that 'The authorities of the importing State are ... not entitled unnecessarily to demand technical or chemical analyses or laboratory tests when the same analyses and tests have already been carried out in another Member State and the results thereof are available to these authorities or can be made available to them on request.'

Having set out in a general way the principle whereby the levels of protection achieved within the various States are presumed to be equivalent, the Court of Justice thus gave this principle concrete form by stipulating the recognition of checks which are carried out therein with a view to verifying compliance with these levels.

The two judgments mentioned above were followed by many others which have made it possible to clarify this case-law. At least two of these are worthy of mention: one is of interest in that it supplements the case-law, and the other in that it reveals the law's limitations.

The first of these judgments dates from 1986 and relates to woodworking machines. The European Commission had called into question French legislation in this area. The reason for this was that woodworking machines were required by this legislation not only to meet certain design specifications but also to be approved prior to their placement on the market, with tests which were capable of being performed only in French laboratories approved by the French Ministry of Employment. Needless to say, such provisions were evidently liable to restrict trade in woodworking machines within the Community ... .

However, it should also be acknowledged that woodworking machines are particularly dangerous, as is shown by the number of industrial accidents caused by this type of equipment.

In this case, the Court confirmed the validity of the French regulations on the basis of the need to protect workers: it acknowledged that the French requirements differ from those in force in other EC Member States and that, in the absence of technical harmonization on the basis of Article 100, the French authorities were justified in refusing to allow onto their territory dangerous machines which did not guarantee users the level of protection laid down by the French regulations.

The Court stressed the need to take account of factors such as suitable training for users when evaluating the degree to which the health and lives of people are protected. 
This judgment is interesting in that, following the Cassis de Dijon ruling and subsequent judgments, the opinion had been voiced by many in the Community that the Court of Justice cared little about the safety of citizens and that the free movement of goods was the only matter which concerned it. In delivering the Woodworking machines judgment, the Court demonstrated that this was certainly not the case and that it was concerned that safety should in fact be guaranteed within the various Member States:

The last ruling which is worthy of mention is the judgment on beer which was delivered in 1987. In this judgment, which is familiar even to the general public, the Court of Justice ruled that the provisions of the famous 'Reinheitsgebot', the German purity law, were illegal under the Treaty of Rome. Following this ruling, a number of German brewers decided to promote the provisions of the purity law by themselves with the aid of a private certification mark which used the same requirements ('RAL' mark), but of course on a purely voluntary basis. Thanks to a well-run marketing and promotion policy, these brewers thus succeeded in reimposing compliance with the provisions of the 'Reinheitsgebot' on a major part of the market, including products for export.

The interesting aspect of this operation consists in the success achieved by professionals in making use of a legal document on a private basis, and the success which, to all intents and purposes, they achieved in imposing this document on the market by means of quality marks which were in principle purely voluntary. This case defines the limits governing the application of the Cassis de Dijon ruling and, more generally, the use of law to counter technical barriers to trade. This case was also what sparked the Community into launching a policy to promote the preparation of European standards and the recognition of private forms of certification in a voluntary context (see Part 2, Chapters 3,4 and 5 below).

The foregoing examples show that application of the Court of Justice's ruling on the Cassis de Dijon case is leading Member States to apply the principle of 'mutual recognition' in three areas which are closely connected.

The first of these areas relates to regulations and procedures for design and manufacture. This means that Member States are not entitled to demand that imported products have the technical characteristics laid down for products manufactured on their territory, while these imported products guarantee the same level of protection for users or allow other requirements which are legitimate with regard to Community law to be satisfied in an equivalent way.

The principle of mutual recognition also means that the importing State takes account of the checks, analyses and tests carried out in another Member State provided that the results thereof are made available and make it possible to ascertain that the product meets the intended objective of its regulations in a suitable and satisfactory manner. This prevents the inevitable waste of time and money which results from, repeating checks and tests.

Finally, and this represents the last of the three factors mentioned above, these results must be taken into account if the bodies and laboratories which issued them offer guarantees of technical expertise, professional competence and independence which are both adequate and necessary. The Commission takes the view that this is the case, in 
particular, when such bodies and laboratories are accredited on the basis of the criteria set out in the 'EN 45000' series of standards.

This brief examination of the efforts made by the Court of Justice to combat technical barriers to trade should be concluded by stressing the success of these efforts: after all, the principles identified by the Court in its various judgments, particularly the principle of mutual recognition, have subsequently been incorporated into Community law, as will be seen later on in this study.

\subsubsection{The Single Act}

In the mid-1980s, it became obvious to all parties concerned that a number of radical measures needed to be taken if the European Economic Community was really to become a single internal market. The Commission compiled a list of concrete proposals, which was distributed in 1985 in the form of the 'White Paper', and which for the first time gave a target date for the creation of the internal market: this was the famous date of 31 December 1992.

The Council of the Heads of State or Government of the Community took up the Commission's proposals, and it was in this way that the Single Act came to be adopted and subsequently came into force on 1 July 1987. Two articles of the Single Act, which is a treaty which modifies a number of provisions of the Treaty of Rome with a view to achieving greater Community integration, directly relate to the fight against technical barriers to trade: Articles 100A and 118A.

\subsubsection{Article 100A}

Article $100 \mathrm{~A}$, the text of which is given below, modifies the technical harmonization system in the Community - a system which, as mentioned above, was both ponderous and ineffective. The main elements of this provision are as follows:

' 1 - By way of derogation from Article 100 and save where otherwise provided in this Treaty, the following provisions shall apply for the achievement of the objectives set out in Article 8A. The Council shall, acting by a qualified majority on a proposal from the Commission in cooperation with the European Parliament and the Economic and Social Committee, adopt the measures for the approximation of the provisions laid down by law, regulation or administrative action in Member States which have as their object the establishment and functioning of the internal market.

2 - Paragraph 1 shall not apply to fiscal provisions, to provisions relating to the free movement of persons nor to those relating to the rights and interests of employed persons.

3 - The Commission, in its proposals laid down in paragraph 1 concerning health, safety, environmental protection and consumer protection, will take as a base a high level of protection. 
4 - If, after the adoption of a harmonization measure by the Council acting by a qualified majority, a Member State deems it necessary to apply national provisions on grounds of major needs referred to in Article 36, or relating to protection of the environment or the working environment, it shall notify the Commission of these provisions.

The Commission shall confirm the provisions involved after having verified that they are not a means of arbitrary discrimination or a disguised restriction on trade between Member States.

By way of derogation from the procedure laid down in Articles 169 and 170, the Commission or any Member State may bring the matter directly before the Court of Justice if it considers that another Member State is making improper use of the powers provided for in this Article.

5 - The harmonization measures referred to above shall, in appropriate cases, include a safeguard clause authorizing the Member States to take, for one or more of the non-economic reasons referred to in Article 36, provisional measures subject to a Community control procedure'.

First modification: with regard to harmonization, the Council of Ministers shall, except in certain exceptional cases, act in future by a weighted qualified majority. This means that Directives are passed with a two-thirds majority of the votes and that States are each allocated a certain number of votes on the basis of Article 148 of the Treaty. As a result, decisions can be taken more easily and quickly, while at least three States, irrespective of their size, are in fact required to block the Community voting process.

Second modification: the process whereby Directives are drawn up has been 'democratized'. The reason for this is that Directives used to be exclusively a matter for the Commission and the Council of Ministers, with the European Parliament's involvement being confined to the provision of a purely consultative opinion. A 'cooperation' procedure with the European Parliament is provided for under Article 100A. Without going into details, it should be noted that the Parliament has thus acquired powers to modify the text proposed following a vote by the Council of Ministers.

The other provisions of Article 100A - particularly paragraphs 3,4 and 5 - make provision in a general way for measures which are intended to reassure Member States which were fearful that the adoption of Directives by a qualified majority would prejudice their fundamental rights or even those of their citizens with regard to safety, health, etc. Paragraphs 4 and 5 thus deal with safeguard measures: Paragraph 4 provides for the possibility of a posteriori exceptional measures, i.e. following the adoption of a Community document, while Paragraph 5 reminds the European legislators to make provision for a safeguard clause in harmonization documents which require it. It should be noted that the provisions of Paragraph 4 have yet to be used.

Article 100A should thus enable the decision-making process within the Community to be improved and speeded up, particularly by being used in conjunction with the doctrine of the New Approach. This doctrine, which will be enlarged on in Chapter 3, consists in easing the strain on Community legislation and enabling it to respond quickly to technical 
progress through use of the so-called 'reference to standards' practice, i.e. by referring to standards (mainly European ones) in order to apply directive provisions on a practical basis.

\subsubsection{Article 118A}

One of the most politically and economically sensitive areas of technical harmonization is safety within the working environment. It has already been seen (with the judgment on woodworking machines) that safety requirements intended to protect workers took precedence over the free movement of goods when these two objectives conflicted with each other. It is also known that actual working conditions are far from being identical in all Member States, and that it is economically unrealistic to hope for the problem to resolve itself by a quick levelling-up process.

Article 118A (see below), which governs the principles of technical harmonization as applied to safety at work, attempts to resolve these conflicting aspects in the following way: unlike the Directives adopted pursuant to Article 100A, the Directives relating to harmonization of working conditions are 'minimal' Directives to which each State may add its own requirements, to achieve 'more stringent protection'. However, these measures must be compatible with the Treaty.

In other words, this means that a State may impose supplementary safety precautions or arrangements provided that these do not modify the conditions of free movement. In the case of the safety of machines, for example, it is conceivable that a State might stipulate that certain types of machinery should be protected by an insubstantial barrier. It could not, on the other hand, stipulate in its legislation that protective devices must be incorporated in equipment placed on the market if no provision had been made for this under the Directive on the technical harmonization of machinery.

' 1 - Member States shall pay particular attention to encouraging improvements, especially in the working environment, as regards the health and safety of workers, and shall set as their objective the harmonization of conditions in this area, while maintaining the improvements made.

2 - In order to help achieve the objective laid down in the first paragraph, the Council, acting by a qualified majority on a proposal from the Commission, in cooperation with the European Parliament and after consulting the Economic and Social Committee, shall adopt, by means of Directives, minimum requirements for gradual implementation, having regard to the conditions and technical rules existing in each of the Member States.

Such Directives shall avoid imposing administrative, financial and legal constraints in a way which would hold back the creation and development of small and medium-sized undertakings.

3 - The provisions adopted pursuant to this Article shall not prevent any Member State from maintaining or introducing more stringent measures for the protection of working conditions compatible with this Treaty.' 


\subsubsection{Directive $83 / 189 / E E C$}

This is the main tool used to prevent technical barriers to trade in the Community. This document is also used for other purposes since it enables the situation as regards harmonization and regulation in the various countries to be assessed and allows for Community-level needs - either in terms of mutual recognition or European standardization - to be deduced on the basis of this assessment.

The concept of prevention took shape relatively early on in the Community's history since it was as long ago as 1969 that ministers signed an agreement relating to not only the standstill arrangement as regards technical regulations but also the provision of information to the Community, an agreement which was revised in 1973 but never applied very effectively.

At the beginning of the $1980 \mathrm{~s}$, the Commission decided to propose a more stringent document with a broader scope. This led to Directive $83 / 189$ /EEC being passed on 28 March 1983, a Directive establishing 'a procedure for the provision of information in the field of technical standards and regulations'. This Directive was modified once, on 22 March 1988. The text of the Directive is provided in Appendix 3 of this study. It is in the process of being revised at the present time with the twin aim of simplifying it and increasing its effectiveness.

\subsubsection{The objectives of Directive $83 / 189 /$ EEC}

The first objective of this Directive consists in creating transparency in the field of technical standards and regulations because, as has already been seen, the foremost problem of exporters is one of awareness of the applicable documents.

The second objective is to prevent the creation of new obstacles to trade by intervening at an early stage in the procedure whereby technical regulations are formulated: this represents the preventive function of Directive $83 / 189 / \mathrm{EEC}$.

The third and final objective which, though less widely known about, is no less important than the first two, consists in promoting European harmonization and the emergence of European standardization once 'Community' needs have been identified and assessed in the light of initiatives undertaken at national level with respect to regulation and standardization; such promotional activities are, in particular, carried out using the mandates procedure which enables Community authorities to invite European standards institutions to draw up European standards.

\subsubsection{The content of Directive $83 / 189 / \mathrm{EEC}$}

Scope: the Directive applies not only to technical regulations - i.e. requirements of a mandatory nature, whether de jure or de facto, which have been enacted by public authorities - but also to standards enacted by the of ficially recognized bodies listed in 
Appendix 2 of the Directive (in other words, the national standards institutions and also the corresponding electrotechnical Committees).

In addition, since it was revised in 1988, Directive $83 / 189 / \mathrm{EEC}$ has applied not only to industrial products but also to agricultural produce and medicines, which had initially been excluded.

The revision, mentioned earlier, which is currently being envisaged would consist in supplementing the definition of a technical specification by making it clear that the notion of a 'sales designation', i.e. the name under which a product is sold in a Member State, constitutes a technical specification. In addition, it would be specified that conformity assessment procedures and production processes and methods (for all products) also constitute technical specifications within the meaning of the Directive.

Finally, the revision would make it compulsory to cater not only for technical specifications sensu stricto, as at the present time, but also for the whole corpus of regulatory requirements which affects the life of a product, e.g. those relating to the life-cycle of a product after its placement on the market and which deal, inter alia, with its use, maintenance, disposal, etc. Lastly, the proposal clarifies the notion of a technical regulation, which is applicable de facto in a Member State.

Provisions relating to technical regulations: Articles 8 and 9 of the Directive oblige any Member State to notify the Commission of any draft technical regulation (with the Commission then passing this information on to the other Member States), and to wait at least three months (save in the event of a duly substantiated emergency) before adopting the said draft: this represents the minimum standstill period.

During this period, the Commission or another Member State may deliver a 'detailed opinion' in opposition to the draft text in the event that they consider that the adoption of the latter would be liable to create a technical barrier to trade and harm the effective operation of the internal market; the effect of this is to put back by a further three months the date on which the text may be adopted.

In addition, if a Member State document risks creating an obstacle to the free movement of goods, the Member State concerned must normally amend the text thereof so as to eliminate this risk. Furthermore, the additional period will be nine months, and not three, if the Commission gives notice of its intention of proposing a Directive on the subject in question.

The 1988 reform introduced an additional provision enabling the Commission to prevent Member States adopting texts relating to a matter covered by a proposed Directive or regulation, by imposing a standstill period of 12 months, counting from the date on which the proposed Community text is submitted.

Under the current revised draft, this provision is to be amended by increasing this period to a total of 18 months, counting from the date on which the Commission receives the national draft. Finally, it is also proposed that Member States refrain from laying down regulations on a particular subject as soon as the Council adopts a common position on the same subject. 
Provisions relating to standards (see Chapter 2 below): Provision is made for the national standards institutions to provide the Commission, CEN (or Cenelec with regard to the electrotechnical field) and the other national standards institutions, with annual notification of their standards programme and updates thereto, and to provide the said bodies with four-monthly notification of new draft standards which have reached the publiccomment stage. The standards institutions of EFTA member countries have participated in this part of the procedure right from the start.

The essential difference as regards technical regulations results from standards bodies having the status of institutions constituted under private law: this means that a Directive cannot impose a standstill obligation with regard to standards, except when a mandate for the preparation of a European standard is in operation. In this case, it is envisaged that Member States must use every possible means to ensure that the standards institution in their country does not draw up standards on the same subject, and that it refrains from doing so for six months after the date on which the mandate expires.

It should be noted that this provision was incorporated voluntarily and in parallel in the rules of procedure of the European standards institutions since the initiation of European activities automatically results in a standstill on national activities, as explained in the first part of this study.

It should also be noted that in May 1988 Cenelec adopted a procedure known as the 'De Vilamoura' procedure, which relates to European standardization in the electrotechnical sector; this procedure provides for a standstill period of three months with regard to national notifications in the event of another country wishing to take part in activities started at national level, and also the systematic examination of national drafts with a view to converting them into European standards.

Likewise, the Directive cannot formally constrain national standards institutions to accept the comments of the other national institutions. On the other hand, Article 3 of the Directive specifies that the Commission must be 'informed [of the] wish' of one or more standards institutions to be involved in the standardization activities of another national standards institution or to see a European standard drawn up, and this possibility was formally adopted by CEN/Cenelec in 1988 (CEN/Cenelec Memorandum No 7, published in April 1989).

The current proposals to amend the Directive from the point of view of standards tend to simplify the procedure and make it more effective. The obligation to provide notification would therefore no longer apply to standards programmes, nor to national standards which represent a mere transposition of an international or European standard; instead, this obligation would apply only to purely national activities, though at a sufficiently early stage to enable the comments of the parties concerned to be taken into account.

Finally, the proposal envisages provisions which would result in the Directive being aligned with provisions already adopted by the members of CEN and Cenelec with regard to reciprocal involvement in activities, standstill arrangements and the public-comment procedure. 
It should be noted that Directive $83 / 189 / \mathrm{EEC}$ is the tool which has made it possible to establish on solid legal foundations the procedure whereby European standards institutions are 'mandated' by the European Commission with a view to creating a European standard. This procedure is enlarged on in Chapter 2 below. Finally, it should be pointed out that Appendix 1 of the Directive provides a list of European standards institutions which are formally recognized by the Community institutions and which can be assigned standardization 'mandates', namely CEN, Cenelec and, since 15 July 1992, ETSI in the case of the telecommunications sector.

\subsubsection{The operation of Directive $83 / 189 /$ EEC}

Directive $83 / 189 /$ EEC is administered by the Commission, with the assistance of a Standing Committee; the latter is made up of representatives of the Member States who are the officials responsible for standardization policies at national level, and is chaired by a representative of the Commission (Article 5).

Since its implementation on 1 January 1985, the Directive has broadly proved its usefulness with regard to technical regulations and has made it possible not only to prevent the creation of new barriers to trade but also to initiate Community harmonization policies in certain areas where a need for this was felt.

As an historical sidenote, it is interesting to note that the first detailed opinion which was issued related to a subject which has subsequently become very important in Community policy: tax incentives in favour of unleaded petrol, as originally contemplated in a unilateral manner by Germany.

This usefulness of the Directive, coupled with the general move towards alignment between the EC and EFTA, led the latter, in December 1987, to incorporate a new article in its Convention of establishment for the first time in the organization's 30-year history, in order to impose on the States which had signed the EFTA Convention, obligations relating to technical regulations which are similar to those set forth in Directive 83/189/EEC.

A 'crossover' agreement between the EC and EFTA which was signed on 19 December 1989 subsequently made it possible to establish a procedure for the exchange of information which had been collected in this way in all the countries of western Europe and also allowed for a reciprocal option for 'detailed opinions'. This agreement came into force on 1 November 1990.

With regard to standards, the usefulness of the procedure laid down in Directive $83 / 189 / \mathrm{EEC}$, as initially conceived, is less clear for two reasons: the smaller degree of obligation attaching to standards in the Directive, and the very large quantity of draft standards issued every year in Europe, which far exceeds that for technical standards, making the system costly, difficult to manage and unreliable (in too many cases, new drafts are notified when the public-comment stage is over or almost over, while the notifications which 'swell' the statistics are sometimes merely a rerun of international standards, etc.). 
To give an idea of the scale of the procedure, it could be pointed out that in 1991, for example, 400 draft technical regulations had been the subject of notification, as compared with 10210 draft standards, with the second figure also including national standards representing a mere transposition of European or international standards. If the number of draft standards is corrected to include only purely 'national' drafts, the figure is a more reasonable one of 2193 , i.e. only $21.5 \%$ of the total (as compared with $70 \%$ in 1987 and $43 \%$ in 1989 for example, representing a steady and large-scale decrease).

It should be noted that these figures relate only to notifications from EC countries. The order of magnitude is the same if EFTA countries are included.

It was all of these considerations which prompted the Commission, the Member States and CEN/Cenelec to examine the procedures presented above for modernizing the Directive.

To end this chapter, it should be noted that the Maastricht Treaty barely modifies the provisions which apply to technical harmonization, except as regards the joint decisionmaking procedure (Council and European Parliament) in Article 100A. 


\section{Relations between European standards institutions and European institutions}

\subsection{Relations with Community institutions}

Since 1983, the policy pursued by the Community with regard to harmonization has been based on a series of basic documents which take various legal forms and which can be grouped into two categories:

(i) documents which set out the principles under which the European Community and European standardization are linked and regulate the various aspects of this relationship: this chapter is devoted to these documents;

(ii) documents which precisely govern the use of standardization within the Community legal system. These documents primarily include the resolution of 7 May 1985 advocating reference to standards in connection with Community harmonizations, but also documents relating to public contracts, information technology, Community energy policy and lastly, of course, resolutions and decisions relating to the evaluation and certification of conformity. Documents in this second category will be examined in Chapters 3 and 4 of this part of the study.

\subsubsection{Official reference documents of the European Communities}

Three basic documents establish official links between standardization and the European institutions:

- Directive $83 / 189 / E E C$ laying down a procedure for the provision of information in the field of technical standards and regulations (this document has already been examined in Chapter 2 of this part and is appended to this study as Appendix 3).

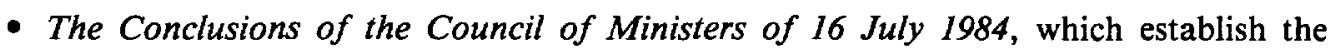
general outlines of Community standardization policy for future years. This document includes the following fundamental sentence:

'The Council believes that standardization goes a long way towards ensuring that [...] products can be marketed freely and also towards creating a standard technical environment for undertakings in all countries, which improves competitiveness [...].'

To this end, the Council adopts four main guidelines for the future:

(i) Transparency (Directive 83/189/EEC and regular examination of existing regulations which are likely to constitute technical barriers to trade). 
(ii) Support for European standards institutions via Community institutions.

(iii) Systematic formulation of European standards on new technologies as soon as the latter develop.

(iv) Use of the practice of referring to standards in Community harmonization legislation.

- The resolution of the Council of Ministers of 18 June 1992, which takes stock of European harmonization policy which has been pursued since the beginning of the 1980s, notes and supports the developments which are going on within European standards institutions, and confirms the European Community's fundamental approach which consists in extending as much as possible the use of European standardization in connection not only with the policy of creating a single internal market but also industrial policy in the broadest sense of the term.

Although they do not have the same legal value, these three documents have made it possible to create an increasingly tightly knit system of links between the EC and CEN, Cenelec and ETSI, links which are examined in the following section of the study.

\subsubsection{Contractual agreements between the EC and CEN and Cenelec}

\section{(1) The contract relating to the operation of Directive $83 / 189 / E E C$ in relation to standards}

Directive $83 / 189 / \mathrm{EEC}$, whose full title is the 'Directive laying down a procedure for the provision of information in the field of technical standards and regulations' and which was adopted on 28 March 1983 by the Council of Ministers of the European Communities, has been implemented as from 1 January 1985. It represents the first tool of this importance concerning cooperation between the EC and CEN and Cenelec, particularly by virtue of Articles 2, 3, 4, 6 and 7 thereof and the joint contract signed by the Commission and the European standards institutions in order to implement it.

As was seen in the previous chapter, apart from the rights and obligations which the Directive creates for Member States, the national standards institutions also undertake to notify the Commission and the other national standards institutions of their standards programmes and draft standards via the Central Secretariats of CEN and Cenelec.

Let us briefly recall the main provisions which apply to standards:

If one or other of the standards institutions in Europe considers that a draft which is being drawn up in another country potentially constitutes a technical barrier to trade, it may make comments, or ask to be involved in the activities, in accordance with a procedure accepted by the members of CEN and Cenelec and recorded in their joint Memorandum No 7, or finally ask for a European standard to be drawn up.

It should be stressed that this last option is also open to the Directive's Standing Committee, which is made up of representatives of the Member States, in which case 
there is a legal obligation to comply with the standstill arrangement on national activities. It should be noted that this standstill arrangement also applies jointly, though in a contractual way, to the members of CEN and those of Cenelec when they decide to draw up European documents.

The Central Secretariats of CEN and Cenelec and their members have had to make great efforts to set up this system owing to the very large number of documents which are notified every year (several thousand). The Europeans standards institutions have therefore computerized the system. Nevertheless, this system has turned out to be cumbersome and costly to use with respect to the benefits which have been derived from it.

This is the main reason why, as seen above, the Commission departments are currently engaged on revising the Directive, a task which is intended to improve the way in which the obligations imposed under the Directive are integrated in the general system of voluntary European standardization. This revision process should be completed some time in 1994.

\section{(2) General guidelines for cooperation}

The 'Council Conclusions' of July 1984 coupled with the adoption of Directive $83 / 189 / \mathrm{EEC}$ have in this way given the Commission the necessary legal and political footing for negotiating with CEN and Cenelec the terms of a cooperation which is intended to last for several years. This led to the 'General guidelines for cooperation between the European Commission and the European standards institutions CEN and Cenelec' being signed on 13 November 1984; these guidelines were incorporated in Memorandum No 4, which is attached to this study as Appendix 4.

The aim of this agreement is to organize relations between the Commission and these bodies in order to collaborate as effectively as possibly in the fight against technical barriers to trade and to increase the competitiveness of European industry, both in its domestic market and that of third countries.

To this end, the partners agree to use European standards on a priority basis, which will involve increasing the standardization capability at European level. This agreement therefore comprises undertakings on the part of each of the parties:

For its part, the Commission undertakes to propose the use of European standards in the field of technical harmonization whenever possible, and to promote the latter in the sectors of new technologies.

In order to make it easier to draw up the necessary European standards, the Commission will conclude contracts with CEN, Cenelec or ETSI, either on a case-by-case basis, or under multi-annual programmes, with financial support.

In addition, while these European standards are being drawn up, the Commission will in principle refrain from drawing up, either by itself or through others, technical specifications which have the same object. 
However, the Commission reserves the right to organize technical activities on the preparation of a draft standard within a framework other than the standardization framework, even if the final document must be passed on to the European standards institutions for the purposes of producing a European standard.

It should be noted that this clause has hitherto not been specifically applied. Finally, the Commission undertakes to make reference, in so far as is possible, to European standards in the specifications of its own calls for tenders.

CEN and Cenelec, in return, undertake to strengthen their structures in such a way as to be able to meet the additional workload which is thus foreseeable.

In addition, the European standards institutions will pass on to the Commission all information requested by the latter on the progress of activities, and invite its representatives to participate in the activities of CEN and Cenelec, both at technical level and at a more political level.

Finally, in order to ensure that European standards are indeed suitable for the use which is intended to be made of them, in harmonization directives for example, the European standards institutions undertake to ensure that all the parties concerned are effectively involved in technical activities, and that European standards meet essential safety requirements. With regard to standardization 'practice', CEN and Cenelec are responsible for ensuring that the national institutions comply with the obligations imposed on them by the rules of procedure with respect to the application of European documents.

\section{(3) Standardization mandates}

The procedure whereby the Commission 'gives a mandate' to CEN or Cenelec to produce European standards on a particular subject existed before the agreements mentioned above were signed. However, it was not formalized and had only been used very infrequently.

Following the signing of the 'General guidelines for cooperation', a framework contract 'relating to the provision of services with regard to European standardization' was negotiated between the Commission and the European standards institutions and signed in autumn 1985 .

This contract, which was revised in 1992, aims to regulate the administrative, financial and legal aspects of the preparation of European standards on the basis of mandates given by the Commission. Each mandate is the subject of a 'purchase order' which puts the undertakings of each party in concrete form and specifies a number of characteristics such as the object of the standard(s), any essential requirements which have to be met, any international standards which have to be used, the time-scales and, of course, financing in the event of there being a funding commitment on the part of the Commission. This procedure has been extended to cover ETSI.

The number of standards which are currently the subject of a mandate is around 2300 for the three bodies. 
Three categories of sectors are involved. The first of these is made up of the major sectors which are the subject of European policies to harmonize bodies of legislation; the second is made up of sectors in which a policy of technological development has been initiated, while the third category is made up of sectors in which a policy designed to bring about integration of the markets has been initiated. The first category includes the medical sector and covers gas-operated and pressurized equipment, machinery (including safety at the workplace), products intended for the construction industry, telecommunications, etc., while the second covers information technology, biotechnology, advanced ceramics and the aerospace industry; lastly, the third category covers the agri-foodstuffs sector, the industrial transport services sector, the water-supply sector and the energy sector.

It should be noted that, in the case of these last two categories, the mandates given by the Commission only 'validate' the willingness of the business interests to work together: the Commission merely provides, via the mandates, additional resources for European standardization and in this way makes known the Community's support for the integrative activities initiated by the business interests.

Where conformity with standards is a method of proof provided for by the Directives (new approach Directives), the Commission publishes in the Official Journal of the European Communities (OJ) a list of the titles of European standards which are liable to be used in connection with this method of proof. These standards are designated by the name of 'harmonized standards'. It should be noted that this qualifier does not conceal any difference in the way that the standards are drawn up and adopted, and only concerns the use which may be made of them.

\subsubsection{Green Paper on European standardization and Council resolution of 18 June 1992}

At the beginning of 1991, the Commission published a communication known as the 'Green Paper' in which it takes stock of the standardization policy which has been pursued since 1983 and proposes a number of measures or guidelines which it considers need to be adopted in order to improve the effectiveness of European standardization not only in terms of producing, disseminating and promoting standards and making them transparent but also as regards structures at European level. The reason for this was that, given the very large number of mandates given to European standards institutions, the Commission was afraid that the existing working procedures would not be suitable for the new scale of European standardization operations.

This publication (OJ C 20 of 28 January 1991) naturally prompted numerous reactions, and an equal number of counter-proposals. Certain ideas, such as the abolition of the obligatory transposition of European standards into national standards, the drastic curtailment of the public-comment periods, and even the creation of a European political superstructure responsible for guiding European standardization were rejected by the vast majority of partners. 
Other ideas, on the other hand, fitted in with a development which was perceived as being desirable by these same partners, and are in the process of being implemented in one form or another by the European standards institutions (in particular, the proposals designed to make the process whereby standards are drawn up more effective, raise the profile of European standards, increase international cooperation, etc.).

Following the consultation process initiated by the Green Paper, the Commission passed on a communication (final COM (91) 521 of 16 December 1991, see OJ C 96 of 15 April 1992) to the Council of Ministers. Discussions on this matter finally led to resolution 92/C/173/01 relating to the role of European standardization in the European economy being adopted by the Council of Ministers on 18 June 1992. This resolution, which is appended to this study as Appendix 5, was published in OJ C 173/1 of 9 July 1992.

This document, which runs to some 24 paragraphs, recalls the main measures so far adopted by the Community which are conferring a growing importance on standardization; the Council of Ministers then states that, though organized on a voluntary basis, European standardization also serves public interests and that, in this respect, the partnership between the European Community and the European standards institutions should be strengthened and extended.

The resolution goes on to confirm a number of guidelines with regard to Community policy in the field of standardization, and urges the development of certain initiatives:

It recalls the Community's attachment to the consistent and independent system based on consensus and decision-making on a national basis, as set up in practice by CEN, Cenelec and ETSI, and recognizes that fragmentation of this system needs to be avoided since this would inevitably lead to greater bureaucracy at European level.

It confirms the Community's interest in the development of international standardization, and the effective use of international standards by all parties involved in international commerce.

It welcomes the endeavours made by the European standards institutions to increase their effectiveness and open them up to all business interests, who are themselves invited to take an active part in the activities of the European standards institutions, and to facilitate access to European standards. It calls for these endeavours to be continued.

It expresses a desire for greater harmonization between standardization and research, and considers that standardization should, now more than ever, be used as a means of bringing about the economic integration of Europe. In this respect, the Community will continue to implement the New Approach and will increase the general use of standards as a technical basis for future European legislation on specifications applicable to products and services alike, or for test methods.

Finally, it urges the Community to continue with its financial support for European standardization, and invites the governments to ensure that the national standards institutions play their full part. 


\subsection{Relations with the European Free Trade Association (EFTA)}

The European Free Trade Association (EFTA) currently comprises the following countries: Austria, Finland, Iceland, Liechtenstein, Norway, Sweden and Switzerland. Created shortly after the signing of the Treaty of Rome in order to establish a free-trade area between the signatory countries, the association in fact pursues more extensive objectives with regard to the free movement of goods, but without its members being linked by obligations which are as stringent as those of the Treaty of Rome. As a result, it cannot as such, use legal tools of the type which exist within the framework of the Community (harmonization Directives, in particular).

Nevertheless, EFTA has long pursued a policy of alignment with the Community on a large number of levels. Quite naturally, in view of the economic history and the proximity of the various countries of Europe, one of the areas in which cooperation is most marked is the free circulation of goods. This is even one of the main objectives incorporated in the 'Declaration of Luxembourg' which was adopted on 9 April 1984 following a meeting at ministerial level between the Community and EFTA. More specifically, standardization represents one of the areas in which the cohesion of western Europe is most marked, and the countries of EFTA have been members of CEN and Cenelec right from the start.

However, as we have seen above, the obligations of standards institutions in EFTA countries which are members of $\mathrm{CEN}$ and Cenelec are less extensive than those imposed on their EC-member counterparts. This is a reflection of the situation which prevails at the level of the States.

Despite this difference, a complex structure has, since $1983 / 84$, been put in place by CEN and Cenelec and the Secretariat of EFTA in order to organize cooperation between these bodies in as similar a way as possible, as exists with the European Commission.

Thus, as seen above in Chapter 2, the countries of EFTA have taken part in the 'standards' part of the procedure established by Directive 83/189/EEC as soon the latter came into operation in 1985. Since they were also eager to intensify the fight against technical barriers to trade and deepen cooperation with the European Economic Community, the countries of EFTA decided in 1987 to modify the convention establishing EFTA by supplementing it with an Article 12a, a provision of fundamental importance which resulted in similar obligations to those imposed on EC countries by virtue of Directive 83/189/EEC being imposed on the members of EFTA with regard to regulations. As a result of this decision and an agreement between the European Community and the countries of EFTA, a mutual procedure for the exchange of information in the field of technical regulations was able to come into force in November 1990.

Harmonization between EFTA and the Community is continuing, particularly with the conclusion in May 1992 of the overall negotiations known as agreements on the 'European Economic Area', which are giving rise to a treaty. The quasi-systematic nature of EFTA's participation in all the agreements between the European standards institutions and the Community is thus confirmed. One additional stage in the future might consist in abolishing the rule under which EFTA countries are, in certain cases, exempted from 
implementing European standards which have been adopted by a qualified majority (see Section 2.4.5. in the first part of this study).

Finally, all policy pursued by EFTA countries with regard to preventing and eliminating technical barriers to trade is formulated within a special group which was set up in July 1984, namely the 'EFTA Committee on Technical Barriers to Trade' (TBT Committee). On the basis of guidelines adopted by this group, the Secretariat of EFTA frequently holds meetings with the European Commission in order to formulate, in so far as is possible, a joint policy on all matters relating to technical harmonization and the use of standards in industrial policy. 


\section{The European standard - A regulator of competition and a driving force behind technical progress}

\section{Introduction}

As was seen in the first chapter of this study, standardization provides a key way of organizing economic relations since it is used both as a tool in inter-industry and commercial relations and as a reference in public relations, while it also provides a basis for many conformity certification procedures which are intended to allow products to gain access to the market under the best possible conditions from the point of view of producers and consumers alike.

The prime way in which European standards are used is to replace national standards which deal with the same subject - the function for which they are designed - and they play exactly the same role as national standards. They also have the clear advantage of facilitating the free movement of goods and allowing potentially considerable economies of scale since they are normally used in the 18 countries of western Europe at the same time.

Lastly, they have assumed growing importance in connection with the creation of the European internal market, in respect of which they now represent an essential tool as regards not only technical harmonization, but also industrial cohesion and, finally, technical support for Community legislation in general, whether in terms of public contracts, energy policy, the environment, etc. It is this role, which is venerated and underscored by the most recent resolution on this subject by the EC Council of Ministers (on 18 June 1992), which we will return to in this chapter.

It should first of all be noted that for a number of years the weakness of the European structure on technical and industrial matters - which was reflected, inter alia, in the absence of any incentive to technical harmonization as regards standardization (since, when such harmonization took place, it was carried out for purely regulatory purposes and solely by means of directives) - resulted in European standardization only playing an entirely minor role.

In 1980, for example, only 64 European standards (ENs) were in existence, as compared with the national collections of the three largest countries of Europe, each of which comprised more than 10000 standards at that time. In short, European standardization represented a subsidiary system with respect to national and international forms of standardization, with the notable exception of the electrotechnical sector to which we will return in the following section. 
This state of affairs was also due in part to the fact that, for many years, standards tended to be considered by a number of parties - including the public authorities - as being a tool used to create technical barriers to trade.

The first half of the 1980 s were decisive in changing thinking on standardization, and European standardization in particular. This was due to a combination of factors, two of which will be enlarged on later on in this chapter but are worth mentioning at this juncture:

(i) The consideration which had started to be given to creating a 'single internal market', which resulted in the European Commission publishing the 'White Paper of 1985', the adoption of which by the Council of the Heads of State or Government led to the modification of the Treaty of Rome by the Single Act of 1987. The reason for this was that, as part of this reflective process, it was decided to use new methods to create the internal market, which resulted in the adoption of the "new approach of reference to standards' with regard to technical harmonization by means of Directives.

(ii) The Community's commitment to a policy of supporting research and development in the European IT industry, a commitment which was embodied in the Esprit programme. In connection with this programme, the role of standards as a cohesive factor was quickly realized and, owing to the crucial importance of this industrial sector for the European economy, gave standardization the positive aura which it had in part been lacking before.

It was thus that the second half of the 1980s saw the implementation of concepts which underlie the current development of European standardization: the European standard represents an essential tool for creating the single internal market since not only has it become one of the main factors which regulate competition in Europe but it is also used as a driving force behind technical progress.

This new policy first manifested itself on 16 July 1984,-when the EC Council of Ministers adopted conclusions determining the future outline of Community activities with regard to standardization. The key sentence in these conclusions clearly shows the way in which the public authorities' attitude to standardization had changed:

'The Council believes that standardization goes a long way towards ensuring that industrial products can be marketed freely and also towards creating a standard technical environment for undertakings in all countries, which improves competitiveness not only on the Community market but also on external markets, especially in new technology.'

In its conclusions, the Council then adopts a number of principles which may be translated into the following guidelines with regard to European standardization policy:

Transparency with regard to technical regulations and standardization, as established by Directive $83 / 189 / \mathrm{EEC}$, must make it possible to regulate a priori matters which 'might have adverse repercussions on the operation of the internal market';

Use of the practice of referring to standards should be extended within Community technical harmonization legislation; 
European standardization capacity should be bolstered in order to promote Community harmonization and also to keep up with and encourage industrial development, notably in new technology and particularly with a view to opening up public works and supply contracts.

These conclusions embody the thrust of Community action as pursued in recent years, an aspect which we will now examine in detail.

\subsection{The new approach}

The acknowledgement of the limits on harmonization by the establishment of Directives based on Article 100 which are passed unanimously and contain detailed technical requirements has led to two essential reforms: the adoption within the context of the Single Act of an Article 100A which allows Directives to be adopted by a qualified majority (see Part 2, Chapter 1 above) and the decision to use the practice of referring to standards in Community legislation.

Following the Council's conclusions of July 1984, the Commission brought together a group of experts from the various States to prepare a document to this effect. This led to the Council of Ministers adopting a resolution 'on a new approach to technical harmonization and standards' (85/C 136/01, published in OJ C 136 of 4 June 1985) on 7 May 1985, the text of which is reproduced in Appendix 6.

The basic principle of this new approach consists in 'referring to standards - primarily European standards, but national ones if need be, as a transitional measure - for the purposes of defining the technical characteristics of products'. The policy which is to be pursued is explained in detail in Annex II of the document, which describes the basic principles on which the New Approach is based and the conditions which determine the success of this system, and provides an outline Directive which is intended to serve as a guide to the drafting of 'new approach' Directives.

\subsubsection{The main principles of the new approach}

These are four in number:

(i) Directives based on Article 100 will in future be limited to the harmonization of 'essential requirements' relating to safety (or other requirements in the general interest) with which products placed on the European market must conform.

(ii) Technical specifications which are of use in complying with essential requirements will be drawn up in connection with standardization, taking account of the current stage of technology.

(iii) Standards drawn up in this way will maintain their voluntary status.

(iv) Products which conform to the standards will be presumed to conform to the essential requirements of the Directive(s), and may therefore be placed directly on the 
market provided that the conformity evaluation procedures are complied with. However, when the producer elects not to comply with the standards, which is perfectly possible, or in the absence of relevant standards, he will be obliged to prove that his products conform to the essential requirements.

\subsubsection{Description of a 'standard' new approach Directive}

The principle is that all new approach Directives are formulated on the basis of the same system. The provisions described below therefore apply roughly speaking to new approach Directives, given that in certain cases 'deviations' with respect to the latter have been introduced to cater for the specific nature of certain sectors or fields:

\section{Article 1: Scope}

This article describes the range of products covered and the nature of the risks to be avoided. Two points are to be noted: the range of products covered will be broad, unlike with Directives under the old approach which often only covered one product, or even one of the elements involved in the manufacture of a product (as with cars, for example). On the other hand, although the possibility of several Directives being adopted on one and the same product is not precluded, the Community legislator will endeavour to cover all the risks associated with a product within the context of a single Directive so as to simplify the work of not only producers but also the supervisory authorities of the Member States.

\section{Article 2: General clause for placing on the market}

The products covered may be placed on the market only if they do not endanger the safety of persons, domestic animals or goods when properly installed and maintained and used for the purposes for which they are intended.

\section{Article 3: Essential safety requirements}

These must be worded precisely enough in order to create legally binding obligations which can be enforced by the Member States or courts, and in order to enable the certification bodies straight away to certify products as being in conformity with the essential requirements, in the absence of standards, or if the producer elects to dispense with the latter. This clause is of fundamental importance since it prevents standards from becoming obligatory de jure.

\section{Article 4: Free movement clause}

This obliges the Member States to accept the free movement of products which conform to Articles 2 and 3 (general clause for placing on the market and compliance with essential requirements). 


\section{Article 5: Means of proof of conformity and effects}

This article puts the preceding articles in concrete form: products which are accompanied by a means of certification declaring that they are in conformity (these are described in Article 8) shall be presumed to be in conformity and may therefore be able to move freely. It should be recalled that the obligation to which products are subject is conformity to the essential requirements. One of the ways in which conformity to the latter may be enjoyed consists in conformity with the harmonized standards or with the national standards whose references are published in the OJ (see Article 6 below with regard to management of the list of standards).

\section{Article 6: Management of the lists of standards}

The new approach introduces a new concept with regard to European harmonization, namely the concept of a 'harmonized standard'.

The latter is defined as follows: 'technical specification adopted by a European standards institution on the basis of a mandate from the Commission granted in accordance with Directive 83/189/EEC'.

Nevertheless, harmonized standards should not be considered as representing a specific category of European standards. Rather, a legal concept is involved which has nothing to do with standardization practice since a harmonized standard may be any type of European document adopted by the European standards institutions, irrespective of whether it is an EN or an HD.

It is therefore up to the European standards institutions to draw up new standards or identify from among existing standards (or standards which are being drawn up) those which may be covered by a mandate and formally submit them to the Commission as harmonized standards. The submission of such a list presupposes that the European standards institutions verify beforehand that the content of these standards meets the essential requirements of the Directives.

It is then up to the Commission to publish the references of these standards in the Official Journal of the European Communities (C Series). Such publication alone will mean that the harmonized standards are presumed to be in conformity with the essential requirements of the Directives.

The only European bodies whose documents may be recognized as 'harmonized standards' are those with which the Commission has signed an agreement to this effect, pursuant to Directive 83/189/EEC in which these bodies are listed in Annex 1.

With regard to standards of purely national origin, these may be used only on a temporary basis, and their acceptance by the Directive management committee, notification of which is subsequently given to the Member States by the Commission, automatically implies the preparation by the Commission of a standardization mandate for the European bodies on the subject in question. 
It should be noted that the procedure whereby use is made of standards of this type, even on a temporary basis, has up to now not been utilized in new approach Directives. In cases where the absence of European standards represented too much of a deficiency, the Commission and the Member States have preferred to postpone the compulsory implementation date of the Directives concerned (see below).

In the case of both harmonized standards and national standards, the Commission publishes the list of references in the OJ and at the same time forwards this list to the national authorities, which are also required to publish it. Finally, when it appears that standards on the list do not correspond to the needs of the Directive, or no longer do so, they may be withdrawn from the list on the recommendation of the Directive Management Committee.

\section{Article 7: Safeguard clause}

This article, which is of fundamental importance, enables Member States to take all necessary measures to protect interests which are deemed to be vital, as described in Article 36 of the Treaty of Rome and interpreted by the case-law of the Court of Justice of the European Communities. The only restriction on its use by Member States, in the event that the product in question is accompanied by one of the means of conformity provided for in the Directive, involves the obligation placed on the Member State concerned to inform the Commission forthwith of the measures taken. The latter will then pass the information on to the other Member States, which must, if the measure is confirmed, apply it likewise.

\section{Article 8: Means of certification of conformity}

The principle adopted consists in offering manufacturers several methods for certifying that their products conform to Community requirements. It is specified that, depending on the products and hazards covered by the Directive, the choice of manufacturers between the various procedures may be limited, or even removed (i.e. the Directives may stipulate a specific means of certification of conformity).

The provisions envisaged have since been supplemented by the Council's adoption of the resolution of 21 December $1989(90 / C 10)$ and Decision 90/683 of 13 December 1990 on modules and by the introduction of the CE marking (see Chapter 4, Section 2 below for a an account of the entire body of Community policy relating to the evaluation and certification of conformity).

\section{Article 9: Standing committee}

This article provides for the setting-up of specific committees responsible for managing the Directives. In the case of some of these, this function is, in actual fact, carried out by the Directive 83/189/EEC Committee. 
It is remarkable to note that, with a few exceptions which are studied below, this system has been followed during the preparation of the dozen new approach Directives which currently exist.

\subsubsection{Conclusion}

If the basic characteristics of the new approach had to be summed up in a single sentence, it could be said that this method in fact makes it possible better to distinguish between those aspects of Community harmonization activities which fall within the province of the law and those which fall within the province of technology, and to differentiate between matters which fall within the competence of public authorities and those which are the responsibility of manufacturers and importers.

Over and above providing a new method, the new approach in fact represents a change in Community thinking on harmonization which thus becomes more liberal in essence since it defines areas of freedom within a regulatory system by clarifying the responsibilities of each economic partner: the public authorities are assigned responsibility for legal aspects (essential requirements and eligible conformity certification procedures) and sanctions (safeguard clauses); the economic partners are assigned responsibility for technology (standards) and for placement on the market (choice with regard to compliance with the standards and between the procedures provided for certification of conformity).

\subsection{Harmonization Directives already adopted}

Since the adoption of the resolution of 7 May 1985, 11 new approach Directives have been adopted (these are listed below). Rather than describing all these Directives in detail, this study describes some of the elements of each of them, beginning with the Directive which preceded them all, and which has in part served as a model for formulating the new approach doctrine, namely Directive $73 / 23$ /EEC (also known as the 'low voltage' Directive) on electrical equipment.

The attention of the reader is drawn to the fact that the Commission has published a guide to the 'new approach' and sectoral guides relating to the various 'new approach' directives. These guides describe a number of the provisions of these legal instruments in a more extensive way and with less legal jargon than the Directives themselves. 


\subsubsection{List of new approach Directives which have been adopted}

\begin{tabular}{|c|c|c|c|c|c|}
\hline Directive & Reference & Official Journal Publication & Date of adoption & $\begin{array}{l}\text { Date of entry } \\
\text { into force }\end{array}$ & $\begin{array}{l}\text { Date of end of } \\
\text { transitional period (') }\end{array}$ \\
\hline 1. Low voltage $\left({ }^{2}\right)$ & $73 / 23 / \mathrm{EEC}$ & OJ L 77 of 26.3 .1973$, p. 29 & 19.2.1973 & 18.8 .1974 & n.a. \\
\hline 2. Simple pressure vessels & $\begin{array}{l}\text { 87/404/EEC } \\
\text { 90/488/EEC }\end{array}$ & $\begin{array}{l}\text { OJ L } 220 \text { of } 8.8 .1987, \text { p. } 48 \\
\text { OJ L } 270 \text { of } 2.10 .1990 \text {, p. } 25\end{array}$ & $\begin{array}{l}25.6 .1987 \\
17.9 .1990\end{array}$ & $\begin{array}{l}1.7 .1990 \\
1.7 .1991\end{array}$ & $\begin{array}{l}1.7 .1992 \\
\text {.n.a. }\end{array}$ \\
\hline 3. Safety of toys & $87 / 378 / \mathrm{EEC}$ & OJ L 187 of $16.7 .1988, p .1$ & 3.5 .1988 & 1.1.1990 & n.a. \\
\hline 4. Construction products & 89/106/EEC & OJ L 40 of 11.2 .1989$, p. 12 & 21.12 .1988 & 27.6 .1991 & not fixed \\
\hline 5. Electromagnetic compatibility (EMC) & $\begin{array}{l}\text { 89/336/EEC } \\
\text { 92/31/EEC }\end{array}$ & $\begin{array}{l}\text { OJ L } 139 \text { of } 23.5 .1989 \text {, p. } 19 \\
\text { OJ L } 126 \text { of } 12.2 .1992 \text {, p. } 11\end{array}$ & $\begin{array}{l}3.5 .1989 \\
12.7 .1992\end{array}$ & $\begin{array}{c}1.1 .1992 \\
12.11 .1992\end{array}$ & $\begin{array}{l}\text { 31.12.1995 } \\
\text { n.a. }\end{array}$ \\
\hline 6. Safety of machines & $\begin{array}{l}\text { 89/392/EEC } \\
91 / 368 / \mathrm{EEC} \\
93 / 44 / \mathrm{EEC}\end{array}$ & $\begin{array}{l}\text { OJ L } 183 \text { of } 29.6 .1989, \text { p. } 9 \\
\text { OJ L } 198 \text { of } 22.7 .1991 \text {, p. } 16 \\
\text { OJ L } 175 \text { of } 19.7 .1993 \text {, p. } 12\end{array}$ & $\begin{array}{l}14.6 .1989 \\
20.6 .1991 \\
14.6 .1993\end{array}$ & $\begin{array}{c}31.12 .1992 \\
1.1 .1993 \\
1.1 .1995\end{array}$ & $\begin{array}{c}31.12 .1994\left({ }^{3}\right) \\
\text { n.a. } \\
31.12 .1996\end{array}$ \\
\hline 7. Personal protection equipment & $\begin{array}{l}\text { 89/686/EEC } \\
\text { 93/95/EEC }\end{array}$ & $\begin{array}{l}\text { OJ L } 399 \text { of } 30.12 .1989, \text { p. } 18 \\
\text { OJ L } 276 \text { of } 9.11 .1993, \text { p. } 11\end{array}$ & $\begin{array}{l}21.12 .1989 \\
29.10 .1993\end{array}$ & $\begin{array}{c}1.7 .1992 \\
29.1 .1994\end{array}$ & $\begin{array}{l}\text { 30.6.1995 } \\
\text { n.a. }\end{array}$ \\
\hline 8. Non-automatic weighing machines & $90 / 384 / \mathrm{EEC}$ & OJ L 189 of 20.7 .1990$, p. 1 & 20.6 .1990 & 1.1.1993 & 1.1.2003 \\
\hline 9. Active implantable medicinal devices & 90/385/EEC & OJ L 189 of 20.7 .1990 , p. 17 & 20.6 .1990 & 1.1 .1993 & 31.12.1994 \\
\hline 10. Appliances burning gaseous fuels & 90/396/EEC & OJ L 196 of 26.6 .1990$, p. 15 & 29.6.1990 & 1.1 .1992 & 31.12 .1995 \\
\hline 11. Telecommunications terminal equipment & $\begin{array}{l}91 / 263 / \mathrm{EEC} \\
93 / 97 / \mathrm{EE}\end{array}$ & $\begin{array}{l}\text { OJ L } 128 \text { of } 23.5 .1991, \text { p. } 1 \\
\text { OJ L } 290 \text { of } 24.11 .1993, \text { p. } 1\end{array}$ & $\begin{array}{c}29.4 .1991 \\
29.10 .1993\end{array}$ & $\begin{array}{l}6.11 .1992 \\
1.5 .1995\end{array}$ & $\begin{array}{l}\text { n.a. } \\
\text { n.a. }\end{array}$ \\
\hline $\begin{array}{l}\text { 12. New hot-water boilers fired with liquid or } \\
\text { gaseous fuels }\end{array}$ & 92/42/EEC & OJ L 167 of 22.6 .1992$, p. 17 & 21.5 .1992 & 1.1 .1994 & 31.12 .1997 \\
\hline 13. Explosives for civil uses & 93/15/EEC & OJ L 121 of 15.5 .1993$, p. 20 & 5.4 .1993 & 1.1 .1995 & 31.12 .2002 \\
\hline 14. Medical devices & 93/42/EEC & OJ L 169 of 12.7 .1993$, p. 1 & 14.6.1993 & 1.1 .1995 & 13.6.1998 \\
\hline 15. Global Directive amending Directives 1-12 & 93/68/EEC & OJ L 220 of 30.8 .1993$, p. 1 & 22.7 .1993 & 1.1.1995 & n.a. \\
\hline
\end{tabular}

NB: Directive No. 15 amends Directives 1-12.

(') n.a. = not applicable.

( $\left.{ }^{2}\right)$ This Directive predates the new approach by a long time, but is nevertheless based on the principle of reference to standards and can therefore, in this respect, be considered to be a precursor of the 'new approach' Directives.

(') In the case of equipment relating to roll-over protection systems (ROPS) and falling-object protection systems (FOPS), the final date of the transitional period has been specified as

being 31 December 1995 . 


\subsubsection{The low voltage Directive (73/23/EEC of 19 February 1973)}

The 'low voltage' Directive, the full title of which is in fact the 'Council Directive on the harmonization of the laws of Members States relating to electrical equipment designed for use within certain voltage limits', has the honour of being the 'ancestor' of the new approach Directives. The reason for this is that, having being adopted as long ago as 1973, it was the only Community harmonization document which used the practice of generalized reference to standards until the 1980s. This was due in large part to the fact that, even at this early stage, a large number of European Directives were available in this sector, most of which had been transposed on the basis of the IEC's international standards.

It should be recalled at this point that the electrotechnical sector (industrial manufacturers of electrotechnical equipment and electricity distributors alike) was the first sector to get round to producing international standards, and that it thus found a merited 'reward' in the Community authorities'. use of the fruits of its labours.

This Directive, which came into force in 1974 in most countries of the European Community, relates to any electrical equipment which is intended to be used at a nominal voltage of between 50 and $1000 \mathrm{~V}$ in the case of alternating current, and between 75 and $1500 \mathrm{~V}$ in the case of direct current, with the exception of equipment designed for use in an explosive atmosphere, medical equipment, electrical components of lifts and goods lifts, electric meters, devices for powering electric fences, specialized electrical equipment designed for use on ships, aircraft and railways, power sockets for domestic use and radio interference. It should be noted that almost all these excluded items are dealt with by other documents.

The absence of harmonization is mainly due to the existing stock of sockets, but also to differences regarding installation regulations. Nevertheless, the European standardization process has already adopted standard EN 50075 for the $2.5 \mathrm{~A}$ plug known as the 'Europlug' which is used for large number of electrical appliances. Cenelec is continuing with standardization work, and the chances are high that $16 \mathrm{~A}$ sockets and plugs will end up being harmonized.

Safety objectives are specified in Annex 1 of the Directive and relate to the protection of persons and domestic animals from hazards of an electrical, thermal or mechanical nature and other hazards associated with equipment covered by the Directive. These are, therefore requirements which are defined as being safety objectives.

Irrespective of however few harmonized standards have yet been drawn up and published, the Directive specifies that the competent administrative authorities should also consider, with a view to its placement on the market or free trade, electrical equipment which meets the provisions, in terms of safety, of the International Commission on rules for the approval of electrical equipment (CEE-el) or of the International Electrotechnical Commission (IEC). 
All the European standards to which reference may be made are, moreover, published for information purposes in the OJ. As with the new approach Directives, it is possible to place on the market equipment which does not conform to the standards, as from the time that the safety objectives are complied with.

With regard to methods for certifying conformity, the Directive provides either for marks of conformity or certificates of conformity, or, failing these, a declaration of conformity issued by the manufacturer. Article 8 of the Directive also provides for the placement on the market of a product which conforms to the safety objectives by means of a special certification procedure.

The only differences, albeit important ones, from the new approach Directives which have now been drafted consist in the wording of the safety objectives - which are currently designated as being essential requirements which are in principle much more detailed - in the absence of the CE marking. In reality, it is clear that the safety requirements apply in the same way in most cases, since it is much less expensive for manufacturers to have a single production line. In addition, this provision takes account of the fact that requirements on electrical safety are sometimes very different from one country to the next (as in the United States of America), and that the Directive should not end up hindering exports!

Finally, it should be noted that a reform of the low voltage Directive is currently envisaged with a view to aligning some of its provisions with those of the 'new approach' Directives, particularly as regards the CE marking and module A.

\subsubsection{The Directive on simple pressure vessels (87/404/EEC of 25 June 1987, as amended by Directive 90/488/EEC of 17 September 1990)}

This was the first sector selected by the Commission for application of the new approach doctrine. This choice initially sparked a certain amount of criticism owing to the fact that the pressure vessel sector is one of the sectors in which regulation at national level began right back in the 19th century as a result of the first accidents caused by steam engines: the range of regulations in the various Member States was therefore very varied and comprehensive, and a whole body of national practices relating to matters of testing, checks, insurance, etc. had come to be grafted on.

This explains why an initial attempt at harmonization had largely failed, leading only to a framework Directive in 1976 and three implementing Directives relating to gas cylinders (Directives 84/525/EEC, 84/526/EEC and 84/527/EEC). Article 22 of the framework Directive on the recognition of tests carried out in the Member State of the manufacturer in accordance with the legislation of the importing Member State has not been applied.

Despite the pessimism of those who thought it would be impossible to apply the new approach to pressure vessels, the Commission's gamble came off since as early as March 1986 it was able to forward to the Council a draft Directive on simple pressure vessels (an 


\section{Directive on simple pressure vessels}

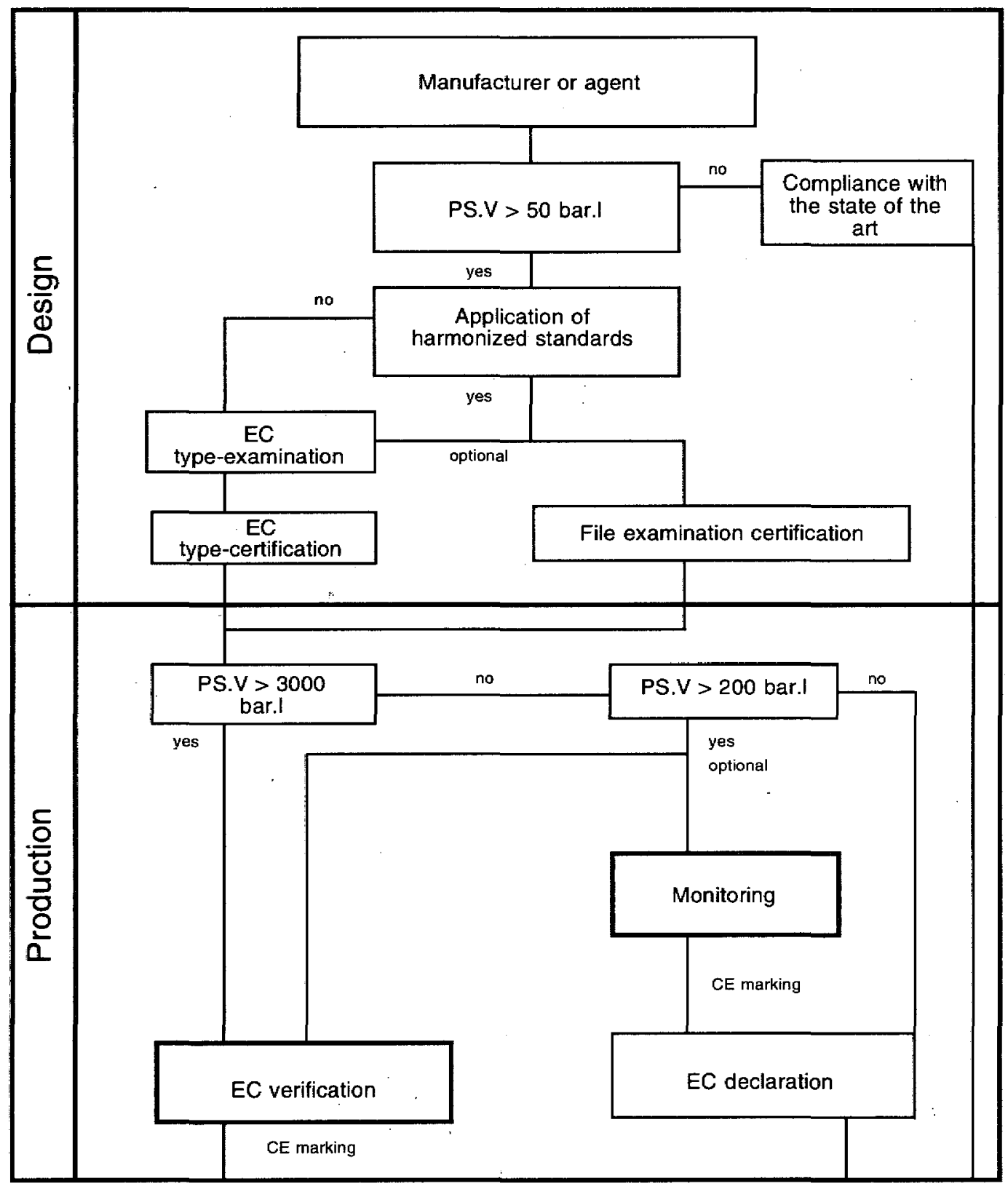

Placement on the market 
'old approach' Directive on the same subject had been hanging fire for years). Thanks to the cooperation of all parties involved and the political will of the Member States to show that they had decided to get involved in the new approach, this draft was adopted on 25 June 1987.

Initially scheduled to come into force on $1 \mathrm{July} 1990$, Directive $87 / 404 / \mathrm{EEC}$ had to be amended in order to authorize, for a transitional period running until 1 July 1992 , the placement on the market of pressure vessels conforming to national regulations which predate it. The existence of the transitional period is due to the following factors: the nonavailability on the planned date of the necessarytEuropean standards, the need to be able to dispose of equipment in stock and the need to allow manufacturers to adapt gradually to the certification procedures.

The Directive applies to mass-produced simple pressure vessels, i.e. any welded vessel which is subject to a relative internal pressure of more than $0.5 \mathrm{bar}$, which is designed to hold air or nitrogen and which is not intended to be exposed to flames. The Directive does not cover vessels which have been specifically designèd for use within the nuclear industry and whose failure may cause an emission of radioactivity, vessels designed to equip or to power boats or aircraft, or fire extinguishers.

The essential safety requirements are defined in Annex 1 of the Directive in the case of vessels in which the product of PS.V (pressure $x$ volume) is greater than 50 bar $x$ litre. In the case of other vessels, it is sufficient to comply with the relevant 'state of the art' which exists in the Member State in question.

The conformity certification procedures which have been adopted for applying the CE marking are explained in the diagram below.

Finally, it should be pointed out when the CE marking is applied to the various pressure vessels or to a rating plate of a fixed type, it must be affixed in such a way that it is visible, legible and indelible, and must comprise the last two digits of the year in which it was applied and also the distinguishing number of the notified body involved.

\subsubsection{The Directive on toys (88/378/EEC of 3 May 1988)}

This Directive, which came into force on 1 January 1990, concerns toys, with the latter being defined as products which are designed or clearly intended to be used for play purposes by children under the age of 14. Twenty or so products, which are listed in Annex 1 of the Directive, are not considered to constitute toys within the meaning of the Directive (e.g. slings and catapults, babies' dummies, dolls in traditional regional dress, etc.).

The usual general clause on placement on the market has been supplemented by a provision which is intended to cater for 'foreseeable use, bearing in mind the normal behaviour of children'. 
The notion of foreseeable use is therefore broadly extended beyond common law in this case. The risks associated with use, whether for children or third parties, are connected with the design, construction, composition or application of the toy, and these cannot be completely eliminated except by modifying the product itself. The way in which the toy is used must therefore be in keeping with the children's capabilities, particularly in the case of toys intended for children under the age of three.

This principle means that a minimum age for the various types of toys, and/or the need to ensure that they are used only under the supervision of an adult, must be specified. Hence, also, the obligation to mark the product or its packaging with certain details (listed in Annex 4 of the Directive).

The essential safety requirements, which are listed in Annex 2 of the Directive, relate to the physical and mechanical properties of toys, their flammability, chemical properties and electrical properties. In addition, toys must be able to meet hygiene and cleanliness conditions in such a way to as preclude risks of infection, disease and contamination. Finally, toys must not contain radioactive elements or substances in forms or proportions which are liable to harm a child's health.

CEN has adopted five European standards on the safety of toys:

(i) EN 71, Part 1 on the mechanical and physical properties of toys;

(ii) EN 71, Part 2 on the flammability of toys;

(iii) EN 71, Part 3 on the migration of certain elements;

(iv) EN 71, Part 4 on experimental sets for chemistry;

(v) EN 71, Part 5 on chemical toys (sets) other than experimental sets.

CEN is also developing another European standard on graphic symbols which may be used in toy-labelling to give warnings on children's ages (for toys not intended for children under the age of three).

The requirements to be met with regard to electric toys, meanwhile, are covered by a Cenelec harmonization document, namely HD $271 \mathrm{~S} 1$ and its three amendments. A draft European standard on the safety of electric toys, which will replace this harmonization document, is to be adopted by Cenelec.

A classic application of the new approach, the 'toys' Directive specifies that manufacturers and importers who are established in the Union and who place on the market toys which meet the relevant standards need only put together technical documentation which is intended to be made available to the competent authorities, and to apply the CE marking to the toy or its packaging in a visible, indelible and legible manner. Manufacturers or importers who have elected not to comply with the standards must, for their part, follow the 'EC type-examination' procedure by submitting a model to a notified body which will issue them with 'EC-type certification' if the toys meet the essential requirements. They may then apply the $C E$ marking to toys which conform to the type examined. In addition to the CE marking, toys or their packaging must also bear the name and/or trade name and/or trade mark and also the address of the manufacturer, his agent or the importer in the Union so as to be able to identify easily those responsible for placement on the market. 
For obvious reasons, an additional precaution with regard to monitoring the market is also provided for in Article 12 of the 'toys' Directive, which specifies that 'Member States shall take the necessary measures to ensure that sample checks are carried out on toys which are on their market, so as to verify their conformity with this Directive'.

\subsubsection{The Directive on construction products (89/106/EEC of 21 December 1988)}

The Directive relating to construction products was adopted by the Council on 21 December 1988 and notified to the Member States on 27 December 1988. It should have been transposed by all the Member States within 30 months of this notification, i.e. by 27 June 1991.

Most of the Member States have in fact carried out this transposition.

Since 27 June 1991, the Directive has therefore formally been in force. However, its actual implementation has been deferred since this is dependent on the existence of harmonized technical specifications, standards harmonized by CEN/Cenelec and European technical approvals to be drawn up by the EOTA, following the Commission's adoption of the interpretative documents and selection of the conformity certification procedure for each product or group of products.

This Directive provides the best example of application of the new approach. After all, its scope is very extensive, with it defining a construction product as being 'any product which is manufactured with a view to being incorporated in a durable way in construction works, which cover not only buildings but also civil engineering works'.

This definition essentially covers materials, products and elements, installations and their components, in so far as they are placed on the market in this form. As a result, products which are manufactured, put together or assembled directly on the building site are not covered by the Directive.

The characteristics and performance levels of construction products are meaningful only with regard to construction works in which they are to be incorporated in a durable manner. This is why this Directive diverges significantly from the other 'new approach' Directives with respect to essential requirements: the six essential requirements do not refer to the products themselves but are aimed at the end-product of the construction process, i.e. all construction works.

The essential requirements specified in Annex 1 of the Directive are worded in terms of objectives:

mechanical strength and stability;

safety in the event of fire;

hygiene, health and the environment;

safety in use; 
noise protection;

energy saving and thermal insulation.

In view of the fact that these essential requirements apply to construction works, the Directive provides for their transposition in terms of objectives which apply to products by means of interpretative documents. These documents do not have restrictive legal force and serve as a link between the essential requirements and the harmonized technical specifications for products.

Each of these six essential requirements will thus be covered by an interpretative document. The latter will also indicate classes or levels for specific cases, if necessary.

Unlike the other 'new approach' Directives, this one does not provide for the possibility of certification of conformity based directly on the essential requirements. On the contrary, such certification of conformity is in this case to be based on harmonized technical specifications, i.e. harmonized European standards (drawn up by CEN/Cenelec under the mandate of the Commission) on the one hand, and European technical approvals on the other.

The harmonized standard is the European technical specification par excellence. The Commission's mandates are based on the interpretative documents and are directed only at the risks and dangers stipulated in the essential requirements. These standards, which are preferably formulated in terms of performance, will put the essential requirements for the products in concrete form. The references of these standards, which are not mandatory, will be published in the Official Journal of the European Community, C Series. Compliance with these standards on the part of the manufacturer confers on them an irrefutable presumption of conformity for the products concerned at the time of placement on the market.

In exceptional cases, and in so far as harmonized specifications do not exist, national technical specifications may be recognized in their place.

In the event that a harmonized standard does not (yet) exist - which is particularly the case with innovative products or products which depart in a significant way from harmonized standards, when the latter exist - the Directive makes provision for European technical approval.

European technical approval does not constitute certification of conformity, but rather a technical specification which is defined as being 'the technical assessment for use, based on compliance with the essential requirements laid down for works in which the product is to be used'. It is founded on examinations, tests and an assessment based on the interpretative documents and, if they exist, on the European technical approval guides.

Technical approvals will be issued, in accordance with common procedures, when a request is made to the technical approval bodies designated and notified by the Member States, following coordination within the European body, at the EOTA. 
European technical approval is issued for five years and may be extended:

Technical approval may be issued either on the basis of a guide or, if such a guide does not (yet) exist, on a case-by-case basis.

European technical approval guides are to be drawn up by the EOTA under the mandate of the Commission. These guides represent a harmonized assessment of the fitness for use of a product or group of products. When a guide exists, it forms the basis for issuance of the technical approval for the product in question.

As soon as the technology referred to in the guides has become the state of the art, the said guides will be transferred under mandate to $\mathrm{CEN} /$ Cenelec with a view to the drafting of harmonized standards.

In accordance with the stipulations of the Directive, the national bodies which are competent to issue European technical approvals, as designated and notified by the Member States, grouped together in 1990 within the European Organization for Technical Approval (EOTA). This body was permanently established in Brussels in 1993. Cooperation between the Commission and the EOTA is regulated by a convention drawn up in this connection and signed by the two parties.

Under the 'construction products' Directive, certification of conformity is carried out on the basis of harmonized technical specifications, which may be standards or European technical approvals.

Annex III of the Directive has defined seven methods which may be determined in a system. However, the Directive itself has stipulated two preferential systems for certification of conformity, namely: certification of the product by a third party on the one hand, and a declaration of conformity issued by the manufacturer on the other hand, with the latter system having three variants (two of which involve the partial involvement of a third party). In all these systems, production control at the factory plays an important part.

These systems take particular account of current practices and needs within the construction products sector without, however, departing fundamentally from the modules established as part of the global approach with regard to certification of conformity.

Compliance with the harmonized technical standards and the required conformity certification procedure confers a right to apply the CE marking to the products, their packaging or accompanying documentation; according to the 'construction products' Directive, this CE marking must be supplemented by a series of details relating to identification of the product, its performance characteristics and the technical specifications. The CE marking is a mark of conformity and not one of quality.

The reason for this is that the CE marking is mandatory in order to place construction products on the market. Only in the case of products 'which have a very minor effect on health and safety' may a declaration of conformity with the 'state of the art' be issued by the manufacturer. In this case, products must not bear the $\mathrm{CE}$ marking. No products falling into this category have so far been defined and, as a result, the Commission has not drawn up or published a list of such products. 
Under the Directive, the Community legislator has entrusted the Commission with a series of tasks associated with the implementation and management of the Directive. The Commission is assisted by a Standing Committee on Construction. The latter has, on the one hand, a consultative remit covering any matters arising from the implementation and practical application of the Directive and, on the other hand, regulatory powers to draw up classes of requirements, define the conformity certification procedure, decide on interpretative documents and recognize national technical specifications as harmonized specifications.

As a regulatory committee, the Standing Committee delivers its opinion by a qualified majority.

Measures are then to be adopted by the Commission and notified to the Member States. When the measures envisaged do not conform to the opinion of the Committee, or in the absence of an opinion, the Commission must refer the measures to be taken to the Council.

The Standing Committee on Construction, which is made up of representatives appointed by the Member States, was set up in 1989. Via its regular meetings, this Committee has to date made a significant contribution to implementation of the Directive.

As provided for by the Community legislator, the Directive has a progressive and evolutive nature.

In 1992, the Commission conferred on CEN/Cenelec a package of 33 mandates covering the bulk of the products to be standardized and their test methods. The majority of these 1500 standards are planned to be drawn up before 1994-95.

Preparatory work on the selection of certification of conformity for the products or groups of products is continuing. Adoption by the Commission of the six interpretative documents will take place during 1993.

\subsubsection{The Directive on electromagnetic compatibility (89/336/EEC of 3 May 1989)}

Although the effective date of the Directive is 1 January 1992, provision is made for a transitional period until 1 January 1996; during this transitional period, manufacturers may apply - if they so wish - either the national system existing on 30 June 1992 or the Community system.

The Directive relates to electrical and electromagnetic apparatus and also equipment and installations which contain electrical and/or electronic components. The Directive does not cover equipment constructed by amateur radio enthusiasts for their own use, motor vehicles or medical electrical apparatus. 
The essential requirements are aimed at ensuring that the equipment in question is afforded protection against external electromagnetic phenomena. They are also intended to prevent the said equipment from emitting electromagnetic interference which is liable to inhibit other equipment or radio and telecommunications systems. Thus, the Directive specifies that 'the apparatus [...] must be so constructed that:

(a) the electromagnetic disturbance it generates does not exceed a level allowing radio and telecommunications equipment and other apparatus to operate as intended;

(b) the apparatus has an adequate level of intrinsic immunity to electromagnetic disturbance to enable it to operate as intended'.

The European standards for applying this Directive are drawn up within Cenelec (TC 110).

The procedures for certifying that a product conforms to the Directive are as follows:

(a) either the EC declaration of conformity drawn up by the manufacturer when the latter has applied the appropriate harmonized standards (Article 10, paragraph 1);

(b) or the EC declaration of conformity drawn up by the manufacturer after obtaining a certificate issued by a competent body following submission of a technical file when the manufacturer has not applied the harmonized standards (Article 10, paragraph 2);

(c) the same procedure as that described in Article 10, paragraph 1 applies in the special case of apparatus designed for transmitting radio communications, after the manufacturer has obtained EC type-certification issued by a notified body (Article 10, paragraph 5).

\subsubsection{The Directive on safety of machines (89/392/EEC of 14 June 1989, as amended by Directive 91/368/EEC of 20 June 1991)}

This is one of the economic sectors in which harmonization of the various bodies of national law had been considered a priority objective in the $1960 \mathrm{~s}$, as part of the first major programmes to eliminate technical barriers to trade within the EC. During the 1970 s, two 'framework Directives' had been drawn up by the Commission, and a number of Directives relating to specific machines were adopted during this period; however, all the difficulties associated with the planned type of harmonization became increasingly apparent at the same time. In order for the planned type of harmonization to be effective, Directives needed to incorporate all elements of the technical doctrine on safety, for all categories of machines: in reality, an impossible task since, even at the level of each Member State, all the elements of the doctrine were far from being clearly explained.

In addition, machine manufacturers had indeed tried to make use of the international standardization process in an attempt to facilitate trade and increase production runs. However, it was very quickly realized at ISO that the various parties involved were unable to reach agreement on the content of standards which could only be envisaged in relation to a common vision of safety (particularly on the legal front), which was in fact nonexistent. 
More often than not, the international standardization process was therefore reduced to the publication of standards on terms, general concepts or test methods, without affecting the various aspects of the requirements which enable safety levels to be laid down.

From the moment work was started on drawing up what was later to become the 'machines' Directive, the acceptance of standardization by the public authorities responsible for safety at work became evident, and European standardization activities aroused much greater interest than ever before. Within a programming committee which subsequently became TSB 2, CEN was thus able to draw up a doctrine, an overall work programme and a timetable for carrying out the various activities required.

Directive $89 / 392 /$ EEC is scheduled to come into force on 1 January 1993, with a transitional period until 31 December 1994, by which time Member States must accept machines which conform to the national regulations in force on 31 December 1992. Directive 91/368/EEC amends the general Directive by incorporating machines which present risks due to lifting and/or mobility. In the case of machines or equipment already covered by old approach Directives (industrial trucks, roll-over and falling-object protection systems, etc.), the effective date is deferred until 1 July 1995 with a transitional period scheduled to run until 31 December 1995.

For the sake of simplicity, this section will refer only to 'the Directive', even when both documents are involved.

The 'construction products' Directive is the Directive with the widest scope and, as a result, the greatest impact on the creation of the internal market. The reason for this is that the Directive applies to all machines, i.e. any 'assembly of linked parts or components, at least one of which moves, with the appropriate actuators, control and power circuits, etc., joined together for a specific application, in particular for the processing, treatment, moving or packaging of a material.

An assembly of machines which, in order to contribute to an identical result, are arranged and controlled in such a way as to be interdependent in their operation, shall also be deemed to constitute a "machine". The same applies to an interchangeable item of equipment modifying the function of a machine, which is placed on the market with the aim of being joined to a machine or a series of different machines or a tractor by the operator himself, in so far as this equipment is not a spare part or a tool.'

It is to be noted that when, in the case of a machine, the risks are mainly of an electrical origin, this machine is then covered by the 'low voltage' Directive. In addition, when the risks are covered by a Directive or specific Directives in the case of a machine, the 'machines' Directive ceases to apply to these risks when the specific documents in question come into force. Finally, the 'machines' Directive does not cover a number of appliances or devices, since these are dealt with by other (Community or national) documents.

The essential requirements are detailed in Annex 1 of the 'machines' Directive. The Member States are free to supplement these essential requirements concerning the 'machines' product with national requirements on use, particularly with a view to protecting 
workers, in so far as these provisions do not entail modifications being made to the construction of machines conforming to the Directive and provided, of course, that they conform to the Treaty of Rome.

The essential requirements mainly concern:

the principles for integrating safety, including the materials and products used, lighting and the design of the machine with a view to its handling;

the controls, their safety, their reliability, their start-up procedure, the normal and emergency shut-down devices, possible faults with the power-supply system or the control circuit, any software;

protection against mechanical risks, risks of breakage in service, risks associated with falling or discharged objects, or with surfaces, edges or corners, risks associated with combined machines or variations in the speed of rotation of tools and with moving parts in general;

protectors and protection devices which must be robust enough to prevent any additional risk, solidly attached and non-detachable without tools;

measures to provide protection against risks associated with electric power, static electricity, forms of power other than electricity, possible assembly defects, extreme temperatures, risks of fire or explosion, or risks associated with noise, vibrations, radiation and laser equipment;

protection measures concerning maintenance, etc.

Over and above these essential requirements, which are general and apply to all machines, Annex 1 provides for other essential requirements for certain types of machines, e.g. machinery used in the agri-foodstuffs sector, portable and/or manually controlled machines, machines for processing woods and similar materials, and all kinds of machines which according to national laws are deemed to be particularly sensitive.

Finally, Directive 91/368 /ECC has made it possible to supplement the essential requirements by adding those relating to the following risks:

risks associated with mobility or lifting operations;

risks inherent in machines which are intended to be used solely for underground work.

It should be noted that non-conforming machines may be displayed at trade fairs, for example, provided that a clearly visible sign indicates that the machines do not conform and that it is impossible to purchase them before they have been brought into conformity. Similarly, parts of machines which are intended to be incorporated in a machine and which are unable to operate independently may be traded freely, even if they do not conform to the Directive, provided that it is mentioned that it is prohibited to put them into service before the machine in which they are to be incorporated is declared to be in conformity with the provisions of the Directive.

With regard to conformity certification methods, the 'machines' Directive contains provisions which are slightly unusual in view of the new approach doctrine. The reason for this is that it is difficult to use harmonized standards to demonstrate conformity in 
this case since there are not enough harmonized standards to cover all the essential requirements of all the machines falling under the Directive: its scope is too extensive, and technical progress is going on all the time in this field, which means that standardization is in a state of continual flux.

Nevertheless, the various parties involved in European harmonization, who have been brought together within TSB 2 (Technical Sector Board on 'mechanical engineering'), have formulated an original doctrine with regard to machines which is designed to offset these drawbacks by means of 'horizontal' standards covering the various issues of safety (it should be pointed out at this juncture that the first two horizontal standards, and the most important ones, were adopted in 1992 under the reference EN 292 Parts 1 and 2), standards covering machine components which are critical to safety (locking devices, protectors, etc.) and, finally, 'vertical' standards covering machines or groups of special machines.

The Directive also specifies that, in the absence of harmonized standards, the Member States may notify the parties concerned of the documents (national standards or technical specifications) which are useful for the correct application of the essential requirements. Be that as it may, the Directive provides for simplified conformity certification procedures so as to cater for the problem which has just been mentioned and to allow machines to be placed on the market without waiting for some hypothetical kind of full harmonization process to be completed; these simplified procedures enable the manufacturer to give a personal declaration of conformity with the essential requirements, even in the absence of standards or if he has elected not to comply with them, provided that the machine in question does not belong to the category of machines considered to be 'high-risk', as listed in Annex IV of the Directive (this category essentially comprises woodworking machines, press machines and a number of the machines covered by Directive 91/368/EEC).

In this case, the only obligation on the manufacturer consists in declaring conformity, affixing the $\mathrm{CE}$ marking and compiling a technical file which he must keep on his premises (a description of the file is provided in Annex $V$ of the Directive). If the machine is one of those listed in Annex IV, the manufacturer must then refer the matter to a notified body and send it a technical file.

If the manufacturer has not complied with the standards or has only partially complied with them, or if such standards do not exist, the notified body then goes on to carry out an EC type-examination.

If the manufacturer has complied with the standards, he can choose between three procedures: EC type-examination, certification of the suitability of the file by the notified body following verification that the standards have been correctly applied, or a simple acknowledgement of receipt of the file by the notified body.

In all cases where an EC type-examination has been carried out, the EC declaration must certify conformity with the model submitted, and not just with the essential requirements of the Directive. 


\section{Machines Directive}

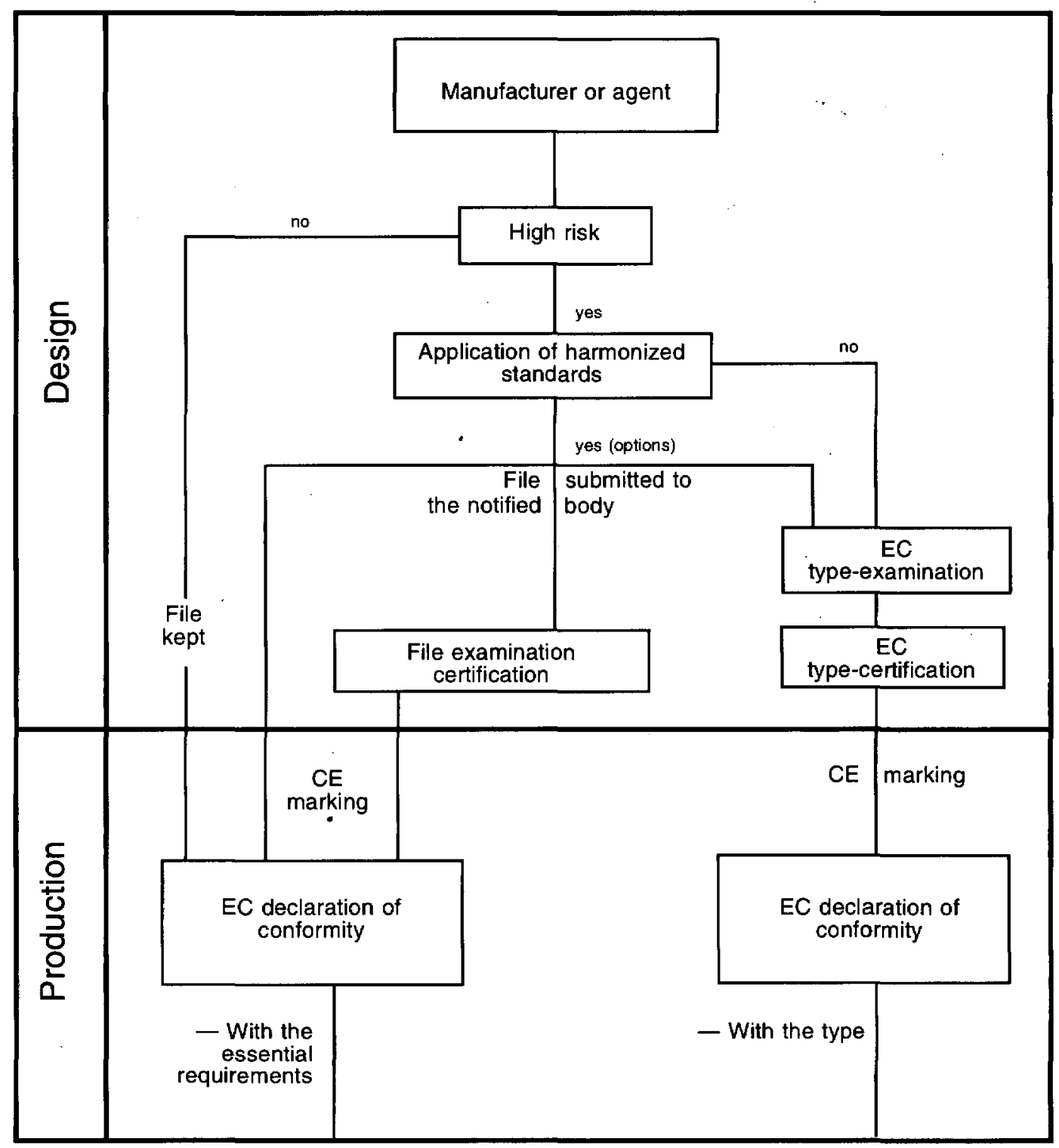

Placement on the market 
The organization chart below summarizes the provisions which apply with regard to certification of conformity, and which have just been described.

Finally, it should be made clear that the CE marking, which must be affixed to all machines, must comprise the last two digits of the year in which it is affixed, and that all the obligations described above are incumbent on the manufacturer, his agent, or, if these parties have not complied with them, on the party placing the machine on the market or the party assembling or constructing it for the purposes of personal use.

The 'machines' Directive is one of those managed by a standing committee set up for this purpose.

\subsubsection{The Directive on personal protection equipment 189/686/EEC of 21 December 1989)}

The Directive on 'personal protection equipment' (PPE) came into force on 1 July 1992. Bearing in mind the scale of European standardization work which is required, provision has been made for a transitional period during which PPE which conforms to previous national laws may be placed on the market, provided that these laws do not conflict with the provisions of the Treaty of Rome, with this transitional period lasting until 31 December 1992. On 29 October 1993, the Council approved an extension of this transitional period until 30 June 1995 (see Directive 93/95/EEC).

For the purposes of the application of the Directive, the term PPE denotes 'any device or appliance designed to be worn or held by an individual for protection against one or more health and safety hazards'. The term PPE is also deemed to cover components thereof, the assembly formed by several PPE, systems connecting PPE to other complementary external devices and, finally, protective devices or appliances (whether separable or not) which are integral with an individual non-protective item of equipment. The Directive does not cover PPE already dealt with by another Directive, PPE specific to the armed forces or forces which maintain law and order, PPE intended for self-defence or private use, or PPE designed to protect or rescue persons on board ships or aircraft and which are not carried on a permanent basis.

The essential safety requirements detailed in Annex 2 of the Directive are either general in scope ('PPE must provide adequate protection against all risk encountered') or complementary in nature, taking account of the type of PPE concerned or the risk in question. The general requirements relate to design principles, harmlessness, factors of comfort and efficiency, and information for users.

As in other Community documents relating to the health of users (including the 'machines' Directive in particular), this Directive provides for the possibility of Member States taking measures which complement the Directive, provided that these measures do not entail obligations to modify PPE which conform to the Directive (in practical terms, therefore, these are normally usage specifications). 
Owing to the particularly sensitive aspects of health and PPE safety, provision is made for the mandatory involvement of a notified body in the conformity certification procedures, irrespective of whether the standards are applied, except if the PPE in question is of simple design and is intended to protect the user against minimal risks. The procedure is simplified, however, if use is made of the standards.

In addition, one of the special features of the Directive is that it contains a provision (Article 5, paragraph 5) obliging Member States to take measures enabling both sides of industry to exert an influence, at national level, on the procedure whereby harmonized standards are drawn up and monitored.

The complexity of the certification procedures varies according to the type of PPE in question: the reason for this is that, with the exception of PPE of simple design 'whose designers assume that the user can himself assess their effectiveness against minimal risks, the effects of which, when they are gradual, may be perceived in good time and without danger by the user' (listed in Article 8, paragraph 3), in respect of which the manufacturer need only keep the technical file available to the authorities and affix the CE marking himself, all types of PPE must undergo EC type-examination prior to manufacture.

In addition, in the case of PPE 'of complex design which are intended to provide protection against lethal dangers or which may seriously and irreversibly harm health,. and whose designer assumes that the user cannot detect the immediate effects in time' (listed in Article 8, paragraph 4), a simple declaration of conformity following the EC type-examination is not sufficient and there must be either an EC quality assurance system for the end-product, under the conditions described in Article 11, in order to ensure that production is homogeneous and conforms to the type which has been granted the EC type-approval certificate, or an EC quality assurance system for production with approval of the quality system and monitoring by the notified body responsible.

Finally, in the event that a notified body is involved and carries out an EC typeexamination, the CE marking comprises the number of this body in the case of all PPE of complex design. The mark must be affixed to each PPE and/or its packaging in a visible, legible and indelible manner, for the entire lifetime of the PPE.

The role of the Standing Committee responsible for managing the PPE Directive is provided for in Directive 89/392/EEC on machines. Mandates to be given to CEN and, if appropriate, to Cenelec are supported by the Directive $83 / 189 / \mathrm{EEC} \mathrm{Committee.}$

\subsubsection{The Directive on non-automatic weighing machines (90/384/EEC of 20 June 1990)}

Although this Directive is scheduled to come into force on 1 January 1993, provision has been made for a transitional period of 10 years; during this transitional period, machines which conform to national regulations in force prior to the said date may still be placed on the market and put into service. 
The Directive covers non-automatic weighing machines, i.e. measuring instruments which require the assistance of an operator and which serve to determine the mass of a body or other variables, quantities, parameters or characteristics associated with mass, by using the effect of gravity on the body being measured.

The Directive distinguishes between two categories of machines:

(i) those designed to determine mass in:

(1) commercial transactions

(2) the calculation of tolls, tariffs, taxes, premiums, fines, payments, indemnities or fees of a similar kind

(3) the application of a law or regulations, judicial expert's report

(4) medical practice with regard to the weighing of patients for reasons of supervision, diagnosis and medical treatment

(5) the making-up of prescription medicines in pharmacies and during analyses carried out in medical and pharmaceutical laboratories

(6) direct sale to the public and the preparation of pre-packaging.

(ii) those designed to determine mass in any other applications, e.g. for domestic use or in an industrial control process. Machines in this second category do not have to comply with the essential requirements of the Directive, bear the $C E$ marking or undergo conformity certification procedures. However, they must bear the trade mark or name of the manufacturer and indicate their maximum capacity in a form which is clearly visible, easy to read and indelible.

The essential requirements are aimed at protecting the public against incorrect results arising from weighing operations carried out by these machines. These requirements are based on Recommendation No 76 of the International Legal Metrology Organization (ILMO) and relate not only to metrological considerations but also to matters of design and construction. For example, machines which have been correctly installed and which operate in the environment for which they have been designed must retain all their metrological qualities.

In the event of electromagnetic interference, they are required either not to exhibit significant defects, or to detect such defects and reveal them by means of a visual or audible alarm. Machines must not have characteristics which are liable to facilitate their fraudulent use, and the chances of accidental improper use must be minimized. These general specifications are supplemented by a number of other requirements, which are specified in Annex 1 of the Directive.

With regard to conformity assessment procedures, the manufacturer or his agent established in the Union have two options: EC verification on an individual basis, or the EC type-examination, followed either by EC verification in which the notified body carries out additional checks to verify conformity with the approved type, or by the EC declaration of conformity, drawn up by the manufacturer or his agent. 
This second procedure entails implementing a quality assurance system approved by a notified body and subject to EC monitoring on the part of the same body. (Note: the EC type-examination is not mandatory for machines which do not use electronic devices and in which the load-measuring device does not use a spring to balance the load.) In cases where the procedure used is the EC verification procedure, the $\mathrm{CE}$ marking is affixed to the machine by the notified body itself.

It should be noted that the validity of the EC type-certificate, which is issued by the notified body at the end of the EC type-examination procedure, is limited to 10 years; these certificates can be renewed without restriction except if fundamental changes are made to the design of the machine. Modifications made to the approved type must in any case be approved by the notified body which issued the EC type-certificate if these changes affect conformity with the essential requirements or the conditions under which the machine is used.

\subsubsection{The Directive on active implantable medical devices (90/385/EEC of 20 June 1990)}

Applicable as from 1 January 1993, the Directive on active implantable medical devices provides for a transitional period lasting until 31 December 1994.

The Directive applies to active implantable medical devices. A product is consequently covered by the Directive if it is a medical device which, under the terms of the Directive, can be designated as being active and implantable.

Such devices are deemed to be 'any instrument, appliance, equipment, material or other article used alone or in combination, including accessories and software involved in the proper operation thereof, which is intended by the manufacturer to be used in humans for the purposes of diagnosing, preventing, controlling, treating or alleviating a disease or injury, for studying or replacing or modifying the anatomy or a physiological process, or for the purposes of design control, and whose principal intended action is not obtained by pharmacological, chemical or immunological agents or by metabolism, but whose operation may be assisted by such agents' (this is so as to differentiate them from drugs).

Secondly, these devices must be active, i.e. depend on a source of energy other than that generated directly by the human body or gravity (which excludes, for instance, prostheses with a purely mechanical action, such as artificial hips).

Thirdly, the device in question must be implantable in the human body and be intended to remain in it.

The essential requirements are defined in Annex 1, and comprise not only general requirements, including requirements on results ('devices must achieve the performance levels ascribed to them by the manufacturer'), but also requirements on design and construction (sterility, compatibility with their environment, reliability of the energy source, etc.). 


\section{Directive on active implantable medical devices}

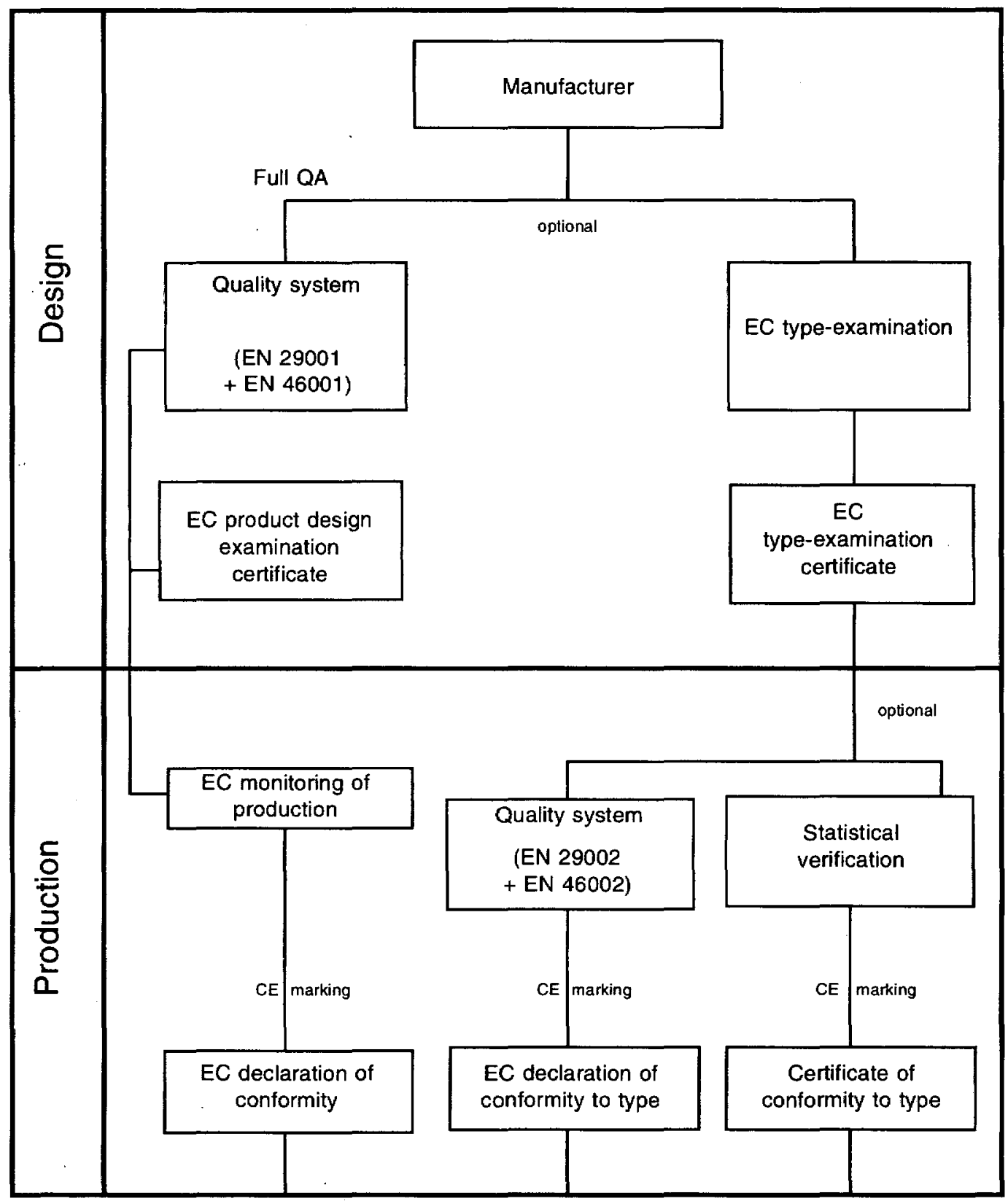

Placement on the market 
It should be noted that directions permitting identification of the manufacturer are included in the essential requirements.

With regard to certification of conformity, the CE marking is not required either for devices intended for clinical investigations or for custom-made devices (i.e. intended for a particular patient and specially manufactured to the specifications of a medical specialist). The reason for this is that these devices are covered by the provisions of a special annex, which provides for 'declaration' procedures involving the manufacturer or his agent. In the case of other devices, the conformity certification procedures are described in the organization chart on the following page, and all entail the involvement of a notified body.

Finally, it should be pointed out that the CE marking is affixed to the packaging so as to ensure sterility and, if necessary, to the commercial packaging and also to the instruction leaflet. It is accompanied by the notified body's identification number.

\subsubsection{The Directive on appliances burning gaseous fuels (90/396/EEC of 19 June 1990)}

Although this Directive is scheduled to come into force on 1 January 1992, provision has been made for a transitional period which runs until 31 December 1995; during this transitional period, appliances burning gaseous fuels which conform to national regulations in force prior to the said date may still be placed on the market and put into shortterm service.

The Directive covers gas-fuelled appliances for cooking, heating, hot-water production, cooling, lighting and washing and also safety, control and adjustment devices and other sub-assemblies intended to be incorporated in an appliance burning gaseous fuels. The Directive does not cover appliances which are specifically intended to be used in industrial processes.

The essential requirements relate to the health and safety of persons and animals, safety of property and energy-saving. Specifications relating to essential requirements cover the design and manufacture of the appliances, the materials used, the directions for use and also the technical instructions. Standards for the application of these essential requirements are drawn up within CEN. Several Technical Committees are involved in this work.

The conformity certification methods adopted differ according to whether the items concerned are mass-produced products (EC type-examination followed, at production level, by one of the three procedures involving declaration of conformity or EC verification of conformity) or appliances manufactured on an individual basis or in small batches (EC verification per item). The $\mathrm{CE}$ marking which must be affixed to each appliance exhibits the same characteristics as that envisaged for PPE (see above).

In the case of equipment, no provision is made for the application of the CE marking, although certification must be issued by the notified body declaring that the equipment conforms to the applicable provisions of the Directive. 


\subsubsection{The Directive on telecommunications terminal equipment (91/263/EEC of 29 April 1991)}

The first attempts at European harmonization in the field of telecommunications equipment were not made until quite late on, possibly because this is a sector whose economic importance only became apparent once the services offered began to multiply and terminals became increasingly diverse. In addition, this sector was characterized by the determining role of the authorities responsible for managing networks and drawing up recommendations at the international and European levels. Recourse to rule-making was common practice at national level.

The first moves towards harmonization were made in the mid-1980s with the adoption of a Directive $(86 / 361 / \mathrm{EEC})$ introducing an initial staging post towards mutual recognition of the various types of approval for telecommunications terminal equipment. This Directive, and the decision which followed in 1987 (87/95/EEC), were also major factors in the setting-up of ETSI.

The Directive defines telecommunications terminal equipment as equipment which is 'intended to be connected to the public telecommunications network, i.e:

(a) to be connected directly to the termination of a public telecommunications network,

or

(b) to "interface" with a public telecommunications network by being connected directly or indirectly to the termination of a public telecommunications network in order to send, process or receive information.'

The final stage in the process to harmonize regulations in Europe governing equipment for connection to telecommunications networks was taken with the signing on 29 April 1991 of a Directive to this effect; this Directive came into force on 6 November 1992, the date on which the first Directive $(86 / 361 / \mathrm{EEC})$ was repealed. No provision is made for a transitional period, although approvals granted before the Directive came into force continue to be valid for the period initially envisaged under these approvals.

The interfacing of equipment via a network, with a view to ensuring end-to-end compatibility, is an essential requirement only in justified cases.

The Directive is very much in line with the new approach in the field of standardization with regard to the first two essential requirements (Article 4a-4b; Article 6-1). In the case of the other essential requirements, the Directive makes provision (where necessary) for technical specifications contained in standards drawn up by European standards institutions, or in a part of these standards, to be adopted by the Commission in the form of common technical rules which are regulatory in nature.

With regard to certification of conformity, the manufacturer has a choice between the EC type-examination procedure, which is carried out by a notified body, or the EC declaration of conformity, accompanied by a quality assurance system of the EN 29002 type, 
which must be approved by a notified body. In both cases, the notified body is entitled to carry out checks in the plant at random intervals.

The outcome of the two procedures consists in the application of the CE marking and an administrative decision to authorize connection of the terminal equipment to the public telecommunications network. In addition to the identification number of the notified body responsible, the $\mathrm{CE}$ marking is therefore accompanied by a symbol indicating that the equipment is both intended and suitable for connection to the public network.

It should be noted that any equipment which is simply 'capable' of being connected to the network must be accompanied, when it is placed on the market, by a declaration stating that it is not 'intended to be connected to the public telecommunications network'; it must also bear the same symbol as that accompanying the CE marking, but surrounded by a circle comprising a diagonal bar.

The Commission is assisted in the management of the Directive by an advisory committee known as the Approvals Committee for Telecommunications Equipment (ACTE).

However, when decisions have to be taken on matters relating to regulatory aspects or the determination of justified cases of essential requirements with regard to the interfacing of terminals via the network, these decisions are taken by a qualified majority.

Directive 91/263/EEC was supplemented on 29 October 1993 by Council Directive 93/97/EEC relating to ground satellite communications station equipment.

\subsubsection{The Directive on new hot-water boilers fired with liquid or gaseous fuels (92/42/EEC of 21 May 1992)}

This Directive came into force on 1 January 1994, with a transitional period running until 31 December 1997; during this transitional period, States must accept the marketing of appliances which conform to the regulations in force on their territory on 21 May 1992 (the date on which the Directive was adopted).

Directive $92 / 42 / \mathrm{EEC}$, ties in with the entire corpus of Community policy on energy-saving (see Section 3.7 below), which takes account of requirements on safety, energy outputs and environmental protection while at the same time attempting to establish the free movement of goods.

The Directive applies to new hot-water boilers fired with liquid or gaseous fuels which have a nominal output of at least 4 kilowatts, but no more than 400 kilowatts. It does not apply to boilers designed to be used with other fuels or individually produced boilers. In the case of twin-purpose boilers, the provisions of the Directive apply only to the 'heating' function and not to the 'supply of hot water for domestic use' function.

The essential requirements relate to the output of the boilers, in accordance with a table set forth in Article 5, paragraph 1 of the. Directive. It should be pointed out that States are 
authorized to determine the conditions under which the boilers are put into service on the basis of local climatic conditions and also the energy and occupancy characteristics of the buildings. The function of the harmonized standards consists, in particular, in laying down valid verification methods for both production and measures.

With regard to certification of conformity, the system envisaged is the common-law system of the New Approach (CE marking and declaration of conformity following a type-examination procedure and either an inspection of production by the notified body, production quality assurance or product quality assurance: this involves modules $B+C$, D or E; refer to Chapter 4, Section 2 below); however, the system has one special feature which is described in Article 6: in addition to the CE marking, Member States may decide to apply a specific system of labels which make it possible to identify clearly the energy performance characteristics of the boilers, by using a system of stars for boilers whose output levels are better than those required for standard boilers, as determined in the Directive.

\subsubsection{The Directive on explosives for civil uses (93/15/EEC of 5 April 1993)}

This Directive on the harmonization of the provisions relating to the placing on the market and supervision of explosives for civil uses, which is based on Article 100A of the Treaty, was adopted by the Council on 5 April 1993. Its objective is twofold:

(1) to harmonize the conditions under which explosives for civil uses are placed on the market,

and

(2) to set up a system for supervising transfers of explosives within the Community territory, as an alternative to the system which depended on physical border checks.

The system for supervising transfers of explosives will apply from 1 October 1993, while the rules governing placement on the market will apply with effect from 1 January 1995. Given the scale of the European standardization work which is required, provision has been made for a transitional period running until 31 December 2002; during this transitional period, explosives for civil uses which conform to previous national laws may be placed on the market provided that these laws do not conflict with the provisions of the Treaty.

With regard to the definition of explosives, reference has been made to Class 1 of the 'United Nations recommendations on the transport of dangerous goods'. The Directive does not cover explosives which are intended to be used by the armed forces or the police, or pyrotechnic articles. In the case of munitions, the Directive makes provision only for transfer regulations.

The essential requirements on safety are specified in Annex 1 of the Directive. These requirements relate to the various physical, chemical, thermal and mechanical properties 
of explosives, and are necessary to ensure that the latter entail the least possible risk to human life and health, the integrity of property and that of the environment throughout their useful life. These requirements are therefore defined in fairly broad terms.

Work on European standards involving the transposition of the essential requirements on safety has recently been started.

With regard to conformity certification methods, the Directive provides for two options:

(1) EC type-examination (module B) and, at the option of the manufacturer, conformity to type (module $C$ ) or the procedure relating to the quality assurance of production (module D) or that of the product (module E) or verification carried out on the product (module F);

(2) verification on an individual basis (module $G$ ).

The second part of the Directive falls outside the scope of the new approach and relates to the supervision of transfers within the Union with a view to preventing illicit trading.

\subsubsection{The Directive on medical devices (93/42/EEC of 14 June 1993)}

This Directive relates to the design, manufacture and placement on the market of the numerous medical devices which are not covered by the preceding Directive on active implantable medical devices, which provided the main part of legislation in this area. This Directive does not apply to devices intended for in vitro diagnosis purposes, in respect of which provisions are currently being drawn up.

This Directive will apply with effect from 1 January 1995 . During the transitional period (scheduled to run until June 1998), devices may be placed on the market, within the Member States, in accordance with pre-existing regulations, in parallel with devices which will be sold under the new legislation enabling the CE marking to be affixed to each type of device.

This Directive is based on the new approach with regard to technical harmonization and standardization and, as a result, provides for a number of essential requirements. In order to be able to bear the CE marking, devices must conform to the specific requirements governing each type of device.

The manufacture of medical devices calls for differing levels of technology. The risks for the patient, user or other individuals vary according to the intended use of the devices.

These risks are dealt with in the 'essential requirements' of the Directive. These requirements specify the characteristics which devices must exhibit in order to achieve the envisaged performance levels, while guaranteeing the maximum level of safety.

Devices are subdivided into four categories in such a way as to distinguish the risks associated with each one of the many devices covered by the Directive (Article 11). 
In the case of the lowest-risk categories, the quality assurance procedures are essentially based on declarations by the manufacturer. In the case of the highest-risk categories, the procedures involve the application of a comprehensive quality assurance system for design, manufacture and placement on the market. The submission of specific design files is required in the case of certain devices. Other procedures combine product verification or type-examination with quality control of manufacture.

A number of notified bodies appointed by the Member States are responsible for evaluating and certifying the quality assurance system of manufacturers and, in the case of certain categories of devices, verifying certain aspects associated with the products, in such a way as to enable the CE marking to be affixed.

Annex IX lays down rules on the classification of medical devices. The specific characteristics defined therein spell out which conformity assessment procedures are applicable.

Devices are categorized on the basis of the method and site of application and also the associated risks. The latter depend on certain characteristics: devices which are active or non-active, invasive or non-invasive; temporary, short-term or long-term use; use for therapeutic or diagnostic purposes; usage in conjunction with products which are liable to be considered to constitute drugs.

The Directive provides for special arrangements for devices intended for specific clinical investigations and also for 'custom-made' devices intended for a particular patient which are manufactured to a specialist's specifications. Such devices - which do not bear the CE marking - must, as far as possible, meet the essential requirements, and any divergences from the latter must be pointed out in a declaration.

Certain procedures provide for experience gained to be assessed using devices which have been placed on the market. The Member States may apply a safeguard clause and demand the withdrawal from the market of devices which endanger or may endanger the health or safety of patients, users or other individuals.

\subsubsection{Draft new approach Directives currently being drawn up}

protection systems and appliances used in explosive atmospheres (ATEX)

lifts

pleasure boats

medical devices intended for in vitro diagnosis

pressure vessels

public transport cable systems

measuring instruments

precious metals. 


\subsection{Public contracts}

\subsubsection{Introduction and applicable documents}

Generally speaking, public contracts are contracts which are awarded in writing and in return for payment by public authorities, with a view to the performance of works and the provision of services and supplies. Although purchase contracts are obviously covered, so too are leasing contracts, including lease-purchase contracts.

Public contracts account for a major part of gross domestic product (GDP) in the Union. For example, it is generally estimated that purchasing carried out by the authorities alone accounts for some $9 \%$ of GDP, a figure which rises to around $15 \%$ if purchases made by public undertakings are included. In view of the importance of public contracts in economic terms, this was one sector which needed to be opened up to competition as a matter of priority in connection with the creation of the single internal market. This opening-up process has been pursued in three directions: the provision of information via existing rules governing procedures for awarding public contracts, which is designed to make them more transparent and guarantee the opening-up of contracts, the extension of these rules to services and sectors which have hitherto not been covered, and the monitoring of compliance with these various rules. This has led to the present availability of the following documents:

Council Directive 93/36/EEC of 14 June 1993 relating to the coordination of procedures for awarding public supply contracts, which will come into force on 14 June 1994. This Directive will cancel and replace Directives 77/62/EEC, 80/767/EEC and $88 / 295 / \mathrm{EEC}$, which are already in force.

Council Directive 93/37/EEC of 14 June 1993 relating to the coordination of procedures for awarding public works contracts, which came into force on 1 July 1993 . This Directive will cancel and replace Directives 71/305/EEC and 89/440/EEC.

Council Directive 92/50/EEC of 18 June 1992 relating to the coordination of procedures for awarding public service contracts, which came into force on 1 July 1993.

Directive 89/665/EEC of 21 December 1989 relating to appeals procedures with regard to the award of public contracts, which came into force on 21 December 1991.

Directive 90/531/EEC of 17 September 1990 relating to supply and works contracts in the water, energy, transport and telecommunications sectors, still referred to as the 'excluded sectors' Directive (since the sectors involved were formerly excluded from the preceding Directives), which came into force on 1 January 1993. This Directive will be replaced on 1 July 1994 by Directive 93/38/EEC, which extends its coverage to include service contracts.

Directive 92/13/EEC, which came into force on 1 January 1993 and which provides for appeal procedures in the field of the excluded sectors.

Transparency and non-discrimination are the key words of these documents, irrespective of what their scope may be. 


\subsubsection{Definition of the public contracts referred to in the documents}

When the Community decided to tackle the issue of public contracts, one of the trickiest points was defining what constitutes a contracting authority. There were three reasons for this problem: firstly, the legal and economic structures of the Member States differed widely; secondly, definitions of 'public contracts' varied considerably and, thirdly, the so-called 'public' sector was traditionally much more extensive in some States than in others. For obvious political and economic reasons, it was essential to come up with a degree of obligation on the various Member States which, if not comparable, was as least as similar as possible.

Following these discussions, the various partners reached a broad level of agreement on the line that, under Community law and for the purposes of public contracts, the basic public authorities are made up of the States, including the federated States in the case of federal States such as Germany and Italy, the various regional authorities, and the various public bodies of an administrative nature which depend on the first and/or second type of authorities.

Other bodies may be added depending on circumstances: to find out precisely which ones, it is necessary to 'refer to Directive $93 / 37 / \mathrm{EEC}$ on 'public works', which has in an annex thereto lists of 'public agencies and equivalent bodies'. The most extensive list is to be found in the Directive relating to contracts awarded in the water, energy, transport and telecommunications sectors, where 'contracting bodies' are understood to include not only the public authorities but also public undertakings, and also undertakings with a private status which enjoy special or exclusive rights. Clearly, these definitions meet criteria which are more factual and economic than purely legal in nature, and have been formulated with the aim of achieving equal treatment for the various national bodies responsible for the 'excluded sectors', irrespective of their legal form.

\subsubsection{Provisions of the public contract documents with regard to standardization}

Rather than analysing the various Directives relating to public contracts, the aim of this study is confined to determining the role of European harmonization in arrangements for opening up these contracts.

National standards have long formed part of the technical specifications to which reference was made in connection with the award of public contracts in the various States. The use of national standards was even mandatory in certain cases, in order to achieve economic rationality and transparency with respect to calls for tenders and also equal conditions for tenderers.

The provisions of the European Directives on 'public contracts' with regard to technical specifications are based on the same principles of economy, transparency and equality of suppliers with respect to calls for tenders: first of all, the technical specifications must appear in the general documents or specifications peculiar to each contract in such a way 
as to guarantee their accessibility; in addition, the contracting authorities must use European standards, technical approvals (construction products field) and common technical specifications (telecommunications field) as a reference in technical specifications for their calls for tenders.

If a document of 'European' origin does not exist, the technical specifications may be defined by referring - in order of preference - to. national standards transposing international standards, to national standards, or to any other standard.

These are provisions which impose a high degree of constraint, particularly with respect to the philosophy of the new approach. The reason for this political choice is that there are no grounds for the resistance which had become apparent over the years towards a real opening-up of public contracts to disappear, without stringent measures being taken to force the contracting bodies to change their practices. Indeed, one of the mechanisms to which these contracting bodies resorted consisted in using national technical specifications in a discriminatory manner. One of the aims of the 'public contract' documents is to prevent such practices.

With a view to being realistic, however, provision has been made for a number of exemptions enabling the contracting body to be released from its obligations vis-à-vis standards:

when the use of existing standards would be inappropriate bearing in mind the innovative nature of the draft in question;

when the standards do not contain provisions enabling conformity to be established, or when there are no technical means for this purpose;

if the use of standards obliges the contracting body to purchase supplies which are incompatible with the installations already used, or involves disproportionate costs or technical difficulties. Recourse to this exemption arrangement is, however, subject to one condition: it must be accompanied by a clearly defined and recorded strategy with a view to a transition to European standards within a certain period of time. (NB: this is a provision which is very similar to the type ' $\mathrm{B}$ ' exemptions permitted in European harmonization documents or HDs.)

It should be stressed that recourse to these exemptions obliges the contracting body to indicate the grounds for it in the call for tenders published in the Official Journal of the European Communities - unless this is impossible - and in all instances in its internal documents, and also to supply this information on request to the Commission and the Member States.

Lastly, and as a general point, it is prohibited to incorporate in calls for tenders 'technical specifications which mention goods of a specific make or source or of a particular process and which have the effect of favouring or eliminating certain undertakings or products. In particular, the indication of trade marks, patents, types or specific origin or production shall be prohibited; however, such an indication accompanied by the words "or equivalent" shall be authorized where the subject of the contract cannot otherwise be described ...' (Article 7, paragraph 6 of Directive 77/62/EEC relating to public supply contracts, as introduced by Article 8 of Directive 88/295/EEC). 
The Directive on excluded sectors also exhibits a number of characteristics which are peculiar to it:

- An additional obligation with regard to transparency, since the contracting bodies must pass on to suppliers or interested undertakings which request them, the technical specifications which are regularly used in their contracts or those which they intend to use in the course of the following budgetary year.

- An additional exemption option if the European technical specification is unsuitable for the particular application envisaged or if it does not take account of the technological developments which have taken place since its adoption. In this case, however, the contracting body must notify the standards institution concerned of the reasons why the European technical specifications are inappropriate, and request their revision.

- Provisions regarding the qualification of suppliers: the qualification system must be managed on the basis of objective criteria. If quality assurance forms part of such a system, the available European standards must be used. It is the later nature of the excluded sectors Directive with respect to the others which has made it possible to make this link between the qualification systems of suppliers and the European 'global approach' in the area of quality assurance (see Chapter 4 below).

Finally, the last provision which is worth mentioning concerns the Directive on appeal procedures in the field of the excluded sectors, which provides for a voluntary certification system enabling undertakings which are subject to the provisions of the public contract Directives to arrange for their contract award procedures to be evaluated and to report a positive evaluation in the Official Journal of the European Communities. This will be something of a 'certificate of good European conduct', which will be issued by an external and independent body following an examination of the contracting body.

This examination will cover the following points in particular:

the way in which the award of contracts is organized within

the contracting body

training

internal management of the system and measures for monitoring, checking and verifying the system

the operation of the system in particular cases, with sampling tests being carried out if necessary.

However, the practical arrangements have yet to be taken, despite the fact that the Commission has given CEN a mandate to work out the standardization measures required. Work has already started and the subjects dealt with in the European standard(s) will relate to the criteria applicable to the individuals carrying out the certification process, good practices to be followed in the performance of the examination, the method to be used for carrying out the certification process, and the presentation of the examination results. 
In conclusion, recourse to European standards in procedures for awarding public contracts has three objectives:

(i) To 'raise the moral standards' of public contracts by ensuring that the process is transparent, since standards are by definition documents which are accessible to any interested party, not only when they are published but also at the drafting stage.

(ii) To achieve rationalization in economic terms by reducing costs not only for purchasers but also suppliers and even the end-user, in the long term.

(iii) To improve the quality of the products and services concerned and, as a result, trust between the various economic partners.

Of these three aspects, only the first is peculiar to public contracts, with the other two representing objectives which are inherent in the standardization process.

The only problem now consists in the very large quantity of standards which are needed to ensure satisfactory application of these documents (in respect of which a number of mandates have already been given by the Commission, e.g. with regard to the supply and distribution of water and also as regards energy).

The Commission and its partners in European standardization - CEN, Cenelec and ETSI - are now faced with choices on priorities, and major programming work needs to be carried out before launching into over-ambitious projects which may result in failure.

\subsection{Standards as a tool of Community industrial policy}

\subsubsection{General}

The concept of industrial policy has for many years been the subject of frequent controversy within the Community, with this controversy being due as much to problems in defining the concept (what types of initiative does the term 'industrial policy' cover?) as to problems which are a priori ideological in nature and which result in the word itself being banned or, conversely, in the concept being seen as a universal panacea.

Fortunately, a growing consensus has developed in recent years on the type of policy required in the Community to meet the challenges of the last decade of the millennium and provide European industry with the conditions and environment needed for it to be competitive in an open world.

The first element of this consensus is that solutions to problems of competition need to be sought increasingly at Community level, and not at a purely national level.

The second element of this consensus is that the main question is not whether industrial policy is appropriate, since all governments now acknowledge that they have a major impact on industrial performance and development by their various actions, irrespective of what labels they give them. 
The third element of this consensus is of fundamental importance and relates to the minimum initiatives which should be pursued by States with regard to industrial policy in free-market economies: the vast majority of the economic partners within the Community, including States, consider that the role of the latter should consist in creating favourable conditions for industrial development on a horizontal, cross-sectoral level. In other words, States should organize, act as a catalyst for, and pioneer innovation.

By virtue of its characteristics, standardization is in this light a highly suitable tool: it provides a common forum for all the parties involved (whether public or private) to decide jointly on the options to be adopted and to draw up development programmes; being European in nature, it contributes not only to the elimination of technical barriers to trade but also to the economies of scale brought about by the opening-up of a single internal market and to the competitiveness of enterprises; since it is voluntary and consensual in essence, it is in keeping with the liberal philosophy of the European economy; as it is an evolutionary process, it makes it possible to reflect the current state of technology and can develop simultaneously with research, etc.

This aspect of standards had also been stressed when the Council of Ministers adopted their first resolution on standardization in 1984. The resolution of June 1992 confirmed and developed this point, and several Community 'industrial' policies have since given standards an important place. It will be seen later on that information technology provides one example in this regard, though it is far from being the only one: in the fields of telecommunications, biotechnology and road and rail transport - to name just a few - the European standard provides one of the mechanisms for achieving European integration.

This is the reason why the European Commission is increasingly giving European standards institutions mandates for drawing up standards which are not all necessarily intended to be used in connection with Community legislation.

To illustrate this aspect, the following grounds were cited by the European Commission when, in 1992, it established the mandate given to CEN in the field of biotechnology:

'This request concerns the establishment of European standards in the field of biotechnology, which is a series of techniques finding application in a number of industrial sectors and in agriculture. The trans-sectoral nature of biotechnology makes it imperative that wherever possible common standards should be established in order to reinforce the industrial base and to improve competitiveness on Community and external markets.

In its Communication entitled "Promoting the competitive environment for the industrial activities based on biotechnology within the Community" the Commission "... following the principles of subsidiarity and Community policy on the use of standardization ... considers that it is appropriate to mobilize the considerable technical expertise available in industry to support the targets of the legislation already adopted at Community level ...". Furthermore the Commission explicitly commits itself to draw up a clear and precise mandate for CEN "... in order that work in the field of standards may fully complement the Community's legislative work ..." 
Standards for biotechnology will cover a wide area of application of biotechnology, both areas of which are not subject to "biotechnology legislation" and those which are regulated. ${ }^{2}$ Standards will support industrial activities in the area of biotechnology covering operations with both non-genetically modified organisms and genetically modified organisms (GMOs), with both non-pathogenic and pathogenic micro-organisms.

Three horizontal legislative acts have so far been adopted at EC level which relate directly to biotechnology. Two Directives deal exclusively with GMOs: Directive 90/219/EEC covering their contained use, and $90 / 220 / \mathrm{EEC}$ their deliberate release. Directive $90 / 679 / \mathrm{EEC}$ on the protection of workers from risks related to the exposure of biological agents covers both GMOs and non-modified organisms. Products covered by vertical legislation already in existence, particularly in relation to food and agriculture, can very well be derived from biotechnology; and legislation covering the use of genetically modified organisms in these products is in preparation. The standardization activities covered by this mandate will support these legislative actions and help to build a common approach on technical questions.

As well as serving industrial policy ends standards will define in concrete terms the technical specifications, codes, methods of analysis, etc. which are the necessary technical complement to the legislation. Since biotechnology is in rapid evolution the reliance on standards for these technical questions will enable the latest technology to be modified in support of both existing and future legislation. It goes without saying that national or Community mandatory requirements will at all times take precedence over voluntary standards.'

It is clear from this that a standard is designed to be a tool at the service of legislation on technical harmonization and industrial development alike, and that, in giving CEN a mandate, the Commission is acting on behalf of not only the authorities but also all the economic partners and, to a certain extent perhaps, acting as their spur as well.

\subsubsection{The example of information technology}

The field of information technology provides an excellent example from the point of view of illustrating all the topics which have so far been dealt with. After all, this field very clearly involves 'private' partners, for obvious reasons of technical and economic rationality, while its economic and strategic importance is such that it has justified special decisions by the Community authorities with regard to public contracts and research, and even technical harmonization if the telecommunications field is included in this sector. In this section, however, we will confine ourselves to information technology in the "traditional' sense of the term.

\footnotetext{
${ }^{2}$ It should be noted that, in terms of volume of production, the majority of industrial operations will use neither GMOs nor pathogens and of those which use GMOs the majority will fall into Class I.
} 
As they extend and renew their range of products, computer manufacturers are faced with the problem of ensuring that products carrying their mark are able to communicate with each other.

The concept of 'network architecture' has emerged in the strategy of the main manufacturers. This is a sort of logical infrastructure serving as a permanent reference system for the design of new products and guaranteeing interworking of hardware designed according to it.

\section{The seven-layer OSI model}

In the 1970 s the major users, starting with the PTT research centres, especially in Europe, also studied this concept of general network architecture, seeing it as a promising way of facilitating access by hardware of different makes to the same telecommunications network.

At that time, experts from CCITT (International Telegraph and Telephone Consultative Committee) and ISO proposed a general model of data communication protocols known as the OSI (Open Systems Interconnection) model, also called the 'seven-layer model'.

In layman's terms, these seven layers correspond to various stages in information processing (information bits) and are designed so that if two systems are compatible layer by layer they can automatically communicate with each other.

To make this concept clear to the layman, an analogy with the international postal service may be used. If two people in two different countries A and B are to be able to write to each other, the postal administrations must agree on a number of things such as the physical carriage of the mail from A to B and the address coding, and the writer must also use a reference system (signature, etc.) enabling the addressee to identify him and of course a language which the addressee can understand.

Thus, to construct a model of the postal system four layers would have to be used, for each of which compatibility would have to be established between the systems of the two countries so as to enable information to go from A to B and to be used.

These compatibility procedures will of course be different for mail sent by the conventional post and mail in the form of a telegram since a letter sent from country $A$ by the conventional post cannot be received in $B$ in the form of a telegram. It is therefore necessary to add to the standards for the general modelling of the information processing system, which contain numerous options (conventional letter or telegram, etc.) through more specific standards known as functional standards which specify the options to be adopted for a particular service, such as the telegram.

Interworking of hardware designed in conformity with these functional standards is therefore possible, which is the main objective of standardization.

\section{European functional standards}

At the beginning of the 1980s, however, there was a big gap between the concept of a theoretical model of this kind, which had the advantage of being independent of techno- 
logical choices, and the availability of the stock of operational standards that were needed if it was to be effectively put into practice.

The gap was made all the greater by the fact that some large computer manufacturers had no faith in the future of this approach and preferred to continue developing their own pattern of architecture which had the advantage not only of continuity but also of allowing a 'captive market' approach to sales that was possible either because of the size of the manufacturer or because of the existence of large domestic public procurement markets.

This situation could have led to the classic 'chicken and egg' syndrome if 1982 had not seen the emergence of an unusual combination of interests in favour of implementing a programme for the production of the standards needed for the OSI system:

Under the Esprit programme, 12 European computer manufacturers reached the conclusion that development would be impossible unless their various products were able to work compatibly and for that purpose the OSI model offered the best common language.

The European Community was anxious to establish a European IT area in which common standards would be applied for public procurement and telecommunications networks so as to guarantee the economic and technical cohesion of the European market. The OSI model was therefore welcomed as it also provided an international reference system allowing dialogue between Europe and the USA in particular.

CEN, Cenelec and CEPT were prepared to adapt their operating structures and priorities to provide an institutional framework suited to the specific case of information technology.

Excellent cooperation between CEN, Cenelec and CEPT.

To implement this new policy the three bodies set up a joint committee, the Information Technology Steering Committee (ITSTC) with an equal number of representatives from each of the organizations, the function of which was to design and then monitor the implementation of the development policy for functional standards. It should be noted that ETSI replaced CEPT on the ITSTC in 1989.

The main instruments of this policy were developed in less than a year:

the formal adoption by Europe of ISO standards describing the bases of the OSI system: these standards are catalogued in a regularly updated document known as 'HD 40001'; the formal definition of the concept of functional standards in the Memorandum for Information Technology No 1 (M-IT-01) adopted by the three organizations;

the overall programme and timetable for the functional standards needed to meet European requirements: this is M-IT-02 and its supplement (setting out the timetable), also adopted by the three organizations and regularly updated;

the establishment of a special status of European standard known as ENV, suited to the specific problem of functional standards which need to be drawn up and adopted in a short time (see Part 1, Chapter 2, Section 4.7 above); 
while these instruments were being established, a number of working parties started to prepare the first functional standards which were formally adopted in the summer of 1986.

This active pursuit of a European policy rekindled international interest in the OSI model: for its part, ISO further developed the concept of functional standards and, even more importantly, a number of powerful users in the United States (General Motors, Boeing, public procurement agencies through the National Bureau of Standards and Technology (NBS)) made a start on drafting functional standards ('profiles') to meet their own needs with the idea of later imposing them on their suppliers.

There gradually emerged in the Unites States a concept of a workshop for the preparation of profiles in a less formal setting than the official standardizing bodies: all experts interested in a particular topic met to seek a technical consensus, contemporaneous with technological developments, on the selection of the options allowed by the OSI standards.

As a reaction to the affirmation of the role of user organizations in the USA, similar organizations were formed or strengthened in Europe: EMUG (European MAP Users' Group) for industrial plant, Ositop for administration, RARE for research, etc., and it became apparent that Europe needed a single forum in which all these sectoral interests could be expressed under conditions that would further strengthen and speed up standardization.

Thus, EWOS (European workshop for open systems) was set up as an informal association of seven organizations with the purpose of drawing up documents to be incorporated in the standardizing process at international or European level and allowing balanced discussion with the equivalent bodies in the United States and Japan, which are known as OIW (OSI implementators' workshop) and AOW (Asia-Oceania workshop) respectively.

\section{Towards open-systems environment standards}

After standardizing the functional standards for specific functions such as messaging, file transfers, etc., the regional groups envisage extending their area of activities beyond the confines of specific functions defined on the basis of the OSI reference model. The ultimate aim is to promote applications software offering portability, interoperability and 'parameterability', i.e. able to be adapted easily to user requirements, and to speed up the penetration of computing environments which are rich in such potential.

Consequently, an open system according to the new OSE (open systems environment) concept may be defined as involving an optimum of interfaces, services and exchange and processing formats which thus enable applications software:

to be compatible with other remote applications or applications resident in the same system;

to be portable at low cost across a wide range of systems;

to be user-friendly in terms of man-machine interaction. 
New areas have thus become highly important in recent years, such as computerintegrated production, home automation, data graphics, data processing and the exchange of medical data, electronic funds transfer, etc.

\section{Verification of conformity and certification in IT}

The concept of OSI functional standards originated from an analysis of the need for compatible working of products: these standards will be credible only if the products claiming to conform to them can effectively interoperate, which is why testing and certification is so important in a field in which innovation is ever present.

From the outset of the OSI work, the European Commission provided financial backing for the establishment of operational testing services to verify conformity with functional standards. Two successive calls for tender were issued with the twofold objective of developing test centres open to the public and establishing technical cooperation between the bodies concerned so as to avoid divergences from one country to another re-emerging in the verification of conformity. Five calls for tender have so far been issued under the name of 'CTS' (conformance testing service).

Alongside that activity now involving some 15 bodies in Europe, CEN, Cenelec and CEPT busied themselves with providing arrangements for mutual recognition ensuring that certificates issued in different countries were equivalent.

Thus, in 1987, the ITSTC adopted a memorandum entitled M-IT-03 relating to matters of certification. This memorandum served as a basis for the establishment of the ECITC (European Committee for IT Testing and Certification), which is responsible for harmonizing the mutual recognition system for test reports which should, in the long term, involve all aspects of the certification of IT products and not just OSI aspects. Five mutual recognition groups have so far been set up: the OSTC (open systems testing consortium) for electronic messaging and file transfer; Etcom (European testing and certification for office and manufacturing) for OSI products relating to local networks; EMCIT (European testing of electromagnetic compatibility of IT products) for electromagnetic aspects; ITQS (IT quality systems) in connection with the EN 29000 series of standards; and, finally, the GLATC (Agreement Group for Graphics and Languages Testing and Certification) for validating programming language compilers and data graphics systems.

\subsection{Research and development and European standards}

Traditionally, the concept of standards and the concept of research and development used to appear to be diametrically opposed: by codifying the current state of technology, standards were ipso facto felt by many business interests to keep technology at the same point of development, thus curbing industrial creativity. This is not the case at all provided that certain rules are observed when the standard is drawn up (in order to avoid the pitfall of compiling over-descriptive documents), and provided that the status of the 
standard corresponds to the current state of technology (hence the importance of ENVs, European prestandards) and, lastly, on condition that standards are frequently revised. The correct approach therefore consists in knowing how to adapt and use the technique of standardization, and not to be unaware of these aspects.

After all, research findings must in principle be translated into practical applications at some stage, if possible without unnecessary costs and delays (we are not referring to basic research in this context). To do this, data of a technical, economic, social and even ethical nature must always be taken into consideration, since technological innovations are not introduced into an 'empty' environment.

In this respect, catering for existing standards at the research and development stage makes it possible not only to avoid oversights which might have a major impact on future marketing but also to take proper account of possible interfaces, achieve economies of scale and adapt the product to market requirements.

The same advantages may be anticipated from starting up the standardizing process during the research and development stage, so that the standard is available at the same time as the product. In addition to these advantages there is also the fact that, in the case of large-scale research projects which are set to lead to products with a large take-up, not making mistakes about a standard at the outset, makes it possible not only to increase the product's chances of success on the market but also to put oneself in a strong position on international markets and avoid very expensive reconversions later on.

European research projects are of particular importance in this regard because undertaking preparations on European standardization at the right time represents a major step towards achieving a common market which is not hampered by technical regulations and standards which differ from one country to the next. Harmonization a posteriori, which is inevitable in most cases, is much more costly than standardization a priori.

This is why the European Union and, beyond this, all the countries of western Europe have taken this issue on board and are striving to ensure that the subject of standardization is taken into account in research and development projects financed at European level, in so far as this is necessary of course.

The scale of the Community's involvement in this sphere only became significant with the launch of the Esprit programme (see Section 4 below), within which European standardization of open systems developed on the basis of the international model. Subsequent Community programmes which built on this initial success have, virtually without exception, taken account of standardization. For example, the programme of Community action in telecommunications puts the savings achieved in the hardware market by the adoption of common European standards at between 5 and $10 \%$, i.e. close to ECU 1 billion per annum. As a result, the RACE programme caters for the provision of finance for the drafting of European standards concerning the wide-band integrated network. 
Finally, it should be noted that the research and development projects under the Eureka programmes (which bring together enterprises in EEC and EFTA countries alike) also generally have a standardization aspect to them.

In conclusion, the crucial point that, far from conflicting with each other, standardization and research and development are complementary as soon as their respective roles are properly understood and respected, is one which should be stressed. The author of this study has often heard engineers and company managers describe how simply taking part in work on drafting standards had given them ideas on further improving their products, and that this fact alone justified the investment they had made in standardization.

Lastly, it should be pointed out that the EC Council of Ministers has reaffirmed the supreme importance of the link between research and standardization for the future of industry in Europe in its resolution of 18 June 1992 and has undertaken to continue with initiatives already started in this area.

If readers wish to find out more about the subject of 'research and development and standardization', the European Commission published a guide with this very title in 1992, produced by Antoine Thiard and Wilhelm F. Pfau.

\subsection{Standardization and intellectual property law}

The effect of standardization is to put ideas and solutions to technical or economic problems in the public domain and facilitate their use by the greatest possible number of business interests.

Clearly, this concept is exactly the opposite of the concept of protecting intellectual property which, via the notion of the patent, is designed to keep ideas or solutions in the private domain.

This contradiction means that, when standards are being drafted, the use of provisions covered by patents should be avoided as far as possible because otherwise the free use and application of the standard will be hampered by privileges attaching to the owners of the patent.

The standardization code of practice, which is codified in the Directives of ISO and the IEC (Part 2 - 1989 edition, Annex A, see box below) or in CEN/Cenelec Memorandum No 8, calls on all parties involved in drafting a standard, including at the public-comment stage, to specify any provisions of the draft standard which they know to be covered by patents. These provisions apply in principle to international draft standards as well as to national and European ones. 
'Although, in exceptional cases, technical considerations justify the drafting of an international standard in terms which necessitate the use of a provision which is already patented, such a measure does not, in principle, give rise to an objection, even if the terms are such that there is no possible alternative. In this case, the following procedure must be adhered to:

(a) ISO and the IEC cannot give authorized or exhaustive information on the existence, validity or sphere of application of a patent and similar property rights, although it is desirable for information which is as full as possible to be provided. This is why the author of a proposal of this type must draw the attention of the technical committee or sub-committee to any patent or similar property right which is known at world level or to any other known current application for a patent, although ISO and the IEC cannot give guarantees as to the value of such information;

(b) if, for technical reasons, the proposal is accepted, the author of the proposal must request any known holder of the patent for a declaration stating that he would be prepared to negotiate licences for patents and similar property rights, under reasonable conditions, with any parties worldwide who might request them. The declaration of the patent-holder must be registered, as the case may be, in the files of ISO's central secretariat or the IEC's central office, and reference to it must be made in the corresponding international standard. If the patent-holder does not provide such a declaration, the technical committee must not proceed with the inclusion of the patented provision unless the Council of ISO or of the IEC authorizes it;

(c) if, following publication of the international standard, it emerges that licences for the patent or similar property rights cannot be obtained under reasonable conditions, the international standard must be referred to the technical committee for a fresh examination.'

Although databases on patents make searches easier, standards institutions cannot take responsibility for ensuring that the provisions which they are envisaging adopting as standards are not subject to a patent, or undertake to carry out all searches enabling the existence of any patents to be identified.

Under these conditions, three solutions may be envisaged when a patent problem arises in connection with a draft standard:

The draft standard can be modified to prevent reliance on provisions covered by the patent. A functional and non-descriptive approach to the standard may sometimes enable this objective to be achieved.

The patent-holder agrees to negotiate licences for his patent under financially reasonable and non-discriminatory conditions (i.e. he undertakes to grant a licence under identical conditions to any applicant). If a declaration of this type by the patent-holder is duly registered by the standards institution, the standard may then be published with the inclusion of the provision covered by the patent; the standard must contain a reference to the aforementioned declaration. 
If, lastly, it is not possible to prevent the standard incorporating a patented provision, and if the patent-holder is not able or refuses to subscribe to the aforementioned declaration, the standards institution may then abandon publication of the standard.

Of course, this analysis of the three possible options is only meaningful if the standard is at the draft stage. There have been cases (though these have fortunately been rare) of a problem with patents arising only after the standard has been published, with the patentholder having failed to come forward - whether voluntarily or not - during the drafting process. Considerable difficulties may then arise, especially if the products designed in conformity with the standard are the subject of major contracts, particularly public contracts.

In order to try and eliminate a priori difficulties of this type, ETSI, which considers that telecommunications standards (which relate to advanced technologies which are often covered by patents, and which are frequently used in public contracts) are particularly vulnerable to this problem, has attempted to develop an administrative mechanism whereby parties involved in standardization would be legally constrained to declare their patents and to give up licences relating to such patents (with certain restrictions as regards royalties) or to relinquish their involvement in standardization work. However, the legal complexity of these problems is such that an operational solution has not yet been developed by ETSI.

In addition, the European Commission added its contribution to the debate with its publication on 27 October 1992 of a 'communication on intellectual property rights and standardization', which supports the position of ISO (and thus of CEN and Cenelec) with respect to ETSI's position. The reason for this is that it is difficult to impose a different system by pleading the specificity of one sector with respect to others since, at the present time, all sectors are undergoing very fast-moving technological innovations (this is most certainly the case in telecommunications, but also in information technology, biotechnology, energy, etc.).

In conclusion, the opinion which currently prevails in the world is that a patent takes 'precedence' over a standard, in the legal sense of the word, but that this precedence must be 'attenuated' by the conciliatory spirit of the various parties which generally prevails throughout the standards-drafting process. The reason for this is that, if a patent exists, the drafters of the standard first seek to get round this difficulty by avoiding the inclusion in the standard of provisions covered by the patent. Such provisions are only used if the drafters cannot do otherwise, by requesting the patent-holder's authorization and also carefully handling the interests of the other parties involved since the patent-holder must declare in writing that he is willing to grant licences 'under reasonable conditions'.

Finally, it should also be noted that, in certain cases, the use of patented solutions in standards encourages a broader application of the patented invention and thus represents an advantage for the inventor. However, in view of the law as it now stands and also present thinking, the abolition of rights acquired by the patent-holder is not a possible option under any circumstances. 


\subsection{Conclusion: The standard as a general tool for supporting legislation and European construction}

As seen in the foregoing sections, the standard has become one of the European Union's main tools in connection not only with policies for eliminating technical barriers to trade and opening up public contracts, but also with policies which are geared to promoting the harmonious development of a strong and competitive European industry which is open to the rest of the world.

Over and above these policies, a number of Community initiatives to use the standard as a general tool for supporting legislation and Community construction have been launched in recent years, and the Council resolution of 18 June 1992 confirms this approach: as a result, two of the Community's most important policies, which relate to energy and environmental protection, are partly based on the use of standards, and the same approach is contemplated in another sector of fundamental importance, namely the agrifoodstuffs sector.

Rather than giving a lengthy account of the various policies, a good idea of the way in which standards may be used as a general tool to support Community construction may be gained by quoting the conclusions of the Commission document of 9 June 1992 on standardization in the field of energy:

'Standardization in the energy sector is of prime importance in achieving the internal market and also with regard to environmental impact reduction, safety and energy efficiency, and the development and spread of advanced energy techniques. The economic impact resulting from the generalization of the benefits must also be stressed.

The creation of the single energy market presupposes a major strengthening of standardization, both as regards the quality of energy products and facilities for producing, transporting and distributing these products. This does not preclude technical harmonization at Community level in cases where national regulations compartmentalize the market.

Sectors in which standardization requires increased effort include the following, in particular:

petroleum products (in line with environmental requirements)

facilities for refining and distributing oil

facilities for producing, transporting and distributing electricity

facilities for transporting and distributing gas

renewable forms of energy

environmental protection. 
The diversity of the energy sector imposes a diversified approach to its technical harmonization and standardization. The means to achieving it will consequently be diverse, such as:

the drafting of European standards, without Community legislation explicitly requiring them. Applications to draft these European standards must firstly come from the parties which are directly concerned, but may if necessary also be formulated via standardization mandates. If the standard was not sufficient to get the Member States to abolish or adapt the national regulations which conflict with it, Community legislation making reference to the standard obligatory would be envisaged;

if necessary, Community harmonization legislation. Where possible, this legislation would be based on the new approach and would contain a generalized reference to European standards in the sector in which mandatory or quasi-mandatory national technical specification still compartmentalize the markets;

energy programmes geared to a specific objective such as energy efficiency or the development of renewable forms of energy, and comprising a standardization part. These programmes also help to achieve the environmental objectives, particularly the stabilization of $\mathrm{CO}_{2}$ emissions between 1990 and the year 2000 which is aimed at by the Union.'

It is clear from reading this document that the hallmark of this policy (and also the other policies quoted) is that it gives an extremely broad role to standardization: it is necessary not only to ensure the free movement of goods and services but also to enable a real opening-up of public contracts, ensure that all European consumers are satisfactorily supplied, promote technological and industrial development and the level of quality and safety of products and, lastly, to protect the environment. When used in support of these various objectives, the European standard thus becomes one of the most important tools of European policy in general, over and above its established status as a regulator of competition.

In the light of the most recent developments, it is clear that it is indeed this role which the European standard is expected to fulfil in the years to come, justifying the interest shown in it by all business interests. 


\section{European Community policy on the assessment and certification of conformity}

When the EC Council adopted the doctrine of reference to standards on 7 May 1985, this body had invited the Commission to prepare, in cooperation with the group of senior officials responsible for harmonization policies at State level, a complement to the new approach which would deal with problems in assessing and certifying conformity.

After all, as has already been mentioned a number of times, technical barriers to trade which are caused by regulations and standards very often conceal other barriers which are more difficult to surmount and which are due to the systems used for certifying conformity. In order to guarantee the effective implementation of the 'reference to standards' Directives and, in particular, to ensure the establishment in Europe of the climate of trust which is indispensable between all the parties involved (not only end-consumers but also manufacturers, operators in the field of testing and certification, and supervisory authorities in the Member States which are responsible for enforcing the Directives), it has quickly become apparent that it is necessary to deal with these questions a priori on the basis of coherent principles.

In addition, the new approach policy is directed not only at eliminating technical barriers to trade, but also at promoting, in so far as possible, increased quality of the products placed on the European market. And quality necessarily implies conformity certification systems.

Finally, the very complexity of the existing systems (whether European or national ones), including in the regulatory context, meant that this area needed to be restored to order and clarified.

On 24 July 1989, therefore, the Commission submitted to the Council a communication on a global approach to certification and testing subtitled 'Quality instruments for industrial products' which contained a number of proposals in this area (Document Com(89) 209 final, published in OJ C 231 of 8 September 1989 and OJ C 267 of 19 October 1989). The main elements of this global approach were adopted by a Council of Ministers resolution of 21 December 1989 (resolution 90/C 10/01, published in OJ C 10 of 16 January 1990), which is appended to this study as Appendix 7.

As the title of the Commission's communication shows, it is a question of implementing an integrated approach designed to establish trust between the parties involved in Europe in the field of assessment and certification of conformity. 
In the regulatory field, two of the most important points of the Council resolution necessitated additional documents to enable the global approach to be implemented: one of these documents was designed to harmonize the procedures for assessing and certifying conformity between the various new approach Directives', with the other being intended to explain the operation of the $\mathrm{CE}$ marking, which indicates conformity with regulatory requirements.

The first of these two documents was adopted by the Council of Ministers on 13 December 1990 (the 'modules' Decision, which is reproduced in Appendix 8), while the other was examined by the various authorities concerned. This second document (the draft regulation on the $\mathrm{CE}$ marking) was converted into a proposal for a Directive amending 12 Directives already adopted and into a proposal for a decision supplementing the 'modules Decision' with regard to the application and use of the CE marking.

The policies underlying these two documents are examined in Section 4.2. below.

\subsection{The global approach and the Council resolution of 21 December 1989.}

The aim of the global approach consists in 'creating the necessary conditions for implementing the principle of mutual recognition of proof of conformity, both in the regulatory sphere and the non-regulatory sphere'. To this end, it proposes a package of measures which can be implemented directly and also guiding principles calling for other decisions or interpretative documents to be applied. The whole package was adopted by the Council of Ministers in its resolution of 21 December 1989 and the analysis given below repeats all the doctrinal elements existing at the present time, even if these do not appear directly in the said resolution.

The main elements of the European policy on assessment of conformity which was thus decided on are as follows:

\section{(1) In the regulatory sphere}

- the need for a single Community system for dealing with the procedures for assessing and certifying conformity in the new approach Directives. (This is the modules system mentioned above which was adopted via the Council Decision of 13 December 1990 and which is presented below in Section 4.2.1.);

- the choice of criteria which must be involved in the designation of notified bodies: i.e. the bodies which the national authorities choose to designate to the Commission for the purposes of applying the conformity assessment and certification procedures in their country.

Whereas under 'old approach' harmonization Directives no information was given to Member States with regard to the bodies which could or had to be notified to fulfil these functions, the Council resolution and a number of subsequent documents specify the need to have a number of rules to ensure that, here too, the Community's actions bear the stamp of consistency. 
As from the moment when the role of the notified bodies is of fundamental importance in order not only to protect public interests (health, safety, etc.) but also to achieve the free movement of goods under satisfactory conditions, particularly from the point of view of creating the indispensable climate of trust, States are required only to notify bodies

which are installed on their territory, since the Member State must be able to monitor the notified bodies and ensure that they carry through to a successful conclusion the briefs entrusted to them

and which meet a number of criteria: independence from the customer, impartiality, professional integrity and technical competence, transparency of the applicable procedures, possession of the necessary technical and human resources, possession of a civil liability insurance policy, and a guarantee of professional secrecy.

In order to be able to be notified, a body must be able to fulfil all the functions of at least one module (see Section 4.2.1. below), and if possible several modules.

Subcontracting, the aim of which is to increase scope for conformity assessment by using the capabilities of the broadest possible range of existing bodies (all not meeting the necessary conditions to be notified), is encouraged subject to certain conditions which are all geared to guaranteeing the required level of trust: first of all, a notified body may not under any circumstances subcontract all the tasks for which it has been notified. It must retain its operations management role and, in particular, is responsible for the crucial task of evaluating and appraising the conformity of the product in question.

In addition, the obligations mentioned above in terms of competence, etc. also apply to the body benefiting from the subcontracting. The subcontracting relationship must be the subject of a contract, to ensure the transparency of the whole procedure. Finally, it is clear that the notified body keeps its liability intact.

When States notify bodies which can provide proof of their conformity with those standards of the EN 45000 series which concern them, by means of an accreditation procedure or some other method, these bodies are assumed to meet the Community requirements in this regard. However, Member States which have notified bodies which are unable to demonstrate a priori their conformity with these standards may be asked to supply the Commission with proof demonstrating the validity of notifying the bodies in question.

- Harmonization of the procedures, conditions of use and significance of the CE marking in the various Directives. (See Section 4.2.2. below for the draft Community regulation on this subject. It should be noted that the term ' $\mathrm{CE}$ marking' must in fact be used.).

- Relations with third countries: in this connection, the Council establishes the conditions for entering into mutual recognition agreements on the basis of Article 113 of the Treaty (which relates to common commercial policy) by recalling that the Community endeavours to promote international trade in products which are subject to regulation.

A decision by the Council of Ministers authorizing the Commission to negotiate mutual recognition agreements under certain conditions was adopted pursuant to the 
global approach in the course of autumn 1992. The main points of this decision are examined later on in Section 4.2.3.

\section{(2) In the regulatory and non-regulatory spheres}

- EN 45000: use of these European standards, which were examined in Part 1, Chapter 3 and which relate to the competence of the bodies involved in the conformity assessment and certification procedures, is recommended by the Council in both the regulatory and non-regulatory context. The setting-up of accreditation systems on the basis of these standards is strongly encouraged, but not demanded.

- EN 29000: the Council likewise generally encourages the use of the quality assurances practices set forth in the EN 29000 (ISO 9000) series of standards. However, they are not imposed. Thus, the 'modules' Decision specifies that, in principle, when the Directives grant the manufacturer the option of using modules based on quality assurance practices, the manufacturer must also be able to resort to modules which do not call on these practices, i.e. to resort, for example, to a combination of a type test and a product check by an outside body.

- Upgrading measures: as it is clear that differences exist between the Member States with regard to the infrastructure of testing and certification bodies, and that these differences may turn out to be detrimental to the effective operation of Community Directives, the Council has requested the Commission to prepare a programme of studies and measures to be taken, which may include the estimation of Community finance with a view to supporting the upgrading of systems in certain countries.

\section{(3) In the non-regulatory sphere}

(This expression has the following meaning in this context: the sphere in which conformity assessment and certification procedures are not made mandatory.)

- The creation of the EOTC (see Chapter 5, Section 5 below): the regulatory authorities are interested in progress being made in Europe in the sphere of certification and testing for non-regulatory purposes for two reasons:

(i) firstly, just as at national level they are involved in defining the legal framework of these activities and ensuring compliance with a number of principles, they want a certain level of discipline to be maintained at European level;

(ii) secondly, in connection with the creation of the single internal Community market, they are responsible for ensuring that conditions allowing free competition obtain and, as a result, are responsible for encouraging a reduction in technical barriers to trade which are due to the multiplicity of testing and certification procedures in the unregulated sector.

However, the role of the regulatory authorities in this sphere - whether these may be the national authorities or the Community - can only be to provide incentives and provide a 
framework for the business interests. It is a question of making offers and suggestions, and not imposing things. This is why, in its resolution, the Council contented itself with expressing the conviction that

'the promotion of mutual recognition agreements on testing and certification between bodies operating in the non-regulatory sphere is essential to the creation of the internal market. The establishment of a flexible and unbureaucratic testing and certification organization at European level, the essential role of which is to promote such agreements and provide the best setting for their formulation, should contribute significantly to the pursuit of this objective'.

It was on the basis of this declaration, which called for an initiative to be taken by the parties concerned, that a memorandum of understanding was signed in April 1990 between the Communities, the Secretariat of EFTA, CEN and Cenelec to create a European body responsible for promoting the recognition of testing and certification in the non-regulatory sphere: namely, the EOTC (European Organization for Testing and Certification). The functions of this organization are examined in the following chapter.

\subsection{The implementation of the Global Approach at regulatory level}

The European Commission turned the period 1990-92 to good account by formulating the additional documents required for the implementation of the Global Approach in the regulatory sphere. The document on CE marking was adopted on 22 July 1993 (see Section 4.2.2.).

\subsubsection{The Council Decision on modules of 13 December 1990}

(Decision No 90/683/EEC, published in OJ L 380/13 of 31 December 1990, reproduced in Appendix 8).

\subsubsection{The principles}

The text of this Council Decision comprises a single article and an annex. The single article of the Decision deserves to be quoted in its entirety:

'The procedures for conformity assessment which are to be used in the technical harmonization Directives relating to the marketing of industrial products will be chosen from among the modules listed in the Annex and in accordance with the criteria set out in this Decision and in the general guidelines in the Annex. These procedures may only depart from the modules when the specific circumstances of a particular sector or Directive so warrant. Such departures from the modules must be limited in extent and must be explicitly justified in the relevant Directive. The Commission will report periodically on the functioning of the Decision, and on whether conformity assessment procedures are working satisfactorily or need to be modified.' 


\section{Conformity assessment modules}

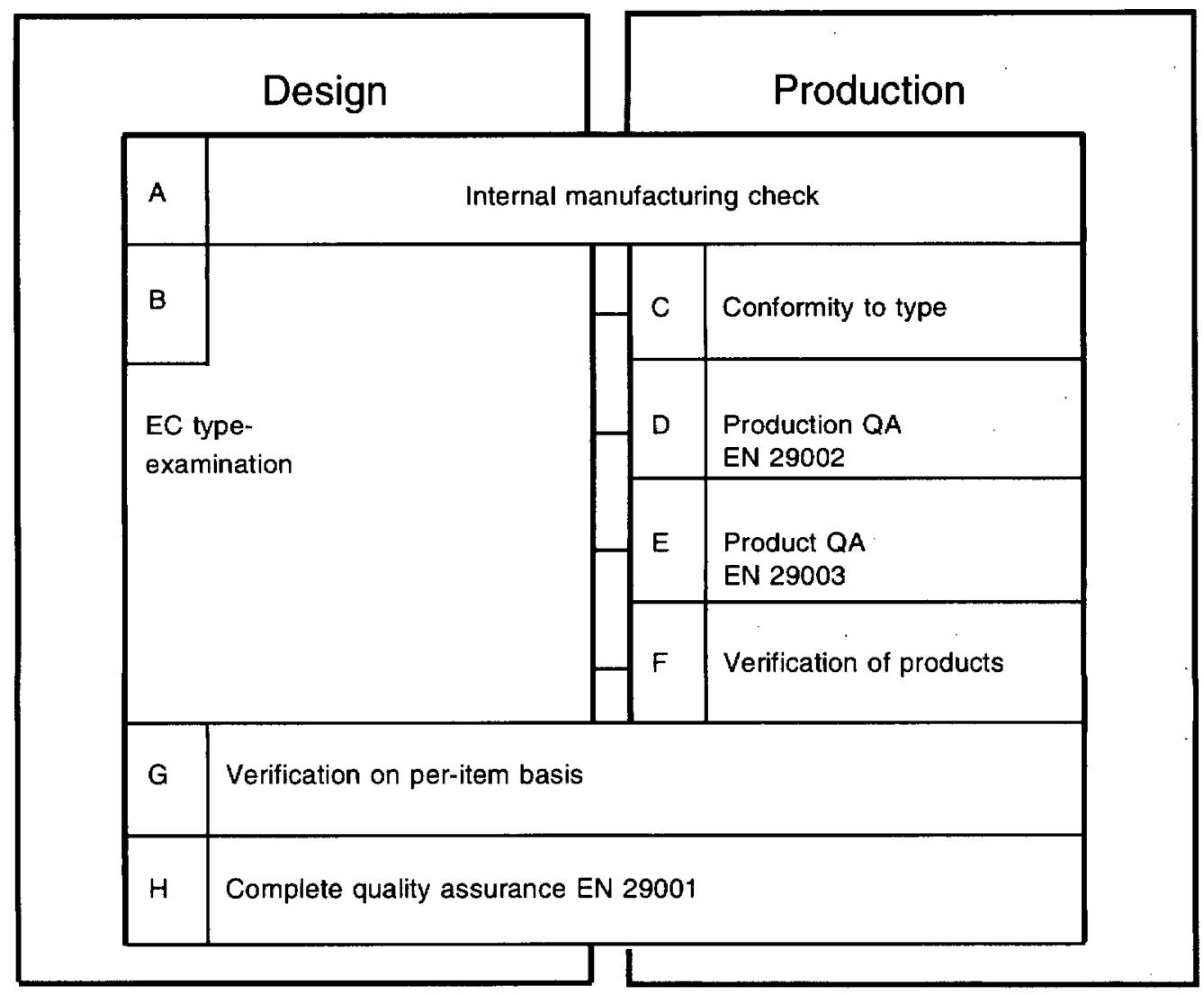


The intentions of the Council of Ministers are clear from this: it is first of all necessary to impose on Community legislation a framework for conformity assessment from which it is not, in principle, permissible to depart. The reason for this principle is as follows: in the case of not only the regulatory authorities but also conformity assessment bodies and, of course, manufacturers and importers, it is essential for the various procedures provided for in the Directives to be harmonized, i.e. it is essential that the same words in fact have the same meaning and that Community legislation is homogeneous.

After all, a number of products may be subject concurrently to several Directives (for example, gas appliances for large kitchens are covered by the gas Directive, the construction products Directive and, possibly, by the low voltage Directive and national documents concerning the safety of buildings open to the public), and the obligations to which they are subject in this case must at least be mutually compatible, if not identical, so that suppliers of these products can adhere to them.

In addition, the public authorities - particularly the supervisory authorities - must have clear and consistent documents to carry out their functions.

Secondly, the Council of Ministers has endeavoured to highlight the importance of the balance between health and safety requirements and the economic aspect of conformity assessment and certification procedures. The reason for this is that in some cases the cost of third-party involvement represents a not inconsiderable element of the cost price of the products.

It is thus very clearly explained in the Decision that the procedures adopted when the Directives are drafted must take account of these demands ('the Directives should avoid imposing unnecessarily the use of modules which would be too onerous relative to the objectives of the Directive concerned'). Finally, in order to respect as far as possible the principles of trust and freedom of choice which are characteristic of a free-market economy, it is specified that the range of modules offered to suppliers must be as broad as possible.

In this approach, the Council has therefore wanted to offer the various business interests two choices: under the Directives, the public authorities may adopt only some of the modules proposed, and may thus guide the choice which manufacturers/suppliers will then make from among the modules offered in the Directive(s) which apply to the products they are marketing.

\subsubsection{The modules}

The modules form the basis of the conformity assessment procedures to be used in the Directives. These modules may relate either to the design phase of the products, their production phase, or to both phases at the same time, but always necessitate a check on both phases which may be carried out by the supplier himself or by a notified body. The complexity and stringency of the modules varies according to the risks associated with the products concerned. 
The Community legislator can choose between eight modules (see the table below).

As can be seen, the modules offer a broad range of options since, depending on the Directives, recourse may be had to a very simple formula such as that of module A (which leaves the supplier with responsibility for the conformity assessment and certification methods by means of an internal manufacturing check and a declaration of conformity) or highly stringent modules such as modules $G$ and $H$, which respectively impose verification on a per-item basis by a notified body and a complete quality assurance system of the type described in standard EN 29001, with the involvement of a notified body to approve the system and check its continued application.

Under the new approach, module A must in principle be reserved for cases where the manufacturer has complied with the harmonized standards, and/or cases where the risks incurred do not justify more cumbersome procedures (machines Directive, toys Directive, etc.).

On the other hand, it is clear that, as seen above in the examination of the various new approach Directives which have been adopted, only modules which provide for the 'heavy' involvement of a notified body are acceptable for products such as active implantable medicinal devices (where the procedures provided for correspond to modules $\mathrm{B}+\mathrm{D}, \mathrm{B}+\mathrm{F}$, and $\mathrm{H}$ ).

\subsubsection{The Directive and decision on the CE marking}

By way of a preliminary comment, it should be noted that it was not until very recently that the terms 'CE marque' and 'CE marking' have both come to be used side by side. Initially, all the documents adopted by the European Communities referred to the ' $\mathrm{CE}$ marque'. However, the expression which is to be adopted on a permanent basis is ' $\mathrm{CE}$ marking', so as to bring the terminology into line with the actual situation regarding this sign of conformity, which is not a marque in the usual sense of the term owing to the conditions relating to its application and also its significance, as will be seen later on (with regard to definitions, please refer to Part 1, Chapter 3).

As stated above, the conditions governing the application and use of the CE marking of conformity with the Directives had been highlighted by the Council of Ministers in its resolution of December 1989. The reason for this was the need to prevent any possible confusion between the $\mathrm{CE}$ marking and other marques or markings applied to the product.

With a view to clarifying the various concepts associated with the $C E$ marking, the European Commission proposed a 'regulation concerning the application and use of the CE marking(que) of conformity for industrial products' (Document COM(91) 145 end SYN 336) to the Council of Ministers in 1991. This draft regulation was submitted to the various authorities, which stated their position on this matter (Economic and Social Committee, European Parliament, Council of Ministers). 
Following discussions, the Council adopted two legal acts on 22 July 1993 (see OJ L 220 of 30 August 1993):

(1) Directive 93/68/EEC amending the 12 'new approach' Directives already adopted and also the 'low voltage' Directive.

(2) Decision 93/465/EEC supplementing the 'modules' Decision with provisions relating to the application and use of the CE marking.

Without going into details, these documents can be summarized as follows:

The CE marking is the visible sign indicating that the products are authorized to be placed freely on the market of the entire territory of the Community, and not simply to move within it.

The CE marking indicates, for checking purposes, conformity with all the provisions of the various Directives. It is first and foremost intended for the supervisory authorities of the various Member States, and not for the end-consumer. When several Directives providing for the CE marking apply to one and the same product, the application of the CE marking indicates conformity with all the applicable Directives. In this case, the OJ publication references for these Directives must be indicated in the accompanying documents, directions or instructions.

The CE marking does not indicate the conformity assessment procedure adopted; in other words, it does not specify the modules on the basis of which certification of conformity has been established.

The CE marking is in all cases applied by the manufacturer or his authorized agent, and not by the notified body which was involved (in the event that the module in question is one which provides for the involvement of a notified body). As a general rule, it is applied to the product or its packaging.

The CE marking is accompanied, if appropriate, by a code identifying the notified body involved. This code corresponds to the serial number assigned by the European Commission when the body in question is notified by a Member State. A single code is assigned per body, even if the latter is notified in connection with several Directives.

It is prohibited to apply to products or packaging any signs which might deceive the user as to the CE marking. It should be noted that the concept of deception covers not only shape (style, etc.) but also the significance of the signs in question (they must not cover characteristics covered by the Directive(s)). However, the application of other marques is possible provided that they do not reduce the visibility or legibility of the CE marking.

In order to be able to bring these provisions fully into force, the Community documents amend the various new approach Directives already adopted by introducing provisions governing the CE marking and, in the case of those Directives which did not yet contain them, provisions on the choice of modules. These elements modify the substance of the Directives only with regard to CE marking aspects, and any consequences which are directly associated with them. The examination of these elements which was undertaken in Part 2, Chapter 3 of this study is still therefore valid to a large extent. Finally, an extension of the CE marking to the low voltage Directive has been adopted. 


\subsubsection{Relations with third countries in the regulatory sphere}

When the resolution of 21 December 1989 on the global approach was adopted, it had been clearly recalled by the Council that the 'Community endeavour's to promote international trade in products subject to regulation'.

The Commission and the Council looked into the best ways of achieving this objective and came to the conclusion that there are two main ways of doing this without adversely affecting the integrity of Community legislation:

(i) The option of a notified body subcontracting work to a body located in a third country, under the same conditions as those which apply to this practice on the territory of the Community.

(ii) Direct recognition by the Community of bodies located on the territory of third countries, so as to carry out assessment and certification of conformity under the Directives.

In this case, it is necessary to negotiate agreements covering mutual acceptance by the parties of the certificates, marks of conformity and test reports issued by the bodies designated in the agreement, with regard to the assessment of conformity required in the sphere(s) covered by the agreement.

This second option, in respect of which the Council authorized the Commission to enter into negotiations by a decision of 21 September 1992, can be used only in certain cases. The reason for this is that, although Community legislation on technical harmonization is most certainly designed to achieve free movement, the latter may only be achieved on the basis of a high level of protection and safeguards for the fundamental interests of European citizens.

Granting bodies which are not located on the territory of the Community the same rights as for European bodies can therefore only be done subject to a number of conditions. These conditions are first of all geared to preserving the high level of safety enjoyed by European citizens and the trust which the various operators have in the mechanisms of the European market and, secondly, to enabling European enterprises, including operators involved in testing and certification, to gain access to the markets of third countries. under conditions which are no less favourable than those granted to these selfsame countries by the Community.

It is understood that future agreements will not be aimed at the mutual recognition of the parties' standards and regulations, and will only cover products originating from the parties under agreements within the meaning of Council Regulation EEC No 802/68 of 27 June 1968 relating to the common definition of the concept of origin of goods (OJ L 148 of 28 June 1968). In addition, agreements concluded by a third country with other parties outside the Community are not applicable. 
From the technical point of view, the conditions which apply to the signing of an agreement with a third country are the same as those which apply to the Community's notified bodies:

- the level of competence of the bodies concerned is the same as that required for Community bodies, and must be maintained at this level;

- agreements are restricted to duly designated bodies.

From the policy point of view, the Union will favour signatory countries of the GATT code on technical barriers to trade, in order to encourage support for the broadest possible multilateral policy.

From the economic point of view, agreements must be balanced with regard to the benefits which ensue for the parties. In other words, the Union will assess the practical results of any agreement with regard to market access for the products in question. Agreements will have to guarantee equivalent ease of access (which does not mean that formalities must be identical).

After all, it must be stressed that procuring a certificate of conformity for a product subject to Community legislation signifies immediate access to the markets of the $\mathbf{1 2}$ Member States of the European Union, which is not necessarily the case with certificates of conformity obtained in other countries, where the authorities or local practices may require additional formalities to be completed before market access is gained.

In this case, the certificate merely represents the first stage of the procedures to be followed. It is clear that such a situation would not constitute a balanced solution.

These provisions do not apply to the countries of EFTA since a number of general provisions are laid down under the agreement providing for the creation of the EEA (European Economic Area). 


\section{Organization of voluntary certification in the single internal market}

\subsection{Market access for products: Non-regulatory requirements}

We have seen in the chapter on technical barriers to trade that the procedures for approval, checking, certification, etc. enabling conformity of products to regulatory requirements to be established could in themselves constitute not inconsiderable barriers to the international movement of products.

Mutatis mutandis, the same phenomena often appear in the behaviour of business interests with regard to the application of voluntary standards: what could be more logical, if one is responsible for purchasing within a large enterprise, than concerning oneself with the proof of conformity of products for which one has signed a contract, under the technical conditions of this contract, which are often expressed in the form of reference to standards? What could be more natural than accepting as a method of proof mechanisms which operate either within the enterprise itself (e.g. quality assurance audit carried out by the specialized departments of the principals) or which are the responsibility of independent outside bodies which one knows, whose documentation one is used to using and in which one has confidence. Finally, what could be more natural for these independent bodies, in respect of which such inspection or certification activities for private purposes make up a large part (or even the entirety) of their turnover, than trying to develop customer loyalty and extend their client base by developing special services which are tailored to the specific needs of these customers and which one seeks to demonstrate are superior to other comparable services on the market.

These represent natural mechanisms whereby markets are compartmentalized and which, on the basis of the behaviour of business interests, are similar to the technical barriers to trade described above. It should also be pointed out that the most formidable barriers to trade are precisely those which result from an intimate combination of market practices and regulatory requirements, with the former legitimizing the latter and vice versa.

Quite obviously, the European internal market cannot function properly if such widespread practices are maintained, practices which increase product distribution costs and particularly penalize small and medium-sized enterprises. However, the institutions established by the Treaty of Rome are barely able to solve this problem by themselves, since it is the business practice of private operators which is involved. Only a process of a voluntary nature, geared around giving business interests incentives which are diametrically opposed to those resulting in the modes of behaviour mentioned above, is capable of getting results, i.e. establishing new practices which are generally accepted throughout the territory of the European single market. 


\subsection{The objective: To establish mutual recognition by winning the confidence of business interests}

Although some enterprises or professional circles are still keen on safeguarding their traditional national markets as a matter of priority, practices which seek to achieve economic growth by taking advantage of the opportunities afforded by the European internal market are multiplying. The selfsame national certifying bodies or laboratories mentioned above may thus come under pressure from their customers, who are interested in securing, with their help, access to the inspection or certification procedures practised on the markets which interest them: in order to win over this type of enterprise, certifying bodies or laboratories must be able to demonstrate their ability to give their services a European scope by developing networks of cooperation with equivalent bodies in other countries, and in any event by seeking to erase the specific national characteristics which stand in the way of a partnership with these foreign organizations.

To take a specific example, when a laboratory currently has to invest heavily in testing facilities for a particular market, a choice has to be made between two options: the first option involves methods and testing facilities sui generis, which may be hoped to give rise to a captive market as a result of the reputation gained by the laboratory; the second option involves methods and facilities which, in order to carry out tests to establish conformity with a specification which is increasingly taking the form of a European standard, is itself the result of concerted action between the main competent European laboratories, the objective of which is a testing or certification market with a European bias, but which is subject to real competition.

The second option will be chosen more frequently if the individuals responsible for the laboratory or certification system in question consider that the level of confidence which the business interests of other countries will have in their services is felt to be adequate by their own usual customers and enterprises in their country, with a view to supporting their exports to the European market.

Efforts to speed up shifts in the practices of laboratories, certification bodies and enterprises towards attitudes which further the integration of the internal market then boil down to the following question: by what mechanisms is it possible to promote the development of confidence on the part of business interests in the services of different testing or certification bodies from those with which they have long been used to working in their own country?

\subsection{The four essential conditions for instilling confidence}

\subsubsection{The existence of a recognized technical doctrine at European level}

As explained in Chapter 3 of the first part of this study, certification procedures intended for a broad range of enterprises or consumers are meaningful only in so far as customers 
are familiar with the reference system against which products are assessed and have a certain amount of faith in this system.

One basic condition which has to be met if recognized procedures at European level are to develop therefore revolves around the ability of business interests in several countries to be familiar with and think highly of the reference system proposed to them.

This objective may be achieved in several ways: dominant operators (manufacturers or certification bodies) can try to impose their reference system on as large a part of the European market as possible simply by commercial means. More often than not, however, the fragmentation of markets means that the only effective approach consists in defining a reference system acceptable to the main business interests by means of negotiation.

By and large, European harmonization is then the prime channel via which such harmonization of certification reference systems takes place. This means that European standards deal with all the test specifications which make it possible to carry out product certification in accordance with a common methodology.

Other possible channels exist, however: laboratories and certification bodies may, in a private context, try to secure European agreements; public authorities may also, as part of their economic policies, promote the development of work of this kind on the harmonization of reference systems: one example of this is the voluntary European procedure for labelling and certifying products which are least harmful to the environment, a procedure established by EEC ruling No $880 / 92$ adopted by the Council of Ministers on 23 March 1992 and published in OJ L 99/1 of 11 April 1992.

\subsubsection{Negotiations between suppliers and customers, on a sector-by- sector basis, at European level}

When harmonization of the certification reference system has been achieved within the framework of European standardization, it is evident that the process whereby consensus is arrived at, is also aimed at producers and their customers; the latter will therefore already be prepared to accept the use of these standards in connection with certification procedures operating at the level of the European market.

Even in this favourable case, however, experience shows that operators on the market in one country will often be highly reticent to recognize certificates issued by the certification system of another country.

In order for such feelings of reluctance to be moderated, a close relationship must exist between the business interests of the various countries so as to ensure that the benefits to be gained from mutual recognition of national certificates - which arise from not repeating the procedures on the various markets - will be equitably distributed, and also that there will be no undesirable effects on the markets as a result of the mutual recognition agreements. 
These negotiations are often complicated by the fact that major differences may exist in the ways in which the certification systems actually operate, or in their actual commercial influence, depending on the countries involved, even if the technical reference systems are identical.

It is mainly to facilitate contact and then negotiations between business partners which may result in mutual recognition agreements that the EOTC was set up, with a role of paramount importance being given to the Sectoral Committees, which are authorized to bring together the parties involved in the various major economic sectors.

\subsubsection{The ability of technical bodies to establish technical and commercial cooperation}

No mutual recognition agreement can function satisfactorily unless the certification bodies, laboratories and inspection bodies involved in it, have built up relationships of trust so that the many incidents which may arise in the course of technical operations (differences in the interpretation of test results, for instance) serve to strengthen joint control of problems and do not feed arguments at the expense of the client companies.

To achieve this outcome, it is also necessary for the parties responsible for the certification systems to be fully involved in negotiations aimed at establishing mutual recognition agreements. It is also necessary that ideas can be exchanged by the various teams of technical staff involved, so as to create a climate of cooperation in so far as is possible.

Finally, these negotiations must have a commercial element: price-fixing arrangements for the various procedural elements and the commercial and legal mechanisms which enable certification marks for one system to be granted on the basis of another differ according to circumstances and are sometimes difficult to finalize.

Here lies another objective of the EOTC: the task of developing, within Europe, a capability to assist the progress of such negotiations by accumulating information and experience on the various situations encountered.

\subsubsection{Overall political will to achieve the objective}

Enterprises, customers, laboratories, etc. exist in most sectors of activity which, particularly as a result of their positions on the market, would be willing to work towards the coordination of European agreements establishing harmonized certification and testing systems. However, these selfsame sectors are also characterized by powerful constraints which run counter to such moves. Making it easier to deal with the difficult question of establishing mutual recognition agreements is not necessarily enough. It is also necessary to offer those undertaking such negotiations a certain degree of political and economic clarity, and to create a legal framework which can 'sanctify' these arrangements with a view to developing their economic impact and reputation on the markets. 
This is still one of the main tasks which the EOTC was set up to address, and a factor which has led the main parties involved. in technical harmonization to support the development of this new organization.

\subsection{Existing European certification agreements}

In order to have an economic impact which is not purely marginal, agreements on reciprocity and cooperation in the sphere of certification must be based on technical specifications which enjoy a degree of harmonization between the various countries involved in such agreements, which is extensive enough to be recognized not only by certification operators but also by the market as a whole.

This is the reason why the historical precedence of standards harmonization in the electrotechnical sector quite naturally led to this sector playing a pioneering role in the harmonization of certification practices as well. Experiments carried out in other sectors have also been brought into play more recently, and have had a more restricted impact. Nevertheless, it may be expected that the rapid progress of European standardization over and above the electrotechnical sector - will, with the active support of the EOTC, lead to a major increase in certification agreements and their economic significance within the next few years. This section therefore examines the main European certification agreements existing in 1993, starting with the electrotechnical sector which, overall, has historical precedence in this sphere.

There are, of course, a large number of other bilateral agreements which enable a testing or certification body to offer its foreign customers a better service, by calling on the services of another body located in the country of origin of these customers. A systematic register of such agreements does not exist at the present time. In addition, these agreements are obviously not confined to the European context, and a number of them involve parties in the USA, Canada, the Far East, etc.

Finally, this section does not describe existing European agreements on the mutual recognition of national systems for accrediting test laboratories, reference calibration facilities or quality assurance.

Operational information on the various certification services which exist within European Union and EFTA countries can be accessed via the Certificat database, which is available in hard-copy or electronic form; this system was developed by AFNOR, with contributions to its initial investment having been made by the EC, EFTA and CEN and with the national members of CEN having been involved in the provision of data.

\subsubsection{The electrotechnical sector}

\subsubsection{The CCA (Cenelec Certification Agreement)}

This Agreement came into being in 1968, but was revised in 1973 as a result of the signing of the low voltage Directive, which established the equivalence of national certification 
marks on a statutory basis provided that such marks are based on harmonized standards. The Agreement enables national marks of conformity to be issued on the basis of tests or certificates issued in another country, in accordance with the same standards.

This Agreement has been signed by 17 certifying bodies in the electrotechnical sector which are established in the Community and EFTA countries, and is based on the principle of a single partner per member country of Cenelec for each product or category of products.

The Agreement relates to low-voltage electrical equipment within the meaning of Directive $73 / 23 /$ EEC. In practice, it covers domestic electric appliances, electrical components, electronic appliances, luminaires and their fittings, and appliances for electrical installations (in the electromedical field, for example). This Agreement also covers specific aspects such as standards relating to electromagnetic interference.

In 1991, close on 5000 products were the subject of test reports which were officially notified under this Agreement, leading to national certificates being issued by the competent bodies in countries which had not carried out the tests.

\subsubsection{The HAR Agreement}

This Agreement, which was concluded in 1974 and revised in 1989, covers electrical wiring and cabling which conforms to European standards. A number of bodies in $16 \mathrm{EC}$ and EFTA countries have signed this Agreement, which is based on the involvement of a single certification body per country.

The agreement allows for the issue of a single European mark (HAR) accompanied by the national logo, with this mark being uniformly recognized by all the signatory bodies of the participating countries.

Conformity tests are carried out on the basis of standards adopted by Cenelec, and the Agreement provides for the carrying out of inspections and monitoring of production units based on the specifications of standard EN 29002 to be introduced with effect from 1996.

In 1991, some 222 enterprises had been issued with nearly a thousand HAR mark licences.

\subsubsection{The CECC (Cenelec Electronic Components) Agreement}

This Agreement, which was signed in 1970 by 15 certifying bodies drawn from the countries of the EC and EFTA, allows for the issue of certificates for electronic components, with these certificates being mutually recognized by the signatories. Certificates may relate to the issue of a European mark, the quality assurance of products, distributors or test laboratories, or to the type-approval of electronic components.

The tests and inspection procedures are carried out in accordance with CECC-approved specifications by national. inspection bodies recognized by the CECC. 
In 1991, some 269 manufacturers, 121 distributors and 40 test laboratories had been issued with CECC certificates, with 2590 groups of components having been certified.

\subsubsection{Emedca (European Active Medical Device Certification Agreement)}

This Agreement, which was concluded in 1991 by 13 certification bodies drawn from 13 EC and EFTA countries, is aimed at the mutual recognition of conformity tests carried out with a view to awarding national marks of conformity, on the basis of standards adopted by Cenelec (EN 60601, Parts 1 and 2) which are themselves based on standards adopted at international level by the IEC. This Agreement, which was introduced recently, has not yet been the subject of significant applications from the economic point of view.

\subsubsection{The LOVAG (Low Voltage Agreement Group) Agreement}

Like the CCA, this Agreement, which was concluded in 1991 by five national bodies drawn from the countries of the EC and EFTA, relates to low-voltage electrical equipment; this Agreement allows for the issue of harmonized certificates of conformity as a result of a strengthening of coordination between the bodies concerned with regard to the practical interpretation of standards, the presentation of test results, and administrative aspects.

\subsubsection{The STL-A Agreement}

This agreement, which was concluded by six testing bodies drawn from the countries of the EC and EFTA, relates to the recognition of short-circuit tests performed on highvoltage equipment.

It enables standards to be uniformly applied in the course of testing, allows for the issue of a test and certification report in accordance with a harmonized format and, if appropriate, makes it possible to organize a system for marking appliances.

\subsubsection{The LUM Agreement}

This Agreement, which was concluded in 1992 by 15 testing and certification bodies which had already signed up to the CCA, relates to the award of a mark of conformity for luminaires which conform to European standards.

It represents something of an extension of the CCA in that the signatories to the LUM Agreement must already have signed the CCA. The LUM Agreement specifies that the European mark of conformity for luminaires is to be based on tests of conformity to the EN 60598 series of standards and also the results of production inspections carried out in accordance with standard EN 29002 with effect from 1995. 


\subsubsection{The EMCEL Agreement}

This Agreement, which was concluded in 1992 by nine laboratories in seven EC and EFTA countries, relates to the mutual recognition of test results for electrotechnical appliances (including electronic appliances) in the field of electromagnetic interference.

This Agreement will make it possible to issue, in accordance with a harmonized format, test reports drawn up in accordance with harmonized protocols and in conformity with international standards. Under this Agreement, the test protocols used will be made public if they are not (yet) described by the standards.

\subsubsection{The Cencer certification system}

\subsubsection{Objectives and development of the system}

Cencer, which was initiated by CEN in 1983, was developed with a view to offering the business interests involved in the process of harmonizing European standards within the framework of the Technical Committees, a means of speeding things up so as to reduce technical barriers to trade caused by national procedures of certification of conformity to these standards.

This framework, which is described in Part 3 of CEN's Rules of Procedure and validated by the organization, in principle offers two options for putting negotiations in the field of certification in concrete form:

(i) with the first option, the market players wish to continue to operate certification solely through the national systems and marks of conformity; in this case, the Cencer rules specify that the outcome of the negotiations should result in a satisfactory level of harmonization of the conformity tests and inspection procedures which allows the various national systems to operate on the basis of tests and checks carried out via its own procedures, or via procedures developed by other systems under a Cencer agreement for a specific product.

Although a minimal approach of this type will always necessitate administrative processing of certification applications in each country, this approach safeguards the national marks of conformity which consumers are used to in certain sectors and countries.

(ii) with the second option, the market players wish to operate in a unified market where, in so far as this is possible, the repetition of national procedures will be eliminated: in this context, the Cencer system offers the possibility of a single European mark which is valid in all CEN countries and which will be assigned to a specific product, in accordance with fully harmonized standards, in any country in which the organizations participating in the system are located.

With both options, a committee (known as CCC: CEN Certification Committee) is set up for each product at the request of the market players, initially with the aim of bringing the technical negotiations needed to create the system to a satisfactory conclusion, and 
subsequently, when the system is up and running, in order to monitor operations and provide the necessary coordination.

Until 1992, this system had few specific applications owing to the fairly slow emergence of European standards which must incorporate, for a specific product, not only product specifications and test methods but also conformity assessment procedures.

Since 1992, a combination of two important factors has speeded up events:

(i) firstly, the emergence of the EOTC as a forum in which new stimuli will gradually facilitate the creation of a larger number of mutual recognition agreements for testing and inspection results between a whole series of organizations, outstripping the number of national standards institutions in CEN;

(ii) secondly, the creation of the internal market is becoming a reality: since 1993, European standards have increasingly become a commercial reference on the market for a growing number of products. As a result, the interest expressed by the market players in solutions which simplify conformity assessment throughout Europe is growing considerably.

The speeding-up of technical activities within the CCCs is the direct consequence of such a development and several new operational agreements should be concluded in 1993/94.

Another consequence is that CEN has initiated a reform of its rules whereby it manages certification work.

This reform process is aimed at providing industry and other market players with a sophisticated service while at the same time taking account of the development of an overall European organization, particularly with regard to the setting-up of the EOTC structures.

\subsubsection{The spheres of application of the Cencer system}

Thermostatic valves

This agreement, which has been operational for several years, allows for the CEN mark to be granted to products which conform to standard EN 215-HD 1215, following conformity tests and an inspection of production sites. Two laboratories and inspection bodies from eight EC and EFTA countries are collaborating on the operation of this agreement, which currently covers 21 manufacturers representing the major part of the European market for these products.

Taps (sanitaryware), ceramic tiles, plastic piping, terracotta piping, copper piping, concrete conduits, radiators and heat exchangers, and plywood structures are currently the subject of activities to prepare the way for the conclusion of specific agreements. Some of these agreements could be operational by 1994. 


\subsubsection{The information technology sector}

Users have for a long time pressed for computer equipment, even if produced by different manufacturers, to operate compatibly within networks.

This pressure has led to a set of standards being drawn up in accordance with a concept known as OSI (Open Systems Interconnection), which is intended to harmonize the architecture elements of computer products relative to interface functions. In this field as in others, however, the demonstration of actual compatibility, as verified during tests and carried out in accordance with protocols which are independent of the manufacturer, remains a central element. Additional harmonization work has therefore been initiated with a view to defining protocols for European (or international) tests.

Quite naturally, the organizations which are competent to perform these tests, and which have by and large been involved in drawing up these harmonized protocols (often as part of research programmes financed by the Commission), have banded together to establish mutual recognition agreements for their test results. This activity is fully coordinated by an EOTC sectoral committee, the ECITC (see Section 5.5.).

\subsubsection{Open Systems Testing Consortium (OSTC)}

This agreement, which been operational since 1990, was signed by 13 testing bodies from eight EC and EFTA countries, and has been officially recognized by the EOTC since 1992.

The testing services covered by this agreement essentially relate to conformity with international and European OSI standards concerning MHS, FTAM, 'Directory Services', 'Network Management', 'Transport and Session' and ISDN. With regard to MHS and FTAM, the agreement also provides for the mutual recognition of certificates of conformity.

\subsubsection{European Testing Consortium for Office and Manufacturing (ETCOM)}

This agreement, which has been concluded by 11 laboratories from seven European countries, provides for the mutual recognition of tests of conformity to OSI standards for products relating to local networks.

\subsubsection{European testing of electromagnetic compatibility of information technology products (EMCIT)}

This agreement, which brings together 23 laboratories from 11 European countries, provides for the mutual recognition of test results for computer hardware with regard to emissions, electromagnetic radiation and sensitivity to such radiation in accordance with specifications laid down by European and international standards. 


\subsubsection{Assessment and certification of quality systems in information technology (ITQS)}

This agreement brings together 10 organizations which are competent to carry out audits and certification of conformity to the specifications of the ISO 9000 series of standards on quality assurance, in the field of information technology.

\subsubsection{GLATC}

This agreement, which brings together seven laboratories from four European countries, covers the mutual recognition of validation tests for graphics systems (CGJ, GKS, $\mathrm{CAD} / \mathrm{CAM}$ ) and language compiling (COBOL, Fortran, Pascal, C).

This agreement had initially been negotiated as part of the Cencer system.

\subsubsection{Triple X Agreement Group (3X AG)}

This agreement, which was recently concluded by three bodies, aims to provide harmonized testing and certification services to European standard ENV 41901 relating to protocols for the interconnection of information systems.

\subsubsection{POSIX Agreement Group for Testing and Certification (POSAT)}

This agreement has been concluded by four bodies from three countries and is designed to provide a harmonized service of testing and certification of conformity to standard ISO/IEC 9945 relating to POSIX products.

\subsubsection{European Fire and Security Group}

This is a cooperation agreement concluded by three bodies which come under the aegis of associations of insurance companies in three countries (Germany, England and France). The inadequacy of harmonized specifications or standards and regulatory divergences in this sector are still such that, as it currently stands, this agreement cannot function as a true mutual recognition agreement.

\subsubsection{Quality assurance: $E Q-N e t$}

In recent years, a number of certification bodies have been set up, or broadened their activities, in the sphere of conformity assessment and certification to the EN 29000 series of standards (ISO 9000 series): one of the prime aims of these standards and also the existence of third-party certification in this area was to eliminate the excessive duplication of quality assurance audits by second-party customers, and it was essential for the 
credibility of certification bodies to eliminate the risk of enterprises being certified by several certification bodies for different countries or customers.

Although no multilateral mutual recognition agreements exist at the present time, this led to 20 bilateral agreements, with some of these agreements having a considerable impact on the equivalence of certificates and cooperation between the signatory organizations.

A specific European forum, EQ-Net, has been set up by 17 European certification bodies with a view to developing collaboration in areas of mutual interest. For example, it has been possible to provide, via EQ-NET, a service of coordinated audits for companies wishing to be certified, although these companies have to (or prefer to) go through several national certification bodies because they have production units in these countries.

\subsection{The EOTC: European Organization for Testing and Certification}

\subsubsection{Background}

Following the Council of Ministers' resolution of 21 December 1989, negotiations continued between four of the main European parties involved in implementing the new approach - namely, the European Commission, the Secretariat of EFTA, CEN and Cenelec - with a view to setting up a system allowing for the mutual recognition of testing and certification on a voluntary basis.

The key sentence of the Council resolution which lay behind this initiative should be recalled: 'The promotion of mutual recognition agreements on testing and certification between bodies operating in the non-regulatory sphere is essential for the completion of the internal market.'

The reason why the four bodies involved, which are not naturally responsible for dealing with these matters on an institutional basis, took charge of this process was the absence of any other parties organized in a representative way at European level in 1989.

The prime challenge in this sphere consists in the number of parties involved: in the case of operators alone, the Certificat database mentioned above lists more than a thousand bodies which are competent to issue certificates in Europe! Not to mention manufacturers (both customers and principals in this area), consumers, associations and the public authorities, which do not necessarily play a direct role but which are involved in ensuring compliance with a number of basic rules and 'approving' bodies, etc. In 1989, therefore, no forum existed for all the parties involved simply because there were so many of them, but also because up to that time there had been no incentive in Europe to unite.

It was against this background that the four parties mentioned above agreed on a memorandum of understanding to set up the European Organization for Testing and Certification (EOTC); this was done in a relatively short space of time since the memorandum was signed on 25 April 1990, i.e. less than six months after the Council of Ministers' resolution had provided the initial impetus. 
Following a two-year trial period, it was decided to establish the EOTC as an international non-profit-making association registered in accordance with Belgian law, whose statutes were approved by the authorities on 17 April 1993. In fact, the EOTC is run quite independently of the original signatories of the memorandum of understanding.

\subsubsection{Description}

\subsubsection{Objectives and principles}

As shown earlier on in this chapter (Section 5.3.), success with mutual recognition can only be achieved if a number of conditions are satisfied. The principles on which the EOTC is based therefore take account of these conditions and can thus be inferred from the memorandum:

Economic usefulness for the European market, primarily for manufacturers, though also for the end-consumer: the EOTC must aim to achieve savings in the procurement of voluntary certification and test reports by reducing the need to go through several bodies in order to gain access to the various national markets in Europe. In addition, the EOTC must, if possible, ensure that the systems on offer really meet the needs of the market.

Effectiveness: in a sphere in which a large number of players are involved and in which the interests of the various parties are not necessarily convergent, it has been felt to be essential to give priority to the sectoral approach, i.e. encouraging the various sectors of industry to organize themselves by using the framework provided by the EOTC.

Creating trust: as has repeatedly been seen above, this is essential for success. The EOTC must therefore do everything possible to promote greater mutual awareness between the various players and establish solid foundations on which agreements can be negotiated. This is why the key words of the EOTC are transparency (of procedures) and representativeness.

The highly liberal nature of the approach adopted within the EOTC should be stressed. In this respect, it is interesting to note that neither the Council of Ministers' resolution of December 1989 nor the memorandum of understanding setting up the EOTC provide any clues on the fundamental question of whether priority should be given to a European mark or to national marks. Of course, this is not an oversight but an intentional omission.

The reason for this is that although it might appear at first sight that the European mark constitutes a universal panacea for the free movement of goods in the voluntary sphere (in the same way as with the CE marking in the regulatory sphere), numerous studies have shown that this is not the case because, in the voluntary sphere, national marks of conformity or safety have over the years built up a commercial image in the various countries, and it is these particular marks and not any old mark which are requested by the various business interests. It was therefore felt to be more efficacious, in most cases, to opt for mutual recognition of tests and marks, so as to respond better to the requirements of customers by providing them with products bearing the mark which they recognize, rather than opting to create European marks which would replace the existing national marks. 
In new-technology sectors, however, or in areas where known marks do no not exist, it is clear that it might be advantageous to resort directly to European marks, with the consumer not being used to any particular national mark.

\subsubsection{The role of the EOTC}

On the basis of these objectives and principles, the role of the EOTC, which provides a partnership with all the parties involved in the social and economic spheres, can therefore be defined as follows:

To provide a forum for formulating/adopting criteria for accepting recognition agreements on testing and certification; it is not a question of substituting these for the criteria formulated within the framework of standardization, which relate to the quality of the services provided by the various operators and players (the EN 45000 and EN 29000 series of standards), but of giving guidance to the various operators who comply with the aforementioned European standards so that they can negotiate agreements under conditions which are transparent and recognized by all.

Two sorts of trust are thus involved here: trust between operators, who must comply with the European standards in order to have access to mutual recognition agreements, and trust on the part of all the other parties, who are familiar with the conditions under which these agreements are signed and implemented.

To recognize agreements on the basis of the criteria adopted: this does not mean an accreditation procedure, which would involve technical checks on the premises of the various operators who have applied for the 'blessing' of recognition agreements for tests or marks which they reach with their partners. After all, such a procedure would mean duplicating the exiting national procedures, and would inevitably result in the creation of additional bureaucracy.

However, it is of fundamental importance for the credibility of the whole system that the members of the EOTC forums and the EOTC secretariat who are called on to recognize agreements (the sectoral committees or the Board, as the case may be) actually ensure that the conditions (including those on transparency) laid down by the EOTC in this area are adhered to by the signatories. To this end, the EOTC adopted guidelines in 1991 which stipulate, among other things, that agreements must be effective with regard to recognition (good intentions are not enough), the need for compliance with the EN 45000 standards concerned, etc.

To promote these agreements: this EOTC objective is based on two ideas. First of all, what would be the use of an agreement which would remain confidential? Manufacturers must be able to know the opportunities offered to them with regard to mutual recognition so that they can make the most of them, initially within the context of the internal European market, and perhaps subsequently on international markets.

In addition, operators (testing and certification bodies) which conclude agreements do not necessarily have any immediate interest in doing so, with the apparent mechanical effect consisting in decreasing their market. However, the publicity devoted to them via the promotion of agreements helps in some way to 'correct' any loss in turnover and 'reward' their conduct. This publicity also enables them to attract new customers in the form of manufacturers to whom they can thus offer a broader range of services. 


\section{Structure of EOTC}

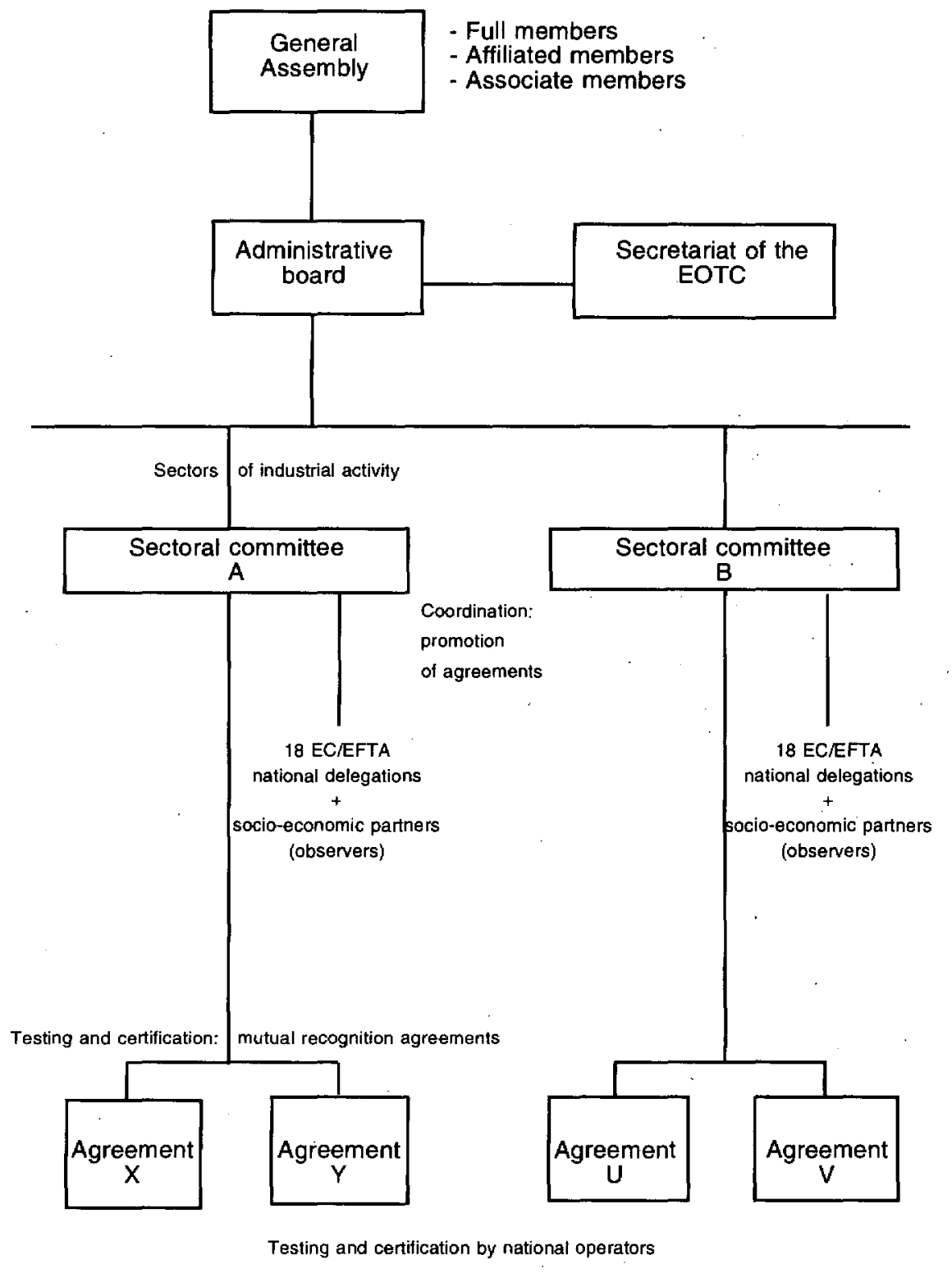


As a result, one of the first promotional initiatives undertaken by the EOTC has been the publication of a 'Register of recognized agreements', which is available to all interested parties.

\subsubsection{The current structure of the EOTC}

The EOTC has a 'bottom up' structure, for reasons of efficiency, and operates according to the principle of putting the emphasis on structures which bring the business interests concerned directly together, thus allowing for a management approach which gets as near as possible to the interests and needs expressed by the market.

The various operational elements of this structure (shown in the organization chart on the preceding page) are as follows: agreement groups, sectoral committees, an Administrative Board and a General Assembly.

The agreement groups form the very foundation of the EOTC. They bring together parties who have decided to sign one or more agreements recognizing the equivalence of the services provided by all concerned. Such services may relate to products, services or even disciplines (e.g. metrology). In order to be recognized, agreement groups must meet a number of conditions and must submit their application either to the sectoral committee under whose aegis they come or to the General Assembly of the EOTC itself if they are not covered by a sectoral committee.

The main conditions, as defined by the EOTC in 1991, are as follows:

- an agreement group must bring together signatories from at least three European countries, and must be open to members from other European countries under conditions which are equivalent to those offered to the constituent members; this final element may involve an 'entry fee' for new signatories, taking account of the investment made by the preceding signatories;

- the signatories of the agreement group must comply with those standards of the EN 45000 series which apply to them;

- the agreement must have as its objective either the mutual recognition of testing or calibration results, inspection reports, product certificates or quality systems; or the harmonization of procedures for calibration, testing, inspection, certification and/or accreditation;

- the agreement must be effective in order to come into force: the EOTC does not recognize good intentions.

Recognized agreement groups are listed in a public register published by the Central Secretariat of the EOTC. There are nine such groups at the present time (see Appendix 8).

The sectoral committees are made up of national delegations representing all the parties involved in conformity assessment activities in a particular sector, i.e. manufacturers and users, end-consumers, standardizers, public authorities, etc. In addition, representatives of agreement groups covering agreements concluded in this sector and also representatives of interested European organizations may participate as observers. 
The main object of the sectoral committees is to promote the signing of groups of agreements in their sector in an orderly way. The sectoral committees are also responsible for ensuring that agreements concluded in their sector meet the criteria defined by the EOTC, not only during the recognition phase but subsequently as well.

Two sectoral committees have so far been recognized by the EOTC: Elsecom in the - electrotechnical sector, and the ECITC in the information technology sector. A further sectoral committee covering the water sector has been recognized on a provisional basis.

The Administrative Board is made up of a limited number of members of the General Assembly (9). It is involved in managing the organization and prepares the work of the GA.

The General Assembly: this body is made up of delegates from the 16 States of the EC and EFTA (Iceland, Luxembourg and Liechtenstein are not members), each representing the interests organized directly at European level (industry, consumers and associations).

It also comprises advisers in the form of representatives from the four signatory parties of the memorandum of understanding setting up the EOTC (EC, EFTA, CEN and Cenelec), which were joined by ETSI in 1992 and a number of groupings bringing together operators at European level such as Eurolab (testing laboratories), WECC/WELAC (calibration, accreditation of laboratories), etc.

Affiliation to the General Assembly as an Affiliated Member is open to any national testing and certification body which is not a member of the countries of the European Union or EFTA, but which is planning to join these organizations. There are no affiliates at the present time, though discussions are under way with potential applicants in mind.

Affiliation to the General Assembly as an Associate Member is open to any non-profitmaking organization at European level which is interested in the work of the EOTC and in promoting its activities, and which does not have links with any category of affiliation. The first associate member of the EOTC is FEACO (European Federation of Management Consultants' Associations).

The role of the General Assembly is to decide on the EOTC's strategy and its budget, coordinate the activities of the various operational elements of the structure to prevent the possibility of overlap, recognize sectoral committees and agreement groups where sectoral committees do not exist, promote the link between standardization and conformity assessment activities, provide a last-resort appeal body in the event of disputes and, of course, generally promote the association's objectives.

The Association's administrative activities are supported by the Secretariat of the EOTC, which is located at Egmont House, rue d'Egmontstraat 15, 1050 Brussels (Tel.: 3225024141 , Fax: 322502.4239 ). 
Part 3: Relations between Europe and the rest of the world 


\section{Access for third countries to standardization and certification: The principles}

The countries of Western Europe are essentially exporters. It is therefore obviously in their interests for world trade to be as highly developed as possible. This is the reason why CEN, Cenelec, ETSI and the EOTC have always applied a policy of openness to the rest of the world, while at the same time retaining their freedom of action and their willingness for European unification.

More than that, the basic principle which underlies European harmonization is the principle of subsidiarity with respect to international harmonization: in other words, whenever an international standard exists on a particular subject, $\mathrm{CEN}$ and Cenelec make the greatest possible use of it to draw up the European standard. The same applies in the case of ETIS. As regards the EOTC, this organization is still too young to have established relations with countries outside Europe, with its priority up to now clearly being the European market. Be that as it may, all the events which it has organized have been open to any participant, from whatever country, while its secretariat has always responded to requests for information from whatever quarter.

Finally, it should be recalled that all the countries of Western Europe are members of GATT, are signatories to the Code on Technical Barriers to Trade which will be examined below in Chapter 3, and place their trading policy within the context of the principles which apply within this organization.

In addition, the fact that a product originating from a third country can be traded freely and now has to comply with only a single common rule for all the countries of the European Union (and soon EFTA) represents enormous progress with respect not only to the previous situation but also the situation which still prevails in many non-European countries, including the largest ones.

When the European policy to create a single internal market was put in place, the political authorities of the Community and the European standards institutions decided to place their actions resolutely within a context of openness to international trade. In this light, they felt it necessary to initiate a process explaining the measures which were going to be taken across the world, particularly in the United States, they adopted measures guaranteeing the transparency of their activities and decided to conclude agreements with ISO and the IEC in order to bring European standardization closer into line with international standardization. 


\subsection{Relations with countries authorized to form part of the European Economic Area}

The period 1989-90 saw the collapse of the planned-economy regimes of the countries of Central and Eastern Europe. Standardization and certification in these countries had been organized in a completely different way from countries with free-market economies. The reason for this was that all these systems were controlled by the State administration and were closely linked with economic planning. To give some idea of these systems, it could be pointed out that standards were drawn up by the standards institution or the administrations without any reference to the usual procedures of consensus, that compliance with them was mandatory, and that the Director-General of the standards institution in the various countries in question was a senior official, generally holding the rank of vice-minister. Finally, there was some level of harmonization of standards between the various countries within the framework of Comecon or the CMEA (Council for Mutual Economic Assistance).

When these countries decided to change their economic systems and align themselves with the economic systems of western European countries, the question arose as to what would become of their standardization/certification/quality systems. After all, the adoption of a free-market economy pre-supposes that the corpus of rules governing the economy are also freely based.

The geographical and cultural proximity of the countries of Central and Eastern Europe meant that they quite naturally turned to their western European neighbours in this connection.

In 1990, the European standards institutions and the European Community, each within the scope of their powers, adopted the necessary measures to provide their neighbours with the required support.

\subsubsection{The status of affiliate to CEN and Cenelec}

At their General Assemblies in 1990 and 1991, CEN and Cenelec adopted resolutions which were intended to facilitate the integration of the countries of Central and Eastern Europe into the European standardization process by granting them a special status, namely that of 'affiliate'. It should be recalled at this point that ETSI, like the CEPT, was already open to these countries.

Under the terms of resolution CEN/AG/5/1990, affiliate status may be granted to the standards institution of one of these countries under the following conditions: the country concerned must be a European one with close links with the EC or EFTA (i.e. likely to become a member thereof) in the technical, scientific, political and social spheres.

Applications are examined on a case-by-case basis with special account being taken of the positions of the EC and EFTA, as expressed by the EC or the Secretariat of EFTA, and consideration being given to the situation of these countries from the point of view of ISO/IEC and GATT. 
Affiliate status is granted unanimously by the members of the General Assembly of CEN and Cenelec respectively.

It should be stressed at this point that the various countries of Central and Eastern Europe have always had a single standards institution for all the sectors of activity of the economy, and that those bodies which are liable to apply to Cenelec for affiliate status are the same as those which are likely to apply to CEN for the same thing. Since affiliate status is governed by identical conditions in the case of CEN and Cenelec, the term 'CEN' should be taken to denote 'Cenelec' as well, and vice versa, in what follows.

In return for an annual membership fee, affiliate status confers the following rights and obligations:

\section{Right to take part in meetings}

These bodies are entitled to attend meetings of the General Assembly, Technical Committees and Sub-Committees as observers and, consequently, to receive all documentation of relevance to these various meetings. With regard to participation in working groups, the participation of these bodies is left to the discretion of the authority responsible. affiliates cannot sit on the Administrative Board, the Technical Board or Technical Sector Boards, or take part in Cencer.

It should be noted that the representatives of the affiliate must be officially appointed by the latter, otherwise they cannot attend the various meetings. Such appointments are made at the Secretariat of the authority responsible, with a copy being forwarded to the Central Secretariat of CEN in all cases.

Right of access to the publications of the European standards institutions

NB: these policies are not yet definitive and may change in future years.

- European draft standards: All European draft standards are sent to the affiliate at the same time as to the members (CEN/Cenelec inquiries and drafts subjected to a formal vote); affiliates are entitled to pass comments on draft standards and also to reproduce and sell them, but solely in their country.

- Official publications: Affiliates are entitled to translate and apply European publications (ENs, HDs, ENVs and CRs) in their country. They are requested to ensure that conflicting national standards are withdrawn when this is feasible, and to proceed with implementation in accordance with CEN's Rules of Procedure and the PNE rules (rules on the presentation of European Standards) as well as rules on the numbering of standards; when the withdrawal of national documents is impossible, the affiliate must notify the Central Secretariat of CEN of the references of these documents.

- Other publications and information: affiliates receive copies of CEN's promotional and information documents, and also copies of the ICONE and Infopro registers, following agreement by the EC and EFTA.

The standards institutions of the following countries have to date been granted CEN affiliate status: Bulgaria, Cyprus, Hungary, Lithuania, Poland, Romania, Slovakia, Slovenia, Czech Republic and Turkey. The same countries, apart from Bulgaria, Cyprus and Lithuania, are also affiliates to Cenelec. 


\subsubsection{The PHARE programme}

As from 1989, the European Community has taken measures to help the countries of Central and Eastern Europe in their transition to market economies. Numerous aid programmes have been adopted in various spheres. With regard to standardization, metrology, quality and certification, aid projects are being carried out as part of a programme known as PHARE (action plan for coordinated aid to Poland and Hungary); this programme was initially devised solely for Poland and Hungary but has since been extended to cover all the countries of Eastern Europe, including the Baltic States, Slovenia and Albania.

It should be noted that the Commonwealth of Independent States has a specific programme known as TACIS. Aid provided under the PHARE programme between 1989 and 1992 totalled around ECU 2.5 billion.

The programme is financed by annual grants in the form of donations defined by the EC budget. This programme is also open to co-financing, either by a Member State via a defined programme or by non-member States such as the EFTA countries.

Under PHARE, a specific sub-programme known as PRAQ (regional quality assurance programme) has been set up for assistance on standardization/quality/certification/metrology; this programme is intended for the same countries as those benefiting from the PHARE programme, with $14 \%$ of all support being provided by the EFTA countries.

PRAQ has three main objectives:

(i) to improve the quality of goods and services available in the countries of Central and Eastern Europe,

(ii) to facilitate trade between the countries of Central and Eastern Europe and those of western Europe,

(iii) to stimulate exports from the countries of Central and Eastern Europe to industrialized Western nations.

As things currently stand, the countries covered by the PHARE programme need institutional and legislative reforms with regard to metrology/standardization/certification/quality, and the programme is made up of four main parts:

(i) ' technical assistance in reforming legislation and institutions,

(ii) a fund for training by Western institutions,

(iii) a fund to promote technical exchanges with Western Europe,

(iv) technical and financial assistance to make business interests aware of the standardization, certification and quality assurance process.

Management of this regional programme has been entrusted to CEN's third-country unit (see Section 1.3 below). However, the Commission reserves the right to manage directly certain initiatives which do not form part of this programme. 


\subsection{Relations with other countries}

Relations between CEN/Cenelec and the countries outside Central and Eastern Europe are also governed by special arrangements which are intended to establish transparency and trust. This matter is one of several which, where possible, is dealt with within the Joint Presidents Group so as to come up with common positions for the European standards institutions, or at least for CEN and Cenelec, with ETSI having a different structure (see Part 1, Section 2.2.4. on ETSI). As a result, CEN and Cenelec have (apart from their own documents) adopted a common position which is reproduced in a letter of 27 June 1989 signed by their two Presidents and sent to the Presidents and Secretaries of all the technical bodies of CEN and Cenelec.

With regard to CEN, this letter forms the reference document, although it is supplemented by the Vienna Agreement signed with ISO (see Chapter 2 below).

With regard to Cenelec, the reference document is Memorandum No 16, which was adopted in 1991 and which explains the main lines of relations between Cenelec and the IEC on the one hand and between third countries and Cenelec on the other.

The principles of this common policy of openness are as follows:

Access to the standards programmes of CEN and Cenelec is not only free, but welcome; standards institutions in third countries are also able to comment on this programme, and this includes making suggestions on additions and changes.

In the same way, European draft standards are accessible to anyone requesting access to them, and it is possible for a third-country standards institution to arrange for observations to be passed on to CEN and Cenelec, with these two organizations taking account of such observations where possible. CEN and Cenelec may, if need be, go so far as to organize a meeting so that parties outside Europe can set out their position.

The option of sending observers to observe the operations of CEN and Cenelec is only provided for under agreements which these bodies have signed with ISO and the IEC allowing for exceptions - and is governed by the latter. The reason for this is that it would be harmful for all the parties involved if a parallel international organization were to be recreated by means of regional standardization.

\subsection{CEN's 'third-country' unit}

At the same time as the arrangements mentioned above were adopted, CEN decided in 1990 to set up, with the support of the EC and the Secretariat of EFTA, a unit with the twin role of passing on required information on European standardization to third countries and providing support on standardization (in the broad sense of the term) to any countries which require it, relying essentially - but not exclusively - on the competence of the members of CEN, Cenelec and ETSI.

With regard to the second part of its brief, CEN's third-country unit plays a central role as a relay between the EC and the Secretariat of EFTA on the one hand, and Cenelec and ETSI on the other, and lastly the national members of CEN. 
After all, it is necessary to make competent experts from all over Europe available to countries benefiting from a programme of aid and assistance provided by the European Union and EFTA. When the EC decides to implement a support programme in the sphere of standardization/quality/metrology/certification, it relies on the third-country unit to draw up a call for tenders which is then disseminated on a broad scale. CEN's thirdcountry unit is then entrusted by the EC with examining the responses to this call for tenders (it should be stressed that responses do not all necessarily originate from CEN members since consultants, testing and inspection bodies, etc. may also apply) and forwarding to the EC those applications which it considers to be most suitable for the assignments envisaged. Once the EC has made its choice, the third-country unit embarks on the operational part of its role, which consists in organizing the implementation of the programme or assignment which is contemplated.

Although the activities of the third-country unit are mainly directed at countries benefiting from the PHARE programme, they are also geared to other countries in respect of which assistance programmes have been concluded with the EC and EFTA (Tunisia, Malta, Israel, Mexico, etc.). 


\section{Relations with international standards institutions: The Vienna and Lugano Agreements}

As explained above, international standardization is of vital importance for European countries. This is why one of the fundamental elements of their 'foreign policy' consists in relations with international standards institutions. Each within its sphere, CEN and Cenelec have thus concluded agreements with their international partner which are aimed at harmonizing European and international standardization.

\subsection{The Vienna Agreement (ISO/CEN)}

The technical cooperation agreement between ISO and CEN, which is known as the Vienna Agreement, was approved on 27 June 1991 by CEN's Administrative Board following its approval by ISO's Executive Board at its meeting on 16-17 May 1991.

It replaces the Agreement on the exchange of technical information between ISO and CEN known as the Lisbon Agreement, which was concluded in 1989.

The aim of this agreement is to make possible one of the policy principles on which CEN has always based its activities, namely to secure the highest possible degree of identity between European and international standards and thus avoid the duplication of standardization work in so far as is possible.

The agreement was disseminated to all the Presidents and Secretaries of Technical Committees and sub-committees of ISO and CEN during 1991, with guidelines concerning its application.

The agreement covers the following points:

Exchange of information: the central Secretariats of the two organizations exchange not only their general documentation but also work programmes, the relevant resolutions of the Technical Boards, proposals for new studies, the texts of standards at the draft stage, etc. This therefore represents a very full exchange of documentation, even at early stages in working procedures, with the specific aim of ensuring the best possible technical cooperation later on if the two organizations decide to work together in whatever form.

Cooperation on drafting standards: such cooperation may take a number of different forms:

- By correspondence: the two central secretariats compile a list of technical authorities 'of mutual interest', and the task of developing cooperation is then entrusted to the 
respective secretariats of these authorities. This is particularly the case with rapporteur secretariats (clause 2.5 of the Rules of Procedure of CEN/Cenelec), where the member body which has the Secretariat of an ISO Committee also in principle has the Secretariat of the corresponding CEN Committee and is responsible for providing liaison between the two. (These arrangements also apply to IEC/Cenelec reports).

- By mutual representation at meetings: representatives of the technical authorities of each organization can take part in the work of the other - this includes attendance via the sending of observers (no more than two individuals).

Cooperation by transferring work from CEN to ISO: the substance of this provision has been examined in Part 1, Chapter 2, Section 4.4. It is designed to ensure right at the start of work that the results of European and international standardization will be as close as possible. It should be noted that these arrangements become fully meaningful only if all the parties involved respect the spirit of this cooperation and transpose adopted documents into national standards - this also applies to members of ISO which are not members of CEN which, by virtue of their status, are not bound to as strict a code of discipline as their European counterparts with regard to the incorporation of standards in their national collections.

Adoption of existing international standards as European standards: this procedure, which has also been examined above, enables CEN to adopt international standards as European standards. This procedure has, for example, been followed with regard to the adoption in all CEN/Cenelec member countries of the ISO 9000 series of standards on quality assurance.

Parallel approval of standards: this involves taking parallel votes on documents originating from the technical committees of ISO or CEN.

Review of observations by member committees of ISO: these committees can pass on comments on prENs and prHDs which are being approved within CEN. Where possible, the latter endeavours to take account of such comments when preparing the final document.

Provision is also made for monitoring the effective operation of the agreement, with joint coordination meetings and the creation of a joint ISO/CEN coordination group of technical boards. This joint group has, in particular, formulated guidelines which are intended to assist the TC Secretaries and Presidents with implementing the provisions of the agreement.

The implementation of the Vienna Agreement had already produced the following results by the end of September 1992:

235 ISO standards had been adopted without change by CEN as European standards; 786 ISO standards or ISO/DIS drafts had undergone an approval procedure within CEN; it was planned to work together on 72 documents under the supervision of ISO's Central Secretariat, and 44 under the supervision of CEN's Central Secretariat (the difference in procedure depends on the origin of the document), and a parallel vote had been taken on eight documents (five originating from ISO and three from CEN). 
It can therefore be concluded that this agreement has very quickly demonstrated the relevance of its objectives and the usefulness of its provisions for all parties. The full text of the Vienna Agreement is reproduced in Appendix 10.

\subsection{The Lugano Agreement (IEC/Cenelec)}

In the same way as for CEN and ISO, but with the added advantage of long-standing experience of cooperation and joint activities, Cenelec and the IEC have embarked on formal collaboration via an agreement on the exchange of technical information which was signed in 1989 and subsequently supplemented by a cooperation agreement. This agreement, which is known as the Lugano Agreement, was ratified by Cenelec's General Assembly on 30 October 1991 and by the Council of the IEC on 11 October 1991. It has the same objectives as the Vienna Agreement, but places greater stress on the need for speed.

Its objectives can be quoted here in extenso:

'to ensure the speedy joint adoption and prompt publication of international standards, i.e. to give preference to the provision of results at the proper time rather than the quest for an excessive degree of perfection;

to ensure rational use of the available resources. Full account of the technical aspects of the content of the standard should therefore preferably be taken at international level;

to speed up drastically the process whereby standards are prepared in response to market demands.'

The two agreements, which should be considered as forming a single entity, cover the following aspects:

the exchange of information between the central secretariats and technical bodies of Cenelec and the IEC. The provisions are virtually identical to those of the Vienna Agreement, even as regards the use of rapporteur secretariats;

joint planning of new activities with regard to Cenelec (all the members of Cenelec which form part of the IEC are involved in planning within the latter). The principle set forth is that, when Cenelec is contemplating new activities, it will systematically consider whether such activities could be carried out within the IEC. Once decisions have been taken, several procedures exist for doing this, with these procedures being similar to those existing under the Vienna Agreement (broadening of the remit of an IEC TC, implementation by an IEC TC, etc.);

parallel voting on international draft standards: the procedure is in this case virtually automatic - several exceptions apart, all international draft standards which are put to the vote within the IEC are voted on in the same way within Cenelec;

parallel voting on draft European standards: it is the Cenelec Technical Board which decides on the procedure to be followed with regard to existing European standards. As regards drafts which are in hand, the procedure is automatic.

The main difference between the Vienna and Lugano Agreements lies in the fact that recourse to IEC is more automatic than recourse to ISO. 
There are two main factors which may explain this state of affairs: first of all, the IEC has fewer members than ISO (48 instead of 90 ), and the activities of the IEC therefore have more in common with those of Cenelec than as regards the other areas of standardization dealt with by CEN and ISO. Secondly, there is already a long history of cooperation between the IEC and Cenelec - in recent years, for example, around $85 \%$ of Cenelec's activities were already being carried out on the basis of IEC standards.

The full text of the Lugano Agreement is reproduced in Appendix 11. 


\section{GATT}

The fight against technical barriers to trade is going on not only within the European Community but also at multilateral level, within GATT (General Agreement on Tariffs and Trade).

The reason for this is that once the negotiations of the GATT Tokyo Round were held, an Agreement on Technical Barriers to Trade (Standards Code) was formulated and put forward to be signed by the Contracting Parties in 1979. Around 40 States have since signed this Agreement, which came into force in January 1980. With regard to the EC, the Commission is a co-signatory with the Member States by virtue of the powers conferred on it with regard to trade policy by Article 113 of the Treaty of Rome.

The aim of the Agreement is to ensure that when governments or other bodies with a public status, or standards institutions, adopt technical regulations or standards, whether for reasons of health, safety, consumer or environmental protection or for other purposes, such regulations and standards must not create unnecessary barriers to trade.

The Agreement specifies in particular that central governments or bodies under their control must notify the other signatory Parties, via the Secretariat of GATT, of their draft technical regulations in so far as the latter are likely to have a notable impact on the other Parties' trade. This also includes an obligation on any signatory State to create a central information point which must accede to any requests for information on regulations, standards and certification, provided that such requests are reasonable (i.e. they must not result in excessively detailed research, except in return for payment).

The Standards Code also obliges signatories to use international standards as the basis for their own standards and regulations where possible, and to ensure equal treatment for their own nationals and those of other signatory countries on all matters concerning standards, technical regulations and certification.

Finally, the Code provides for differentiated treatment in favour of developing countries and also measures to assist the latter in applying technical regulations and standards.

The Code also contains provisions on the settlement of disputes.

When the Uruguay Round negotiations started in 1986, it was decided to revise all existing codes and, if necessary, improve them. This procedure was also adopted in the case of the Standards Code, and a number of revisions should by now have been adopted at the end of the negotiations. 
The new Code thus provides for improvements which are aimed at increasing the transparency of the documents, making the Code more operational and strengthening some of the obligations of the Parties. Of these substantial revisions, the most important one concerns a point which up to now represented one of the Code's weaknesses: the fact that it does not contain obligations other than on the signatory States.

The fact is that the parties involved in standards, technical regulations and certification go far beyond States, as has been seen throughout this study. It should also be added that, even at public level, central governments do not cover every situation since local governments in Federal States, e.g. in the United States or Germany, have powers of their own with regard to standards, technical regulations and certification.

In the case of standards, the negotiators have decided to rectify this situation by drawing up a 'code of good practice' which is open to signature by all the parties involved, irrespective of whether these are public or private bodies or whether they operate on a national, regional or local basis. The code of good practice adopts and explains the provisions of the Standards Code which have so far applied solely to GATT signatory States (transparency, liaison with international standardization, equal treatment, openness, etc.), though it must be said in its favour that it makes it possible to bring together and place obligations on all the public and private parties in this area, while at the same time remaining voluntary.

The international standards bodies, and particularly ISO and the IEC, are associated with the work of GATT's Committee on Technical Barriers to Trade since both bodies take part in the Committee's meetings as observers.

It should also be stressed that once the new Standards Code and its code of good practice have been adopted, the role of the ISO/IEC information centre in Geneva could be extended. The international standards institutions would in this way be more closely associated with the activities of the signatory States, as is already the case at European level.

In addition, an ISO/IEC initiative to formulate a code of good practice which would complement the GATT code could help extend and strengthen at private level activities undertaken at public level which come under the responsibility of the Parties. 


\section{Part 4 - Conclusion}


At the end of this brief study examining what European standardization is, how it is carried out and by whom, what its purpose is and how it is used by the various business interests (particularly the public authorities), it will have become clear that besides providing an excellent way of bringing about the construction of Europe in all its aspects, European standardization has now become an essential condition for the success of a large number of initiatives undertaken in this sphere.

In addition, standardization and the disciplines associated with it - assessment and certification of conformity, quality control and metrology - of course retain their crucial function as a means to improving competitiveness, a role they have always had.

Ignorance of European standardization was still possible several years ago. Ignorance of it now, whether on the part of company managers, executives, consumers, trade unionists, researchers, lawyers or civil servants - would be more than a mistake. After all, in placing standardization at the service of legislation and European policies, the public authorities have relinquished part of their traditional prerogatives, in line with recent changes in the notion of the State's role.

Standardization is available to all and, by having recourse to it, the public authorities have given business interests responsibility for their destiny. It is now up to these parties to demonstrate through their use of standardization, by making it come alive not only as their desires dictate but also by considering its wider role in organizing societies, that they have the necessary maturity to take on this task. 


\section{Appendixes}




\section{List of Appendixes ${ }^{1}$}

Appendix 1: List of members of CEN (Part 1, Chapter 2, paragraph 2.2)

Appendix 2: List of members of Cenelec (Part 1, Chapter 2, paragraph 2.3)

Appendix 3: Directive 83/189/EEC (Part 2, Chapter 1, paragraph 3.5)

Appendix 4: CEN/Cenelec Memorandum No 4 containing the general guidelines for cooperation between the Commission of the European Communities (CEC) and the European Free Trade Association (EFTA) and the European Free Trade Association and the European standards institutions (Part 2, Chapter 2, paragraph 1.2)

Appendix 5: Resolution of the EC Council of Ministers of 18 June 1992 on European standardization (Part 2, Chapter 2, paragraph 1.3)

Appendix 6: Resolution of the EC Council of Ministers of 7 May 1985 on the new approach (Part 2, Chapter 3)

Appendix 7: Resolution of the EC Council of Ministers of 21 December 1989 on the global approach (Part 2, Chapter 4, paragraph 1)

Appendix 8: Decision of the EC Council of Ministers of 13 December 1990 on modules (Part 2, Chapter 4, paragraph 2)

Appendix 9: List of the members and statutes of the EOTC (Part 2, Chapter 5, paragraph 5)

Appendix 10: Agreement on technical cooperation between ISO and CEN (Vienna Agreement) (Part 3, Chapter 2, paragraph 1)

Appendix 11: IEC-Cenelec Agreement on exchange of technical information between both organizations (1989) (Part 3, Chapter 2, paragraph 2)

\footnotetext{
' The reference in parentheses indicates the first time the appended document is referred to, in cases where such references are numerous.
} 


\section{CEN National Members}

\section{Österreich}

\author{
Österreichisches Normungsinstitut (ON) \\ Postfach 130 \\ Heinestraße 38 \\ A-1021 WIEN \\ Head: Dr. Ing. G. Hartmann \\ Tel. (43-1) 267535613 \\ Telex (047) 115960 NORM A \\ Fax (43-1) $26753 \quad 5650$ \\ Telegrams AUSTRIANORM

\section{Belgique/België}

Institut belge de normalisation/Belgisch Instituut voor Normalisatie $(I B N / B I N)$

Avenue de la Brabançonne 29/Brabançonnelaan 29

B-1040 BRUXELLES/BRUSSEL

Head: Mr P. M. Croon

Tel. (32-2) 7349205

Fax (32-2) 7334264

Telegrams BENOR

\section{Danmark}

Dansk Standard (DS)

Baunegaardsvej 73

DK-2900 Hellerup

Head: Mr J. E. Holmblad

Tel. (45) 39770101

Telex (055) 15615 DANSTA DK

Fax (45) $397702 \quad 02$

Telefax 238-1119203= DSSTAND

Telegrams DANSKSTANDARD

\section{Suomi/Finland}

Suomen Standardisoimislitto r.y. (SFS)

PO Box 116

FIN-00241 HELSINKI

Head: Mr K. Kaartama

Tel. (358-0) 1499331

Fax (358-0) 1464925

Telegrams FINNSTANDARD

\section{France}

Association française de normalisation (AFNOR) Tour Europe F-92049 PARIS-LA DÉFENSE Cedex 7

Head: Mr B. Vaucelle

Tel. (33-1) 42915555
Telex (042) 611974 AFNOR F

Fax (33-1) 42915656

Telefax 933-142915611 = AFNOR

Telegrams AFNOR COURBEVOIE

\section{Deutschland}

Deutsches Institut für Normung e.V. (DIN)

D-10772 BERLIN

Street address:

Burggrafenstraße 6

D-10787 BERLIN

Head: Prof. Dr.-Ing. H. Reihlen

Tel. (49-30) 26010

Telex (041) 184273 DIN D

Fax (49-30) $2601 \quad 1231$

Telefax 2627-308896 = DIN

Telegrams DEUTSCHNORMEN BERLIN

Greece/E $\lambda \lambda \alpha u ́ \delta \alpha$

Hellenic Organization for Standardization (ELOT)

Acharnon Street 313

GR-11145 ATHENS

Head: Mr N. Malagardis

Tel. (30-1) 2015025

Telex (0601) 219621 ELOT GR

Fax (30-1) $20259 \quad 17$

Telegramis ELOTYP ATHENS

\section{Iceland}

Technological Institute of Iceland (STRI)

Keldnaholt

IS-112 REYKJAVIK

Head: Mr J. Thorsteinsson

Tel. (354-1) 687000

Telex (0501) 3020 ISTECH IS

Fax (354-1) 687409

Telegrams IMSI

\section{Ireland}

National Standards Authority of Ireland (NSAI)

Glasnevin

Ireland DUBLIN 9

Head: Mr E. Paterson

Tel. (353-1) 8370101

Telex (0500) 32501 OLAS EI

Fax (353-1) 8369821

Telegrams RESEARCH DUBLIN 


\section{Italia}

Ente nazionale italiano di unificazione (UNI)

Via Battistotti Sassi, 11b

I-20133 MILANO

Head: Dr E. Martinotti

Tel. (39-2) 700241

Telex (043) 312481 UNI I

Fax (39-2) 70106106

Telegrams UNIFICAZIONE

\section{Luxembourg}

Inspection du travail et des mines (ITM)

BP 27

26 , rue Zithe

L-2010 LUXEMBOURG

Head: Mr P. Weber

Tel. (352) 4786154

Telex (0402) 2985 MINTSS LU

Fax (352) $49 \quad 14 \quad 47$

\section{Nederland}

Nederlands Normalisatie-Instituut (NNI)

Postbus 5059

Kalfjeslaan 2

Nederland-2600 GB DELFT

Head: Mr C. De Visser

Tel. (31-15) 690390

Telex (044) 38144 NNI NL

Fax (31-15) 690190

Telegrams NORMALISATIE

Norge

Norges Standardiseringsforbund (NSF)

Postboks 7020

Homansbyen

$\mathrm{N}-0306$ OSLO

Head: Mr I. Jachwitz

Tel. (47-22) 466094

Fax (47-22) 464457

Telegrams STANDARDISERING

\section{Portugal}

Instituto Português da Qualidade (IPQ)

Rua José Estêvão, n. ${ }^{\circ}$ 83-A

P-1199 LISBOA Codex

Head: Mr C. dos Santos

Tel. (351-1) 523978
Telex (0404) 13042 QUALIT P

Fax (351-1) 3530033

Telegrams IGPAI

España

Asociación Española de Normalización y Certificación (AENOR)

Calle Fernández de la $\mathrm{Hoz}, 52$

E-28010 MADRID

Head: Mr R. Naz Pajares

Tel. (34-1) 3104851

Telex (052) 46545 UNOR E

Fax (34-1) 3104976

Telegrams AENOR

\section{Sverige}

Standardiseringskommissionen $i$ Sverige (SIS)

PO Box 3295

Tegnérgatan 11

S-10366 STOCKHOLM

Head: Dr L. Wallin

Tel. (46-8) 6135200

Telex (054) 17453 SIS S

Fax (46-8) 117035

Telegrams STANDARDIS

\section{Schweiz/Suisse/Svizzera}

Schweizerische Normen-Vereinigung (SNV)

Mühlebachstraße 54

CH-8008 ZÜRICH

Head: Dr. H. C. Zürrer

Tel. (41-1) 2545454

Telex (045) $755931 \mathrm{SNV} \mathrm{CH}$

Fax (41-1) 2545474

$\mathrm{X} .400: \mathrm{C}=\mathrm{CH}, \mathrm{A}=\mathrm{ARCOM}, \mathrm{P}=\mathrm{SNV}, \mathrm{O}=\mathrm{SNV}$, $\mathrm{S}=\mathrm{POST}$

\section{United Kingdom}

British Standards Institution (BSI)

2, Park Street

United Kingdom LONDON W1A 2BS

Head: Sir Neville Purvis

Tel. (44-71) 62990.00

Telex (051) 266933 BSILON G

Fax (44-71) 6290506

Telegrams STANDARDS LONDON W.1 


\section{Cenelec National Committees}

\section{Members/Membres/Mitglieder}

\section{AT $\square$ Austria/Autriche/Österreich}

Österreichisches Elektrotechnisches Komitee (ÖEK) beim Österreichischen Verband für Elektro

Eschenbachgasse 9

A-1010 WIEN

Tel. (43-1) 5876373

Fax (43-1) 567408

President

Dipl.-Ing. Helmut Hainitz

General Secretary

Dipl.-Ing. Dr. H. Stärker

Executive Secretary Mr P. Rausch

\section{BE $\square$ Belgium/Belgique/Belgien}

Comité électrotechnique belge (CEB)

Belgisch Elektrotechnisch Comité (BEC)

Avenue Fr. Van Kalken 9

B-1070 BRUXELLES

Tel. (32-2) $55601 \quad 10$

Fax (32-2) 5560120

Telegrams CEB TF 5560110-BRUXELLES

President

Secretary-General

M. R. Laurent

Administrateur délégué

NOVA Electro International

Overhamlaan 44

B-3700 TONGEREN

Tel. (32-12) 232986

Fax (32-12) 262056

M. J. Papier

\section{CH $\square$ Switzerland/Suisse/Schweiz}

Swiss Electrotechnical Committee (CES)

Luppmenstraße 1

CH-8320 FEHRALTORF

Tel. (41-1) 9561170

Fax (41-1) 9561190

President

Dr. Ing. Paul W, Kleiner AWK Engineering $A G$ Leutschenbachstraße 45 CH-8050 ZÜRICH

Tel. (41-1) 3059511

Fax (41-1) 3059519

Secretary-General

Mr R. E. Spaar

\section{DE $\square$ Germany/Allemagne/Deutschland}

Deutsche Elektrotechnische Kommission im DIN und VDE (DKE)

Stresemannallee 15

D-60596 FRANKFURT/MAIN

Tel. (49-69) 63 08-0

Telex 4112871 VDETZ

Fax (49-69) 63 12-925

Teletex 2627-699798= DKED

Telegrams ELEKTROBUND

President

Mr Günter G. Seip Direktor, Siemens AG

ASI 3 GWR

Siemensstraße 10

D-93055 REGENSBURG

Tel. (49-941) 7902252

Fax (49-941) 7902700

Teletex $2627-9418128=\mathrm{Sie}$

IBJR

Secretary Dipl.-Ing. K. Orth

\section{DK $\square$ Denmark/Danemark/Dänemark}

Dansk Standard (DS)

Electrotechnical Sector

Baunegaardsvej 73

DK-2900 Hellerup

(Danish Standards Association)

Tel. (45) 39770101

Fax (45) $3977 \quad 02 \quad 02$

Telex 119203 DS STAND.

President

Mr Niels W. Holm

Managing Director Mr Jacob E. Holmblad

Standardization

Manager

Mr Mogens Winther, Project Manager

Permanent Delegate

of Cenelec/BT Mr Jan Roed

\section{ES $\square$ Spain/Espagne/Spanien}

Asociación Española de Normalización

y Certificación (AENOR)

Comité Electrotécnico Español

Calle Fernández de la $\mathrm{Hoz} 52$

E-28010 MADRID 
Tel. (34-1) 3104851

Fax (34-1) 3104976

Telex (052) 46545-UNOR E

$\begin{array}{ll}\text { Chairman } & \text { Mr I. Tornos } \\ & \text { IBERDROLA } \\ & \text { Calle Claudio Coello 53 } \\ & \text { E-28010 MADRID } \\ & \text { Tel. (34-1) 577 65 65 } \\ & \text { Fax (34-1) } 577 \text { 08 } 48 \\ & \text { Mr R. Naz } \\ \text { General Director } & \text { Mr V. Ruiz de Valbuena } \\ \text { Secretary } & \\ \text { FI } \square \text { Finland/Finlande/Finnland }\end{array}$

Finnish Electrotechnical Standards Association (SESKO)

Särkiniementie 3

PO Box 134

FIN-00211 HELSINKI

Tel. (358-0) 68253406

Telex (57) 122877 SETI SF

Fax (358-0) 68253424

President

Mr K. Rudanko
Nokia Cables
PO Box 419

FIN-00101 HELSINKI

Tel. (358-0) 6825406

Fax (358-0) 6825394

Vice-President

Mr O. Kuusisto

Director

Mr T. Ilomäki

FR $\square$ France/France/Frankreich

Union technique de l'électricité (UTE)

Location address:

Immeuble Lavoisier

4, place des Vosges

La Défense 5-COURBEvoIE

Postal address:

UTE-Cedex 64

F-92052 PARIS-LA DÉFENSE

Tel. (33-1) 46911111

Telex (42) 620816 CEFUTE

Fax:

UTE, Approval Dept (33-1) 47894587

UTE, All Services (33-1) 47894775

UTE, Standardization Dept (33-1) 46911265

Teletex 933-147894908 = UTECEF
President
M. P. R. Sallebert
Director-General
M. J. Benoist

GB $\square$ United Kingdom/Royaume-Uni/Vereinigtes Königreich

British Electrotechnical Committee (BEC)

British Standards Institution (BSI)
2, Park Street

United Kingdom LONDON W1A 2BS

Tel. (44-71) 6299000

Telex (51) 266933 BSILON G (Head Office)

Telex (51) 23218 STANLN G (Sales)

Fax (44-71) 6290506

Telegrams STANDARDS LONDON W1

Chairman

Mr Norman J. A. Holland Consultant: Standards and Directives

Pinehaven, 94 Hiltingbury

Road, Chandler's Ford, Hampshire S05 $1 \mathrm{NZ}$

Tel. (44-0703) 270605

Fax (44-0703) 270605

Secretary

Mr I. Campbell

\section{GR $\square$ Greece/Grèce/Griechenland}

Hellenic Organization for Standardization (ELOT) Acharnon Street 313

GR-11145 ATHENS

Tel. (30-1) 2015025

Telex (601) 219670 ELOT GR

Fax (30-1) 2020776

President

Prof. G. Varoufakis

Managing Director $\mathrm{Mr}$ N. Malagardis

IE $\square$ Ireland/Irlande/Irland

Electro-Technical Council of Ireland (ETCI)

ESB office

Parnell Avenue

Harold's Cross

Ireland DUBLIN 12

Tel. (353-1) 4545819 - 545820

Fax (353-1) 4545821

Chairman Mr S. Elmore

Administrator Mr J. P. Sheehan

Ballymun Road

Tel. (353-1) 8376773

Ireland DUBLIN 9

Telex (500) 32501 OLAS EI

Fax (353-1) 8369821

Head of Secretariat Mr D. O'Regan

\section{IS $\square$ Iceland/Islande/Island}

The Icelandic Council for Standardization (STRI) Technological Institute of Iceland

Keldnaholt

IS-112 REYKJAVIK

Tel. (354-1) 687000

Telex (501) 3020 ISTECH IS

Fax (354-1) $68 \quad 7409$

Telegrams IMSI 
Chairman

Secretary
Mr T. Karlsson

Mr J. Thorsteinsson

IT $\square$ Italy/Italie/Italien

Comitato elettrotecnico italiano (CEI)

Viale Monza 259

I-20126 MILANO

Tel. (39-2) 257731

Telex (43) 312207 CEITALIA

Fax (39-2) 25773210

Telegrams ELETTROCOMIT MILANO

President

Mr Lorenzo Tringali-Casanuova

Secretary-General

Dr. Ing. E. Camagni

\section{LU $\square$ Luxembourg/Luxembourg/Luxemburg}

Service de l'énergie de I'État

34 , avenue de la Porte-Neuve

L-2227 LUXEMBOURG

Tel. (352) 4697 46-1

Fax (352) $22 \quad 2524$

Postal address:

c/o Service de l'énergie de l'État

BP 10

L-2010 LUXEMBOURG

Director

M. Jean-Paul Hoffmann

NL $\square$ Netherlands/Pays-Bas/Niederlande

Nederlands Elektrotechnisch Comité (NEC)

Kalfjeslaan 2

Postbus 5059

Nederlands 2600 GB DELFT

Tel. (31-15) 690390

Telex (44) 38144 NNI NL

Fax (31-15) 690190

Telegrams NORMALISATIE DELFT

President

Vice-Presidents
Mr E. Ribberink

Vice President, European Affairs

Holec Systems \& Components BV

PO BOX 23

Nederlands 7550 AA HEN-

GELO

Tel. (31-74) 464880

Fax (31-74) $46 \quad 42 \quad 208$

Prof. Ir. J. L. de Kroes

Mr C. Ch. Smit
Director

Mr T. D. Roodbergen

Tel. (31-15) 690208

Teletex 204-1173055= NNI

Fax (31-15) 690242

\section{NO $\square$ Norway/Norvège/Norwegen}

Norsk Elektroteknisk Komite (NEK)

Harbitzalléen 2A, SkÝyen

Postboks 280

$\mathrm{N}-0212$ OSLO 2

Tel. (47-22) 526950

Fax (47-22) 526961

Telegrams NORWELCOM

President Mr Knut Herstad Tel. (47-7) 597200 Fax (47-7) 597250

Director Mr B. I. Ødegård

\section{PT $\square$ Portugal/Portugal/Portugal}

Instituto Português da Qualidade (IPQ)

Rua José Estêvão, n. ${ }^{\circ}$ 83-A

P-1199 LISBOA Codex

Tel. (351-1) 523978

Telex (404) 13042 QUALIT P

Fax (351-1) 3530033

President Mr Candido dos Santos

\section{SE $\square$ Sweden/Suède/Schweden}

Svenska Elektriska Kommissionen (SEK)

Kistagången 19

Box 1284

S-16428 KISTA STOCKHOLM

Tel. (46-8) 7507820

Telex (54) 17109 ELNORM S

Fax (46-8) 7518470

Teletex 2401-8126725

Telegrams ELNORM

President

Mr M. Setterwall

Sveriges Elektroindustriförening

Box 5501

S-11485 STOCKHOLM

Tel. (46-8) 7838164

Fax (46-8) $66363 \quad 23$

Vice-Presidents Mr G. Sandqvist

Mr J. Nöu

Director 


\section{APPENDIX 3}

\section{COUNCIL DIRECTIVE}

of 28 March 1983

laying down a procedure for the provision of information in the fleld of technical standards and regulations

$(83 / 189 / E E C)$

\section{THE COUNCIL OF THE EUROPEAN COMMUNITIES,}

Having regard to the Treaty establishing the European Economic Community, and in particular Articles 100 and 213 thereof,

Having regard to the proposal from the Commission ('),

Having regard to the opinion of the European Parliament ( ${ }^{2}$ ),

Having regard to the opinion of the Economic and Social Committee $\left(^{3}\right.$ ),

Whereas the prohibition of quantitative restrictions on the movement of goods and of measures having an equivalent effect is one of the basic principles of the Community;

Whereas barriers to trade resulting from technical regulations relating to products may be allowed only where they are necessary in order to meet essential requirements and have an objective in the public interest of which they constitute the main guarantee:

Whereas it is essential for the Commission to have the necessary information at its disposal before the adoption of technical provisions; whereas, consequently, the Member States which are required to facilitate the achievement of its task pursuant to Article $s$ of the Treaty must notify it of their projects in the field of technical regulations:

Whereas all the Member States must also be informed of the technical regulations contemplated by any one Member State:

Whereas the Commission and the Member States must also be allowed sufficient time in which to propose amendments to a contemplated measure, in order to remove or reduce any barriers which it might create to the free movement of goods;

(I) OJ No C $253,1.10 .1980$, p. 2.

(3) OJ NoC $144,15.6 .1981$, p. 122.
Whereas the Commission must also have the option of proposing or adopting a Community directive governing the subject of the national measure contemplated;

Whereas, in the two instances set out above, the Member State in question must, pursuant to the general obligations laid down in Article 5 of the Treaty, defer implementation of the contemplated measure for a period sufficient to allow either a joint examination of the proposed amendments or the preparation of the proposal for a Council Directive or of the Commission Directive; whereas the time limits laid down in the Agreement of the representatives of the Governments of the Member States meeting within the Council of 28 May 1969 providing for standstill and notification to the Commission ("), as amended by the Agreement of 5 March $1973\left({ }^{3}\right)$, have proved inadequate in the cases concerned and should accordingly be extended;

Whereas the procedure concerning the standstill arrangement and notification of the Commission contained in the abovementioned Agreement of 28 May 1969 remains applicable to products subject to that procedure which are not covered by this Directive:

Whereas, in practice, national technical standards may have the same effects on the free movement of goods as technical regulations:

Whereas it would therefore appear necessary to inform the Commission of draft standards under similar conditions to those which apply to technical regulations; whereas, pursuant to Article 213 of the Treaty, the Commission may, within the limits and under the conditions laid down by the Council in accordance with the provisions of the Treaty, collect any information and carry out any checks required for the performance of the tasks entrusted to it;

Whereas it is also necessary for the Member States and the standards institutions to be informed of standards contemplated by standards institutions in the other Member States;

(4) OJ No C 76, 17.6. 1969, p.9.

(s) OJ No C9, 15. 3. 1973, p.3. 
Whereas it is necessary to set up a Standing Committec, the members of which will be appointed by the Member States with the task of helping the Commission to examine draft national standards and cooperating in its efforts to lessen any adverse effects thereof on the free movement of goods,

\section{HAS ADOPTED THIS DIRECTIVE:}

\section{Arricle I}

For the purposes of this Directive, the following meanings shall apply:

1. 'technical specification', a specification contained in a document which lays down the characteristics required of a product such as jevels of quality, performance, safety or dimensions, including the requirements applicable to the product as regards terminology, symbols, testing and test methods, packaging, marking or labelling:

2. 'standard', a technical specification approved by a recognized standardizing body for repeated or continuous application, with which compliance is not compulsory;

3. 'standards programme', document listing the subjects for which it is intended to draw up or alter a standard:

4. 'draft standard', document containing the text of the technical specifications concerning a given subject, which is being considered for adoption in accordance with the national standards procedure, as that document stands after the preparatory work and as circulated for public comment or scrutiny:

5. 'technical regulation', technical specifications, including the relevant administrative provisions, the observance of which is compulsory, de jure or de facto, in the case of marketing or use in a Member State or a major part thereof, except those laid down by local authorities;

6. 'draft technical regulation', the text of a technical specification including administrative provisions, formulated with the aim of enacting it or of ultimately having it enacted as a technical regulation, the text being at a stage or preparation at which substantial amendments can still be made;

7. 'product, industrially manufactured products other than agricultural products within the meaning of Article 38 (1) of the Treaty, products for human or animal consumption, medicinal products within the meaning of Directive 65/ 65/EEC (') and cosmetic products within the meaning of Directive 76/768/EEC ( $\left.{ }^{2}\right)$.

\section{Article 2}

1. The Commission and the standards institutions in List 1 annexed hereto shall be informed each year, not later than 31 January, of the standards programmes drawn up by the national institutions in List 2 annexed hereto. This information shall be brought up to date every quarter. The Commission may amend or supplement these lists on the basis of communications from the Member States.

2. Standards programmes shall indicate in particular whether the standard:

- will be the transposition in full of an existing international or European standard,

- will be the transposition of an international or European standard incorporating certain national divergences or amendments,

- will be a new national standard,

- will constitute an amendment of a national standard.

After consulting the Committee referred to in Article 5, the Commission may draw up rules for the codified presentation of this information and a plan and criteria for the presentation of standards programmes designed to facilitate their comparison.

3. The Commission shall keep this information at the disposal of the Member States in a form in which the different programmes can be compared.

Article 3

The Commission and the standards institutions shall be informed if one or more standards institutions:

(') Of No 22, 9. 2. 1965, p. 369/65

(2) OJ No L 262, 27.9. 1976, p. 169. 
- wish to be involved passively or actively (by sending an observer) in activities planned by other standards institutions,

- wish a European standard or any other document leading to uniform technical specifications to be drawn up.

\section{Arlicle 4}

At least every four months the standards institutions referred to in List $]$ and the Commission shall receive all new draft standards, except where such standards merely transpose the full text of an international or European standard.

When a draft is communicated it shall be indicated whether the standard will be:

- the transposition of an international or European standard incorporating certain national divergences or amendments,

- a new national standard, or

- an amendment of a national standard.

\section{Article 5}

A Standing Committee shall be set up consisting of representatives appointed by the Member States who may call on the assistance of experts or advisers: its chairman shall be a representative of the Commission.

The Committee shall draw up its own rules of procedure.

\section{Article 6}

1. The Committee shall meet at least twice a year - with the representatives of the standards institutions referred to in List 1.

2. The Commission shall submit to the Committee a report on the implementation and application of the abovementioned procedures and proposals aimed at eliminating existing or foresecable barriers to trade.

3. The Committee shall express its opinion on the communications and proposals referred to in paragraph 2 and may in this connection propose, in particular, that the Commission:

- request the European standards institutions to draw up a European standard within a given time limit,
- ensure where necessary, in order to avoid the risk of barriers to trade, that initialiy the Member States concerned decide amongst themselves on appropriate measures,

- take all appropriate measures.

4. The Committee must be consulted by the Commission:

(a) before any amendment is made to the lists in the Annex (Article 2 (1))

(b) when drawing up the rules for the codified presentation of information and the plan and criteria. for the presentation of standards programmes (Article 2(2)):

(c) when deciding on the actual system whereby the exchange of information provided for in this Directive is to be effected and on any change to it;

(d) when reviewing the operationt of the system set up by this Directive (Article 11).

5. The Committee may be consulted by the Commission on any preliminary draft technical regulation received by the latter.

6. Any question regarding the implementation of this Directive may be submitted to the Committee at the request of its chairman or of a Member State.

7. The proceedings of the Committee and the information to be submitted to it shall be confiden. tial.

However, the Committee and the national authorities may, provided that the necessary precautions are taken, consult, for an expert opinion, natural or legal persons, including persons in the private sector.

\section{Article 7}

1. Member States shall take all appropriate measures to ensure that their standards institutions do not draw up or introduce standards in the field in question while the European standard referred to in the first indent of Article 6 (3) is being drawn up. This undertaking shall lapse unless a European standard has been introduced within six months following expiry of the time limit fixed in accordance with the said indent.

2. Paragraph 1 shall not apply to the work of standards institutions undertaken at the request of the 
public authorities to draw up technical specifications or a standard for specific products for the purpose of enacting a technical regulation for such products.

Member States shall communicate all requests of the kind referred to in the preceding subparagraph to the Commission as draft technical regulations, in accordance with Article 8 (1), and shall state the grounds for their enactment.

\section{Article 8}

1. Member States shall immediately communicate to the Commission any draft technical regulation, except where such technical regulation merely transposes the full text of an international or European standard, in which case information regarding the relevant standard shall suffice; they shall also let the Commission have a brief statement of the grounds which make the enactment of such a technical regulation necessary, where these are not already made clear in the draft.

The Commission shall immediately notify the other Member States of any draft it has received; it may also refer this draft to the Committee for its opinion.

2. The Commission and the Member States may make comments to the Member State which has forwarded a draft technical regulation; that Member State shall take such comments into account as far as possible in the subsequent preparation of the technical regulation.

3. At the express request of a Member State or the Commission, Member States shall communicate to them, without delay, the definitive text of a technical regulation.

4. The information supplied under this Article shall be confidential.

However, the Committee and the national authorities may, provided that the necessary precautions are taken, consult, for an expert opinion, natural or legal persons, including persons in the private sector.

\section{Article 9}

1. Without prejudice to paragraph 2, Member States shall postpone the adoption of a draft technical regulation for six months from the date of the notification referred to in Article 8 (1) if the Commission or another Member State delivers a detailed opinion, within three months of that date, to the effect that the measure envisaged must be amended in order to eliminate or reduce any barriers which it might create to the free movement of goods.
2. The period in paragraph 1 shall be $\mathbf{1 2}$ months if, within three months following the notification referred to in Article 8 (1), the Commission gives notice of its intention of proposing or adopting a Directive on the subject.

3. Paragraphs 1 and 2 shall not apply in those cases where, for urgent reasons relating to the protection of public health or safety, a Member State is obliged to prepare technical regulations in a very short space of time in order to enact and introduce them immediately without any consultations being possible. In such cases the Member State in question shall in the notification provided for in Article' 8 state the grounds warranting the urgent adoption of the measures.

\section{Article 10}

Articles 8 and 9 shall not apply where Member States honour their obligations arising out of Com. munity Directives or commitments arising out of an international agreement where they result in the adoption of uniform technical specifications in the Community.

\section{Aricle II}

No later than four years following the date of notification of this Directive the Commission, in close cooperation with the Committee referred to in Article 5, shall review the operation of the procedures laid down in this Directive and, if need be, submit any relevant proposals for amending them.

\section{Article 12}

I. Member States shall bring into force the measures necessary in order to comply with this Directive within 12 months following its notification and shall forthwith inform the Commission thereof.

2. Member States shall ensure that the texts of the main provisions of national law which they adopt in the field governed by this Directive are communicated to the Commission.

\section{Article 13}

This Directive is addressed to the Member States.

Done at Brusseis, 28 March 1983.

\author{
For the Council \\ The President \\ J. ERTL
}




\section{ANNEX}

LIST 1

Stendards Institutions

\section{AFNOR (France):}

Association française de normalisation.

Tour Europe, Cedex ?

F-92080 Paris-La-Défense

\section{UTE (France):}

Union technique de l'electricité (UTE),

12, place des Etats-Unis,

F.75703 Paris Cedex 16

BSI (United Kingdom):

British Standards.Institution,

2 Park Street,

UK-London WIA 2BS

BEC (United Kingdom):

British Electrotechnical Committee,

British Standards Institution,

2 Park Street,

UK-London WIA 2BS

DS (Dermark) :

Dansk Standardiseringsrâd.

Aurehojvej i2,

Posiboks 77.

DK-2900 Hellerup 12

DEK (Denmark):

Dansk Elektroteknisk Komite (DEK).

Strandgade 36 st.,

DK-1401 Kobenhavn $K$

DIN (Germany):

DIN Deutsches Institut fur Normung e.v.

Burggrafenstrasse 4-10,

Postfach 1107

D-1000 Berlin 30

DKE (Germany):

Deutsche Elektrotechnische Kommission im DIN und VDE (DKE).

Stresemannallee 15 ,

D-6000 Frankfurt am Main 70

ELOT (Greece):

Hellenic Organization for Standardization (ELOT),

Didotou 15,

GR-Albens 144

IBN (Belgium):

Institut belge de normalisation, Belgisch Instituut voor Normalisatie

29, avenue de la Brabançonne (laan)

B-1040 Bruxelles/Brussel
CEB (Belgium):

Comite electrotechnique (CEB)

(Belgisch Elektrotechnische Comitt (BEC)),

3, galerie Ravenstein, bie II,

B-1000 Bruxelles

IIRS (ireland):

Institute for Industrial Research and Standards,

Ballymun Road,

IRL-Dublin 9

ETCI (Ireland):

Electro-Technical Council of Ireland (ETCI),

Institute for Industrial Research and Standards,

Ballymun Road,

IRL-Dublin 9

Luxemboure:

Inspection du travail et des mines,

2. rue des Girondins,

L-Luxembourg

NNI (Netherlands):

Nederlands Normalisatie Instituut.

Postbus 5059.

NL-2600 GB Delft

NEC (Netherlands):

Nederlands Elektrotechnisch Comite (NEC),

Kalfjeslaan 2.

NL-2623 AA Delft T

UNI (Italy):

Ente nazionale italiano di unificazione.

piazza Armando Diaz 2.

1-20123 Milano

CEI (1taly):

Comitato elettrotecnico italiano (CEI),

viale Monza 259,

1.20126 Milano

CEN:

Comité européen de normalisation,

rue de Brederade.

Bruxelles

CENELEC:

Comite europten de normalisation

electrotechnique,

rue de Brederode.

Bruxelles

LIST 2

National gandards institutions in the Member States of the European Commualty

(Same as those in List I except for CEN and CENELEC) 


\title{
APPENDIX 4
}

\section{CEN/Cenelec}

\section{The Joint European Standards Institution}

\author{
Memorandum No 4 \\ General guidelines \\ for cooperation between the Commission of the European \\ Communities (CEC) and the European Free Trade Association (EFTA) \\ and \\ the European standards institutions
}

\section{EDITION 2}

1985

\section{Contents}

General guidelines for cooperation between:

Part 1

the Commission of the European Communities (CEC)
Part 2

the European Free Trade

Association

(EFTA)

and

the European Standards Institutions:

the European Committee for Standardization (CEN)

the European Committee for Electrotechnical Standardization (Cenelec)

(translated from the French)

\section{Part 1}

\section{Introduction}

1. These general guidelines constitute the first formal agreement on general principles between the Commission of the European Communities and the two European standards bodies CEN and Cenelec whereby the three signatory parties cooperate in the framework of the EEC Treaty Article 100 on the removal of non-tariff barriers to trade. Before this time the cooperation between the Commission and CEN for the non-electrical 
sector and between the Commission and Cenelcom, Cenelec from 1973, for the electrical sector, had always been organized on the basis of informal 'gentlemen's agreements'. CEN worked according to specific mandates to produce European Standards to be used in the technical annexes to EEC Directives; Cenelec worked according to a few specific mandates (for example, European standards for equipment for use in potentially explosive atmospheres) and also, after February 1973, on a large-scale programme of harmonizing national standards in the field of the low voltage Directive.

2. By the end of the 1970's both CEN and Cenelec were convinced of the need for a clearer statement in written form of their two gentlemen's agreements with the Commission. To open negotiations in July 1979, a joint CEN/Cenelec delegation visited Commissioner Viscount Davignon and the senior officials of the Commission's DG Ill 'Internal Market and Industrial Affairs'. The aim was to define what the different parties expected of each other and what could be done to improve coordination, planning, and production of the right harmonization results at the right time.

3. Several approaches to produce a document acceptable to all parties were tried. The combined CEN/Cenelec policy was laid down in a draft memorandum of understanding presented to Commissioner Narjes in mid1983. In the meantime, however, important new developments had been initiated, particularly the preparation of Directive 83/189/EEC laying down a procedure for gathering and disseminating information on technical regulations and standards. For this Directive CEN and Cenelec had to be recognized as partners for the running of the Information procedure. Accordingly their status was officially recognized.

4. On 16 July 1984 a further step was taken towards formal recognition. The EC Council adopted a resolution laying down the principles for a European standardization policy aimed at strengthening the internal market through promoting trade and encouraging the competitiveness of European industry. The findings of the Council's Williams Group, published towards the end of 1984, established that the principle of presumption of conformity to the essential requirements provided for by Directives under Article 100 of the EEC Treaty was recognized to be complied with by products manufactured in accordance with CEN/Cenelec standards. In lay terms, this meant that the concept of general reference to standards would gradually replace the drafting of technical requirements for Technical Annexes to Directives. This principle was confirmed through the adoption of the Council resolution $85 / \mathrm{C} 136 / 01$ by the EC Council on 7 May 1985.

5. In the light of the events of 1983-84, the Commission's DGIII drew up the general guidelines which combined the fruits of all these recent developments with the ideas presented in the draft memorandum of understanding. This document was prepared in parallel with the contracts for the management of the standardization part of the information procedure and the start of agreements for work in the field of information technology. It was presented to CEN and Cenelec for signature in autumn 1984; authorization for the Cenelec signature was given by the Cenelec general assembly meeting in Berlin on 30-31 October 1984 and for the CEN signature during the meeting of the Administrative Board held on 13-14 June 1984.

6. For the history of the development of the EFTA-CEN-Cenelec guidelines see the Introduction to Part 2 of this memorandum.

\section{CEC-CEN-Cenelec general guidelines}

1. On 16 July 1984 the Council adopted a resolution relating to standardization setting the principles for a European standardization policy, which constitutes an extension of the Council Directive 83/189/EEC which establishes an information procedure in the field of technical standards and regulations. This resolution will contribute towards the setting-up of a Community strategy aimed at reinforcing the internal market as the basis for a European economic area by:

- improving trade in goods by progressively removing barriers resulting from differing national technical specifications;

- strengthening the competitiveness of European industry both on the internal market and on the markets of third countries, particularly in the field of new technologies by having greater recourse to international standards harmonized at European level, sufficiently detailed to be implemented or, when they do not exist, to European standards which anticipate the work in progress at international level.

Amongst these general principles figure the priority to be granted to European Standards, and the operational corollary, i.e. the reinforcement of the standardizing capacity at European level. 
2. In order to attain these objectives,

- the work on Community harmonization (Article 100 of the EEC Treaty) should be aimed more resolutely at producing formulas which fix the objectives to be met by the products for safety reasons and other aspects of public interest and refer to European Standards for the definition of their relevant technical characteristics. Moreover, a larger recourse to standardization in this context can contribute to appreciable progress in the field of certification, especially where recognition within the Community is concerned;

- when new technologies are involved, it is essential for standardization at European level, on the one hand, to take place at a sufficiently early stage and to be carried out over periods compatible with the rate of technological development and, on the other hand, to promote the adoption of standards reflecting technical progress so as to take the greatest advantage of the European market dimension.

3. The pursuit of this objective requires, to be efficient, and to transcend the delays and difficulties encountered at present, rapid strengthening of standardization capacity at European level and adequate representation of all the parties concerned in the process of preparing European standards.

This calls for the closest possible cooperation between the Commission and the European standards bodies CEN and Cenelec and necessitates the broadest possible exchange of information and consultation on matters of mutual interest.

4. For its part, the Commission intends to contribute to the strengthening of European standardization:

- by proposing that a general reference be made whenever the conditions are fulfilled, to the European Standards in the field of technical harmonization;

- by promoting, in the field of standardization of information technologies, actions which aim at a uniform application of international standards, when they exist or of anticipative standards in the absence of the former. Such actions should take account of the special characteristics of the sector and the structural modifications corresponding to these new tasks;

- by assigning to CEN and Cenelec, in their spheres of competence, the task of preparing European Standards particularly within the framework of multiannual programmes which will be drawn up according to Article 6 of Directive 83/189/EEC in close contact with the Technical Standards and Regulations Committee. This will be realized within the framework of contracts signed with the CEN and Cenelec, which will provide financial support within the limits of available budgetary assets;

- by renouncing, during the time granted to CEN and Cenelec to draw up a standard on its request, to draw up or have drawn up technical specifications on the same subject, except where a Commission initiative turns out to be necessary in the public interest;

- by asking the opinion of CEN and Cenelec on general and specific matters relating to standardization;

- by reserving the possibility of organizing the technical preparatory work of a draft standard without having recourse to CEN and Cenelec; in such a case and for those subjects falling within the competences of CEN and Cenelec,

- the Commission will invite qualified experts designated by CEN and Cenelec to take part in the work and in the working meetings organized by its services, which are of interest to CEN and Cenelec; it will communicate the necessary documents to CEN and Cenelec;

- the draft standard thus drawn up will be submitted to the decision-making procedure of CEN and Cenelec in order to obtain a European standard;

- In support of the dissemination of European Standards, the Commission will publish regularly in the Official Journal of the European Communities the standardization programmes entrusted to CEN and Cenelec together with the titles of the European standards adopted. For the same purpose, the Commission will refer, wherever possible, to the appropriate European standards in the specifications set out in its invitations to tender.

5. For their part the European standards institutions CEN and Cenelec will ensure that the collaboration between them be reinforced and will specify the details more fully. Moreover: 
- CEN and Cenelec will permanently maintain the requisite infrastructure in the case of both the Central Secretariat/Secretariat-General and the Technical Committees so as to be able to accomplish the tasks covered by the contracts to be concluded, ensuring in particular the control of the execution of the pluriannual programmes;

- CEN and Cenelec will call upon the Commission to participate in the meetings of the Technical Committees. A Commission representative will be invited to take part in the meetings of the Technical Boards. CEN and Cenelec will report regularly, at intervals to be specified, on the state of progress of the work, the completion of the programme or the reasons for delays in the work. In addition, they will provide all information requested by the Commission on the implementation of a programme;

- in order to establish the grounds for a large recognition of the importance of European Standards, CEN and Cenelec will ensure that the interested circles, especially public authorities, manufacturers, users, consumers, trade unions, can, if they so wish, be effectively associated in the drawing-up of European Standards: the Commission will, should the case arise, help in the definition of the appropriate modalities;

- $\mathrm{CEN}$ and Cenelec will ensure that the standards drawn up satisfy the essential requirements for the protection of citizens (safety, health...) set either by the Directives to which the standardization mandates are related, or by the standardization mandates themselves;

- CEN and Cenelec will unify their voting procedures for the adoption of standards, at least in those cases where the standard originates in a Commission mandate;

- CEN and Cenelec will ensure that the national standards institutes of the Community transpose the European standards in their national framework as national standards or at least withdraw and refrain from introducing any diverging national standard. CEN and Cenelec will also make every effort, in the case of harmonization documents, to ensure that national deviations be effectively removed by the agreed deadlines.

Brussels, 13 November 1984

(signed)

For the Commission

Mr Braun
For the European

Committee for

Standardization

Mr Croon

Mr Vardakas
For the European Committee

for Electrotechnical

Standardization

Mr Wiechers

Mr Tronnier

\section{Part 2}

\section{Introduction}

1. As early as December 1981 EFTA had declared its interest in cooperating with the European Community countries and CEN and Cenelec to establish a procedure for the exchange of information on standardization programmes and draft standards. EFTA's participation in the information procedure was confirmed by contract in spring 1984. The EFTA Secretariat also followed with close interest the preparation of the general guidelines agreement between the Commission, CEN and Cenelec. At the Nice EFTA-Cenelec Liaison Committee meeting, in November 1983, opinions were sounded on the possibility of drafting a similar agreement governing EFTA-CEN-Cenelec relations. The Cenelec 14th General Assembly meeting in Nice endorsed this proposal and invited further action in the matter, while in CEN it was during the 9th General Assembly held in Athens in September 1983 that discussions started.

2. In the statement known as the Luxembourg Declaration, adopted on 9 April 1984 at the ministerial level by the EFTA countries, the European Community and its Member States, orientations were laid down for future EFTA-EC cooperation inter alia, with the aim of improving the free circulation of industrial goods. One of the priority areas for cooperation was the elimination of technical barriers to trade including harmonization of standards. 
3. On 8 May 1984 the EFTA Councils adopted a set of principles on standardization policy in Europe which define EFTA views and objectives as regards European standardization activities. In this set of principles the EFTA countries confirmed their support of activities aiming at greater European harmonization of standards and technical regulations. The EFTA countries further declared their interest in strengthening their contractual ties with CEN and Cenelec and their readiness to support the practical work of CEN and Cenelec, inter alia, by giving standardization mandates and contributing to the costs of specific tasks.

4. In July 1984 the EFTA Committee on Technical Barriers to Trade was established. Among its first tasks was the drafting of an EFTA-CEN-Cenelec agreement in the form of the present general guidelines. The final draft prepared by the Committee was endorsed for signature by the EFTA Councils on 14 March 1985 and presented to CEN and Cenelec for signature later in the same month. Authorization for the Cenelec signature on 30 April 1985 was given at the Cenelec General Assembly in Stockholm on 23 and 24 April 1985 and for CEN following a circular letter of 1 April 1985 to its members.

\section{EFTA-CEN-Cenelec general guidelines}

1. On 8 May 1984 the EFTA Councils adopted a set of principles as a basis for the future activities of the EFTA countries in respect of European standardization. These principles contribute to the wider aims of intensifying the efforts to eliminate barriers to trade and of strengthening and broadening the instruments for cooperation in areas of particular importance for a competitive and dynamic European industry.

2. Among the principles laid down by the Councils in furtherance of these objectives the following are of a general character:

(a) The EFTA countries support activities aiming at a greater harmonization of standards and technical regulations in order to eliminate and avoid barriers to trade. The EFTA countries are ready to study in a positive way all initiatives pertaining to a strengthening and broadening of standardization in a West European framework. They are willing to pursue these objectives in close collaboration with the European Community.

(b) The EFTA countries appreciate the work of CEN and Cenelec to further European standardization. They expect CEN and Cenelec to retain their role as the common European standards institutions. To this end they support efforts to improve the functioning and the decision-making of these organizations.

(c) The EFTA countries are willing to contribute to the establishment of priorities in the field of standardization and harmonization. They are ready to work in close collaboration with the Community in identifying sectors where priority work should be undertaken.

(d) The EFTA countries will continue their efforts to identify standardization programmes to be carried out by $\mathrm{CEN}$ and Cenelec in addition to the mandates already given.

3. In order to pursue efficiently the objectives and principles mentioned above a strong standardization capacity at the European level is necessary. This calls for the closest possible cooperation between EFTA and CEN and Cenelec and necessitates the broadest possible exchange of information and consultation on matters of mutual interest.

4. EFTA has decided to participate fully in the information procedure on standards and has concluded financial and legal arrangements to that effect with $\mathrm{CEN}$ and Cenelec.

5. For their part the EFTA countries intend to contribute further to European standardization in the following ways:

(a) The EFTA countries will promote uniform application of international standards on the European level.

(b) When preparing technical regulations the EFTA countries will, whenever practicable, make reference to national standards identical to European standards (EN) or equivalent to harmonization documents (HD) drawn up by CEN and Cenelec. 
(c) EFTA will assign to CEN and Cenelec, in their spheres of competence, the task of preparing European standards. The contractual arrangements and the financial assistance necessary for fulfilling these tasks will be agreed upon between the parties.

(d) All appropriate measures will be taken by the EFTA countries to ensure that national standards are not introduced while European standards are being drawn up at the request of EFTA.

(e) In the work carried out in EFTA relating to European standardization, the opinion of CEN and Cenelec on general and specific matters concerning standardization will, whenever practicable, be sought.

6. For their part the European standards institutions CEN and Cenelec will ensure that the collaboration between them is reinforced and will specify the details more fully. Moreover, CEN and Cenelec will take the following action:

(a) CEN and Cenelec will permanently maintain the requisite infrastructure in the case of both the Central Secretariat/Secretariat-General and the Technical Committees so as to be able to accomplish the tasks given by EFTA.

(b) CEN and Cenelec will call upon EFTA to participate in the meetings of the Technical Committees. An EFTA representative will be invited to take part in the meetings of the Technical Boards. CEN and Cenelec will report regularly on the state of progress of the work.

(c) In order to establish the grounds for wide recognition of the importance of European standards, CEN and Cenelec will ensure that the interested circles, especially public authorities, manufacturers, users, consumers, trade unions, can, if they so wish, be effectively associated with the drawing-up of European standards.

(d) CEN and Cenelec will ensure that the standards drawn up satisfy the essential requirements for the protection of citizens such as safety and health as well as other requirements set by EFTA in the mandates to be given to CEN and Cenelec. CEN and Cenelec will inform EFTA of difficulties encountered in standardization work requested by EFTA which are due to existing legal requirements within EFTA countries so that EFTA may recommend corrective efforts at government level.

(e) CEN and Cenelec will unify their voting procedures for the adoption of standards and ensure that the requirements to implement the results of European standardization work at national level are clearly defined.

(f) CEN and Cenelec will make every effort, within their competence in the case of harmonization documents, to ensure that national deviations are effectively removed by agreed deadlines.

Geneva, 30 April 1985

(signed)

For the European

Free Trade

Association

Per Kleppe

Secretary-General
For the European

Committee for

Standardization

P. Croon

President
For the European Committee

for Electrotechnical

Standardization

W.K. Wiechers

President 


\section{APPENDIX 5}

\section{COUNCIL}

\section{COUNCIL RESOLUTION}

of 18 June 1992

on the role of European standardization in the European economy

$\left(92 / C_{173 / 01)}\right.$

THE COUNCIL OF THE EUROPEAN COMMUNITIES,

1. RECALLING its conclusions on standardization of 16 July 1984 and its resolution of 7 May 1985 on a new approach to technical harmonization and standards (');

2. RECALLING the Community's policy of opening up public procurement, which gives importance to European standardization by requiring that the contracting authorities in Directives 71/305/EEC $\left({ }^{2}\right)$, $77 / 62 / \mathrm{EEC}\left({ }^{3}\right)$, and $90 / 531 / \mathrm{EEC}\left({ }^{4}\right)$ refer to European standards;

3. RECALLING the objectives of the Single Act, including the strengthening of economic and social cohesion;

4. RECALLING the Commission communication on an industrial policy in an open and competitive environment the conclusions of which were approved by the Council on 26 November 1990 ;

5. RECALLING the need for European standards to ensure the interoperability of the trans-European networks in the spirit of the conclusions of the Maastricht European Council;

6. TAKING INTO CONSIDERATION that the extensive and significant discussions among all the parties concerned on the future development of European standardization further to the publication of the
Commission communication of 16 October 1990 (") has highlighted the strategic importance of standardization for the European market;

7. TAKING INTO CONSIDERATION the opinion of the European Parliament ( $\left.{ }^{\circ}\right)$, and that of the Economic and Social Committee ("), the opinion of the interested parties expressed during consultations on that communication and the Commission communication to the Council dated 20 December 1991 on standardization in the European economy (");

8. REITERATES the importance of a cohesive system of European standards, organized by and for the parties concerned, based on transparency, openness, consensus, independence of vested interests, efficiency and decision-taking on the basis of national representations;

9. CONSIDERS that European standardization, while organized on a voluntary basis, also serves the public interest and therefore believes that it is necessary to pursue and extend a partnership at European level between the Community and the European standards organizations;

10. CONFIRMS the interest of an international standardization system capable of producing standards that are actually used by all the partners in international trade and of meeting the requirements of Community policy;

(5) OJ No C 20, 28. 1. 1991, p. 1

() Of No C $240,16.9 .1991$, p. 208

(') OJ No C 120, 6. 5. 1991, p. 28.

(c) OJ No C $96,15.4 .1992$, p. 2 .

() OJ No L $185,16.8 .1971$, p. 5.

(') OJ No L 13, 15. 1. 1977, p. 1.

(') OJ No L $297,29.10 .1990$, p. 1. 
11. ENDORSES the desire to avoid the fragmentation of work on European standardization and increased bureaucracy at the expense of efficiency;

12. WELCOMES the steps already taken by European standards organizations as part of the aforementioned discussions and in particular the decisions relating to efficiency, openness to economic and social partners organized at European level, the transparency of standardization activities and the visibility, accessibility and clear identification of European standards, cooperation with third countries, and the agreements with other international standards organizations, and expresses its interest in these efforts being pursued;

1.3. STRESSES the urgent need for high-quality European standards both for the application of Directives and the implementation of European policies and to respond to market needs;

14. STRESSES the need to increase the effective availability of European standards at national level through their systematic transposition into national standards, so that they may be widely circulated and Community acts efficiently applied;

15. STRESSES the importance of strengthening links between research and development activities and standardization;

16. WILL CONTINUE, wherever possible, the new approach set out in its resolution of 7 May 1985 (1) for the implementation of the Community's technical harmonization policy;

17. CONSIDERS that the use of European standards should be further encouraged as an instrument of economic and industrial integration within the European market and as a technical basis in support of legislation, in particular in defining technical specifications for products and services or for testing methods to be used in other areas falling within the scope of Community legislation;

18. INVITES the European standards organizations to strengthen their coordination in order to optimize the organization of work in view of the limited resources available;

19. ENCOURAGES the European standards organizations jointly to continue and increase their consultations on a regular basis with all the parties concerned, including small and medium-sized undertakings;

20. INVITES the European standards organizations to continue their discussions on a possible harmonized expression of conformity with European standards;

21. INVITES the Commission, where appropriate, to apply the principle of referring to European standards in furure draft Community legistation;

22. INVITES all interested economic circles to organize at European level and coordinate more closely in order to play a constructive and more effective part in their own right in European standardization activities;

23. INVITES Member States to take all appropriate measures to encourage their national standards organizations to comply with the common rules of European standards organizations of which they are members and take effective part in European standardization discussions;

24. UNDERTAKES TO CONTTNUE to grant financial aid, within the limits of overall budget constraints, to European standards organizations so that the standards required for Community legislation and policies can be developed.

(') OJ No C $136,4.6 .1985$, p. 1. 


\section{APPENDIX 6}

(Information)

\section{COUNCIL}

\section{COUNCIL RESOLUTION}

of 7 May 1985

on a new approach to technical harmonization and standards

$(85 / C$ 136/01)

\section{THE COUNCIL,}

in extension of its conclusions on standardization; approved on 16 July 1984 (Annex I);

emphasizes the urgent need to resolve the present situation as regards technical bäriers to trade and dispel the consequent uncertainty for economic operators;

emphasizes the importance and desirability of the new approach which provides for reference to standards - primarily European standards, but national ones if need be, as a transitional measure - for the purposes of defining the technical characteristics of products, an approach outlined by the Commission in its communication of 31 January 1985, which follows certain guidelines adopted by the European Parliament in its resolution of 16 October 1980 and forms part of the extension of the Council's conclusions of 16 July 1984;

arvare that the new approach will have to be accompanied by a policy on the assessment of conformity, calls on the Commission to give this matter priority and to expedite all its work in this area;

approves the guidelines encapsulated in the list of principles and main elements to be embodied in the main part of the Directives (Annex II to this resolution);

calls on the Commission to submit suitable proposals as soon as possible. 
ANNEX I

\section{CONCLUSIONS ON STANDARDIZATION}

Approved by the Council on 16 July 1984

The Council believes that standardization goes a long way wowards ensuring that indusurial products can be marketed freely and also towards creating a standard technical environment for undertakings in all countries, which improves competitiveness not only on the Community market but also on external. markets, especially in new technology.

If recognizes that the objectives being pursued by the Member States wo protect the safety and health of their people as well as the consumer are equally valid in principle, even if different techniques are used to achieve them.

Accordingly, the Council adopts the following principles for a European standardization:policy:

- agreement-by the. Member. Staus to keep a consunt check on the technical regulations -which are applied - whether de jure or de facto - on their territory so as wo withdraw those which are obsolete or unnecessary;

- agreement by the Member States to ensure the mutual recognition of the results of tests and the establishment, where necessary, of harmonized rules as regards the operation of cerrification bodies;

- agreement wo early Communiry consultation at an appropriate level, in accordance with the objectives of Directive 189/83/EEC where major national regulatory initiasives or procedures mighe have adverse repercussions on the operation of the internal market;

- extension of the Community practice in matters of technical harmonization of entrusting the task of defining the rechnical characteristics of produces to standards, preferably European but if necessary nazional, where the conditions necessary for this purpose, parricularly as regards health protection and safeky, are fulfilled;

- a very rapid surengthening of the capacity to standardize, preferably at European level, with a view wo facilitating on the one hand hamonization of legislation by the Community and on the other industrial development; particularly in the field of new technologies, since this could in specific circumstances involve the Community in introducing new procedures to improve the drawing up of standards (e.g. standardization bureaus, ad boc cornmittees). The adoption of European standards would be subriitited w the European standardization bodies for approval.

In high technology sectors particularly, subjects should be identified where common specifications and standards will make for efficient exploitation of the Community dimension and the opening of public works and supply contracts so that the decisions required in this connection may be taken.

\section{ANNEX II}

\section{GUIDELINES FOR A NEW APPROACH TO TECHNICAL HARMONIZATTON AND STANDARDS}

The following are the four fundameneal principies on which the new approach is based:

- legislative harmonization is limited to the adoption, by means of Directives based on Aricle 100 of the EEC Treaty, of the essential safety requirements (or other requirements in the general interest) with which"'products put on the market must conform, and which should therefore enjoy free movement throughout the Community,

- the eask of drawing up the technical specifications needed for the production and placing on the marke of products conforming to the essential requirements established by the Directives, while taking into account the current stage of technology, is entrusted to organizations competent in the standardization 2 reas 
- these technical specifications are not mandatory and maintain their status of voluntary standards,

- but at the same time nacional authorities are obliged w recognize that products manufactured in conformity with harmonized standards (or, provisionally, with national standards) are presumed to conform to the 'essential requirements' established by the Directive. (This signifies that the producer has the choice of not manufacturing in conformity with the standards but that in this event he has an obligation wo prove that his products conform to the essential requirements of the Directive.)

In order that this system may operate it is necessary:

- On the one hand that the standards offer a guarantee of quality with regard to the "essential . requirements' established by the Directives,

- on the other hand that the public authorities keep intace their responsibility for the protection of safety (or other requirements envisaged) on their territory.

The quality of harmonized standards must be ensured by standardization mandates, conferred by the Commission, the execution of which: must conform to the general guidelines which have been the subject of agreement berween the Commission and the European standardization organizations. In so far as national standards are concerned their quality must be verified by a procedure at Community level managed by the Commission, assisted by a standing committee composed of officials from national administrations.

At the same tine safeguard procedures must be provided for, under the management of the Commission assisted by the same committee, in order to allow the competent public authorities the possibility of contesting the conformity of a product, the validity of a certificate or the quality of a standard.

In following this system of legislative harmonization in each area in which it is feasible, the Commission intends to be able to halt the proliferation of excessively technical separate Directives for each product. The scope-of Directives according to the 'general reference to standards' formula should encompass wide product categories and types of risk.

The Community could on the one hand, therefore, complete the extremely complex underaking of harmonizing technical legislation and on the other-hand promote the development and application of European standards. These are essential conditions for the improvement of the compecitiveness of its industry.

OUTLINE OF..'THE PRINCIPLES AND MAIN ELEMENTS WHICH SHOULD MAKE UP THE BODY OF THE DIRECTIVES

\section{A. JUSTIIFICATIONS}

Amongst the traditional principles justifying a Directive the following aspects should be emphasized:

- Member States have the "responsibility of ensuring safety' on their territory (in the home, at the workplace, etc.) of persons, domestic animals and goods, or the respect of other essential protection requirements in the general interest such as health, consumer or environmental provection etc., with regard to the hazards covered by the Directive itself (');

- the nacional provisions ensuring such protection must be harmonized in order to ensure the free movement of goods, without lowering existing and justified levels of protection in the Member Sutes;

- CEN and CENELEC (one or the. other, or both according to the products covered by the Directive) are the competent bodies to adopt European harmonized standards within the scope of the Directive, in accordance with the guidelines which the Commission, after consultation of the Member States, has signed with these bodies ( $\left.{ }^{3}\right)$.

(') For reasons of convenience and ease of drafting the rest of this document refers only to safecy.

(2) For specific sectors of industrial activity ocher competent European bodier for the drawing up of cechnical specifications could be involved. 
1. In this outline a general approach is developed which should be applied according to the needs for legislation by Directives based on Article 100 of the Treaty relating to sectors or families of products as well as types of hazard.

2. The object of the Directive will be specified in each sphere of application according to the typea of hazard (safety, bealth, erivironmental, consumer protection, etc.) and should the need arise wo the circumstances (in the home, at the place of work, under road traffic, conditions, during leisure activities, etc.).

3. Where appropriate, it should be stated that the Member States may make provision, in accordance with Community law, for national regulations concerning the conditions for use of products covered by the scope of the Directive.

4. Concerning the objective mentioned in the second principle, it is obvious that it is carried into effect by the very adoption of the Directive under Article 100 of the Treaty, as the essential safety requirements contained in it are of such a nature as wo ensure the pursuit of such an objective.

\section{B: MAIN ELEMENTS}

\section{Scope}

Definition of the range of products covered, as well as the nature of the hazards it is intended to avert.

The scope should be defined in such a way that a consistent approach to the action is ensured, and that the proliferation of Directives on specific products is avoided. Moreover, it should be noted that the enacting terms of such 2 Directive do not preclude the possibility of several Direceives being adopted on one and the same product according to the various types of hazard associated with that product (for example, mechanical safety of a machine on the one hand and pollution by that machine on the other hand).

\section{General clause for placing on the market}

The products covered by the Directive may be placed on the market only if they do not endanger the safety of persons, domestic animals or goods when properly installed and maintained and used. for the purposes for which they are intended.

1.. The Directives would provide for total harmonization as a general rule. Consequently, any product placed on the market falling within the scope of the Directive must be in conformity with the requirements of the Directive. In cerrain specific conditions, optional harmonization for certain products may prove wo be opportune. The outline Directive, however, is drawn up with a vicw to total harmonization.

Appropriate solutions could be envisaged in order to take account of the need to suppore, in tome Member States, 2 harmonious move towards the introduction of a system of binding regulations, in order.in particular to ensure the establishment of appropriate certification infrastructures.

Point II therefore represents a general clause sesting out the responsibilities of the Member States in relation to the placing of goods on the market.

2. In order to respea the general principle on which the outline Direccive is based, which is to leave to the trade the choice of the means of attestation of conformity and thus to prohibit Member States from setting up any system of control prior to placing on the market (except; of course, in cases where prior control is required by specific Directives for special sectors, as is moreover clearly provided for in point VIII), is is obvious that the national auchorities in order wo acquit themselves of their responsibilities set out in this clause must be allowed to exercise control on the market by way of spot checks.

3. In certain cases, in particular with regard to the protection of workers and consumers, the conditions set out in this clause may be strengthened (foreseeable use).

\section{III: Essential safery requirements}

Deiscripsion of the safety requirements which are essential for the application of the general clause... in point II with which all products covered by the Directive must conform.

1. The essential safety requirements which must be met in the case of prodücts which can be put on the market shall be worded precisely enough in order w ereate, on transposition into nacional law, legally binding obligations which can be enforced. They should be so formulated as to enable the cerrification bodies straight away to certify products as being in conformity, 
having regard to those requirements in the absence of standards. The degree of detail of the wording will depend on the subject matter. If the basic requirements for safety are observed, the general clause in point II can be applied.

2. Amendments to these requirements can be made only by means of a new Council Directive under Article 100 of the Treaty.

\section{Free movement clause}

Obligation on the Member States to accept, under the conditions referred to in point V, the free movement of products which conform to points II and III.

1. Free movement will be ensured in the case of products declared to conform to the procection requirements laid down in the Directive, without recourse as a general rule to prior verification of compliance. with the requirements set out in point III, it being understood that note 2 of point II also applies in this case.

The interpretation to be given to this provision should not have the consequence that third party certification is to be systematically required by the sectoral Directives.

2. The actual aim of the Directives in question is to cover all essential requirements, but in the exceptional case of cover proving incomplete, it would always be possible for a Member State to act under Article 36 of the Treaty.

\section{Means of proof of conformity and effects}

1. Member States shall presume to be in conformity with points II and III products which are accompanied by one of the means of attestation described in point VIII declaring that they are in conformity with:

(a) the harmonized standards adopted by the European standardization body which is particularly competent within the scope of this Directive, when these standards are adopted in accordance with the general guidelines agreed between that body and the Commission and the references of which are published in the Official Joumal of the Exropean Communities; such publication should, moreover, also be carried out by the Member States;

(b) or as a transitional measure, and in so far as harmonized standards do not exist in the field covered by such standards, national standards referred to in paragraph.2.

2. Member States shall communicate to the Commission the text of those national standards which they consider to meet points Il and III. The Commission shall forthwith forward this text to the other Member States. In accordance with the procedure laid down in paragraph 2 of Point VI, the Commission shall notify the Member States of the national standards which enjoy the presumption of conformity with points II and III.

Member States are required to publish the references of these standards. The Comission shall also ensure that they are published in the Official Joumal of the European Communities.

3. Member States shall accept that the products for which the manufacturer has not applied any standard (because of absence of a standard as laid down in paragraphs 1 (a) and (b) above or for othër exceptional reasons, are considered to be in conformity with points II and III, when their conformity is demonstrated by one of the neans of attestation set out in point VIII, paragraph 1 (a) and (b).

1. Only those means of attestation provided for in point VIII necessarily carry presumption of conformity:

2. The presumption of conformity is constituted by the fact that the conformity of a product to harmonized or national standards is declared by one of the means of attestation set out. in point VIII. When the product is not in conformity with a standard, because the standards do not exist or because the manufacturer, for example in cases of innovation, prefers to apply other manufacturing criteria of his choice, conformity to points II and III is declared by the means of an attestation delivered by an independent body.

3. In cases under point V, paragraphs 1 and 3, Member States will therefore have the right, for the presumption to operate, to request at any time one of the means of attestation set out in point VIII. 
4. The drafting and adoption of the harmonized standards mentioned in paragraph 1 (a) by the CEN and CENELEC, these bodies being generally considered to be the "European standards bodies which are particularly -competent', and the obligation relating to transposition into national standards are governed by these two bodies' intermal rules and their regulations relating to standards work. The internal rules of CEN and CENELEC are in the procesi of being harmonized.

However, it is not ruled out that the harmonized standards referred to in paragraph 1 (a) will be prepared outside CEN and CENELEC by other bodies which may assume these functions in paricular areas; in such cases adoption of the harmonized standards shall be submitted for approval by CEN/CENELEC. In any case, the drafting and introduction of the harmonized standards referred to in point $V$...must be subject to the guidelines agreed between the Commission and these organizations. The guidelines deal in particular with the following principles and conditions:

- the availability of suitable staff and technical infrastructure at the standards body which the Commission mandates to proceed wich scandardization;

- the association of public authorities and interested circles (in particular manufacturers, users, consumers, unions);

- the adoption of harmonized standards and their transposition inw national standards or, at least, the annuiment of diverging national standards under conditions approved by the Commission when drawing up a frame of reference for standardization after consultation with the Member States.

5. In the selection of national standards, due considereration will be given to any practical difficulties arising from that selection.

National standards are selected only on 2.transitional basis. Accordingly, when a selection decision is made, the relevani European bodies will in principle be sene instructions to draf and adopt the corresponting European standards within a given period of time and under the conditions stated above.

\section{Manzgement of the list of standards}

1. Where a Member State or the Commission considers that harmonized standards or draft thereof do not fully satisfy points II and III, the Commission or the Mernber State shall bring this to the attention of the committee (point $X$ ) setting out the reasons. The commitue shal] give an opinion as 2 matter of urgency.

The Commission shall, in the light of the commitcee's opinion, notify the Member States of the necessity of withdrawing or not withdrawing the standard from the publication referred to in point $V$, paragraph 1 (2). It shall inform the European standards..body concerned and, if necessary, give it a new or revised mandace.

2. On receipt of the communication referred to in point $V$, paragraph 2 , the Commission shall consult the commitcee. After the committec has given its opinion, the Commission shall, within a given period, notify the Member States whether the rational standard in question thould or should not enjoy presumption of conformity and, if so, be subject to national publication of its references.

If the Commission or a Member State considers that a national standard no longer fulfils the conditions for presumption of conformity to the safery requirements, the Commission shall consult the committee. In the light of the opinion of the committee, it shall notify the Member Stater whether or not the standard in question should continue to enjoy presumption of conformity and in the latuer case be withdrawn from the publications referred to in point $V$, paragraph 2.

As indicated above (see notes to point V, paragraph 2) the Mernber -States have the power wo decide which of their national standards may be considered to be in conformity. with points II and III and thus be subject to the Commission confirmation procedure.

\section{Safeguard clause}

1. Where-a Member State finids that a produci might compromise the safety of individuals, domestic animals or property, it shall take all appropriate measures wo withdraw of prohibit the placing on the market of the product in question or to restrict its free movement even if it is accompanied by one of the means of attestation seferred 10 in point VIII. 
Within a given period of time, and only when the product in question is accompanied by one of the means of attestation provided for in point VIII, the Member State shall inform the Commission of such 2 measure. It will indicate the reasons for its decision and in particular whecher the non-conformity results from:

(a) non-compliance with points II and III (when the product does not conform wo any standard);

(b) incorrect application of the standards referred to in point $\mathrm{V}$;

(c) a shortcoming in the standards themselves.

2. The Commission shall consult the Member States concerned as soonias possible. If the Member Stave: which has taken measures intends to maintain them, the Commission shall refer the matter w the committee within a specified period. Where the Commission, after consultation of the commitree, finds that the action is justified it shall, also within a given period of time, inform the Member State in question and point out to: the other Member States that (all else being equal) they are also obliged to prevent the product in question from being placed on the market.

3. Where failure of the product to comply with points II and III results from a shortcoming in the hermonized standards or in the national standards, the consequences shall be those set out in point VI.

4. Where the non-conforming product is aceompanied by a means of attestation issued by an independent body or by the manufacturer, the competent Member Stare shall take the appropriate measures against the author of the atcestation and inform the Commission and the other Member States.

5. The Commission shall ensure that all Member States are kept informed of the progress and of the outcome of this procedure.

This point describes the consequences when recourse by a Member Stace to the safeguard clause appears to be justified. It does not give any indication on the consequences when recourse does not appear to be justified after expiry of the Community examination procedure, because in such cases the general rules of the Treaty apply.

\section{Means of attestation of conformity}

1: The means of attestation referred to in point $\mathrm{V}$ which the trade may use are:

(a) certificates and marks of conformity issued by a third party;

(b) results of rests carried out by a chird parny;

(c) declaration of conformity issued by the manufacturer or his agent based in the Community. This may be coupled with the requirement for a surveillance system;

(d) other means of attestation which could possibly be determined in the Directive.

2. The choice by trade and industry between these different means may be limited, or even removed, according to the nature of the products and hazards covered by the Directive.

3. National-bodies authorized to issue marks or certificates of conformity shall be notified by each Member State to the Commission and to the other Member States.

1. The appropriate means of attestation will be established and expanded in the specific Directives taking into account the special requirements of their scope. It must be borne in mind that the cerification bodies designated by the Member States for cases (a) and (b) will have to intervene in particular in the absence of standards and where the manufacturer does not observe standards (see point V, paragraph 3).

2. The bodies referred to in paragraph 3 must carry out their duties according to recognized international practices and principles and especially in accordance with ISO Guides. The resporisibility for the control of the operation of these bodies lies with the Member States. Questions concerning the carrying out of tests and certification may be put before the committee set up under point $\mathrm{IX}$. 
3. With regard to the manufacturer's declaration of conformity, the national authorities have the right to ask the manufacturer or the importer to communicate the data relating to the tests carried out concerning safety etc., when they have good grounds for believing that a product does not offer the degree of safety required in all respects. Refusal on the part of the manufacturer or the importer to comunicale these data constitutes sufficient reason to doubt the presumption of conformity.

4. The determination of a limitative list of means of attestation only concerns the system of presumption of conformiry but cannot have the effect of restricting the possibility for a member of the trade wo prove, by any means he sees. fit within the framework of a dispute or cour proceedings, the conformity of the product with points II and III.

\section{Standing committee -}

A standing committee shall be set up chaired by a representative of the Commission and consisting of representatives appointed by the. Member States who may avail themselves of the help of experts or advisers.

The committee shall be convened by its chairman either on his own initiative or at the request of a Member State.

The committee shall draw up its own rules of procedure.

\section{$X$. Tatks and operation of the committe}

1. The committee shall carry out the tasks entrusted to in by virtue of the foregoing points.

2. Furchermore, any question regarding the implementation of a Directive may be submitted to the committee.

The tasks of the commitree shall be concerned with the implementation of the Directive. The object of the consultation of the Commitree prior to the publication of the references of the national scandards is more to provide for a formm for the discussion of the objections which the Commission or a Member State may formulate, than to carry out a systematic examination of the entire contents of the stand ards.

\section{Criteria for choosing the priority areas in which this approach could initially be applied}

1. The need to find 2. new approach to the harmonization of technical regulations, based on 'general reference to standards' and following the lines described earlier, is the outcome of a number- of conditions (oudlined in the first part of this communication) backed up by the experience already acquired by the Community. Consequently it is a general principle, the validity of. which will have to be assessed in practical terms in the various areas in which it will be applied.

The Council rook a similar view in its 'Conclusions' of 16 July 1984 when it confirmed the general need for an extension of the 'general reference to standards' practice, but only provided the necessary conditions were fulfilled, $i$. e. as regards the obligation on public authorities to protect the health and safety of their citizens.

2. Before the priority.areas in which this approach should initially be applied can be chosen, it is therefore necessary to establish a number of selection criteria to bë taken into consideration, eriteria which cannot be taken separacely.

(a) Since the approach calls for the 'essential requirements" to be harmonized and made mandatory by Directives based on Article 100 of the. Treaty, the 'general reference to standards'. approach will be appropriate only where it is genuinely possible to distinguish between 'essential requirements' and 'manufacturing specifications'. In other words, in all areas in which the essential requirements in she public interest are such that a large number of manufacturing specifications have to be included if the public authorities are to keep intact their responsibility for protection of their citizens, the conditions for the 'general reference to standards' approach are not fulfilled as this approach would have little sense. In the light of this statement areas involving safery protection cerrainly appear to have priority over those involving healch protection (which applies to the scope of Directive 83/189). 
(b) If 'general reference to standards' is to be possible, the area concerned must be covered by, or be capable of being covered by, standardization. Areas which are inherently ill suited to standardiz. ation work are certainly the areas referred to in (a) above where the need for regulations is felt unanimously throughout the Community. In other areas there is a standardization capacity or potential and in the latter case the Community should encourage it in close cooperation with both the industry concerned and the European standards bodies, whilst ensuring that the interests of consumers are taken into account.

(c) The progress of technical harmonization work in the Community under the general programme established by the Council resolutions of 1969 and 1973 varies greatly from one industrial sector to another. In manufacturing industry (which appears at first sight better to fulfil the abovementioned criteria) most of the Directives adopted concern three areas: mowr vehicles, metrology and electrical equipment.

The new approach will therefore have to take this state of affairs into account and concentrate mainly on other areas in which there is a lack of Community activities (e.g. many engineering products and building materials) without calling into question regulations that are already well advanced (for example those referring to mowor vehicles). The case of electrical equipment is different: this is the only area to have been tackled by a Directive of the 'general reference to standards' type and should certainly be included in the priority areas for all such products not yet covered, in view of the extremely imporiant part played in this area by international and European standardization.

(d) One of the main purposes of the new approach is to make it possible to settle at a stroke, with the adoption of a single Directive, all the problems concerning regulations: for a very large number of products, without the need for frequent amendments or adaptations to that Directive: Consequently in the selected areas there should be a wide range of products sufficiendy homogeneous 20 allow common 'essential requirements' to be defined. This general criterion is, however, based mainly on practical and labour-saving considerations. There is nothing to prevent a single type of product, in certain cases, from being covered by the 'general reference to standards' formula if all the abovementioned criteria are met.

(e) Finally, mention should be made of one criterion that the Commission, in agreement with industry, has always regarded as essential. There must be grounds for considering that the existence of different regulations does in practice genuinely impede the free movement of goods. In some cases, however, even if these grounds are not obvious, a Directive may appear necessary to protect an essential public interest uniformly throughout the Community. 


\section{APPENDIX 7}

\section{COUNCIL}

\section{COUNCIL RESOLUTION}

of 21 December 1989

on a global approach to conformity assessment

$\left(90 / C_{10 / 01)}\right.$

\section{THE COUNCIL OF THE EUROPEAN COMMUNITIES,}

RECALLING its resolution of 7 May 1985 on a new approach to technical harmonization and standards (') in which it stated that the new approach should be accompanied by a policy on the assessment of conformity;

RECALLING the objectives of the Single European Act, including the strengthening of economic and social cohesion;

STRESSES the importance of a global approach in this area, as outlined by the Commission in its communication of 24 July $1989\left({ }^{3}\right)$, with the aim of creating the conditions which will enable the principle of mutual recognition of proofs of conformity to operate in both the regulatory and the non-regulatory sphere;

TAKING INTO CONSIDERATION the basic lines of that approach,

HEREBY ADOPTS the following guiding principles for a European policy on conformity assessment:

- a consistent approach in Community legislation
should be ensured by devising modules for the
various phases of conformity assessment procedures
and by laying down criteria for the use of those
procedures, for the designation and notification of
bodies under those procedures, and for use of the EC
mark,
- generalized use of the European standards relating to
quality assurance (EN 29000) and to the

(') OJ No C $136,4.6 .1985$, p. 1.

(2) OJ No C 231, 8. 9. 1989, p. 3, and

OJ No C 267, 19. 10. 1989, p. 3. requirements to be fulfilled by the abovementioned bodies concerned (EN 45000), the setting-up of accreditation systems and the use of techniques of intercomparison should be promoted in all Community Member States as well as at Community level,

- the promotion of mutual recognition agreements on certification and testing between bodies operating in the non-regulatory sphere is essential for the completion of the internal market; the setting-up of a flexible, unbureaucratic testing and cerrification organization at European level with the basic role of promoting such agreements and of providing a prime forum within which to frame them should significantly contribute to the furtherance of that objective,

- possible differences in levels of development in the Community and in industrial sectors with regard to quality infrastructure (especially calibration and metrology systems, testing laboratories, certification and inspection bodies, and accreditation systems) such as are likely to have an adverse effect on the operation of the internal market should be studied with a view to the preparation of a programme of Community measures, possibly including budgetary measures, as soon as possible,

- in its relations with third countries the Community will endeavour to promote international trade in regulated products, in particular by concluding mutual recognition agreements on the basis of Article 113 of the Treaty in accordance with Community law and with the Community's international obligations, while ensuring in the latter case that:

- the competence of the third counzry bodies is and remains on a par with that required of their Community counterparts, 
- the mutual recognition arrangements are confined to reports, certificates and marks drawn up and issued directly by the bodies designated in the agreements,

- in cases where the Community wishes to have its own bodies recognized, the agreements establish a balanced situation with regard to the advantages derived by the parties in all matters relating to conformity assessment for the products concerned.

The Commission is requested to submit recommendations to the Council as soon as possible for detailed negotiating directives under Article 113 of the Treaty.

The Council also calls on the Commission to prepare the measures necessary to put this resolution into practice. 


\title{
APPENDIX 8
}

(Acts whose publication is not obligatory)

\section{COUNCIL}

\author{
COUNCIL DECISION \\ of 13 December 1990 \\ concerning the modules for the various phases of the conformity assessment procedures which \\ are intended to be used in the technical harmonization directives
}

(90/683/EEC)

\section{THE COUNCLL OF THE EUROPEAN COMMUNITIES,}

Having regard to the Treaty establishing the European Economic Community, and in particular Article 100a thereof,

Having regard to the proposal from the Commission ('),

In cooperation with the European Parliament ( $\left.{ }^{2}\right)$,

Having regard to the opinion of the Economic and Social Committee ( $\left.{ }^{3}\right)$,

Whereas the Council adopted a resolution on 21 December 1989 concerning a global approach to conformity assessment ( ${ }^{4}$ );

Whereas the introduction of harmonized methods for the assessment of conformity and the adoption of a common doctrine for their implementation are likely to facilitate the adoption of future technical harmonization directives concerning the placing on the market of industrial products and thus be conducive to the completion of the internal market by 31 Decernber 1992;

Whereas such methods should ensure that products are in full conformity with the essential requirements laid down in the technical harmonization directives, in order to provide, in particular, for the health and safety of users and consumers;

Whereas such conformity should be assured without imposing unneccessarily onerous conditions on manufacturers, and by means of clear and comprehensible procedures;

Whereas limited flexibility should be introduced as regards use of additional modules, or variations in the modules, when the specific circumstances of a particular sector or directive so warrant, but not to such a degree as to undercut the purpose of the current Decision and only when explicitly justified,

\section{HAS DECIDED AS FOLLOWS:}

\section{Sole Article}

The procedures for conformity assessment which are to be used in the technical harmonization directives relating to the marketing of industrial products will be chosen from among the modules listed in the Annex and in accordance with the criteria set out in this Decision and in the general guidelines in the Annex. These procedures may only depart from the modules when the specific circumstances of a particular sector or directive so warrant. Such departures from the modules must be limited in extent and must be explicitly justified in the relevant directive. The Commission will report periodically on the functioning of this Decision, and on whether conformity assessment procedures are working satisfactorily or need to be modified.

Done at Brussels, 13 December 1990.

(i) OJ No C $231,8.9 .1989$, p. 3.

(2) OJ No C 149,18.6.1990, p. 162 and Decision of 21 November 1990 (not yet published in the Official Journal).

(J) OJ No C 112, 7. S. 1990, p. 4.

(4) OJ No C 10, 16.1.1990, p. 1. 
ANNEX

\section{CONFORMITY ASSESSMENT PROCEDURES IN THE TECHNICAL HARMONIZATION DIRECTIVES}

\section{GENERAL GUIDELINES}

The principal guidelines for the use of conformity assessment procedures in technical harmonization directives are the following:

(a) the essential objective of a conformity assessment procedure is to enable the public authorities to ensure that products placed on the market conform to the requirements as expressed in the provisions of the directives, in particular with regard to the bealch and safety of users and consumers;

(b) conformity assessment can be subdivided into modules which relate to the design phase of products and to their production phase;

(c) as a general rule a product should be subject to both phases before being able to be placed on the market if the results are positive (");

(d) there are a variety of modules which cover the two phases in a variety of ways. The directives shall set the range of possible choices which can be considered by the Council to give the public authorities the high level of safety they seek, for a given product or product sector;

(c) in setting the range of possible choices open to the manufacturer, the directives, will take into consideration, in particular, such issues as the appropriateness of the modules to the type of products, the nature of the risks involved, the economic infrastructures of the given sector (e.g. existence or non-existence of third parties\}, the rypes and importance of production, etc. The factors that have been taken into account must be explicitly spelled out by the Commission in these directives;

(f) the directives will, in serting the range of possible modules for a given product or product sector, attempt to leave as wide a choice to the manufacturer as is consistent with ensuring compliance with the requirements.

The Directives will set out the criteria governing the conditions in which the manufacturer shall choose the most appropriate modules for his production from the modules laid down by the directives; .

(g) the directives should avoid imposing unnecessarily modules which would be too onerous relative to the objectives of the directive concerned;

(h) notified bodies shopld be encour aged to apply the modules without unnecessary burden for the economic operators. The Commission, in cooperation with the Member States, shall ensure that close cooperation is organized berween the notified badies in order to ensure consistent technical application of the modules;

(i) in order to protect the manufacturers, the technical documentation provided to notified bodies has to be limited to that which is required solely for the purpose of assessment of conformity. Legal protection of confidential information shall be required;

(j) whenever directives provide the manufacturer with the possibility of using modules based on quality assurance techniques, the manufacturer must also be able to have recourse to a combination of modules not using quality assurance, and vice versa, except where compliance with the requirements laid down by the directives requires the exclusive application of a certain procedure;

(k) for the purposes of operating the modules, Member States shall notify on their own responsibility bodies under their jurisdiction which they have chosen from the technically competent bodies complying with the reguirements of the directives. This responsibility involves the obligation for the Member States to ensure that the notified bodies permanently have the technical qualifications requited by the directives and that the latter keep their competent national authorities informed of the performance of their tasks. Where 2 Member State withdraws its notification of a body, it shall take appropriate steps to ensure that the dossiers are processed by another notified body to ensure continuity;

(l) in addition, with regard to conformity assessment, the sub-contracting of work shall be subject to certain conditions guarantceing;

- the competence of the establishment operating as sub-contractor, on the basis of conformity with series EN 45000 standards, and the capability of the Member State that has notified the sub-contracting body to ensure effective monitoring of such compliance,

(") The specific directives may provide for different arrangements. 
- the ability of the body notified to exercise effective responsibility for the work carried out under sub-contract;

(m) notified bodies which can prove their conformity with harmonized standards (EN 45000 series), by submitting an accreditation certificate or other documentary evidence, shall be presumed to conform to the requirements of the directives. Member States having notified bodies unable to prove their conformity with the harmonized standards (EN 45000 series) may be requested to provide the Commission with the appropriate supporting documents on the basis of which notification was carried out;

(n) a list of notified bodies shall be published by the Commission in the Official Journal of the European Communities and constantly updated.

\section{MODULES FOR CONFORMITY ASSESSMENT}

\section{Explanatory notes}

Specific directives may allow the CE mark to be affixed to the packaging or the accompanying documentation, instead of to the product itself.

The declaration of conformity or the certificate of conformity (whichever of the two applies in the directive concerned) shall cover either individual or several products and shall either accompany the product(s) covered or be kept by the manufacturer. The appropriate solution for the directive concerned will be specified.

References to articles refer to the standard paragraphs of Annex I1.B to the Council resolution of 7 May 1985 (OJ No C 136, 4, 6. 1985, p. 1), which have become standard articles in the 'new approach' directives.

The development of computerized communication of certificates and other documents issued by notified bodies is envisaged within INSIS.

Specific directives may use modules $A, C$ and $H$ with additional provisions containing supplementary requirements which figure in the boxes in the modules.

Module $C$ is designed to be used in combination with module $B$ (EC type examination). Modules $D, E$ and $F$ will also normally be used in combination with module $B$; however, in special cases (for example, when dealing with certain products of very simple design and construction) they may be used on their awn.

\section{Module A (internal production control)}

1. This module describes the procedure whereby the manufacturer or his authorized representative established within the Community, who carries out the obligations laid down in point 2, ensures and declares that the products concerned satisfy the requirements of the directive that apply to them. The manufacturer shall affix the CE mark to each product and draw up a written declaration of conformity.

2. The manufacturer shall establish the technical documentation described in paragraph 3 and he or his authorized representative established with the Community shall keep it for a period ending at least 10 years $\left({ }^{\circ}\right)$ after the last product has been manufactured at the disposal of the relevant national authorities for inspection purposes.

Where neither the manufacturer nor his authorized representative is established within the Community, the obligation to keep the technical documentation available shall be the sesponsibility of the person who places the product on the Community market.

3. Technical documentation shall enable the conformity of the product with the requirements of the directive to be assessed. It shall, as far as relevant for such assessment, cover the design, manufacture and operation of the produce $(*)$.

(") The specific directives may alter this period.

(*) The content of the technical documentation shall be laid down directive by directive in accordence with the producte concerned.

For example, the documentation shall contain so far as relevant for assessment

- aeneral description of the product,

- conceptual detign and manufacturing drawings and schemes of components, sub-assemblies, circuits, etc.,

- descriptions and explanations necessary for the understanding of said drawings and schemes and the operation of the product,

- a list of the standards referred to in Arricle $S$, applied in full or in part, and descriptions of the solutions adopted to meet the essential requirements of the directive where the standards referred to in Article 5 have not been applied,

- resulks of design calculations made, examinations carried out, etc.

- eest reports. 
4. The manufacturer or his authorized representative shall keep a copy of the declaration of conformity with the technical documentation.

5. The manufacturer shall take all measures necessary in order that the manufacturing process shall ensure compliance of the manufactured products with the technical documentation referred to in point 2 and with the requirements of the directive that apply to them.

\section{Module Aa}

This module consists of module $A$, plus the following supplementery requirements:

For each product manufactured one or more tests on one or more specific aspects of the product shall be carried out by the manufacturer or on his behalf ("). The tests shall be carried out on the responsibility of a notified body chosen by the manufacturer.

On the responsibility of the notified body, the manufacturer shall affix the former's identification symbol during the manufacturing process.

(*) If this option is adopted in a specific directive, the products concerned and the tests to be carried our must be upecified.

or:

A notified body chosen by the manufacturer shall carry out or have carried out product checks at random intervals. An adequate sample of the final products, taken on site by the notified body, shall be examined and appropriate tests as set out in the relevant standard(s) referred to in Article S, or equivalent tests, thall be carried out to check the conformity of the product with the relevant requirements of the directive.

In those cases where one or more of the products checked do not conform the notified body shall take appropriate measures.

The product checking shall include the following aspects:

(Relevant aspects shall be specified here such as for example the staristical method to be applied, the sampling plan with its operational characteristics, etc.)

On the responsibility of the notified body, the manufacturer shall affix the former's identification symbol during the manufacturing process.

\section{Module B (EC type-examination)}

1. This module describes that part of the procedure by which a notified body ascertains and attests that a specimen, representative of the production envisaged, meets the provisions of the directive that apply to

2. The application for the EC type-examination shall be lodged by the manufacturer or his authorized representative established within the Community with a notified body of his choice.

The application shall include:

- the name and address of the manufacturer and, if the application is lodge by the authorized representative, his name and address in addirion,

- a written declaration that the same applicarion bas not been lodged with any other norified body,

- the rechnical documentation, as described in point 3.

The applicant shall place at the disposal of the notified body a specimen, repesentative of the production envisaged and hereinafter called "rype" ("). The notified body may request further specimens if needed for carrying out the test programme.

(") A type may cover weveral versions of the product provided that the differences betwen the versions do not affect the level of safety and the other requirementu concerning the perfortance of the product. 
3. The technical documentation shall enable the conformity of the product with the requirements of the directive to be assessed. It shall, as far as relevant for such assessment, cover the design, manufacture and operation of the product $(*)$.

4. The notified body shall:

4.1. examine the technical documentation, verify that the type has been manufactured in conformiry with the technical documentation and identify the elements which have been designed in accordance with the relevant provisions of the standards referred to in Article 5, as well as the components which have been designed wirhout applying the relevant provisions of those standards;

4.2. perform or have performed the appropriate examinations and necessary tests to check whether, where the standards referred to in Article 5 have not been applied, the solutions adopted by the manufacturer meet the essential requirements of the Directive;

4.3. perform or have performed the appropriate examinations and necessary tests to check whether, where the manufacturer has chosen to apply the relevant standards, these have actually been applied;

4.4. agree with the applicant the location where the examinations and riecessary tests shall be carried out.

5. Where the type meets the provisions of the directive, the notified body shall issue an EC type-examination certificate to the applicant. The certificate shall contain the name and address of the manufacturer, conclusions of the examination, conditions for its validity and the necessary data for identification of the approved type (**).

A list of the relevant of the technical documentation shall be annexed to the certificate and a copy kept by the notified body.

If the manufacturer is denied a type certification, the notified body shall provide detailed reasons for such denial.

Provision shall be made for an appeals procedure.

6. The applicant shall inform the notified body that holds the technical documentation concerning the EC type-examination certificate of all modifications to the approved product which must receive additional approval where such changes may affect the conformity with the essential requirements or the prescribed conditions for use of the product. This additional a pproval is given in the form of an addition to the original EC rype-examination certificate.

7. Each notified body shall communicate to the other notified bodies the relevant information concerning the EC type-examination certificates and additions issued and withdrawn (***).

8. The other notified bodies may receive copies of the EC type-examination certificates and/or their additions. The annexes to the certificates shall be kept at the disposal of the other notified bodies.

9. The manufacturer or his authorized representative shall keep with the technical documentation copies of EC type-examination certificates and their additions for a period ending at least 10 years (* ") a fter the last product has been manufactured.

Where neither the manufacturer nor his authorized representative is established within the Community, the obligation to keep the technical documentation available shall be the responsibility of the person who places the product on the Community market.

(") The content of the technical documentation shall be laid down directive by directive in accordance with the products concerned:

concerned.
For example, the documentation shall contain as far as is relevant for assessment:

- a general type-description,

- conceptual design and manufacturing drawings and schemes of components, sub-assemblies, circuits, etc.,

- descriptions and explanations necessary for the understanding of said drawings and schemes and the operation of the product,

- a list of the usandards referred to in Article $\$$, applied in full or in part, and descriptions of the solutions adopted to meer the escential requirements of the directive where the standards referred to in Article $S$ have not been applied,

- results of design calculations made, examinations carried out, etc.,

- test reports.

(*) The opecific directives may provide for the certificate to have a period of validity.

(*+*) The specific directives may provide for different arrangements.

(***) The specific directives may alter this period. 
Module C (conformity to type)

1. This module describes that part of the procedure whereby the manufacturer or his authorized representative established within the Community ensures and declares that the products concerned are in conformity with the type as described in the EC type-examination certificate and satisfy the requirements of the directive that applies to them. The manufacturer shall affix the CE mark to each product and draw up a written declaration of conformity.

2. The manufacturer shall take all measures necessary to ensure that the manufacturing process assures compliance of the manufactured products with the type as described in the EC type-examination certificate and with the requirements of the directive that apply to them.

3. The manufacturer or his authorized representative shall keep a copy of the declaration of conformity for 2 period ending at least 10 years $\left({ }^{*}\right)$ after the last product has been manufactured.

Where neither the manufacturer nor his authorized representative is established within the Community, the obligation to keep the technical documentation available shall be the responsibility of the person who places the product on the Community market.

Possible supplementary requirements:

For each product manufactured one or more tests on one ar more specific aspects of the product shall be carried our by the manufacturer or on his behalf $(*)$. The rests shall be carried out on the responsibility of $a$ notified body, chosen by the manufacturer.

On the responsibility of the notified body, the manufacturer shall affix the former's identification symbol during the manufacturing process.

(") If this option is adopted in a specific directive, the products concetned and the tests to be carried out muke be specified.

or:

A notified body chosen by the manufacturer shall carry out or have carried out product checks at random intervals. An adequate sample of the final products, taken on site by the notified body, shall be examined and appropriate tests as set out in the relevant standard(s) referred to in Article 5 , or equivalent tests, shall be carried out to check the conformity of production with the relevant requirements of the directive. In those cases where one or more of the products checked do not conform, the notified body shall cake appropriate measures.

The product checking shall include the following aspects:

(Relevanx aspects shall be specified here such as for example the statistical method to be applied, the sampling plan with its operational characteristics, etc.)

On the responsibility of the notified body, the manufacturer shall affix the former's identification symbol during the manufacturing process.

Module D (**), (production quality assurance)

1. This module describes the procedure whereby the manufacturer who satisfies the obligations of point 2 ensures and declares that the products concerned (are in conformity with the type as described in the EC type-examination certificate and] satisfy the requirements of the directive that apply to them. The manufacturer shall affix the CE mark to each product and draw up a written declaration of conformity. The EC mark shall be accompanied by the identification symbol of the notified body responsible for EC monitoring as specified in point 4 .

2. The manufacturer shall operate an approved quality system for production, final praduct inspection and testing as specified in paragraph 3 and shall be subject to monitoring as specified in point 4.

(*) The apecific directives may alter this period.

(*) Where this module is used without module $B$

- points 2 and 3 of module $A$ must be added berween points 1 and 2 in order to incorporate the need for technical documerisation.

- the words in square brackers must be deleted. 
3. Quality system

3.1. The manufacturer shall lodge an application for assessment of his quality system with a notified body of his choice, for the products concerned.

The application shall include:

- all relevant information for the product category envisaged,

- the documentation concerning the quality system,

- if applicable, the technical documentation of the approved type and a copy of the EC type-examination certificate.

3.2. The quality system shall ensure compliance of the products (with the type as described in the EC type-examination certificate and] with the requirements of the directive that apply to them.

All the elements, requirements and provisions adopted by the manufacturer shall be documented in a systematic and orderly manner in the form of written policies, procedures and instructions. The quality system documentation must permit a consistent interpretation of the quality programmes, plan, manuals and records.

It shall contain in particular and adequate description of:

- the quality objectives and the organizational structure, responsibilities and powers of the management with regard to product quality,

- the manufacturing. quality control and quality assurance techniques, processes and systematic actions that will be used.

- the examinations and tests that will be carried out before, during and after manufacture, and the frequency with which they will be carried out,

- the quality records, such as inspection reports and test data, calibration data, qualification reports of the personnel concerned, etc.,

- the means to monitor the achievement of the required product quality and the effective operation of the quality system.

3.3. The notified body shall assess the quality system to determine whether it satisfies the requirements referred to in point 3.2. It shall presume conformity with these requirements in respect of quality systems that implement the relevant harmonized standard (*).

The auditing tearn shall have at least one member with experience of evaluation in the product technology concerned. The evaluation procedure shall include an inspection visit to the manufacturer's premises.

The decision shall be notified to the manufactuer. The notification shall contain the conclusions of the examination and the reasoned assessment decision.

3.4. The manufacturer shall undertake to fulfil the obligations arising out of the quality system as approved and to uphold it so that it remains adequate and efficient.

The manufactuer or his authorized representative shall keep the notified body that has approved the quality system informed of any intended updating of the quality system.

The notified body shall evaluate the modifications proposed and decide whether the amended quality system will still satisfy the requirements referred to in paragraph 3.2 or whether a re-assessment is required.

It shall notify its decision to the manufacturer. The notification shall contain the conclusions of the examination and the reasoned assessment decision.

4. Surveillance under the responsibility of the notified body

4.1. The purpose of surveillance is to make sure that the manufacturer duly fulfils the obligations arising out of the approved quality system.

4.2. The manufacturer shall allow the notified body entrance for inspection purposes to the locations of manufacture, inspection and testing, and storage and shall provide it with all necessary information, in particular:

- the quality system documentation,

- the quality records, such as inspection reports and test data, calibration data, qualification reports of the personnel concerned, etc.

(") This harmonized standard will be EN 29002 , supplemented, if necessary, to take into account the specific nature of the producs for which is is implemented. 
4.3. The notified body shall periodically $\left\langle^{*}\right)$ carry out audits to make sure that the manufacturer maintains and applies the quality system and shall provide an audit report to the menufacturer.

4.4. Additionally the notified body may pay unexpected visits to the manufacturer. During such visits the notified body may carry out, or cause to be carried out, tests to verify that the quality system is functioning correctly, if necessary. The notified body shall provide the manufacturer with a visit report and, if a test has taken place, with a test report.

5. The manufacturer shall, for a period ending at least 10 years (" ") after the last product has been manufactured, keep at the disposal of the national authorities:

- the documentation referred to in the second indent of point 3.1

- the updating referred to in the second paragraph of point 3.4,

- the decisions and reports from the notified body which are referred to in the final paragraph of point 3.4 , points 4.3 and 4.4 .

6. Each notified body shall give the other notified bodies the relevant information concerning the quality system approvals issued and withdrawn (" ").

\section{Module E $\{* * *)$ (product quality assurance)}

1. This module describes the procedure whereby the manufacturer who satisfies the obligations of point 2 ensures and declares that the products concerned fare in conformity with the type as described in the EC type-examination certificate and] satisfy the requirements of the directive that apply to them. The manufacturer shall affix the $\mathrm{CE}$ mark to each product and draw up a written declaration of conformity. The CE mark shall be accompanied by the identification symbol of the notified body responsible for surveillance as specified in point 4.

2. The manufacturer shall operate an approved quality system for final product inspection and testing as specified in paragraph 3 and shall be subject to surveillance as specified in point 4.

3. Quality system

3.1. The manufacturer shall lodge an application for assessment of his qualiry system for the products concerned, with a notified body of his choice.

The application shall include:

- all relevant information for the product category envisaged,

- the quality system's documentation,

- if applicable, the technical documentation of the approved type and a copy of the. EC type-examination certificate.

3.2. Under the quality system, each product shall be examined and appropriate tests as set out in the relevant standard(s) referred to in Article 5 or equivalent tests shall be carried out in order to ensure its conformity with the relevant requirements of the directive. All the elements, requirements and provisions adopted by the manufacturer shall be documented in a systematic and orderly manner in the form of written policies, procedures and instructions. This quality system documentation shall ensure a common understanding of the quality programmes, plans, manuals and records.

It shall contain in particular and adequate description of:

- the quality objectives and the organizational structure, responsibilities and powers of the management with regard to product quality;

- the examinations and tests that will be carried out after manufacture, .

- the means to monitor the effective operation of the quality system,

- quality records, such as inspection reports and test data, calibration data, qualification reports of the personnel concerned, etc.

(") In the specific directives, the frequency may be specified.

(*) The specific directives may alter this period.

(i**) The specific directives may provide for different arrangements.

(a...) When this module is uned without module B:

- points 2 and 3 of module $A$ must be added between points 1 and 2 in order to incorporate the need for technical documentation,

- the words in square brackets musa be deleted. 
3.3. The notified body shall assess the quality system to determine whether it satisfies the requirements referred to in point 3.2. It shall presume conformity with these requirements in respect of quality systems that implement the relevant harmonized standard (*).

The auditing team shall have at least one member experienced as an assessor in the product technology concerned. The assessment procedure shall include an assessment visit to the manufacturer's premises.

The decision shall be notified to the manufacturer. The notification shall contain the conclusions of the examination and the reasoned assessment decision.

3.4. The manufacturer shall undertake to discharge the obligations arising from the quality system as approved and to maintain it in an appropriate and efficient manner.

The manufacturer or his authorized representative shall keep the notified body which has approved the quality system informed of ant intended updating of the quality system.

The notified body shall evaluate the modifications proposed and decide whether the modified quality system will still satisfy the requirements referred to in paragraph 3.2 or whether a re-assessment is required.

It shall notify its decision to the manufacturer. The notification shall contain the conclusions of the examination and the reasoned assessment decision.

4. Surveillance under the responsibility of the notified body

4.1. The purpose of surveillance is to make sure that the manufacturer duly fulfils the obligations arising out of the approved quality system.

4.2. The manufacturer shall allow the notified body entrance for inspection purposes to the locations of inspection, testing and storage and shall provide it with all necessary information, in particular:

- the quality system documentation,

- the technical documentation,

- the quality records, such as inspection reports and test data, calibration data, qualification reports of the personnel concerned, etc.

4.3. The notified body shall periodically (**) carry out audits to ensure that the manufacturer maintains and applies the quality system and shall provide an audit report to the manufacturer.

4.4. Additionally, the notified body may pay unexpected visits to the manufacturer. At the time of such visits, the notified body may carry out rests or have them carried out in order to check the proper functioning of the quality system where necessary; it shall provide the manufacturer with a visit report and, if a test has been carried out, with a test report.

5. The manufacturer shall, for a period ending at least 10 years $(* \cdots)$ after the last product has been manufactured, keep at the disposal of the national authorities:

- the documentation referred to in the third indent of point 3.1,

- the updating referred to in the second paragraph of point 3.4,

- the decisions and reports from the notified body which are referred to in the final paragraph of point 3.4 , points 4.3 and 4.4 .

6. Each notified body shall forward to the other notified bodies the relevant information concerning the quality system approvals issued and withdrawn ("**).

Module F $(* \cdots *)$ (product verification)

1. This module describes the procedure whereby a manufacturer or his authorized representative established within the Community checks and artests that the products subject to the provisions of point 3 [are in conformity with the type as described in the EC-rype examination certificate and) satisfy the requirements of the directive that apply to them.

(") This harmonized atandard will be EN 29003 , supplemented if necessary to allow for the specific features of the product: for which it is implemented.

(**) The intervals between audits may be specified in the specific directives.

(“.") The specific directives may alter this period.

(…) The tpecific directives may provide for different arrangements.

(….) Where this module is used without module B:

- it must be supplemented by points 2 and 3 of module $\Lambda$ (between points 1 and 2), so as to introduce the need for technical documentation.

- the next in square brackets must be deleted. 
2. The manufacrurer shall rake all measures necessary in order that the manufacturing process ensures conformiry of the products [with the type as described in the EC type-examination certificate and] with the requirements of the directive that apply to them. He shall affix the $\mathrm{CE}$ mark to each product and shall draw up a declaration of conformity.

3. The notified body shall carry out the appropriate examinations and tests in order to check the conformity of the product with the requirements of the directive either by examination and testing of every product as specified in point 4 or by examination and testing of products on a statistical basis, as specified in point 5 , at the choice of the manufacturer (").

3a. The manufacturer or his authorized representative shall keep a copy of the declaration of conformity for a period ending at least 10 years ("*) after the last product has been manufactured.

\section{Verification by examination and testing of every product}

4.1. All products shall be individually examined and appropriate tests as set out in the relevant standard(s) referred to in Article 5 or equivalent tests shall be carried out in order to verify their conformity with [the type as described in the EC-type examination certificate and] the requirements of the directive that apply to them.

4.2. The notified body shall affix or cause to be affixed, jts identification symbol to each approved product and draw up a writsen certificate of conformity relating to the tests carried out.

4.3. The manufactures or his authorized representative shall ensure that he is able to supply the notified body's certificates of conformity on request.

\section{Statistical verification}

5.1. The manufacturer shall present his products in the form of homogeneous lots and shall take all measures necessary in order that the manufacturing process ensures the homogeneity of each lor produced.

5.2. All products thall be available for verification in the form of homogeneous lots. A random sample shal] be drawn from each lot. Products in a sample shall be individually examined and appropriate tests as set out in the relevant standard(s) referred to in Articie 5, or equivalent tests, shall be carried out to ensure their conformity with the requirements of the directive which apply to them and to determine whether the lot is accepted or rejected.

5.3. The statistical procedure shall use the following elements:

(Relevant elements shall be specified here such as, for example, the statistical method to be applied, the sampling plan with its operational characteristics, etc.)

5.4. In the case of accepted lots, the notified body shall affix, or cause to be affixed, its identification symbol to each product and shall draw up a written certificate of conformiry relating to the tests carried out. All products in the lot may be put on the market except those products from the sample which were found not to be in conformity.

If a lot is rejected, the notified body or the competent authority shall take appropriate measures to prevent the putting on the market of that lot. In the event of frequent rejection of loss the notified body may suspend the statistical verification.

The manufacturer may, under the responsibility of the notified body, affix the latter's identification symbol during the manufacturing process.

5.5. The manufacturer or his authorized representarive shall ensure that he is able to supply the norified body's certificates of conformity on request.

Module G (unit verification)

1. This module describes the procedure whereby the manufacturer ensures and declares that the product concerned, which has been issued with the certificate referred to in point 2 , conforms to the requirements of the directive that apply to it. The manufacturer shall affix the CE mark to the praduct and draw up declaration of conformity.

2. The notified body shall examine the individual product and carry out the appropriate tests as set out in the relevant standard(s) referred to in Article $\$$, or equivalent tests, to ensure its conformity with the relevant requirements of the directive.

(") The manufacturer's diecretion may be limited in the specific directives.

(“) The specific direatives may alter this period. 
The notified body shall affix, or cause to be affixed, its identification symbol on the approved product and shall draw up a certificate of conformity concerning the tests carried out.

3. The aim of the technical documentation is to enable conformity with the requirements of the directive to be assessed and the design, manufacture and operation of the product to be understood (")

Module $\mathbf{H}$ (full quality assurance)

1. This module describes the procedure whereby the manufacturer who satisfies the obligations of paragraph 2 ensures and declares that the products concerned satisfy the requirements of the directive that apply to them. The manufacturer shall affix the CE mark to each product and draw up a written declaration of conformity. The CE mark shall be accompanied by the identification symbol of the notified body responsible for the surveillance as specified in point 4 .

2. The manufacturer shall operate an approved quality system for design, manufacture and final product inspection and testing as specified in point 3 and shall be subject to surveillance as specified in point 4.

3. Quality system

3.1. The manufacturer shall lodge an application for assessment of his quality system with a notified body.

The application shall include:

- all relevant information for the product category envisaged,

- the quality system's documentation.

3.2. The quality system shall ensure compliance of the products with the requirements of the directive that apply to them.

All the elements, requirements and provisions adopted by the manufacturer shall be documented in a systematic and orderly manner in the form of written policies, procedures and instructions. This quality system documentation shall ensure a common understanding of the quality policies and procedures such as quality programmes, plans, manuals and records.

It shall contain in particular an adequate description of:

- the quality objectives and the organizational structure, responsibilities and powers of the management with regard to design and product quality,

- the technical design specifications, including standards, that will be applied and, where the standards referred to in Article 5 will not be applied in full, the means that will be used to ensure that the essential requirements of the directive that apply to the products will be met,

- the design control and design verification techniques, processes and systematic actions that will be used when designing the products pertaining to the product category covered,

- the corresponding manufacturing, quality control and quality assurance techniques, processes and systematic actions that will be used,

- thic examinations and tests that will be carried out before, during and after manufacture, and the frequency with which they will be carried out,

- the quality records, such as inspection reports and test data, calibration data, qualification reports of the personnel concerned, etc.,

- the means to monitor the achievement of the required design and product quality and the effective operation of the quality system.

(") The content of the technical documentation shall be laid down directive by directive in accordance with the products concerned. As an example, the documentation shall contain so far as relevane for assessment:

- a general description of the product.

- conceprual design and manufacauring drawings and schemes of components, sub-assemblies, circuits, etc.,

- descriptions and explanations necessary for the understanding of said drawings and schemes and the operation of the product,

- a list of the standards referred to in Article 5 , applied in full or in part, and descriptions of the solutions adopted to meet the exsential requirements of the difective where the standards referred to in Article 5 have not been applied,

- results of desiga calculations made, examinations carried out, etc.

- test reports. 
3.3. The notified body shall assess the quality system to determine whether it satisfies the requirements referred to in point 3.2. It shall presume compliance with these requirements in respect of quality systems that implement the relevant harmonized standard (*).

The auditing team shall have at least one member experienced as an assessor in the product technology concerned. The evaluation procedure shall include an assessment visit to the manufacturer's premises.

The decision shall be notified to the manufacturer. The notification shall contain the conclusions of the examination and the reasoned assessment decision.

3.4. The manufacturer shall undertake to fulfil the obligations arising out of the quality system as approved and to uphold it so that it remains adequate and efficient.

The manufacturer or his authorized representative shall keep the fotified body that has approved the quality system informed of any intended updating of the quality system.

The notified body shall evaluate the modifications proposed and decide whether the amended quality system will still satisfy the requirements referred to in paragraph 3.2 or whether a re-assessment is required.

It shall notify its decision to the manufacturer. The notification shall contain the conclusions of the examination and the reasoned assessment decision.

4. EC surveillance under the responsibility of the notified body

4.1. The purpose of surveillance is to make sure that the manufacturer duly fulfils the obligations arising out of the approved quality system.

4.2. The manufacturer shall allow the notified body entrance for inspection purposes to the locations of design, manufacture, inspection and testing, and storage, and shall provide it with all necessary information, in particular:

- the quality system documentation,

- the quality records as foreseen by the design part of the quality system, such as results of analyses, calculations, tests, etc.,

- the quality records as foreseen by the manufacturing part of the quality system, such as inspection reports and test data, calibration data, qualification reports of the personnel concerned, etc.

4.3. The notified body shall periodically (*) carry out audits to make sure that the manufacturer maintains and applies the quality system and shall provide an audit report to the manufacturer.

4.4. Additionally the notified body may pay unexpected visits to the manufacturer. Ar the time of such visits, the notified body may carry out tests or have them earried out in order to check the proper functioning of the quality system where necessary; it shall provide the manufacturer with a visit report and, if a test has been caried out, with a test report.

5. The manufacturer shall, for a period ending at least 10 years (** ") after the last product has been manufactured, keep at the disposal of the national authorities:

- the documentation referred to in the second indent of the second subparagraph of point 3.1,

- the updating referred to in the second subparagraph of point 3.4 ,

- the decisions and reports from the notified body which are referred to in the final subparagraph of point 3.4 , points 4.3 and 4.4 .

6. Each notified body shall forward to the other notified bodies the relevant information concerning the quality system epprovals issued and withdrawn (***)

(") This harmonized standard shall be EN 29001 , completed if necessary to rake into consideration the specificity of the products for which it is implemented.

(**) In the upecific directives, the frequency may be specified.

(**) The specific directives may alter this period.

(*)*) The specific directives may provide for differene arrangements. 
Possible supplementary requirements:

Design examination

1. The manufacturer shall lodge an application for examination of the design with a single notified body.

2. The application shall enable the design, manufacture and operation of the product to be understood, and shall enable conformity with the requirements of the directive to be assessed.

It shall include:

- the technical design specifications, including standards, that have been applied,

- the necessary supporting evidence for their adequacy, in particular where the standards referred to in Article 5 have not been applied in full. This supporting evidence shall include the results of tests carried out by the appropriate laboracory of the manufacturer or on his behalf.

3. The notified body shall examine the application and where the design meets the provisions of the directive that apply to it shall issue an EC design examination certificate to the applicant. The certificate shall contain the conclusions of the examination, conditions for its validity, the necessary data for identification of the approved design and, if relevant, a description of the product's functioning.

4. The applicant shall keep the notified body that has issued the EC design examination certificate informed of any modification to the approved design. Modifications to the approved design must receive additional approval from the norified body that issued the EC design examination certificate where such changes may affect the conformiry with the essential requirements of the directive or the prescribed conditions for use of the product. This additional approval is given in the form of an addition to the original EC design examination certificate.

5. The notified bodies shall forward to the other notified bodies the relevant information concerning:

- the EC design examination certificates and additions issued,

- the EC design approvals and addirional approvals withdrawn (*).

(") The specific directives may provide for different arrangements. 
CONFORMITY ASSESSMENT PROCEDURES IN COMMUNTTY LEGISLATION

$$
\text { L }
$$
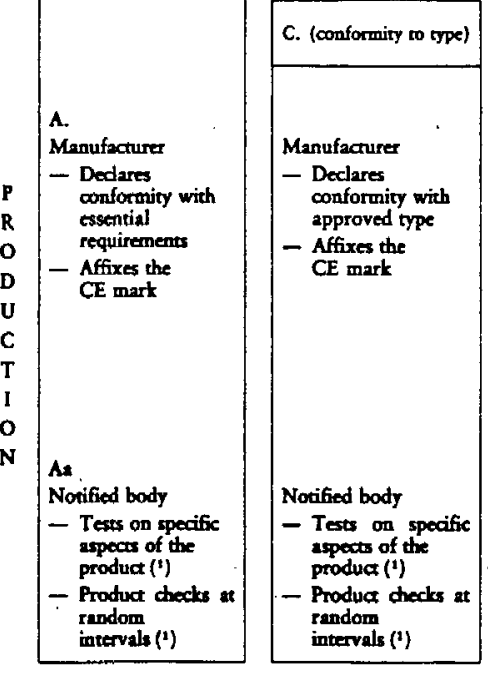

Manufacturer submits to notified body

- Technical dooumentation

- Type

Notified body

- Asoertint conformity with essential requirenents

- Carries our ress, if necessary

- Issues EC type-eramination certificare

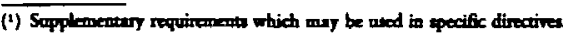




\author{
APPENDIX 9
}

\title{
FList of the members and statutes of the EOTC
}

(24 February, 1994)

\section{National Members}

\author{
Austria \\ Belgium \\ Denmark \\ Finland \\ France \\ Germany \\ Greece \\ Ireland
}

Italy

Netherlands

Norway

Portugal

Spain

Sweden

Switzerland

United Kingdom

\section{European Members}

$\begin{array}{ll}\text { ECITC } & \text { European Committee for Information Technology Testing \& Certification } \\ \text { ELSECOM } & \text { European Electrotechnical Sectoral Committee for Testing and Certification } \\ \text { ESCIF } & \text { European Sectoral Committee for Intrusion \& Fire Protection } \\ \text { EWSC } & \text { European Water Sectorial Committee } \\ \text { ETUC } & \text { European Trade Union Confederation } \\ \text { EUROLAB } & \text { Organisation for the Promotion of Co-operation between Testing Laboratories } \\ \text { EQS } & \text { European Committee for Quality Assessment Certification } \\ \text { EAL } & \text { European Accreditation of Laboratories (WECC + WELAC) } \\ \text { EAC } & \text { European Accreditation of Certification } \\ \text { CEOC } & \text { European Confederation of Independent Inspecting Organisations } \\ \text { UNICE } & \text { Union of Industrial and Employers Confederations of Europe } \\ \text { UNIPEDE } & \text { International Union of Producers and Distributors of Electricity } \\ \text { EEC } & \text { Commission Consumers' Consultative Council } \\ \text { EFTA } & \text { Consumers' Consultative Committee }\end{array}$

\section{Associate Members}

European Federation of Management Consultancy Associations (FEACO) 


\title{
Association internationale
}

\section{Organisation européenne pour les essais et la certification}

\author{
Statuts \\ Titre I - Dénomination, siège, objet
}

\section{Article $1^{*}$ - Dénomination}

1.1. L'association est dénommée «Organisation européenne pour les essais et la certification», ou «European Organization for Testing and Certification», en abrégé «EOTC».

1.2. L'association est une association internationale sans but lucratif, conformément à la loi belge du 25 octobre 1919 qui accorde la personnalité juridique aux associations internationales à but philanthropique, religieux, scientifique, artistique ou pédagogique, telle que modifiée par la loi du 6 décembre 1954.

Article 2 - Siège

2.1. Le siège social de l'association est établi en Belgique, rue de Stassart 33, à Ixelles (Bruxelles). Le siège social peut être transféré en tout autre lieu en Belgique à la simple majorité de l'assemblée générale, publiée aux annexes du Moniteur belge.

2.2. L'association peut également établir, à la simple majorité de l'assemblée générale, d'autres sièges administratifs et sièges d'activités, tant en Belgique qu'à l'étranger.

Article 3 - Objet

3.1. Son objet qui est dénué de lucre est essentiellement à but scientifique et est de créer un point de convergence pour la rationalisation des activités liées à l'évaluation de la conformité en Europe par des méthodes scientifiques, techniques, économiques ou autres et, par là, de créer les conditions dans lesquelles toutes les parties concernées du marché peuvent être assurées que les produits, les services et les procédés qui ont fait l'objet d'un essai ou d'une certification ne devront pas faire l'objet d'un nouvel essai ou d'une nouvelle certification pour que les résultats puissent être acceptés par d'autres parties ou d'autres pays européens.

3.2. L'association peut, dans la poursuite directe ou indirecte de son objet, acquérir tout bien meuble ou immeuble, prendre des engagements contractuels, accepter des donations, vendre, accorder des privilèges sur ses biens, hypothéquer ou transférer tout bien, conformément aux dispositions légales, aux présents statuts et à tout amendement de ceux-ci.

Titre II - Membres

\section{Article 4 - Membres}

4.1. L'association sera composée de membres effectifs $A$ et de membres effectifs $B$. Les membres effectifs $A$ et les membres effectifs B seront soit des membres nationaux, soit des membres européens. 
4.2. Seront acceptées comme membres nationaux toutes communautés nationales pour l'évaluation de la conformité de la Communauté européenne et de l'AELE. Il n'y aura qu'un membre national par pays.

4.3. Seront acceptées comme membres européens toutes organisations, travaillant à l'échelon européen, qui représentent des parties ayant un intérêt à promouvoir les objectifs de l'association.

4.4. Les membres effectifs A seront des personnes morales ou des institutions ou des associations légalement constituées selon les lois et usages de leur pays d'origine.

4.5. Seront acceptés comme membres effectifs B les membres des institutions ou associations qui ne sont pas habilités à être admis comme membres effectifs $\mathrm{A}$ et qui désirent s'intéresser aux activités de l'association par le biais de leurs membres. Les associations et institutions précitées ainsi que les personnes physiques peuvent adhérer comme membres effectifs $B$.

4.6. Les membres effectifs B qui font partie de la même institution ou de la même association n'étant pas habilités à être admis comme membres effectifs $\mathrm{A}$ forment entre eux un consortium et désignent un mandataire qui exercera tous les droits sociaux liés à la qualité de membre de ceux-ci. L'identité du mandataire, ainsi que toute modification d'identité, sera notifiée par écrit au secrétaire général.

4.7. À défaut de désignation de mandataire indiqué au précédent paragraphe ou en cas d'absence d'accord sur le choix de ce mandataire, tous les droits sociaux liés à la qualité de membre sont suspendus jusqu'au moment où le secrétaire général a reçu connaissance de l'identité de ce mandataire.

4.8. Sauf stipulation du contraire, il est entendu que «membre effectif» comprend tant le membre effectif $A$ que le membre effectif $B$, ce dernier toutefois représenté d'office par son mandataire, comme indiqué au sixième paragraphe du présent article.

4.9. L'assemblèe générale peut également créer une catégorie de membres affiliés et une catégorie de membres associés qui n'auront pas de droit de vote à l'assemblée générale.

4.10. Seront acceptés comme «membres affiliés» tous membres nationaux ressortissants de pays européens qui pourront devenir partie de la Communauté européenne ou de l'AELE.

4.11. Seront acceptés comme «membres associés» toutes autres catégories de membres que l'assemblée générale peut décider de créer.

4.12. L'assemblée générale déterminera les critères d'affiliation pour chaque catégorie de membres.

4.13. Le statut de membre ne peut être transféré ou cédé, pour quelque raison que ce soit, à toute autre personne physique ou morale ou association.

\section{Article 5 - Admission}

5.1. Les candidats membres sont admis s'ils satisfont aux critères de l'une des catégories mentionnées à l'article 4 et sont acceptés à la majorité des deux tiers par l'assemblée générale de tous les membres effectifs $\mathbf{A}$ et $\mathbf{B}$, présents ou représentés, comme mentionné à l'article 12 .

5.2. Le fait de poser sa candidature en tant que nouveau membre implique l'approbation par ce dernier des statuts de l'association, de leurs amendements ainsi que des règlements intérieurs éventuels.

\section{Article 6 - Fin de la qualité de membre}

6.1. Un membre perdra sa qualité de membre de l'association dans les cas suivants:

- décès, incapacité ou insolvabilité d'une personne physique;

- dissolution volontaire ou forcée et liquidation d'une personne morale ou d'une association; 
- démission;

- suspension ou expulsion.

6.2. Un membre effectif $B$ qui, pour une raison ou une autre, a cessé d'être membre de l'institution ou de l'association indiquée à l'article 4, paragraphe 4.5, est considéré avoir donné d'office sa démission de l'association sans nécessité d'écrit.

6.3. Les membres peuvent notifier leur démission au conseil d'administration par écrit. La démission ne prendra effet qu'à la fin de l'exercice financier au cours duquel la démission a été notifiée.

6.4. Un membre peut être exclu par l'assemblée générale des membres par décision de la majorité des deux tiers de tous les membres effectifs $A$ et $B$, présents ou représentés, comme mentionné à l'article 12. Le membre, dont l'exclusion est prise en délibération, ne peut voter. L'assemblée générale donnera à ce membre l'occasion de se défendre. Il sera averti de son exclusion.

6.5. Le membre qui a démissionné ou qui est exclu, ses ayants droit ou créanciers n'ont aucun droit sur les actifs de l'association et n'ont aucun droit au remboursement des cotisations ou des donations. Si ce membre (ou ses ayants droit) a une dette envers l'association, cette dette devient immédiatement exigible.

\section{Article 7 - Droits et obligations des membres}

7.1. Chaque membre effectif $\mathrm{A}$ aura une seule voix, à moins que et jusqu'au moment où l'assemblée générale déterminera un système de vote. Une seule voix sera attribuée par consortium de membres effectifs $B$ indiqué à l'article 5 , paragraphe 4.6 , à moins que et jusqu'au moment où l'assemblée générale déterminera un systeme de vote.

7.2. Le droit de vote sera suspendu jusqu'au paiement de la cotisation par le membre effectif.

7.3. Chaque membre paiera sa cotisation annuelle, payable à l'avance, au cours du premier mois de son admission à l'association ou de l'exercice financier. Les cotisations peuvent varier selon la catégorie de membres. Par ailleurs, des cotisations différentes peuvent être dues dans chaque catégorie de membres sur la base de qualités et de critères que l'assemblée générale peut adopter régulièrement.

7.4. Lors de sa réunion ordinaire, l'assemblée générale déterminera les montants des cotisations.

\section{Titre III - Assemblée générale}

\section{Article 8 - Assemblée générale}

8.1. L'assemblée générale est composée de tous les membres effectifs A et B, étant entendu que ces derniers sont uniquement représentés par leur(s) mandataire(s) comme indiqué à l'article 4, paragraphe 4.6. Les membres affiliés et les membres associés peuvent être invités à l'assemblée générale, mais n'ont pas droit de vote. Le conseil d'administration peut inviter des tiers à titre consultatif.

8.2. L'assemblée générale a tous les pouvoirs nécessaires pour la réalisation de l'objet de l'association L'assemblée générale peut également créer ou dissoudre des comités spéciaux et des groupes de travail.

\section{Article $9-$ Réunion ordinaire de l'assemblée générale}

9.1. L'assemblée générale se réunira en réunion ordinaire au moins une fois l'an entre le $1^{\text {er }}$ mars et le 30 juin, sur convocation du conseil d'administration, au siège social de l'association ou à tout autre lieu indiqué dans la convocation. 
9.2. À l'assemblée générale ordinaire, l'assemblée générale approuvera les comptes annuels présentés par le conseil d'administration, tous les rapports requis par les règlements intérieurs ainsi que le budget proposé par le conseil d'administration. L'assemblée générale déterminera également le montant des cotisations à payer par les membres et donnera décharge aux administrateurs.

\section{Article 10 - Réunion extraordinaire}

10.1. Le conseil d'administration sera tenu de convoquer une réunion extraordinaire de l'assemblée générale à la demande d'au moins un cinquième des membres effectifs $A$ et $B$, étant entendu que ces derniers regroupés dans leur(s) consortium(s) comme indiqué à l'article 4, paragraphe 4.6, ne comptent que pour un. La réunion aura lieu dans les trente jours qui suivent la réception de la demande.

10.2. Une réunion extraordinaire de l'assemblée générale peut être convoquée à tout moment par le conseil d'administration.

Article 11 - Convocations, représentations aux assemblées générales

11.1. Les convocations, accompagnées de l'ordre du jour, seront envoyées, par le conseil d'administration, au moins quinze jours avant la réunion, par lettre ordinaire, par télex ou par télécopie.

11.2. Toute convocation à un membre effectif $\mathrm{B}$ est valable lorsqu'elle est faite au mandataire comme indiqué à l'article 4, paragraphe 4.6.

11.3. Tout membre effectif $\mathrm{A}$ ou mandataire, comme indiqué à l'article 4, paragraphe 4.6, qui ne peut pas prendre part à la réunion de l'assemblée générale, peut se faire représenter à cette réunion par un autre membre effectif, porteur d'une procuration écrite. Un membre effectif ne peut être titulaire de plus de deux procurations.

\section{Article 12 - Procédure de vote}

12.1. Les assemblées sont présidées par le président ou, en son absence, par le vice-président.

12.2. Un quorum d'un tiers au moins des membres effectifs [étant entendu que les membres effectifs B regroupés dans leur(s) consortium(s), comme indiqué à l'article 4, paragraphe 4.6, ne comptent que pour un], présents ou représentés, est requis pour voter valablement. Il ne peut être statué que sur les points qui sont à l'ordre du jour.

12.3. Sauf dans les cas spéciaux prévus par la loi ou les présents statuts, ou dans les cas prévus par l'assemblée générale, les décisions sont prises à la simple majorité des membres effectifs, présents ou représentés.

12.4. Les décisions concernant l'admission ou l'exclusion des membres (articles 5 et 6), la révocation des administrateurs (article 14) ainsi que toute autre matière que l'assemblée générale déterminera dans ses règlements intérieurs sont prises à une majorité des deux tiers des membres effectifs, présents ou représentés.

12.5. Toutes les résolutions seront portées à la connaissance de tous les membres.

12.6. En cas de partage des voix, celle du président de la réunion sera prépondérante.

\section{Article 13 - Procès-verbaux}

13.1. Les résolutions de l'assemblée générale seront consignées dans un registre signé par le président et le secrétaire de la réunion ainsi que par tous les membres effectifs qui en expriment le désir. Elles seront consignées dans un registre spécial qui sera conservé au siège de l'association où il sera tenu à la disposition de tous les membres. 


\section{Titre IV - Administration}

\section{Article $14-$ Conseil d'administration}

14.1. L'association sera gérée par un conseil d'administration composé de trois administrateurs au moins. Les administrateurs comprendront le président, le vice-président et le trésorier. Une personne peut assumer plusieurs mandats. Si aucun des administrateurs n'est un ressortisssant belge, l'assemblée générale devra nommer un autre administrateur qui sera un membre belge.

14.2. Le vice-président, le trésorier et tout autre administrateur seront élus parmi les délégués représentant les membres effectifs. Le président ne doit pas nécessairement être un délégué.

14.3. Les administrateurs sont nommés par l'assemblée générale pour une période qui ne peut excéder deux ans. Les administrateurs sortants sont rééligibles. Ils peuvent être révoqués à tout moment par l'assemblée générale à la majorité des deux tiers des membres effectifs, présents ou représentés.

14.4. En cas de vacance au cours d'un mandat, pour cause de décès ou autre, le conseil d'administration peut désigner un administrateur provisoire. Le conseil d'administration décidera de cette nomination à la majorité simple des voix des autres administrateurs. L'administrateur provisoire achèvera le mandat de l'administrateur qu'il remplace.

\section{Article 15 - Secrétaire général}

15.1. L'assemblée générale nommera un secrétaire général. Le secrétaire général ne doit pas nécessairement être un administrateur ou un délégué d'un des membres. Le secrétaire général peut être révoqué à tout moment.

\section{Article 16 - Pouvoirs du conseil d'administration}

16.1. Le conseil d'administration est investi des pouvoirs de gestion et d'administration qui lui sont accordés par l'assemblée générale.

16.2. Dans l'exercice de leurs fonctions, les administrateurs et le secrétaire général ne seront pas personnellement responsables vis-à-vis de tiers. Ils seront néanmoins responsables envers l'association de l'exécution de leurs obligations découlant de leur mandat.

16.3. Celui-ci est exercé à titre gratuit, à l'exception de celui du secrétaire général.

\section{Article 17 - Délégation de pouvoirs}

17.1. Le conseil d'administration peut déléguer certains de ses pouvoirs à une ou plusieurs personnes qui ne doivent pas nécessairement être des administrateurs, et notamment au secrétaire général.

17.2. Le président ou, en son absence, le trésorier est habilité à accepter les donations faites à l'association et à accomplir toutes les formalités nécessaires à leur acquisition conformément à toutes prescriptions légales.

\section{Aricle $18-$ Réunion du conseil d'administration}

18.1. Le conseil d'administration se réunit régulièrement sur convocation du président et/ou du secrétaire général. Le conseil d'administration doit se réunir à la demande écrite de deux administrateurs au moins, adressée au secrétaire général. 
18.2. Les convocations seront envoyées dix jours au moins avant la réunion, par lettre ordinaire, par télex, téléphone ou télécopie. La convocation contiendra l'ordre du jour, la date, l'heure et le lieu de la réunion. Le conseil ne peut valablement délibérer que si la moitié au moins des administrateurs sont présents ou représentés.

18.3. Le secrétaire général participe aux réunions du conseil d'administration, mais n'a aucun droit de vote. Les résolutions du conseil d'administration sont prises à la majorité simple des administrateurs présents ou représentés. En cas de partage des voix, celle du président ou de la personne qui le remplace sera prépondérante.

18.4. En cas d'absence ou d'empêchement du président, le vice-président assumera ses fonctions. En cas d'absence ou d'empêchement du président et du vice-président, le trésorier exerce cette fonction.

\section{Article 19 - Procès-verbaux}

19.1. Les résolutions du conseil d'administration sont consignées dans un registre signé par le président et le secrétaire général et tous les membres du conseil d'administration qui le désirent. Ce livre sera conservé au siège de l'association où il sera tenu à la disposition de tous les membres de l'association.

\section{Article 20 - Représentation de l'association}

20.1. Sauf disposition contraire, tous leśactes qui engagent l'association sont valablement signés par deux administrateurs conjointement, lesquels n'auront pas à justifier leur pouvoir à l'égard des tiers.

20.2. Les actions judiciaires, tant à titre de demandeur qu'à titre de défendeur, seront menées par le conseil d'administration, représenté par le président ou un administrateur désigné à cet effet par celui-ci.

\section{Titre V - Budget, comptes}

Article 21 - Exercice financier et comptes annuels

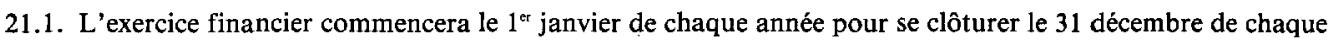
année. Exceptionnellement, le premier exercice financier commencera à la signature des présents statuts et se terminera le 31 décembre 1993.

21.2. Le conseil d'administration soumettra les comptes annuels concernant l'exercice financier précédent à l'assemblée générale pour approbation, ainsi que le budget pour l'exercice financier suivant au cours de la réunion ordinaire de l'assemblée générale dont il est question à l'article 9.

\section{Titre VI - Modification des statuts et liquidation de la société}

\section{Article 22 - Modification des statuts}

22.1. Sans préjudice à l'article 5 de la loi du 25 octobre 1919, les présents statuts peuvent être modifiés à tout moment par une assemblée générale extraordinaire des membres convoqués à l'initiative du conseil d'administration ou à la requête d'un cinquième des membres effectifs [étant entendu que les membres effectifs B regroupés dans leur(s) consortium(s), comme indiqué à l'article 4, paragraphe 4.6, ne comptent que pour un] de l'association.

22.2. La date de l'assemblée générale extraordinaire qui décidera des amendements proposés sera notifiée à tous les membres au moins trois mois à l'avance. 
22.3. Aucune décision ne sera adoptée si elle n'est pas votée à la majorité des deux tiers des voix des membres effectifs de l'association, présents ou représentés, ou si cette assemblée générale ne réunit pas les deux tiers des membres effectifs rétant entendu que les membres effectifs B regroupés dans leur(s) consortium(s) ne comptent que pour un] de l'association, présents ou représentés. Dans ce dernier cas, une nouvelle assemblée générale sera convoquée aux mêmes conditions que la première, et cette seconde assemblée générale statuera définitivement et valablement sur les propositions par une majorité de deux tiers des membres effectifs, présents ou représentés.

22.4. Les modifications des statuts ne prennent effet qu'après approbation par arrêté royal et qu'après qu'elles ont été publiées aux annexes du Moniteur belge, conformément à l'article 3 de la loi du 25 octobre 1919.

Article 23 - Liquidation de l'association

23.1. En temps voulu, l'assemblée générale déterminera les modalités de dissolution et de liquidation de l'association.

Article 24 - Divers

24.1. Tout ce qui n'est pas prévu par les présents statuts, y compris les publications aux annexes du Moniteur belge, sera régi conformément aux dispositions de la loi du 25 octobre 1919, telle qu'amendée.

Vu pour être annexé à l'arrêté royal du 23 mars 1993

$n^{\circ} 13.421 / \mathrm{S}$.

Le ministre de la Justice,

Pour expédition conforme:

Le directeur,
Gezien om te worden gevoegd bij het koninklijk besluit van 23 maart 1993

$\mathrm{nr} 3 / 13.421 / \mathrm{S}$

De Minister van Justitie, (get.)

Voor eensluidende ritgifte:

De Directeur,

M. PEPERSTRAFTE-PLATTEAU 


\section{International Organization for Standardization (ISO) European Committee for Standardization (CEN)}

\section{Agreement on technical cooperation between ISO and CEN (Vienna Agreement)}

\section{Basis for cooperation}

Agreement on exchange of technical information between ISO and CEN approved by the CEN Administrative Board in January 1989 in Lisbon as further development of ISO/Council resolution 11/1987 (so-called Lisbon Agreement).

ISO Council resolution 18/1990 and CEN General Assembly resolution CEN/AG 3/1990 appear in the annex.

\section{General exchange of information at Central Secretariat (CS) level}

The ISO/CS shall regularly issue to the CEN/CS:

- memento, catalogue

- work programme of the ISO/TCs with state of progress, target dates

- for work items proposed by CEN: working drafts and committee drafts

- resolutions of the ISO technical board linked to technical activities and in any case all decisions having an interest for the other party

- Proposals for new fields of technical activity (TS/P)

- texts of DIS, international standards and technical reports in English and French

the CEN/CS shall regularly issue to the ISO/CS:

- memento, catalogue

- CEN general technical report (work programme of the CEN/TCs with state of progress, target dates)

- resolutions of CEN technical board linked to technical activities and in any case all decisions having an interest for the other party

- proposals for new studies (form A)

- texts of prEN/prHD/prENV, at enquiry and formal voting stages, and approved European documents in English and French

Further exchange of available general information shall be possible subject to special agreement between the two CSs.

\section{Cooperation on standards drafting between ISO and CEN}

\subsection{Cooperation by correspondence}

The ISO/CS and the CEN/CS shall establish a list of ISO/TCs (or SCs) and CEN/TCs, including.CEN sectors, which have technical activities of common interest. The list shall also indicate the name of the person in charge 
of the ISO/CEN reporting secretariat, the names of the ISO and CEN committee secretaries and the relevant technical officers of both CSs. The list shall be notified to the respective technical boards.

\subsubsection{Reporting on ISO work to CEN}

ISO/CEN reporting secretariats (according to clause 2.5 of the CEN/Cenelec common rules for standards work Part 2) shall provide information to:

(a) the CEN Technical Board on any ISO work which may be of concern to CEN

(b) the CEN Central Secretariat upon request for preparing investigation reports in areas not covered by CEN technical committees and for which ISO is active

(c) the $\mathrm{CEN} / \mathrm{TC}$ secretariats according to the $\mathrm{CEN} /$ Cenelec internal regulations

- on the progress of the technical work of relevant ISO/TCs with copy to both the ISO and CEN CSs

- on ISO new work item circulated for voting.

\subsubsection{Reporting on CEN work to ISO}

(a) CEN/TC secretariats shall provide information to the ISO/TC secretariat concerned, with copy to both the ISO and CEN CSs, on their programme of technical work, including:

- state of progress

- current work schedule

in so far as such information is not covered by that mentioned under 2 .

(b) The CEN/CS shall provide information to ISO/TC secretariats with copy to the ISO/CS on the programme of technical work of subsectors not covered by CEN/TCs concerning:

- state of progress

- current work schedule

in so far as such information is not covered by that mentioned under 2 .

(c) The CEN/CS shall provide information to the ISO/CS on CEN priorities and expectations concerning subjects belonging to the scope of ISO/TCs and on target dates for work items of ISO/TCs of special interest to CEN, in so far as such information is not covered by that mentioned under 2 . Every effort will be made to meet requests initiated by $\mathrm{CEN}$ within the framework of available resources.

\subsubsection{Written contribution}

The passive involvement in the work of CEN and ISO by way of sending written contribution is well accepted by the two organizations as a contribution towards a more open process of standarization and promotion of harmomzation on the European and international level. Written contributions may emanate from TCs, reporting secretariats (SR) or CSs and are directly addressed to the secretariat of the technical body concerned.

\subsection{Cooperation through mutual representation at meetings}

Appropriate designated representatives of ISO/TC/SC/WGs, who may be chairmen, secretaries, conveners, project leaders, or Central Secretariat technical officers, may have direct contact with relevant $\mathrm{CEN} / \mathrm{TC} / \mathrm{SC} / \mathrm{WGs}$, and up to two representatives may attend meetings of these committees as observers, and of WGs at the invitation of the parent body.

Appropriate designated representatives of $\mathrm{CEN} / \mathrm{TC} / \mathrm{SC} / \mathrm{WGs}$, who may be chairmen, secretaries, conveners, project leaders, or Central Secretariat technical officers, may have direct contact with relevant ISO/TC/SCWOs, and up to two representatives may attend meetings of these committees as observers, and of WGs at the invitation of the parent body. 


\subsection{Cooperation by transfer from CEN to ISO}

\subsubsection{Initiative}

Whenever the need to undertake new work (including the revision of existing standards) is identified in CEN, it is in accordance with its general policy to determine whether it is possible to give preference to the undertaking and completion of this work in time within ISO.

Once the decision has been taken in CEN to transfer the agreed work item to ISO and provided that at least five CEN member bodies have committed themselves to participate, the CEN proposal shall he submitted by the CEN/CS to the ISO/CS and the following procedure, in accordance with the IEC/ISO Directives Part 1: 'Procedures for the technical work' shall he applied:

(a) For new work within the scope of an existing ISO/TC

Information shall be provided in accordance with 2.2 of the IEC/ISO Directives, Part 1 (form on pp. 71-72).

(b) Widening of the scope of an existing ISO/TC

If the request implies a widening of the current scope of the TC/SC concerned, the proposed revised scope shall be submitted to the ISO Technical Board at the same time as the request to undertake a new work item. The additional information shall be given as in (a) above.

(c) For new work in fields not yet covered in ISO

Information shall be provided in accordance with 1.5.3 and 1.5.4 of the IEC/ISO Directives, Part 1 (form on pp. 35/36).

In the above cases, CEN shall he entitled to nominate a project leader and to set a target date for the circulation of the ISO/DIS.

For cases (a) and (b), ISO shall commence work immediately in parallel with the circulation of the proposal to the member bodies under the normal acceptance procedure.

For case (c), the work in ISO shall start following the establishment of the appropriate technical committee, to which any possible CEN work on the matter shall be transferred.

\subsubsection{ISO response and further actions}

ISO shall normally respond within three months to new work proposals submitted to ISO by CEN in accordance with clause 3.3.1. above. CEN shall then draw conclusions regarding its further processing of the work.

Progress of work on such projects shall be checked by the ISO/CS on a monthly basis. Any difficulties or delays shall be reported to the Joint Coordinating Group of the Technical Boards acting as a management body in accordance with its terms of reference set out in clause 6.2 below, to obtain the necessary support from the relevant member bodies and the ISO/CS.

\subsubsection{Saving clause}

If at any time during the procedure, CEN can no longer accept the ISO results (e.g. for technical, procedural or timing reasons) CEN shall notify ISO of its decision and shall process the project separately as a CEN work item. ISO would then decide whether or not to continue to process the ISO version.

\section{Adoption of existing international standards as European standards}

\subsection{General}

International standards may be adopted by CEN as European standards under the PQ (prime questionnaire) procedure or the unique acceptance procedure (UAP). When a ISO standard is proposed for adoption under one 
of these procedures, the CEN/CS shall send copies of the documentation to the ISO/CS, which shall inform the relevant ISO committee secretariat (if this is not held by a CEN member body) of the proposal. The result of the procedure may be:

(1) that the ISO standard is adopted by CEN without change (4.2)

(2) that the ISO standard is proposed for adoption by CEN subject to modification (4.3)

\subsection{ISO standard adopted without change}

No special provisions are required, but the ISO Committee shall be notified of the adoption by ISO/CS and will take this into account when reviewing proposals for revision, confirmation or withdrawal.

\subsection{ISO standard proposed for adoption with modifications}

All comments received under the PQ or UAP procedure shall be conveyed by the CEN/CS to the ISO/CS. The latter shall forward the comments to the secretariat of the relevant ISO Committee which shall arrange for them to be reviewed by the ISO Committee. Within two months, the ISO Committee Secretariat shall inform ISO/CS and the CEN Technical Secretariat or the CEN Reporting Secretariat of the intended action, which may be, in suggested order of priority:

(a) To consider revision of the ISO standard to incorporate the comments received as a result of the PQ or UAP procedure. In this case, the ISO Committee Secretariat shall inform the CEN Technical Secretariat or Reporting Secretariat of the tentative schedule for preparation of the revision. The CEN Technical Secretariat or Reporting Secretariat, after appropriate consultations within CEN, shall inform the ISO Committee Secretariat whether the proposed schedule is acceptable.

(i) If so, the revised ISO standard shall be prepared and may be adopted as a European Standard according to 5.1 below.

(ii) If the ISO Committee cannot or prefers not to prepare a revision of the ISO standard within required European target dates, or for other reasons, the European Standard may be finalized in CEN according to 5.2 below. The amendments agreed within CEN will be offered to ISO by the CEN/CS for further harmonization (for instance, under the fast-track procedure).

(b) To maintain the ISO standard, and accept that the European standard will deviate from the ISO standard.

\section{Parallel approval of standards}

Note: This clause is subject to adjustment to comply with forthcoming amendments of the IEC/ISO Directives.

\subsection{Standards under development within ISO}

With reference to work items defined in clauses 3.3 and 4.3 above for which CEN has accepted to wait for the results from the ISO/TC/SCs, 'parallel voting' shall be carried out in ISO and CEN.

Furthermore, CEN shall use the same method in other appropriate cases.

\section{(a) Main elements of the procedure for parallel voting}

Once an ISO/TC has approved a draft for circulation as a DIS, the ISO/CS shall inform the CEN/CS of the reference assigned to the DIS, including the intended final number of the publication. The CEN/CS shall circulate the voting forms to its members, announcing the document to arrive from the ISO/CS under the reference indicated. A copy shall be sent, if relevant, to the SR or CEN/TC/SC Secretariat.

The ISO/CS, after checking the DIS in accordance with 3.3 above and within the maximum permitted processing time, shall send the DIS to the ISO member bodies (and; on behalf of CEN, to the CEN member bodies for Iceland and Luxembourg). 
The member bodies shall return their votes on the respective voting forms to ISO and CEN. Should the vote returned to CEN differ from that returned to ISO, a detailed technical justification shall be given to CEN, with a copy to ISO, together with the voting papers.

Note: Such a case may arise in view of the different backgrounds and significance of the two votes. ISO: worldwide compromise, not mandatory for national implementation; CEN: European solution, implementation as national standard mandatory for CEN members.

If the voting results in ISO are positive and no valid technical reasons have been expressed which justify a further vote, the ISO/CS shall inform the CEN/CS immediately and proceed to publishing the DIS unaltered as an international standard.

If the voting results in CEN are also positive, the DIS (IS) shall be formally ratified as an EN and implemented by CEN members.

In the case of a negative outcome in CEN but positive outcome in ISO, CEN shall proceed to adopting common modifications which shall be communicated to ISO.

In the event of other results, further processing shall be considered jointly by both sides on a case-by-case basis:

\section{(b) Quality of DIS submitted to member body vote}

In order to achieve a DIS which, from the standpoint of technical content and editorial presentation, is deemed suitable for parallel voting, the relevant committee draft may (within ISO) be submitted to a 'three-month voting procedure' preceding the six months' rule.

At the close of the six months' voting, the results shall be communicated by the ISO/CS to the Secretariat and Chairman of the ISO Committee and to the CEN/CS.

Depending on the voting results, the Chairman and Secretariat of the ISO Committee may decide:

- to publish the international standard with editorial modifications only;

or

- to refer the DIS back to the Committee.

\subsection{Standards under development within CEN}

The Technical Secretariat or Reporting Secretariat shall ensure that copies of drafts are made available to the ISO Committee so that it may comment as such on the successive European drafts. According to circumstances, the ISO Committee may decide to await completion of the European standards, which may then be submitted to ISO (for example, under the fast-track procedure), or may decide that parallel voting be conducted as follows:

Once consensus has been obtained within the CEN Committee, the final text shall be supplied by the TC Secretariat to the CEN/CS, which shall forward the document to the ISO/CS, informing the secretariat of the ISO Committee of this action. The ISO/CS shall circulate the document for DIS voting, which will also serve as the enquiry within CEN, as in 5.1. The CEN ballot paper, however, shall be issued by the CEN/CS. At the end of the voting period, the ISO/CS shall submit the result to the CEN/CS and, for information, to the Secretariat of the ISO Committee and its Chairman. A final text shall be agreed within CEN which shall be submitted to the $\mathrm{CEN} / \mathrm{CS}$ for formal voting and to the ISO/CS for voting as a second DIS. If the voting outcome is positive both in ISO and in CEN, the ISO/CS ad CEN/CS shall both proceed with publication, incorporating agreed editorial changes. If the results are not positive in both organizations, further processing shall be subject to negotiation.

\section{Monitoring}

\subsection{Joint coordination meetings}

Where ISO and CEN Committees already exist and deal with the same subject matter but have not yet reached working arrangements to avoid duplication, the Central Secretariat of each organization should inform the $\mathrm{TC} / \mathrm{SC}$ secretariats of the need to appoint delegates with a view to allocating work: Joint coordination meetings of ISO and CEN Committees should be held to allocate work where necessary and to deal with comments submitted by members as a result of parallel voting on the ISO/DIS and the CEN enquiry. 


\subsection{Joint ISO/CEN Coordinating Group of the Technical Boards}

To initiate and to achieve the above objectives a Joint ISO/CEN Coordinating Group of the Technical Boards has been established with the task of proposing and monitoring the appropriate operating methods and systems, on the understanding that the day-to-day processing shall be handled by both Central Secretariats. The Group comprises three members appointed by each Technical Board and the respective Secretaries, the Chairman and Secretary alternating for each meeting.

The joint tasks are as follows:

- to monitor the general implementation of the Agreement on technical cooperation between ISO and CEN (Vienna Agreement);

- to review and, where necessary, propose revisions to the existing procedures, mechanisms and bases for information exchange, to achieve the objectives of mutual visibility and understanding of work programmes;

- to monitor the progress of projects, of mutual interest and take whatever action may be required to ensure progress towards the completion of projects within planned time scales;

- to advise the Technical Boards of any direct involvement required of them for improving the performance of secretaries and experts appointed by member bodies;

- to maintain working linkages with the technical management bodies of both organizations;

- to review coordination issues on questions of common interest with a view to deciding on work allocation.

\section{Follow-up of comments from ISO member bodies}

CEN agrees to accept comments on prEN and prHD from ISO member bodies outside CEN. These comments should be sent directly to the CEN/CS, with copy to the ISO/CS. The CEN/CS shall forward such comments to the appropriate CEN technical body.

This body shall report back to the CEN/CS. The CEN/CS shall in turn inform the ISO member body of the action taken, with copy to the ISO/CS.

Valuable new ideas which might help support CEN work could also emanate from outside of Western Europe and, if appropriate, could be usefully incorporated in the documents prepared by the CEN Committee. Such contributions shall be handled in the same way as above.

\section{Implementation of the Agreement}

The ISO and CEN Secretaries-General shall take the necessary steps to develop appropriate mechanisms for the practical implementation of the Agreement.

In the event of difficulties arising in the performance of this Agreement, the ISO/TCs, CEN/TCs and CEN Reporting Secretariats shall report to their respective Secretaries-General who shall decide on the necessary corrective measures.

Note: The implementation of the Agreement is to be considered as being within the framework of ISO and CEN procedures and their possible future amendments.

\section{Duration of the Agreement}

This Agreement shall remain in force until such time that ISO or CEN request its revision or its termination giving one year's notice. 
International Organization for standardization (ISO)

European Committee for Standardization (CEN)

\section{Guidelines for TC/SC Chairmen and Secretariats for implementation of the Agreement on technical cooperation between ISO and CEN (Vienna Agreement)}

\section{Introduction}

The Agreement on technical cooperation between ISO and CEN (Vienna Agreement) was formally approved on 27 June 1991 in Vienna by the CEN Administrative Board following its approval by the ISO Executive Board at its meeting on 16 and 17 May 1991 in Geneva.

The Agreement replaced the Agreement on exchange of technical information between ISO and CEN (Lisbon Agreement) concluded in 1989.

The text of the Agreement was distributed to TC/SC chairmen and secretaries

- by ISO, under cover of a circular letter dated 11 July 1991;

- by CEN, under cover of a circular letter dated 3 September 1991;

together with guidelines for the implementation of the Agreement.

The following common ISO/CEN guidelines cancel and replace those issued with the above circular letters. They are structured to reflect the various modes of cooperation between ISO and CEN, as follows:

cooperation by correspondence (Section 1);

cooperation by mutual representation at meetings (Section 2);

application of CEN/Cenelec internal regulations in the framework of the agreement (Section 3);

adoption of existing international standards as European standards (Section 4);

cooperation by transfer of work and parallel approval of standards (Section 5).

The guidelines are accompanied by flow charts summarizing the procedures to be followed in the case of when a work item of interest to CEN is to be developed by ISO (Figure 1) and vice versa (Figure 2).

Note: In order to avoid confusion, subdivisions of these implementation guidelines are referred to as 'sections' to distinguish them from the subdivisions of the Vienna Agreement, which are referred to as 'clauses'.

\section{Cooperation by correspondence (clause 2 and subclause 3.1)}

The provisions for exchange of information in the original Lisbon Agreement remain unchanged. They provide for an exchange of information between the ISO and CEN Central Secretariats, for ISO/CEN Reporting Secretariats (SRs) to provide information to the CEN Technical Board, CEN Central Secretariat and CEN Committee Secretariats as appropriate, and for CEN Committee Secretariats to provide information to ISO Committee Secretariats, with copies to both the ISO and CEN Central Secretariats.

Written contributions may emanate from TCs, SRs or CSs, are expected to reflect a consolidated CEN or ISO view, and are in principle comments on programming or drafting of standards. 


\section{Cooperation through mutual representation at meetings (subclause 3.2 ) and joint coordination meetings (subclause 6.1)}

2.1. When questions of common interest to both ISO and CEN technical bodies call for mutual representation at meetings, the secretariat in agreement with the chairman of the committee concerned, shall advise the Secretary-General of the organization concerned of the names and addresses of liaison representatives to the relevant technical body of the other organization. In principle, only two representatives (not including interpreters) will be permitted and should be chosen from among chairmen, secretaries, conveners, project leaders and Central Secretariat Technical Officers. The action taken has to be reported to the committee members. These representatives shall represent the views of the committee that designated them. Participation in WG meetings is subject to invitation by the parent body of the WG.

2.2. Where ISO and CEN Committees already exist and have overlapping programmes of work, the ISO and/or CEN Central Secretariat, following consultation between them, will organize joint coordination meetings to reach agreement on allocation of work and if necessary, to resolve comments received following parallel voting on DIS and prEN.

\section{Application of $\mathrm{CEN} /$ Cenelec internal regulations in the framework of the Vienna Agreement}

CEN reaffirms the primacy of international standardization work, of avoidance of duplication of activities and of the use of international results wherever possible, however, it is to be acknowledged that CEN duly considers each request for standardization and chooses, according to the advice of its interested parties, amongst the following possibilities:

(a) the submission of an existing document (e.g. originating from ISO) as a draft European standard through the implementation procedures (PQ plus Formal Vote, UAP) as defined in its internal regulations (see Section 4);

Note: UAP is equivalent, but not identical, to the ISO 'fast-track' procedure. As a result of these procedures, modifications to ISO documents by ISO/TCs can be requested by CEN in accordance with clause 4.3.

(b) the request to ISO to prepare a standard on a specific subject (the transfer of work to ISO) as reflected in the Vienna Agreement (clause 3.3) to be implemented in accordance with Section 5:

(c) the use of an associated body (ASB) as defined in its internal regulations;

Note: This permits the introduction of documents prepared by a 'recognized standardizing body' as draft European standards. The CEN concept is equivalent, but not identical, to the ISO concept;

(d) the preparation of standards by the use of its own technical bodies (TC, SC, WG) as defined in internal regulations.

However, the choice of the appropriate route to achieve the preparation of European standards (EN, HD, ENV) shall be made after careful consideration of the CEN internal regulations for technical work, and of the possibilities and limits of the options available.

In the CEN structure such an assessment and the relevant decision are made by the CEN Technical Board (CEN/BT) - or a CEN Sectoral Technical Board (CEN/BTS) by delegation - on the basis of the replies (Form B) received from the CEN members on any proposals for new work items (Form $A$ ).

In deciding on the way to handle the work, several elements have to be considered by the CEN/BT - or CEN/BTS by delegation - and CEN members when sending their replies by means of Form B, such as:

major commercial needs;

importance of international trade;

existence of ISO/TC or CEN/TC with competence in the area concerned; 
insertion in or completion of the existing documentation in the European catalogue;

involvement of industry at international and European level;

regulatory requirements resulting or anticipated from the European Commission;

demonstrated technical barriers to trade (international and European);

required or proposed timetable for the preparation of standards.

However, special attention is to be paid to the following arguments when envisaging the transfer of work to ISO:

- The CEN work item is mandated or not.

The Vienna Agreement does not exclude the transfer of mandated work items to ISO. Nevertheless, in principle the mandated work items are related to European requirements reflected in EC Directives and are linked to very tight target dates and obligations to be reflected in European standards that are to be recognized as 'harmonized standards', suitable for the implementation of the relevant Directive.

- CEN members are prepared to participate in ISO work.

At the end of work in ISO, parallel voting in CEN and ISO will be conducted. In order to be successful at this level, it is necessary that CEN members participate in the ISO work from the very beginning. Provision has been made that if at least five CEN P-members commit themselves to participate actively in ISO/TC work, CEN/BT can decide to transfer the work to ISO, the preparation of standards can begin without delay and CEN is entitled to nominate a project leader.

- The ISO rules allow the nomination of a project leader by CEN for conducting a given project.

It is highly recommended that a CEN work item transferred to ISO be followed by a European project leader. Such a possibility permits a better link with ISO work in case of failure in ISO and the need to continue work in CEN. It is to be noted that the project leader has a particular role in the editing of the prEN submitted to parallel vote.

- Respect of the final control of CEN

While accepting the transfer of given work to ISO, CEN keeps open the option (see subclause 3.3.3) to withdraw at any time the transfer of work to ISO, should ISO not respond to the requirements made (respecting of EC Directives, target dates, etc.). This is particularly true for the mandated EC/EFTA work.

In that case, CEN will notify ISO of its decision to process the project separately as a CEN work item. The ISO/TC/SC shall then decide whether or not to continue to process work in ISO. (It is hoped that such an occurrence will be quite exceptional.)

\section{CEN Standstill}

Once the work item has been approved by the CEN/BT, general dispositions to impose or release standstill apply to CEN members according to the second alternative of the CEN/Cenelec internal regulations clause 6.2.1 (date decided by CEN/BT).

\footnotetext{
This corresponds to the usual practice that the proposer of a work item offers a project leader.
} 


\section{Adoption of existing international standards as European standards (clause 4)}

\subsection{ISO standards adopted without change}

If an ISO standard is adopted by CEN without change, the ISO/TC/SC secretariats will be informed by the ISO Central Secretariat that the ISO standard has been approved as a European standard and will be invited to take this into account when reviewing proposals for revision, confirmation or withdrawal.

\subsection{ISO standard proposed for adoption with modifications}

When the CEN PQ (primary questionnaire) procedure generates comments, these shall be sent by CEN/CS, after appropriate decision of the CEN/BT, to the ISO/CS which will transmit them to the ISO/TC/SC secretariat concerned. The ISO/TC/SC secretary shall consult the members of the TC/SC and within two months shall inform ISO/CS, CEN/CS and the CEN/TC secretariat (or CEN Reporting Secretariat) if the ISO/TC/SC has agreed to revise the ISO standard or not, within the proposed time schedule.

(a) If the response is positive, the ISO standard shall be revised to incorporate the comments received from CEN and shall be processed as a revised international standard and as a European standard using the parallel voting procedure within ISO and CEN (see Section 5).

(b) If the response is negative, CEN will adopt the ISO standard with modifications, under the normal CEN procedure.

\section{Cooperation by transfer of work and parallel approval of standards in ISO and CEN (clause 5.1)}

There are two possible cases of parallel voting:

(i) agreement by the CEN/BT that work be transferred to ISO and that parallel voting be conducted in ISO and CEN (see Section 5.1 below);

(ii) agreement that the work be carried out in CEN and, for which ISO has declared interest, that parallel voting be conducted in CEN and ISO (see Section 5.2 below);

Note: When the time factor is not considered to be critical it will be possible to complete the work in ISO and submit it to CEN for approval through the PQ and formal vote or UAP procedure (see Section 4 above). It will also be possible to propose that an approved EN standard be submitted to ISO under the fast-track procedure (see clause G.4 of Part 1 of the IEC/ISO Directives).

\subsection{Transfer of work from CEN to ISO (subclause 3.3) and parallel approval of standards in ISO and CEN}

As indicated in Section 3, for each new work item, CEN will consider its various procedural options and if its BT/BTS decides to propose the work item to ISO, one of the following cases may arise:

\subsubsection{New work within the scope of an existing $I S O / T C / S C$}

Following the approval of the new work item within CEN and provided that five CEN/ISO P-member bodies commit themselves to participate, work can be transferred to ISO and shall commence immediately within the relevant ISO Committee, the secretariat of which shall simultaneously circulate the proposal for new work ${ }^{1}$ in

\footnotetext{
' CEN Form A will, in this case, serve as the form to be used in ISO for the proposal of the new work item.
} 
accordance with subclause 2.2 of Part 1 of the IEC/ISO Directives together with the list of the ISO member bodies belonging to CEN ready to participate in the work and the proposed target date. Should the above conditions be fulfilled, $\mathrm{CEN}$ is entitled to propose a project leader to initiate the work and take responsibility for controlling the timely advancement of the project, and to set a target date (compatible with Part 1 of the IEC/ISO Directives) for circulation of the ISO/DIS.

Immediately at the end of the three-month voting period, the ISO Committee Secretariat shall inform the ISO and CEN Central Secretariats as to whether the Committee has ratified the proposal for new work and whether the work can be completed by the proposed target date (or shall propose a new target date; CEN will then decide whether the work should proceed in ISO or not).

New work item proposals for which less than five CEN/ISO member bodies commit themselves to participate in the work will be handled as usual (clause 2.2 of Part 1 of the IEC/ISO Directives).

\subsubsection{New work requiring extension of the scope of an existing ISO/TC}

The same procedure as under 5.1.1 shall apply, provided that the chairman and secretary of the ISO Technical Committee concerned agree to recommend the extension of the scope of the TC. Simultaneously with consultation on the CEN/NWI proposal, they shall seek agreement of the TC P-members on the proposed extension of the scope and the Technical Board secretariat will similarly seek the approval of the Technical Board of the extended scope.

If the TC chairman and secretary are opposed to the extension of the scope of the TC, they shall inform the secretariat of the ISO Technical Board without delay. The latter will include this information on the Technical Board ballot paper concerning the proposal to extend the scope of the TC.

\subsubsection{New work in fields not yet covered in ISO}

Upon decision in CEN to transfer the work to ISO, the procedure described in the IEC/ISO Directives for establishment of a new TC will be applied.

\subsubsection{Progress of work - Preparatory stage and Committee stage}

If CEN has agreed to transfer work to ISO by means of the procedure described above, or if as a result of a joint coordination meeting (see Section 2.2) work has been allocated to ISO, work during the preparatory stage and committee stage shall be carried out in accordance with Part 1 of the IEC/ISO Directives.

\subsubsection{Parallel approval in ISO and CEN of standards developed in ISO (clause 5.1)}

The CEN approval process comprises two stages - an enquiry and a formal vote. For parallel voting

the ISO/DIS procedure will be equated with the CEN enquiry,

the two-month confirmation vote (Yes/No) carried out in ISO' will be equated with the CEN formal vote (Yes/No).

The procedure shall be as follows:

When consensus has been reached in the ISO Committee, the Committee Secretariat shall send copies of the Committee draft in English and French to the ISO/Central Secretariat (ISO/CS) with the usual explanatory report for distribution as a draft international standard (DIS). ISO/CS will distribute the DIS to all ISO member bodies and also to the CEN member bodies for Iceland and Luxembourg indicating on the cover page that the DIS covers a subject of interest to European standardization and that consultation of ISO-CEN member bodies on the DIS has the same effect as the CEN enquiry on a draft European standard.

Therefore, CEN/CS will confirm in parallel this status and circulate the German text. Six months will be allowed for voting and commenting on this text. (See below for provisions concerning German versions of prEN).

\footnotetext{
1 This provision will be reconsidered after an experimental period, not later than the end of 1993 .
} 
At the end of this period, the votes and comments will be sent by the ISO/CS to the ISO Committee secretariat for consideration by the Committee and to CEN/CS for information. Once a final text has been agreed upon, this shall be sent, again in English and French, to the ISO/CS, together with a full report, for distribution for a confirmation vote as a second DIS.

ISO/CS will distribute this text for a two month Yes/No vote. The text will simultaneously be notified by $\mathrm{CEN} / \mathrm{CS}$ as being issued for formal vote in CEN. (See below for provisions concerning German versions of prEN).

ISO member bodies shall return their votes to ISO/CS and CEN member bodies also to CEN/CS. Should the vote returned to CEN differ from that returned to ISO, a detailed technical justification shall be given to CEN, with a copy to ISO, together with the voting paper.

The results of the formal vote will be interpreted as follows:

\begin{tabular}{|c|c|c|c|c|}
\hline $\begin{array}{c}\text { Result of vote in } \\
\text { ISO }\end{array}$ & Yes & Yes & No & No \\
\hline $\begin{array}{c}\text { Result of vote in } \\
\text { CEN }\end{array}$ & Yes & No & Yes & No \\
\hline Decision & $\begin{array}{c}\text { Standard ISO xxxx } \\
\text { Standard EN } \\
2 \mathrm{xxxx}\end{array}$ & $\begin{array}{c}\text { Consultation } \\
\text { between ISO and } \\
\text { CEN } \\
\text { Standard ISO xxxx }\end{array}$ & $\begin{array}{c}\text { Consultation } \\
\text { between ISO and } \\
\text { CEN } \\
\text { Standard EN yyyy }\end{array}$ & $\begin{array}{c}\text { Consultation } \\
\text { between ISO and } \\
\text { CEN and return of } \\
\text { document to the } \\
\text { Committee }\end{array}$ \\
\hline
\end{tabular}

If it is decided to publish the international standard, further processing will be, in ISO, in accordance with the IEC/ISO Directives and, in CEN, in accordance with the CEN/Cenelec Internal Regulations.

\section{Provisions for German versions of prENs}

ISO/DIS are normally available in English and French. In CEN, prEN shall be prepared in English, French and German, unless otherwise decided by CEN/BT. It is the responsibility of the CEN German speaking members to prepare, during the ISO/TC work, the German version of the future prEN so that CEN/CS can release this German version at the same time as the ISO/CS sends the French and English version for DIS and for confirmation vote. If at the DIS stage, the German version is still missing, one of the German-speaking members shall be prepared to provide a translation of the ISO text within the first three months of the vote.

\subsection{CEN work of interest to ISO, allocation of work to CEN and parallel approval of standards in CEN and ISO (clause 5.2)}

If an ISO Committee has decided to defer the development of an approved work item to permit its development within CEN, or if as a result of a joint coordination meeting (see section 2.2) it has been agreed to allocate a work item to CEN, work shall proceed in CEN in accordance with Part 2 of the CEN/Cenelec internal regulations up to and including the decision to submit a text for CEN enquiry. The CEN Technical Secretariat or Reporting Secretariat shall ensure that copies of drafts are made available to the corresponding ISO Committee so that it may comment on the successive CEN drafts.

Once a decision has been reached in the CEN Committee to proceed with the enquiry, the text shall be supplied by the CEN/TC Secretariat to the CEN/CS, which will forward the document to the ISO/CS, informing the ISO Committee secretariat of this action.

CEN/CS will conduct its six-month enquiry, according to its rules, for comment by its members, including on the German version. Specific non-CEN-members, with which CEN has formal agreements, will receive the drafts, on which they may send comments to CEN/CS. 
ISO/CS will distribute this document in parallel as a draft international standard to all ISO member bodies indicating on the cover page that the text is being distributed for enquiry in CEN and simultaneously for voting as an ISO/DIS. The text itself shall not be distributed by ISO/CS to the CEN members and CEN affiliate members. Six months will be allowed for voting and commenting on this text. ISO member bodies will be

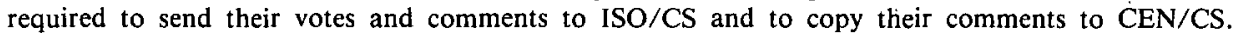

At the end of this period, the comments will be sent directly by the CEN/CS to the CEN Committee Secretariat for consideration by the Committee. CEN/CS will send a copy of the comments received for information to the secretariat of the ISO Committee and its chairman. A final text shall be agreed within CEN which shall be submitted to the CEN/CS for formal voting. The text will be circulated by CEN/CS for formal vote in CEN according to its rules. CEN/CS shall transmit this text to ISO/CS for a simultaneous confirmation vote (Yes/No) as a second DIS. The text itself shall not be distributed by ISO/CS to the CEN members and CEN affiliate members.

ISO member bodies shall return their votes to ISO/CS and in addition CEN member bodies to CEN/CS. Should the vote returned to CEN differ from that returned to ISO, a detailed technical justification shall be given to CEN, with a copy to ISO, together with the voting paper.

The result of the formal vote will be interpreted as follows:

\begin{tabular}{|c|c|c|c|c|}
\hline $\begin{array}{c}\text { Result of vote in } \\
\text { ISO }\end{array}$ & Yes & Yes & No & No \\
\hline $\begin{array}{c}\text { Result of vote in } \\
\text { CEN }\end{array}$ & Yes & No & Yes \\
\hline Decision & $\begin{array}{c}\text { Standard ISO xxxx } \\
\text { Standard EN } \\
2 \text { xxxx }\end{array}$ & $\begin{array}{c}\text { Consultation } \\
\text { between ISO and } \\
\text { CEN } \\
\text { Standard ISO xxxx }\end{array}$ & $\begin{array}{c}\text { Consultation } \\
\text { between ISO and } \\
\text { CEN } \\
\text { Standard EN yyyy }\end{array}$ & $\begin{array}{c}\text { Consultation } \\
\text { between ISO and and return of } \\
\text { document to the } \\
\text { Committee }\end{array}$ \\
\hline
\end{tabular}

If it is decided to publish the international and/or European standard, further processing will be, in ISO, in accordance with the IEC/ISO Directives and, in CEN, in accordance with the CEN/Cenelec internal'regulations.

\section{Joint ISO/CEN Coordinating Group of the Technical Boards (clause 6.2)}

To monitor progress in the implementation of the Vienna Agreement and to ensure progress towards the completion of projects within planned timescales, the ISO and CEN Technical Boards have appointed a Joint ISO/CEN Coordinating Group with terms of reference specified in clause 6.2 of the Agreement.

ISO/TC/SC and CEN/TC/SC secretariats are invited to inform this $\mathrm{JCG}$, through the ISO/CS or CEN/CS, of any difficulty encountered in implementing these guidelines. 


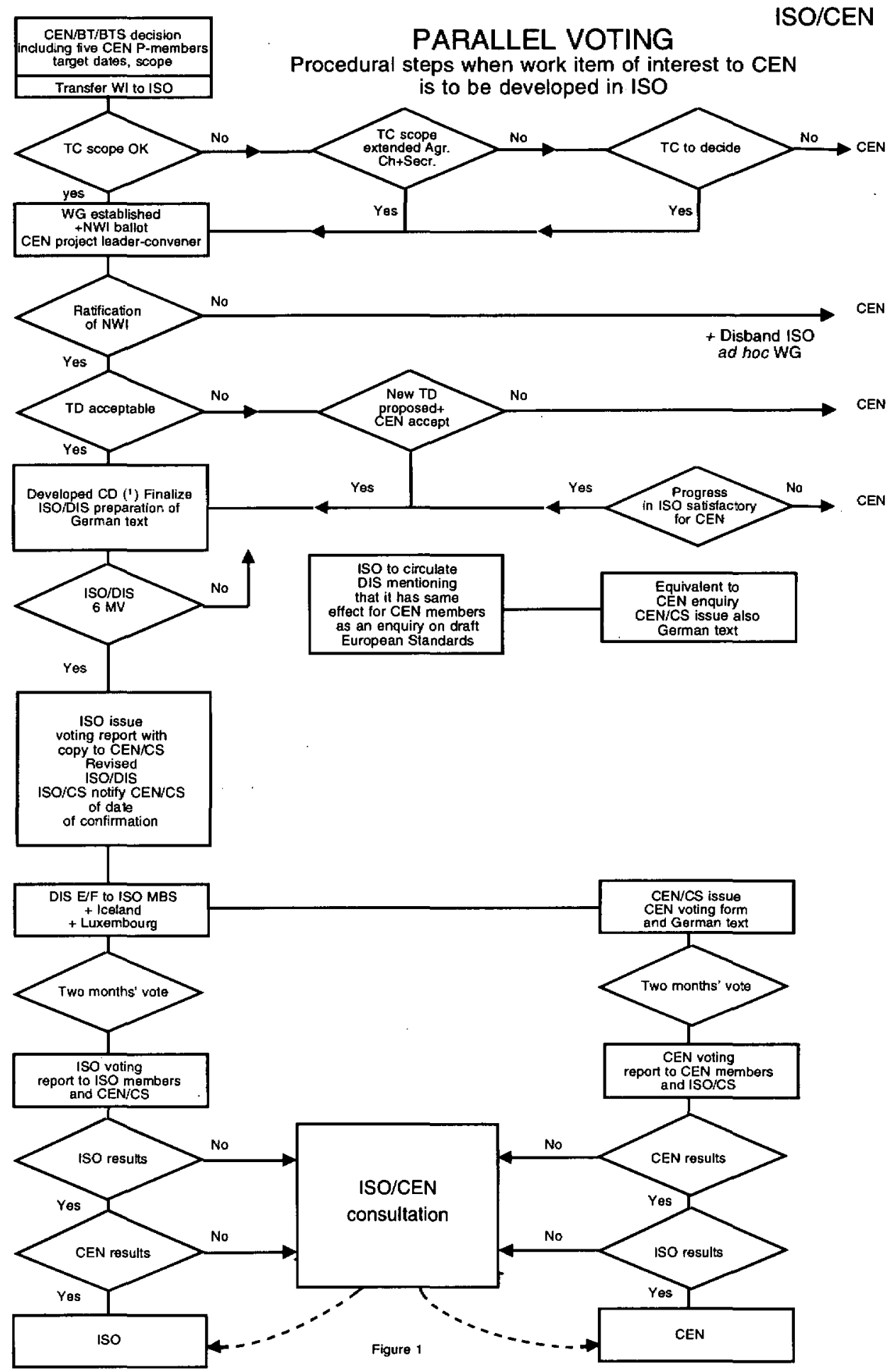

(1) The following procedural steps also apply in the case of a work item common to ISO and CEN and which CEN has agreed should be developed in ISO. 


\section{PARALLEL VOTING}

CEN/ISO

Procedural steps when work item of interest to ISO

is to be developed in CEN

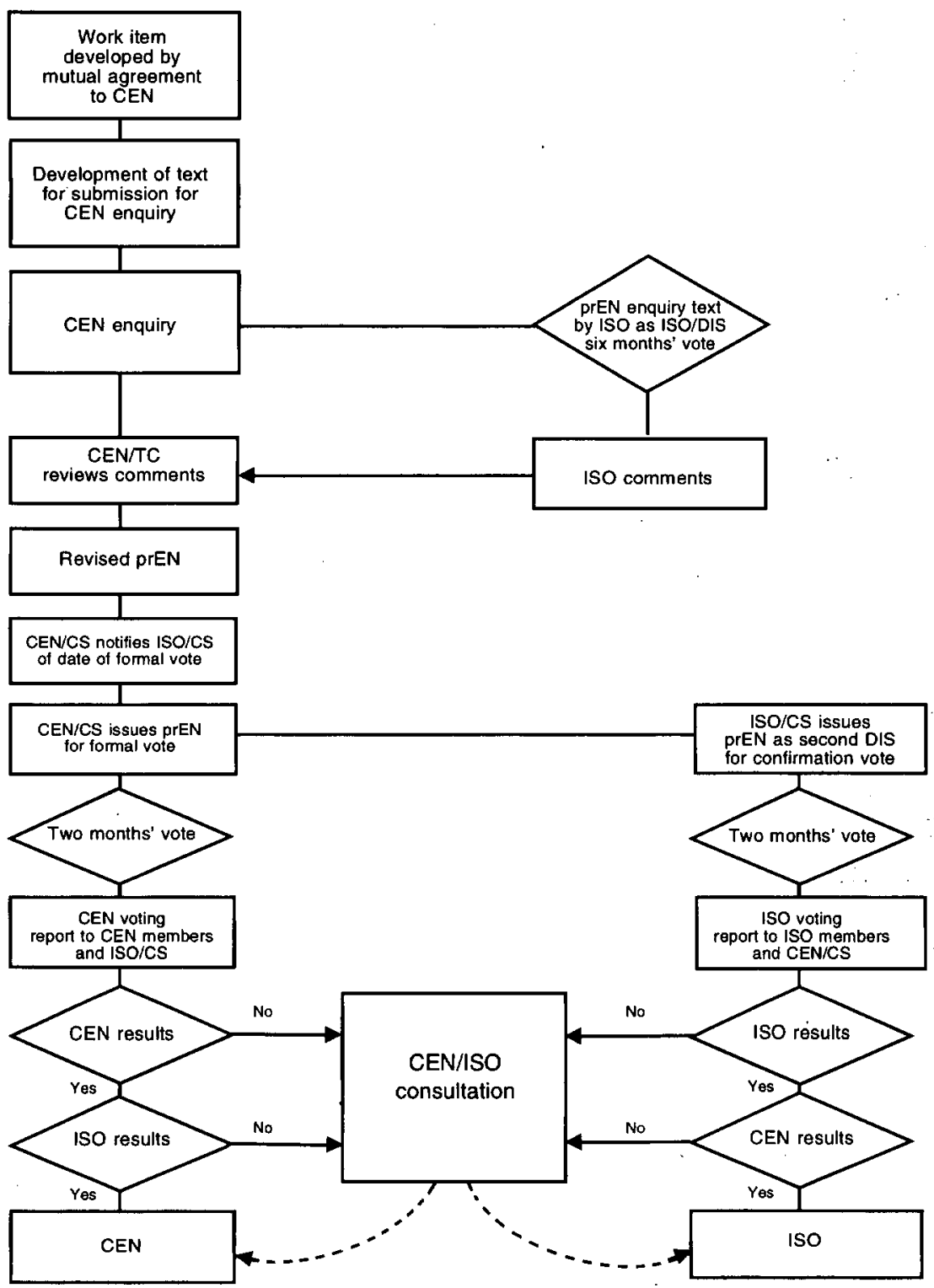

Figure 2 


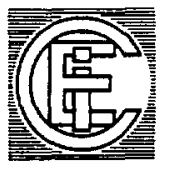

\section{Cenelec}

Standing Cenelec document

CLC(PERM)002

\section{IEC-Cenelec Agreement on exchange of technical information between both organizations (1989)}

This Agreement was approved as Annex Il to document CLC/AG(SG)495 by the 25th Cenelec General Assembly on 2 and 3 May 1989 in Rhodes (Greece), and was approved by the IEC Council under reference 01 (Central Office) 798A on 13 July 1989 in Brighton (United Kingdom).

March Edition 1992

\section{Administrative mechanisms, for monitoring and coordinating technical activities}

\section{Basis for cooperation}

IEC Council resolution on regional standardization (Decision 33/88) approved at the Council meeting held in Istanbul in October 1988. Cenelec agreed to the resolution at its General Assembly held in Helsinki in November 1988 .

\section{Exchange of information at Central Office/Central Secretariat level}

2.1. The IEC/Central Office issues regularly to the Cenelec/Central Secretariat (one copy in English only, where not bilingual):

- the IEC Directory;

- the IEC Catalogue;

- the IEC Yearbook;

- the IEC Central Office management database (work programmes of the IEC Technical Committees and Subcommittees with state of progress, target dates, etc.), on a monthly basis;

- Council and Committee of Action: all Central Office and National Committee reference documents, plus minutes (RM reference); 
- all Technical Committees and Subcommittees: Secretariat and Central Office reference documents, plus minutes of meetings (RM reference);

- ACOS, ACET, ACEC: all Central Office reference documents;

- five copies of the IEC Bulletin.

2.2. The Cenelec/Central Secretariat (CS) issues regularly to the IEC/Central Office:

- the Cenelec memento;

- the Cenelec Catalogue;

- the Cenelec report on current activities (work programme of the Cenelec Technical Board (BT), Technical Committees with state of progress, target dates);

- list of Cenelec/BT decisions on technical activities such as the decision to start new Cenelec standardization projects and, in any case, all decisions having an interest for the other party;

- the European part of the project and draft registers from the information procedure data base;

- the CEN/Cenelec Review - Ongoing activities in European standards;

- three copies of the Cenelec Newsletter.

2.3. Other general information will be made available as the need arises by special agreement between the IEC Central Office and the Cenelec Central Secretariat.

\section{Organization of exchange of information between IEC and Cenelec and vice versa}

In principle the Cenelec/TC numbering system is aligned with the IEC/TC numbering system. However, for some TCs from Cenelec TC 103 onwards the IEC Central Office and the Cenelec Central Secretariat have agreed on a correspondence list between these Cenelec TCs and IEC TCs. For the other areas of activities the Cenelec memento contains a comparative list mapping the IEC/TCs-SCs with the relevant Cenelec/TCs-SCs and/or Cenelec Reporting Secretariats.

\subsection{Reporting on IEC work to Cenelec}

3.1.1. In cases where the IEC TC/SC Secretariat is run by a Cenelec member, the relevant Cenelec TC/SC Secretariat or the Reporting Secretariat is normally (according to clause 2.5 of the CEN/Cenelec common rules for standards work Part 2) entrusted to this Cenelec member. These TC/SC Secretariats or Reporting Secretariats provide information on any IEC work to the Cenelec/BT which could be of use to Cenelec.

3.1.2. In cases where the Cenelec TC/SC Secretariats or Reporting Secretariats are not the same as the IEC TC/SC Secretariats and additional information is not available through the normal channels as laid down under 2.1, these Cenelec Secretariats may call upon the IEC Central Office, with a copy to the Cenelec Central Secretariat, to receive information on:

- the progress of the technical work of relevant IEC/TC-SC

- IEC new work items decided.

3.1.3. The IEC Central Office informs the Cenelec/CS on the findings of the Committee of Action Management Groups (through the Committee of Action documents sent regularly to Cenelec - see 2.1) which may have an influence

- on the Cenelec programming of activities, as well as

- on activities and priorities within the different Cenelec technical bodies. 


\subsection{Reporting on Cenelec work to IEC}

3.2.1. The Cenelec/CS transmits monthly the CEN/Cenelec Review - Ongoing activities in European standards, and twice a year its Report on activities to the IEC Central Office, which in turn will inform the relevant IEC/TC-SC Secretariats. Thereby information on the Cenelec/TC-SC programme of technical work is given which includes:

- its state of progress

- the current work schedule.

3.2.2. In cases where the IEC TC/SC Secretariats are not identical to Cenelec TC/SC Secretariats, additional information on Cenelec work (which is not available through the normal channels laid down under 2.2 above) may be obtained by these IEC Secretariats through the Cenelec Central Secretariat with a copy of the request to the IEC Central Office.

3.2.3. Cenelec/CS informs the IEC Central Office on recommendations of the Cenelec Programming Committees for the start of standardization activities and required priorities and target dates after endorsement of these recommendations by the Cenelec General Assembly.

\section{Implementation of the Agreement}

Both the IEC General Secretary and the Cenelec Secretary-General are responsible for the execution of this Agreement. Any difficulty will be reported to the Presidents of IEC and Cenelec. If necessary the matter can be raised at official meetings of the members of the IEC General Policy Committee and the Cenelec officers.

\section{Use of IEC Standards/DIS (6MR documents) as reference documents within Cenelec}

Ways and means are being considered which will permit the submission of IEC/DIS (6MR documents) to parallel IEC/Cenelec voting.

See Document 02 (Central Office) 371: Recommendation to the IEC Committee of Action from the IEC GPC concerning the approval of IEC DIS (6MR documents).

Note: Clause 5 of this Agreement is superseded by the IEC-Cenelec Agreement of 1991 on common planning of new work and parallel voting. 


\title{
Cenelec
}

\author{
Standing Cenelec document \\ CLC(PERM)003
}

\section{IEC-Cenelec Agreement on common planning of new work and parallel voting 1991}

Initially approved in the fourth quarter of 1990 , the IEC/Cenelec Cooperation Agreement has been reworded and approved by the 30th General Assembly of Cenelec on 29-31 October 1991 in Toulouse (France) as Annex 2 to Document CLC/AG(SG)658, and by the IEC Council on 11 October 1991 in Madrid, under reference 01 (Central Office)838A. This Agreement complements the IEC-Cenelec Agreement on the exchange of technical information between both organizations (1989).

March 1992 Edition

\section{Revised IEC/Cenelec Cooperation Agreement}

\section{Preamble}

The present document is an extension of the IEC/Cenelec Agreement on exchange of technical information between the two organizations dated November 1989. That is, the latter agreement together with the present document are integral parts of the IEC/Cenelec Agreement.

The following text supersedes the documents from the Management Supervisory Group MSG/N3 and N4 as well as IEC document 01 (Central Office) 838 and Cenelec document CLC/BT(SG)1590 Rev., circulated with an accompanying letter dated 17 December 1990.

It is in conformity with the recommendations in IEC documents $02(\mathrm{CO}) 427$ and $427 \mathrm{~A}$.

\section{1: Objectives}

This agreement is intended:

- to expedite the publication and common adoption of international standards, i.e. timely results prevail over an excessive degree of perfection;

- to ensure rational use of available resources. Full technical consideration of the content of the standard should therefore preferably take place at international level;

- to accelerate drastically the standards preparation process in response to market demands. 
To achieve the desired results, the active support of everybody involved in the IEC and Cenelec activities and flexibility in the working methods, are necessary.

\section{Common planning of new work}

Note: Cenelec members are directly involved in the planning of new work in the IEC in their capacity as IEC members. Therefore, the following covers only cases where the need for new work arises within Cenelec.

\subsection{Categories of new work proposals in Cenelec}

When identifying its requirements for new work (including the revision of existing standards), it is the policy of Cenelec to ascertain first whether the IEC can undertake this work.

New work items may arise from decisions at meetings:

- of the Cenelec AG;

- of the BT (on the basis of proposals from technical committees, national committees or other bodies, including the notifications under the Vilamoura procedure or under Directive $83 / 189$ ).

They are categorized as follows:

\subsubsection{Work of European origin}

(a) A proposal for such new work (which would usually be undertaken in an existing or new technical body of Cenelec and lead to the publication of an EN) is accepted in Cenelec if at least five national committees are willing to participate actively in that work. Normally, such a proposal shall then be submitted to the IEC and taken up by the latter unless the IEC1s timescale exceeds Cenelec's planning requirements. 'Normally' implies that the BT (in consultation with the relevant TC/SR, if any) may come to the conclusion that the IEC is unlikely to meet the required timescale. If so, the reasons for this conclusion must be properly recorded in the Cenelec BT files and made known to the IEC/CO.

(b) If there is not sufficient support by Cenelec members (less than five), a BT Working Group (in case of the Vilamoura procedure, under the convenership of the notifying national committee) may be invited to prepare a prEN with the active participation of representatives of one or more countries. In such cases the IEC shall be so advised under the procedure for the exchange of technical information, and the relevant IEC $\mathrm{TC} / \mathrm{SC}$ informed by the $\mathrm{CO}$.

\subsubsection{Common modifications to IEC standards}

When the preparation of new common modifications is considered necessary by Cenelec in order to supplement or modify an existing international standard, the subject will be considered by the Cenelec BT, on a case-by-case basis, for possible submission as a new work item to the IEC. If the BT-decides not to submit a new work item, the IEC shall be so advised.

Note: Common modifications concerning only the selection of European alternatives from 'in some countries' clauses in IEC texts do not need further action.

\subsubsection{Need for revision of an IEC standard}

When an IEC standard is being considered by Cenelec and it emerges that revision is considered necessary, this shall be offered to IEC as a new work item. In this case, Cenelec may decide:

- to adopt the IEC standard if necessary with common modifications;

- to postpone adoption while awaiting the results of its proposal to IEC for revision. 


\subsection{Procedure for submission to IEC}

The proposal for new work falling under the categories 2.1.1 (a), 2.1.2 or 2.1.3 above for which at least five national committees of Cenelec have agreed to participate shall be submitted by Cenelec/CS to the IEC/CO in accordance with the IEC/ISO Directives, Part I, 'Procedures for the technical work' as follows:

\subsubsection{For new work within the scope of an existing IEC/TC}

Information shall be given as required under subclause 2.2 of the procedures (form on pp. 47-48) and shall include, in addition to the names of the five supporting national committees, the nomination of a project leader and the requested target date for the circulation of the DIS.

Note for internal Cenelec use:

In preparing the information required, CS may call for assistance from the relevant TC/SC Secretariat, Reporting Secretariat or notifying NC (in the case of a Vilamoura notification).

\subsubsection{Widening of the scope of an existing $I E C / T C$}

If the request implies a widening of the present scope of the IEC/TC concerned, the proposed revised scope shall be submitted to the IEC by the Cenelec/CS at the same time as the request to undertake a new work item. The additional information shall be given as in 2.2.1 above and in accordance with the IEC/ISO Directives, Part 1 , 1.5.12.

\subsubsection{For new work in fields not covered so far in IEC}

Formal proposals shall be submitted by the Cenelec/CS to the IEC/CO according to the IEC/ISO Directives, Part 1, 1.5.3 and 1.5.4 (form on pp. 31-31).

Note: In cases of doubt, the best procedure to be adopted shall be agreed in consultation between the two General Secretaries and may include the setting-up of an ad hoc group to draft firm proposals for consideration by the IEC/CA and Council. This does not prevent the application of 2.3.1 below.

\subsection{Implementation of the procedure}

2.3.1. Work shall start at Cenelec level in parallel with the IEC consultation.

The IEC undertakes to advise, as quickly as possible, at the latest within six months, whether the work can be incorporated in the current programme of work with a target date as indicated by Cenelec. If the proposal is accepted by IEC, the work is 'promoted', to IEC level.

2.3.2. Work shall be continued at Cenelec level only if the new work proposal is rejected by the IEC or if the IEC's timescale exceeds Cenelec's planning requirements. The resulting prEN shall be sent to the IEC in accordance with clause 4 below.

2.3.3. Information about progress of work on projects submitted by Cenelec to the IEC in accordance with 2.2 will be sent by the IEC/CO to the Cenelec/CS on a monthly basis. Difficulties and delays which cannot be resolved by the IEC, or by negotiation between the IEC and Cenelec General Secretaries, will be reported to the MSG, which will act managerially according to its terms of reference in order to obtain the necessary support from the relevant national committees.

2.3.4. Should it become evident that IEC work is not proceeding in accordance with the agreed target dates, the Cenelec BT will reassess the matter, taking into account all information provided by the IEC. 


\section{Parallel voting on draft international standards}

\subsection{Applicability}

3.1.1. All DIS circulated for vote in IEC are automatically submitted for vote as prEN within Cenelec, with the following exceptions:

- DIS emanating from TC 1 and TC 45 with their Subcommittees are not submitted to parallel voting. However, a specific DIS from these TCs may be considered for parallel voting;

- Draft amendments to IS which have not yet been harmonized by Cenelec as EN or HD, shall not be submitted to parallel voting. Such cases shall be detected by the Cenelec/CS and the IEC/CO shall be informed accordingly.

Note: Drafts for IEC publications other than standards are not circulated for parallel voting.

Note for internal Cenelec use:

It is emphasized that qualifying DIS are automatically submitted to parallel voting, i.e. there is no requirement for prior approval by BT or a TC/SC.

3.1.2. The DIS submitted to voting must be of a quality consistent with the IEC/ISO Directives, in particular clauses 1.1 to 1.4 of Part 3 (objective, style, homogeneity, coherence). So that the DIS is ready for publication, the approved $C D$ shall be subject to full editing before circulation of the DIS.

3.1.3. In view of the existence of an additional official language in Cenelec, an expert of German mother tongue shall be permitted to attend meetings of IEC editing committees as observer.

Notes for internal Cenelec use:

i. The German National Committee, in cooperation with those of Austria and Switzerland, shall be responsible for nominating experts of German mother tongue and shall inform the relevant IEC TC/SC Secretariat(s) accordingly.

ii. It shall also, again in cooperation with those from Austria and Switzerland, be responsible for ensuring that the German language text of the DIS is available in time, where possible on the basis of a translation made at an earlier stage of the work.

3.1.4. A DIS submitted for parallel voting shall cover the entire scope in accordance with the IEC/ISO Directives. This does not exclude, for example, the traditional Part 1/Part 2 concept, where Part 1 covers all generic requirements for a product family and a series of Parts $\mathbf{2}$ give the additional stipulations applying in each Part 2 for one product type only, provided the Part 1 is submitted to voting before, or at the same time as the related part(s) 2 .

Submission of fragments of text of the same DIS in separate voting documents is not permitted.

\subsection{Implementation of the procedures}

3.2.1. In order to facilitate translation into non-official languages, the IEC/CO shall send the edited version of the CD (which may be marked up) approved for circulation as a DIS to the Cenelec/CS as early as possible, and not later than two months before the circulation of the DIS. This edited version of the CD is available on request from the IEC/CO to any IEC National Committee.

3.2.2. The IEC/CO will send, within the maximum permitted processing time, the DIS and the voting paper to IEC members and, in addition, a copy of the DIS only will be forwarded to the Cenelec National Committees of Iceland and Luxembourg. All such documentation will indicate that the DIS is being submitted for parallel voting.

The four-months' voting period is valid for both IEC and Cenelec and shall be timed to start from the date indicated on the voting paper. 
Notes for internal Cenelec use:

i. The Cenelec/CS is responsible for circulating the German language text of the DIS at the same time, having received the text from the German National Committee.

ii. Before voting, the Cenelec National Committees should have completed the public enquiry according to relevant national procedures which should be initiated, whenever possible, at the CD stage.

3.2.3. Simultaneously, the Cenelec/CS will send to its members the voting forms, which will refer to the relevant DIS being dispatched by the IEC/CO. A copy will also be sent by the Cenelec/CS to the Reporting Secretariat, (SR) or Cenelec/TC/SC when relevant.

3.2.4. The national committees send their votes on the respective voting forms to IEC and Cenelec. In case of a negative vote cast within Cenelec, a detailed technical justification must be given to Cenelec/CS (with copy to the IEC/CO), together with the voting form.

\subsection{Ratification stage}

3.3.1. The IEC voting report on the DIS shall be circulated to the IEC national committees and the Cenelec/CS by the IEC/CO not later than six weeks after the end of the voting period.

The Cenelec voting report on the prEN shall be circulated immediately thereafter to the Cenelec national committees and to the IEC/CO by the Cenelec/CS.

3.3.2. If the IEC and the Cenelec results are both positive, the DIS is published as an IS by IEC and it is formally ratified as an EN by the BT. The ratification is normally carried out by correspondence and implies that the BT notes the approval demonstrated by the voting result and established the dates for national implementation.

3.3.3. In the case of a negative Cenelec result, but positive IEC result, the IEC shall proceed to publish the IS. Cenelec BT shall decide what action to take (e.g. a proposal for common modifications as given under 2.1.2)

Note: Such a case may occur in view of the different status of an IS and an EN and hence the different significance to the two votes, i.e.

Within IEC: An IS is based on worldwide consensus, and has the status of a 'recommendation', without obligation to implement.

Within Cenelec: An EN is based on European consensus, and each member is obliged to implement the EN unchanged as a national standard.

3.3.4. Should the IEC result be negative, Cenelec BT will in due time consider what action to take within Cenelec. This could imply, for example, implementation of the DIS as EN if the Cenelec result is positive, or the start of independent European work or the submission of a new proposal to the IEC.

\section{Parallel voting on European standards}

\subsection{Published EN and HD}

In the case of already published EN and HD, the Cenelec BT shall decide on the way to submit such texts to IEC for voting at the DIS level under the provision of G $3.6(\mathrm{p} .106)$ of the IEC/ISO Directives, Part 1.

Such texts must have the same degree of quality as defined under 3.1.2 above. They shall be sent by the Cenelec/CS to the IEC/CO for circulation as DIS. 


\subsection{Parallel voting on prEN}

4.2.1. This applies to work of European origin intended to lead to the publication of EN. This could be a draft developed by a technical body of Cenelec or a national standard or other document approved for final voting by the Cenelec BT.

Note: prENV (draft European prestandards) are not covered by this procedure.

4.2.2. The English and French texts of the prEN shall be sent by the Cenelec/CS to the IEC/CO for parallel voting as DIS.

4.2.3. The handling at the approval and at the ratification stage is similar to the procedure described under 3.2 and 3.3 above with the following additional stipulation:

National committees that are not members of Cenelec shall be allowed to submit a positive vote to the IEC accompanied by a request for inclusion of an 'in some countries' clause, which shall then be referred to the relevant IEC/TC.

To avoid the need for the frequent use of this provision, Cenelec/TCs shall be encouraged, as far as possible, to refer, for example, to rated supply voltage and frequency rather than to specific numerical values thereof.

\section{Abbreviations}

\begin{tabular}{llll} 
& \multicolumn{1}{c}{ Cenelec } & & \multicolumn{1}{c}{ IEC } \\
$\mathrm{AG}$ & $=$ General Assembly & TC/SC & $=$ Technical Committee/Subcommittee \\
CS & $=$ Central Secretariat & CA & $=$ Committee of Action \\
BT & $=$ Technical Board & CO & $=$ Central Office \\
SR & $=$ Reporting Secretariat & CD & $=$ Committee draft \\
prENV & $=$ draft European prestandard & DIS $=$ draft international standard \\
ENV & $=$ European prestandard & IS & $=$ international standard \\
prEN & $=$ draft European standard & & \\
HD & $=$ harmonized document & & \\
EN & $=$ European standard &
\end{tabular}




\section{Procedural steps for IEC}

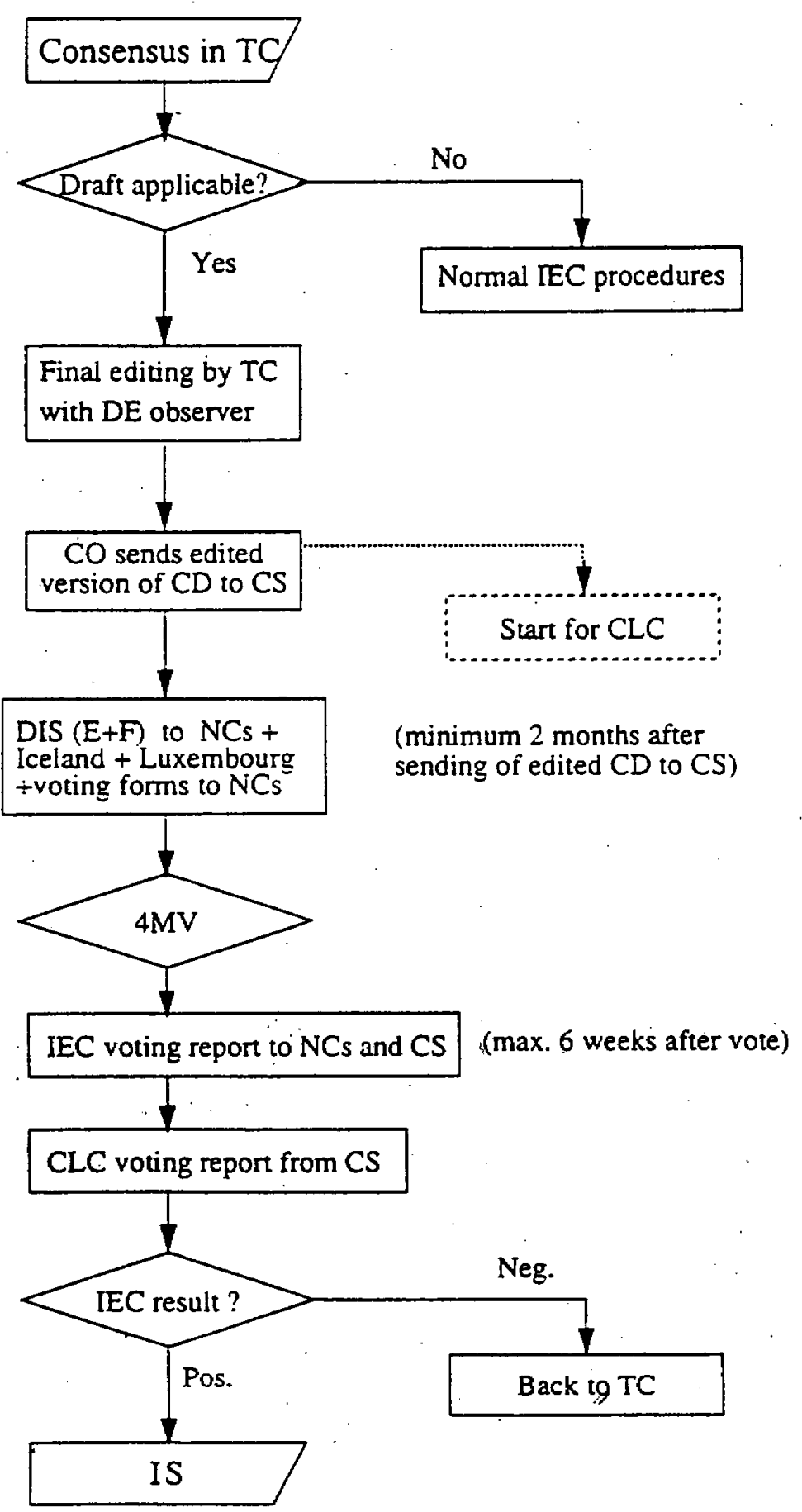

section reference 


\section{Procedural steps for CENELEC}

section reference

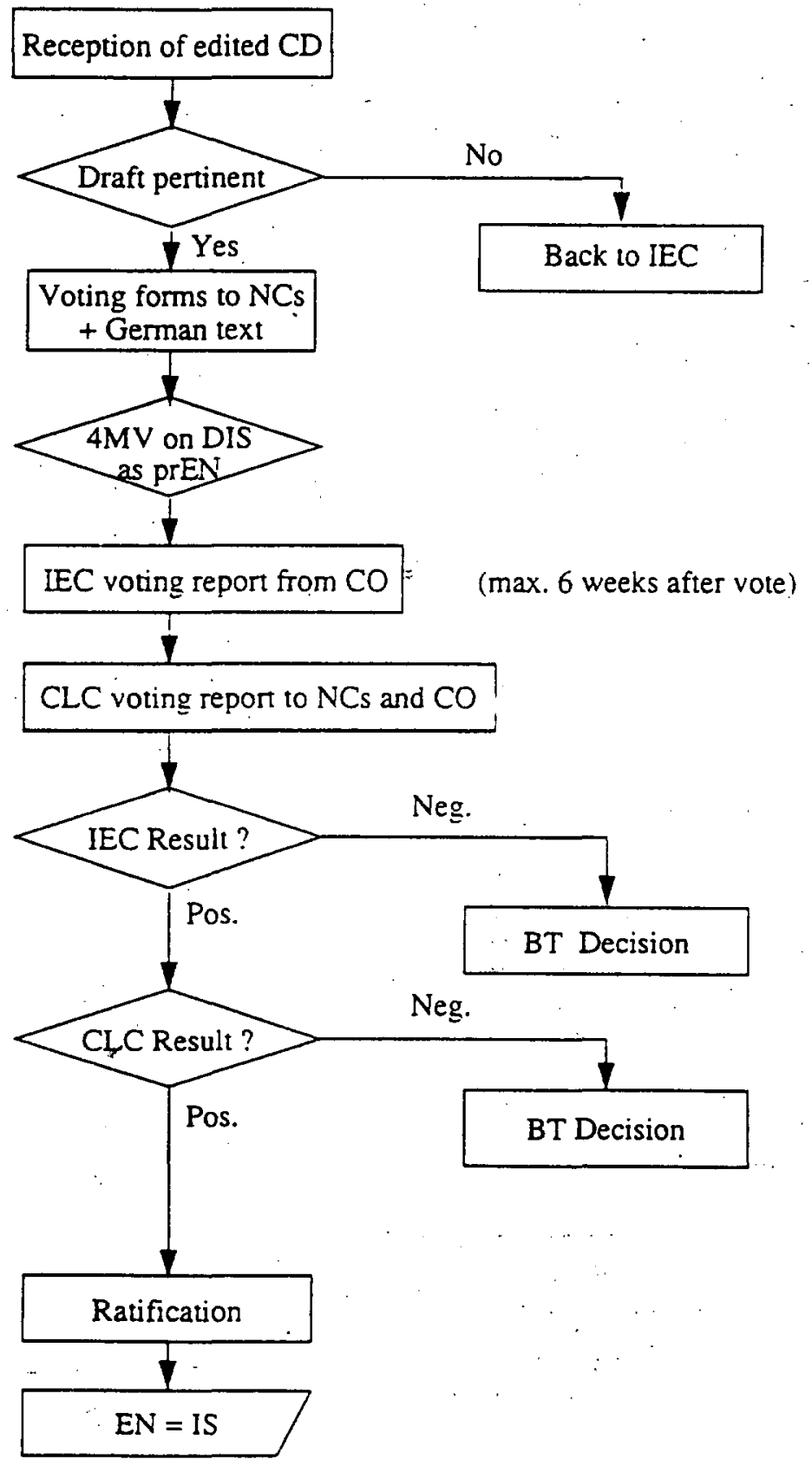




\section{Procedural steps at national level}

section reference

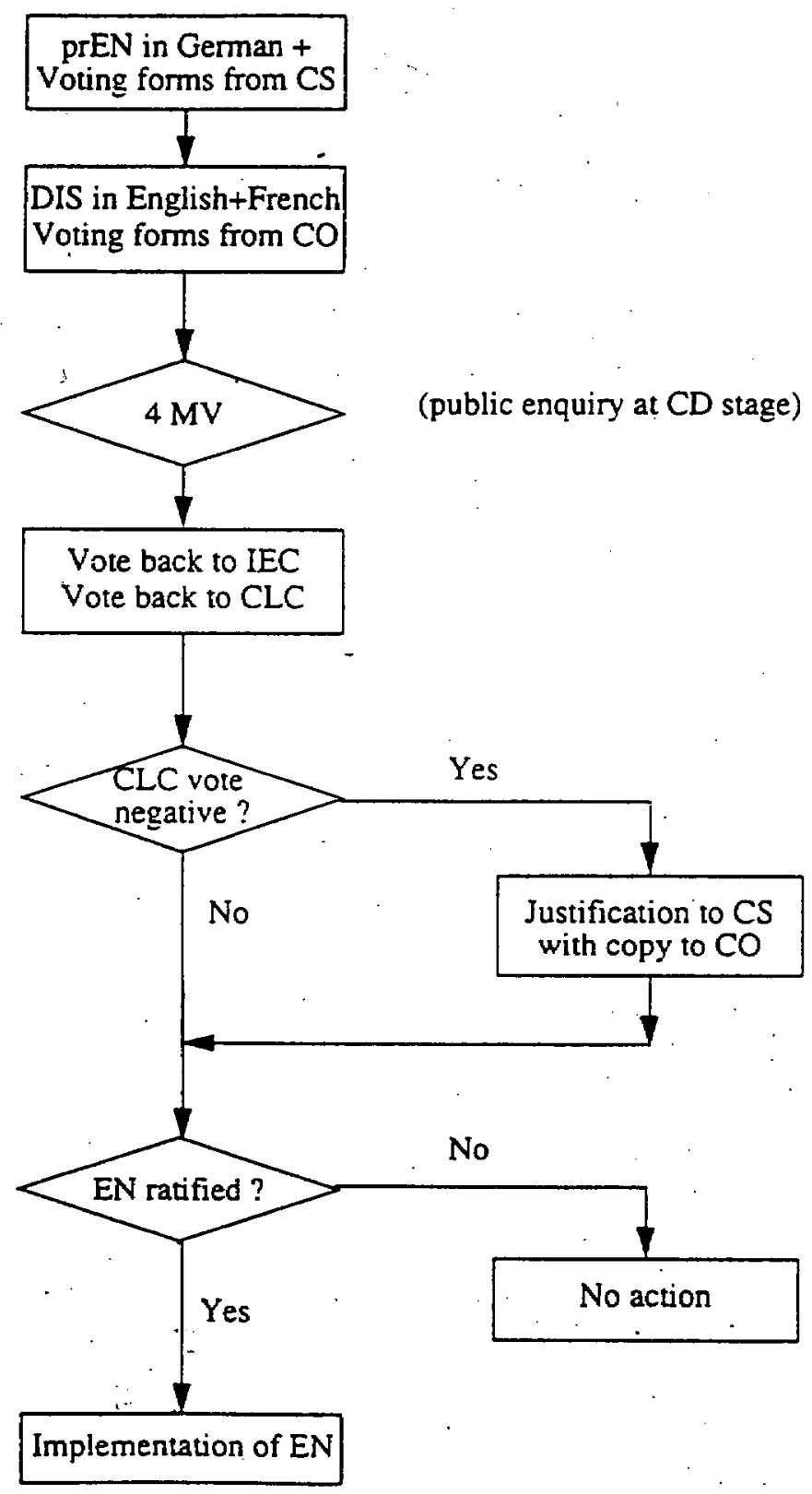




\section{Glossary of acronyms}

ABI.
FR Journal officiel des Communautés européennes
DE Amtsblatt der Europäischen Gemeinschaften

ACTE EN Approvals Committee for Telecommunications Equipment

FR comité d'agrément des équipements de télécommunications

DE Zulassungsausschuß für Telekommunikationsgeräte

AECMA EN European Association of Aerospace Manufacturers

FR Association européenne des constructeurs de matériel aérospatial

DE Europäischen Verband der Luft- und Raumfahrtindustrie

AELE EN European Free Trade Association

FR Association européenne de libre-échange

DE Europäische Freihandelszone

AENOR

Asociación Española de Normalización y Certificación (E)

AFNOR

Association française de normalisation $(F)$

AG

EN General Assembly

FR assemblée générale

DE Generalversammlung

ANSI

EN American National Standards Institute

ASB

EN Associated Standardizing Body

FR organisme associé à activités normatives

DE Assoziierte Organisation

BS

British Standard (GB)

BSI

British Standards Institution (GB)

BT

EN Technical Board

FR bureau technique

DE Technisches Büro

BTS

EN Technical Sector Board

FR bureau technique sectoriel

DE Technisches Sektorbüro

BTTF EN Technical Board Task Force

FR bureau technique task-force

DE Technisches Büro Task Force 

CA EN Administrative Board
FR conseil d'administration
DE Verwaltungsrat
CAD/CAM EN computer-aided design/computer-aided manufacturing
FR conception assistée par ordinateur/fabrication assistée par ordinateur
DE Rechner- und computergestütztes Entwerfen
$\begin{array}{lll}\mathrm{CAO} / \mathrm{FAO} & \mathrm{EN} & \text { see CAD/CAM } \\ & \mathrm{FR} & \text { voir CAD/CAM } \\ & \mathrm{DE} & \text { siehe CAD/CAM }\end{array}$
CAEM EN Council for Mutual Economic Assistance
(Comecon) FR Conseil d'assistance économique mutuelle
DE Rat für gegenseitige Wirtschaftshilfe
CASCO EN Committee for Conformity Assessment of ISO
FR comité pour l'évaluation de la conformité de l'ISO
CCA EN Cenelec Certification Agreement
FR accord de certification du Cenelec
DE Zertifikat Cenelec
CCC EN Certification Committee of CEN (see Cencer)
FR comité de certification du CEN (voir Cencer)
DE Zertifizierungskomitee CEN (siehe Cencer)
2. EN Consumers' Consultativè Council
FR conseil consultatif des consommateurs
DE Beratender Verbraucherrat
CCE $\quad$ EN CEC
Commission of the European Communities (now: European Commission)
FR CCE
Commission des Communautés européennes (maintenant: Commission européenne)
DE KEG
Kommission der Europäischen Gemeinschaften (nun: Europäische Kommission)
CCITT EN International Telegraph and Telephone Consultative Committee
FR Comité consultatif international télégraphique et téléphonique
DE Internationaler Beratender Ausschuß für Telefon und Telegrafie
CE
1. EN European Communities
FR Communauté(s) européenne(s)
DE Europäische Gemeinschaften
2. EN European Commission (EC)
FR Commission européenne (CE)
DE Europäische Kommission (EK)
CECC EN Cenelec Electronic Components Committee
FR comité des composants électroniques du Cenelec
DE Cenelec-Komitee für Bauelemente der Elektronik
CEE EN European Economic Community (EEC)
FR Communauté économique européenne
DE Europäische Wirtschaftsgemeinschaft (EWG) 
CEE-ONU EN Economic Commission for Europe of the United Nations

FR Commission économique pour l'Europe des Nations unies

DE Wirtschaftskommission für Europa und die Vereinten Nationen

CEI EN International Electrotechnical Commission

FR Commission électrotechnique internationale

DE Internationale Elektrotechnische Kommission

CEN EN European Committee for Standardization

FR Comité européen de normalisation

DE Europäisches Komitee für Normung

Cencer EN Certification Committee of CEN

FR comité de certification du CEN

DE Zertifizierungskomitee CEN

Cenelec EN European Committee for Electrotechnical Standardization

FR Comité européen de normalisation électrotechnique

DE Europäisches Komitee für Elektrotechnische Normung

CEPT EN European Conference of Postal and Telecommunications Administrations

FR Conférence européenne des administrations des postes et des télécommunications

DE Europäische Konferenz für Post- und Fernmeldewesen

$\begin{array}{lll}\text { Comecon } & \text { EN } & \text { see CAEM } \\ & \text { FR } & \text { voir CAEM }\end{array}$

DE siehe CAEM

CR EN CEN/Cenelec report

FR rapport du CEN/Cenelec

DE Bericht von CEN/Cenelec

CS EN Central Secretariat (of CEN or Cenelec)

FR secrétariat central (du CEN ou du Cenelec)

DE Zentralsekretariat (von CEN oder Cenelec)

CTS EN conformance testing services

FR services d'essais de conformité

DE Dienststellen für Konformitätsprüfung

DIN

Deutsches Institut für Normung (D)

DIS EN Draft International Standard

FR projet de norme internationale

DE Entwurf Internationale Norm

DS Danskstandard (DK)

ECISS EN European Committee for Iron and Steel Standardization

FR comité européen de normalisation du fer et de l'acier

DE Europäisches Komitee für . Eisen- und Stahlnormung

ECITC EN European Committee for Information Technology Testing and Certification

FR comité européen pour les essais et la certification dans le domaine des technologies de l'information

DE Europäisches Komitee für die Zertifizierung in der:Informationstechnik - Prüfung und Zertifizierung 
Edifact EN Electronic data interchange for administration, commerce and transport

FR échange de données informatisées pour l'administration, le commerce et le transport

DE Elektronischer Datenaustausch für Verwaltung, Handel und Verkehr

EEA EN European Economic Area

FR Espace économique européen

DE Europäischer Wirtschaftsraum (EWR)

EEE EN European Economic Area

FR Espace économique européen

DE Europäischer Wirtschaftsraum (EWR)

EFTA EN European Free Trade Association

FR Association européenne de libre-échange

DE Europäische Freihandelszone

Elsecom EN European Electrotechnical Sectoral Committee for Testing and Certification

FR comité sectoriel européen pour les essais et la certification électrotechniques

DE Europäisches elektrotechnisches sektorielles Komitee für Prüfung und Zertifizierung

EMCEL EN Agreement for electromagnetic compatibility testing of electrical equipment

FR accord d'essais de compatibilité électromagnétique d'équipements électriques

EMCIT EN Agreement for European testing of electromagnetic compatibility of information technology products

EMUG EN European MAP Users' Group

DE Europäische MAP-Benutzergruppe

EN EN European Standard

FR norme européenne

DE Europäische Norm

ENV EN European Pre-Standard

FR prénorme européenne

DE Europäische Vornorm

EOTA EN European Organization for Technical Approval

FR Organisation européenne pour l'agrément technique

DE Europäische Organisation für Technische Zulassungen

EOTC EN European Organization for Testing and Certification

FR Organisation européenne pour les essais et la certification

DE Europäische Organisation für Zertifizierung und Prüfwesen

EPI EN personal protective equipment (PPE)

FR équipement de protection individuelle

DE Persönliche Schutzausrüstung

EQ-Net EN European Quality Certification Network

Esprit EN European strategic programme for research and development in information technology

FR programme stratégique de recherche et de développement dans le domaine des technologies de l'information

DE Europäisches Strategisches Programm für Forschung und Entwicklung auf dem Gebiet der Informationstechnologie 
FR norme européenne de télécommunications

DE Europäische Telekommunikationsnorm

ETSI

EN European Telecommunications Standards Institute

FR Institut européen des normes de télécommunication

DE Europäisches Institut für Telekommunikationsnormen

EU

EN European Union

FR Union européenne

DE Europäische Union

Eurolab EN Organization for Testing in Europe (F)

FR Laboratoire national d'essais (F)

DE Nationales Versuchslabor (F)

EWOS EN European Workshop for Open Systems

FR Atelier européen pour les systèmes ouverts

DE Europäische Arbeitsgruppe für Offene Systeme

FTAM EN file transfer access and management

FR gestion d'accès et de transfert de fiches

DE Dateiübermittlung, Zugriff und Verwaltung

GATT

EN General Agreement on Tariffs and Trade

FR Accord général sur les tarifs douaniers et le commerce

DE Allgemeines Zoll- und Handelsabkommen

GLATC EN Graphics and Language Agreement Group for Testing and Certification

HAR EN Harmonization Agreement for cables and cords

FR accord d'harmonisation pour les câbles et les fils

DE Harmonisierungsabkommen über Kabel und Leitungen

HD

EN harmonization document

FR document d'harmonisation

DE Harmonisierungsdokument

ICONE EN comparative index of national and European standards

FR index comparatif des normes nationales et européennes

DE Vergleichendes Register für nationale und Europäische Normen

IEC EN International Electrotechnical Commission

FR Commission électrotechnique internationale

DE Internationale Elektrotechnische Kommission

ILAC EN International Laboratory Accreditation Conference

FR Conférence internationale sur l'agrément des laboratoires d'essais

$\mathrm{DE}$ Internationale Konferenz für die Anerkennung von Prüflaboratorien

Infopro EN information procedure on standards

FR procédure d'information sur les normes

DE Informationsverfahren für Normung

ISO

EN International Organization for Standardization

FR Organisation internationale de normalisation

DE Internationale Organisation für Normung 


\begin{tabular}{|c|c|c|}
\hline IT & $\begin{array}{l}\text { EN } \\
\text { FR } \\
\text { DE }\end{array}$ & $\begin{array}{l}\text { information technology } \\
\text { technologie de l'information } \\
\text { Informationstechnologie }\end{array}$ \\
\hline ITQS & $\mathrm{EN}$ & $\begin{array}{l}\text { agreement group for assessment and certification of quality systems in the information } \\
\text { technology sector }\end{array}$ \\
\hline ITSTC & $\begin{array}{l}\text { EN } \\
\text { FR } \\
\text { DE }\end{array}$ & $\begin{array}{l}\text { Information Technology Steering Committee } \\
\text { comité directeur de la technologie de l'information } \\
\text { Informationstechnik-Lenkungskomitee }\end{array}$ \\
\hline $\mathrm{JCG}$ & $\begin{array}{l}\text { EN } \\
\text { FR } \\
\text { DE }\end{array}$ & $\begin{array}{l}\text { Joint Coordination Group } \\
\text { groupe commun de coordination } \\
\text { Gemeinsamer Koordinierungsausschuß }\end{array}$ \\
\hline JO & $\begin{array}{l}\text { EN } \\
\text { FR } \\
\text { DE }\end{array}$ & $\begin{array}{l}\text { Official Journal of the European Communities } \\
\text { Journal officiel des Communautés européennes } \\
\text { Amtsblatt der Europäischen Gemeinschaften (ABI.) }\end{array}$ \\
\hline LOVAG & $\begin{array}{l}\text { EN } \\
\text { FR }\end{array}$ & $\begin{array}{l}\text { Low Voltage Agreement Group } \\
\text { groupe d'accord pour la basse tension }\end{array}$ \\
\hline LUM & $\begin{array}{l}\text { EN } \\
\text { FR }\end{array}$ & $\begin{array}{l}\text { Certification Agreement for lights complying with European standards } \\
\text { accord de certification pour des luminaires conformes aux normes européennes }\end{array}$ \\
\hline MAP & $\begin{array}{l}\text { EN } \\
\text { DE }\end{array}$ & $\begin{array}{l}\text { Manufacturing Automation Protocol } \\
\text { Fertigungsautomationsprotokoll }\end{array}$ \\
\hline MHS & $\begin{array}{l}\text { EN } \\
\text { FR } \\
\text { DE }\end{array}$ & $\begin{array}{l}\text { message-handling system } \\
\text { système de messagerie } \\
\text { Nachrichtenübermittlungssystem }\end{array}$ \\
\hline M-IT-01 & EN & Memorandum on information technology No 1. \\
\hline MoU & $\begin{array}{l}\text { EN } \\
\text { FR } \\
\text { DE }\end{array}$ & $\begin{array}{l}\text { Memorandum of Understanding } \\
\text { mémorandum d'accord } \\
\text { Absichtserklärung }\end{array}$ \\
\hline NAMAS & $\mathrm{EN}$ & National Measurement Accreditation Service (GB) \\
\hline NIST & EN & $\begin{array}{l}\text { National Institute of Standards and Technology (USA) } \\
(=\text { formerly NBS) }\end{array}$ \\
\hline NF & & norme française $(F)$ \\
\hline NNI & & Nederlands Normalisatie Instituut (NL) \\
\hline NOREX & $\begin{array}{l}\text { EN } \\
\text { FR } \\
\text { DE }\end{array}$ & $\begin{array}{l}\text { technical standards and regulations at exporting } \\
\text { normes et règles techniques à l'exportation } \\
\text { Normen und Technische Vorschriften für die Ausfuhr }\end{array}$ \\
\hline NS & $\begin{array}{l}\text { EN } \\
\text { FR } \\
\text { DE }\end{array}$ & $\begin{array}{l}\text { National Standard } \\
\text { norme nationale } \\
\text { Nationale Norm }\end{array}$ \\
\hline NSO & $\begin{array}{l}\text { EN } \\
\text { FR } \\
\text { DE }\end{array}$ & $\begin{array}{l}\text { National Standardization Organization } \\
\text { organisme national de normalisation } \\
\text { Organisation für nationale Normung }\end{array}$ \\
\hline
\end{tabular}


OIML EN International Organization for Legal Metrology (IOLM)

FR Organisation internationale de métrologie légale

DE Internationale Organisation für gesetzliches Meßwesen

OIW/OSI · EN OSI Implementors' Workshop

OJ EN Official Journal of the European Communities

FR Journal officiel des Communautés européennes

DE Amtsblatt der Europäischen Gemeinschaften (ABl.)

ONU/UNO EN United Nations Organization

FR Organisation des Nations unies

DE Organisation der Vereinten Nationen

OSE EN open systems environment

OSI EN open systems interconnection

FR interconnexion de systèmes ouverts

DE Offene Kommunikationssysteme

Ositop EN open systems interconnection technical and office protocols

FR groupement des utilisateurs européens de TOP

DE Vereinigung Europäischer Verbände

OSTC EN Open Systems Testing Consortium

DE Europäisches Anerkennungsabkommen für Prüf- und Zertifizierungsstellen

PC

EN Programme Committee

FR comité de programmation

DE Planungsausschuß

PHARE EN Poland and Hungary: aid for economic restructuring

FR Pologne-Hongrie: assistance à la restructuration des économies

DE Aktionsplan für eine koordinierte Hilfe für Polen und Ungarn

PIB EN gross domestic product (GDP)

FR produit intérieur brut

DE Bruttoinlandsprodukt (BIP)

PNE EN rules for presentation of European standards

FR règles pour la présentation des normes européennes

DE Regeln für die Präsentation Europäischer Normen

PNO EN public network operator

FR opérateur de réseau public

POSIX EN portable operating system interface for computer environments

prEN EN Draft European Standard

FR projet de norme européenne

DE Entwurf Europäische Norm

prHD EN draft harmonization document

FR projet de document d'harmonisation

DE Entwurf Harmonisierungsdokument 
RACE EN Research and development in advanced communications technologies for Europe

FR programme communautaire de recherche et développement sur les technologies de pointe dans le domaine des télécommunications en Europe

DE Forschung und Entwicklung für fortgeschrittene europäische Kommunikationstechnologien

RARE EN associated networks for European research

FR réseaux associés pour la recherche européenne

DE Europäisches Forschungsnetz

RNE

Réseau national d'essais pour l'accréditation des laboratoires (F)

SC EN subcommittee

FR sous-comité

DE Unterkomitee

SR EN reporting secretariat

FR secrétariat rapporteur

TACIS EN Technical assistance to the Commonwealth of Independent States and Georgia FR programme d'assistance technique en faveur de la CEI et de la Géorgie

TBT EN technical barriers to trade

FR barrières techniques aux échanges

DE Technische Handelshemmnisse

TC

EN Technical Committee

FR comité technique

DE Technisches Komitee

TF

Task Force

TGA

Trägergemeinschaft für Akkreditierung (D)

THE

Technical Help to Exporters

TI EN information technology

FR technologies de l'information

DE Informationstechnologie

TUTB EN European Trade Union Technical Bureau for Health and Safety

FR Bureau technique syndical européen pour la santé et la sécurité

DE Europäisches Technisches Büro der Gewerkschaften für Gesundheit und Sicherheit

UAP EN unique acceptance procedure

DE Einstuftiges Annahmeverfahren

UE $\quad$ FR European Union

FR Union européenne

DE Europäische Union

UER (EBU) EN European Broadcasting Union

FR Union européenne de la radiodiffusion

DE Europäische Rundfunkunion

Ente Nazionale Italiano di Unificazione (I) 
UNICE EN Union of Industrial and Employers' Confederations of Europe

FR Union des confédérations de l'industrie et des employeurs d'Europe

DE Vereinigung der Wirtschafts- und Arbeitgeberverbände Europas

UTE

Union technique de l'électricité (F) (comité électrotechnique français)

WECC/

WELAC

WELAC

EN Western European Calibration Cooperation

Western European Laboratory Accreditation Conference

WE/EB EN Western European Edifact Board

WG EN working group

FR groupe de travail

DE Arbeitsgruppe 


\section{European Commission}

Common standards for enterprises.

By Florence Nicölas with the cooperation of Jacques Repussard

Luxembourg: Office for Official Publications of the European Communities 1995 - 275 p. $-17.5 \times 25 \mathrm{~cm}$

ISBN 92-826-8110-6

Price (excluding VAT) in Luxembourg: ECU 10 
From the beginning of the 1980s, voluntary standards ceased to be considered at rommunity level as representing a source of technical barriers to trade within Europe, and have instead gone on to become one of the most important mechanisms for bringing about the technical harmonization which is at the heart of the creation of the internal market.

As 1993 came ever nearer and as moves were made to achieve alignment with EFTA countries, so European standardization went hand in hand with the various stages in the process of bringing about the internal market and European economic integration; thanks to the innovative spirit of the new approach, the drafting of European standards which are primarily intended to support Community legislation has, among other things, made it possible to involve all business interests in the harmonization process in an effective way.

European standards now constitute both part of the rules governing competition and a motor for technical progress.

This publication updates and broadens the scope of the previous edition published in 1988 and in particular includes a complete listing of the technical harmonization laws falling under the 'new approach' and sets out European policy with regard to the evaluation and attestation of conformity.

It therefore provides a genuine panorama of European technical harmonization in the broadest sense, covering not only standardization but also the removal of technical barriers to trade, the improvement of access to information, the new and very important subject of the global approach to testing and certification and, lastly, relations between Europe and the rest of the world in all of these areas.

Florence Nicolas comes from the Dordogne area of France. She has a law degree from the University of Nancy, studied at the Institute of Political Studies in Paris and has a DEA diploma in economics. From 1982 to 1985, she was responsible for international affairs in the Industrial Products Quality Department of the French Ministry of Industrial Affairs. After working at AFNOR (French Standards Association) from 1985 , first as Adviser on European Affairs to the Director-General and Delegate-General for the Norex network (sianuards and technical rules for exports), she went on to become Director of European and International Affairs. She represented France in the EOTC Council until the end of 1992 and has been seconded to Japan for 1993 and 1994. She is the co-author of a practical guide to the European Communities (published by Lefebvre, 1994-95).

Jacques Repussard was born in $\mathbf{1 9 5 0}$ and studied at the Ecole polytechnique, the Ecole nationale des ponts et chaussées and the Ecole supérieure de metrologie. He is also a Chief Engineer for Mines. From 198 i to 1985 , he was in charge of the Industrial Products Quality Department, permanent delegate for standardization to the French Ministry of Industrial Affairs and the French representative of the GATT Standards Committee. From 1986 to 1990 , he was Deputy Director-General of AFNOA and Vice-President of the French Quality Assurance Association (AFAQ). Since 1991, he has been Secretary-General of the European Committee for Standardization (CEN).

Price (excluding VAT) in Luxembourg: ECU 10

$\begin{array}{ll}* * & \text { OFFICE FOR OFFICIAL PUBLICATIONS } \\ * & \frac{*}{* 0} * \text { OF THE EUROPEAN COMMUNITIES } \\ \text { L-2985 Luxembourg }\end{array}$
ISBN q2-B己b-BI1)-b

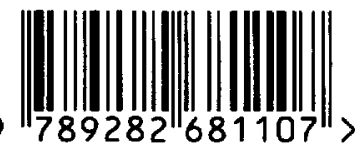

